UNIVERSIDAD POLITÉCNICA DE VALENCIA DEPARTAMENTO DE TECNOLOGÍA DE ALIMENTOS

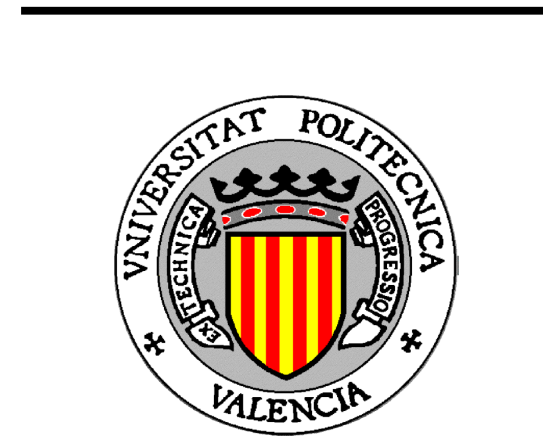

\title{
"DesarRollo de METOdologías ALTERNATIVAS PARA EL ANÁLISIS DE FUNGICIDAS BENZIMIDAZÓLICOS EN MATRICES CÍTRICAS"
}

TESIS DOCTORAL

Presentada por:

Ing. Silvia B. Visciglio

Dirigida por:

Dra. Alicia Estela RONCO

Valencia/Concordia, 14 de diciembre de 2010 

A mi madre, a quien amo y extraño con todo mi corazón y siempre será la luz que ilumine mi camino, la razón de mis esfuerzos y la dueña indiscutible de mis logros en la vida.

Con todo mi cariño. 



\section{AGRADECIMIENTOS}

A mi familia, Juan Carlos y Gastón, por su constante apoyo, por comprender mis ausencias y haber resignado en pos de este sueño muchos momentos compartidos.

A mí querida madre, que me enseñó de esfuerzos y sacrificios, que me acompañó en cada momento y me dio las fuerzas para seguir adelante a pesar de su ausencia. A mi padre, que compartió los esfuerzos de mis estudios y a pesar de los difíciles momentos de su vida, siempre estuvo a mi lado.

A mi abuelo, de quien llevo mucho de lo que soy y a quien deseo parecerme cada día más, por todo lo que me enseñó con su ejemplo y todo lo que aprendí en su memoria.

A mi abuela por haber estado cerca a pesar de la distancia, por apoyarme en mis estudios y estar siempre orgullosa de mis logros.

A la Bqca. María I. Tatiana Montti, Directora del Laboaratorio de Investigación de Residuos de Plaguicidas en Alimentos, compañera de trabajo y amiga; por su incondicional apoyo e incentivo permanente que me llevó a superar muchos momentos difíciles, por compartir sus conocimientos y brindarme su tiempo y esfuerzo para que esta tesis sea una realidad.

A mi directora de tesis, Alicia E. Ronco, quien brindó su conocimiento y dispuso de su valioso tiempo para la corrección y mejora de la misma. 
A mis compañeros de trabajo, en especial al Ing. Fabricio Raviol, por compartir mi esfuerzo y acompañar mi tarea con su apoyo permanente.

Al Ing. Jorge Gerard, por su gestión particular que posibilitó el desarrollo del doctorado en la ciudad de Concordia y permitió a muchos docentes de la Facultad fortalecer su formación profesional.

A los becarios y auxiliares del Laboratorio de Investigación de Residuos de Plaguicidas en Alimentos, quienes colaboraron en las actividades que hicieron posible la obtención de los resultados de este trabajo.

A las Dras. María del Carmen Schvab y María Mercedes Ferreyra, del Laboratorio de Investigación de Microbiología y Biotecnología de la Facultad, por el aporte de información y muestras de jugos cítricos fermentados, que fueran de gran utilidad para el desarrollo de actividades del trabajo.

A profesionales y personal del Instituto Nacional de Tecnología Agropecuaria (INTA Concordia) e industrias citrícolas de la región, por el aporte de muestras de análisis y su colaboración en el desarrollo de los planes de muestreo.

A todos los que de algún modo colaboraron directa o indirectamente para que pudiera concretar mi tesis. 


\section{RESUMEN}

La agroindustria cítrica argentina, que incluye producción, empaque, transporte, tratamiento por frío y producción de jugos concentrados, aceites esenciales, etc.; constituye una de las actividades de fundamental importancia en la economía nacional y regional. Los mercados importadores del mundo y consumidores de productos frescos o industrializados en general, han incrementado considerablemente sus exigencias respecto a los niveles de tolerancia de residuos de agroquímicos en los productos, lo que demanda controles y estrategias de producción adecuadas. Dentro de la amplia gama de plaguicidas de uso corriente en la producción citrícola, los benzimidazoles constituyen un grupo importante de fungicidas sistémicos, que son empleados para el control y tratamiento de enfermedades en citrus. El contenido de residuos de estos fungicidas, constituye un importante parámetro de calidad a controlar al momento de comercializar los frutos, tanto para el consumo fresco como para su empleo como materia prima en la industria cítrica. Las metodologías analíticas tradicionales para la determinación de benzimidazoles, son en general complejas, de elevado costo y tiempo de análisis; lo que llevó a plantear como objetivo del presente trabajo el desarrollo de metodologías alternativas para el análisis de fungicidas benzimidazólicos en matrices cítricas. La propuesta incluyó la aplicación y optimización de metodologías analíticas para la determinación de tiofanato, metiltiofanato y thiabendazole por microextracción en fase sólida y cromatografía gaseosa con detector de nitrógeno-fósforo en frutas, jugos concentrados y productos cítricos fermentados; y la determinación de thiabendazole y carbendazim por extracción en fase sólida y cromatografía líquida de alta resolución con detector de arreglo de diodos en aceites esenciales cítricos. En el primer caso se aplicó microextracción en fase sólida utilizando carbowax/dvinilbenceno como polímero de recubrimiento de la fibra, 10 minutos de extracción con agitación magnética a $2000 \mathrm{rpm}$ y $50 \mathrm{ml}$ de muestra a pH 7. Se determinó la masa total absorbida a un tiempo de equilibrio de 720 minutos, las constantes de distribución y los coeficientes de difusión de los analitos en soluciones estándares y muestras adicionadas. El método resultó lineal, preciso, de elevada exactitud y sensibilidad, con límites de cuantificación que oscilaron en un rango de 0,20 - 0,30 ppb para metiltiofanato, $0,18-0,26 \mathrm{ppb}$ para tiofanato y $0,09-0,17 \mathrm{ppb}$ para thiabendazole; y porcentajes de recuperación comprendidos entre 95 y $98 \%$ para los diferentes analitos y matrices. En muestras incógnita se calibró con muestras adicionas debido a la existencia de efecto matriz. 
Se identificaron los analitos extraidos por la fibra mediante cromatorafía gaseosa y espectrometría de masas. La metodología se aplicó a muestras de empaque y jugos concentrados de industria con adecuada reproducibilidad y compatibilidad con los datos de trazabilidad suministrados. Para la determinación de thiabendazole y carbendazim en aceites esenciales cítricos, se optimizó el proceso extractivo en fase sólida utilizando diol como adsorbente y fase móvil como eluyente, consistente en una mezcla $(40: 60 \mathrm{v} / \mathrm{v})$ de $\mathrm{KPO}_{4} \mathrm{H}_{2} 5 \mathrm{mM}$ y Acetonitrilo/Metanol, aciduladas al $0,01 \%$ con ácido acético. Las longitudes de onda seleccionadas fueron 303 y $285 \mathrm{~nm}$ para thiabendazole y carbendazim respectivamente. El método resultó lineal, preciso, de elevada exactitud y sensibilidad, con límites de cuantificación de 58 y 68 ppb para thiabendazole y; 68 y 75 ppb para carbendazim, en soluciones de estándares y muestras adicionadas respectivamente. Los porcentajes de recuperación oscilaron entre 91 - $94 \%$ para thiabendazole y $96-98 \%$ para carbendazim. En muestras incógnita se calibró con muestras adicionas debido a la existencia de efecto matriz. La metodología se aplicó a muestras de aceites esenciales de industria con adecuada reproducibilidad y compatibilidad con los datos de trazabilidad sumnistrados, en cuanto a la carga residual de fungicidas en fruta ingresada en la línea de producción. Las metodologías desarrolladas permiten brindar al sector citrícola una herramienta de fundamental importancia para la atención y control de las problemáticas vinculadas con la producción, industrialización y comercialización de sus productos; lo que hace prever una elevada factibilidad de transferencia de los resultados al medio.

Palabra claves: fungicidas, benzimidazoles, citrus, microextracción. 


\section{SUMMARY}

The Argentinean citrus agro-industry is a huge importance activity in the national and regional economy. Production, packaging, transport, cold treatment and concentrate juice production, essential oils, etc., are included. The controls and strategies on pesticide residues are increasing because of world importer markets and consumers of fresh or industrialized products requirements. Among the wide range of pesticides commonly used in citrus production, benzimidazoles are an important group of fungicides used for the control and treatment of diseases. The control of these fungicides residues are an important quality parameter when the fruits are going to be used for fresh consumption and for industrialization. The objective of this thesis is to develop alternative methodologies for determination of benzimidazoles pesticides in citrus, avoiding traditional ones that are generally of high cost, complex and high time analysis. The development of analytical methods for determination of thiophanate, thiabendazole and thiophanate methyl by solid phase microextraction and gas chromatography with nitrogen-phosphorus detector in fruits, concentrate juice and fermented products, and the determination of thiabendazole and carbendazim by solid phase extraction and high resolution liquid chromatography with diode array detector in essential oils, were proposed. In the first case, a carbowax / dvinilbencene polymer coating fiber was used with the following conditions: 10 minutes extraction with magnetic stirring at $2000 \mathrm{rpm}$ and $50 \mathrm{ml}$ of $\mathrm{pH} 7$ sample. Total mass absorbed at an equilibrium time of 720 minutes, the distribution constants and diffusion coefficients of the analytes in standard solutions and spiked samples were determined. The method was linear, precise, with high accuracy and sensitivity. The limits of quantification were 0.20 to $0.30 \mathrm{ppb}$ for thiophanate methyl, 0.18 to $0.26 \mathrm{ppb}$ for thiophanate and $0.09-0.17 \mathrm{ppb}$ for thiabendazole, and recovery percentages between 95 and $98 \%$ for different analytes and matrices. The calibration curves for unknown samples analysis were made with spiked samples because of the presence of matrix effect. Extracted analytes were identified by gas chromatography - mass spectrometry. The methodology was applied to packaging house and concentrated juice samples showing good reproducibility and compatibility with traceability data provided. Carbendazim and thiabendazole determination in essential oils were optimized using a solid phase extraction with diol as an adsorbent and mobile phase consisting of acetonitrile / methanol $(40: 60, \mathrm{v} / \mathrm{v}), 5 \mathrm{mM} \mathrm{KPO}_{4} \mathrm{H}_{2}$, acidified to $0.01 \%$ with acetic acid as eluents. The selected wavelengths were 303 and 285 
$\mathrm{nm}$ for thiabendazole and carbendazim respectively. The method was linear, precise, with high accuracy and sensitivity.The limits of quantification were 58 and $68 \mathrm{ppb}$ for thiabendazole and 68 and $75 \mathrm{ppb}$ for carbendazim in standard solutions and spiked samples, respectively. The recovery percentages were $91-94 \%$ for thiabendazole and $96-$ $98 \%$ for carbendazim. The calibration curves for unknown samples analysis were made with spiked samples because of the presence of matrix effect. The methodology was applied to essential oils samples showing good reproducibility and compatibility with traceability data provided related with residues of the processed fruits. The developed methodologies give to the citrus productive sector an important tool for problems controlling associated with production, manufacturing and marketing of this products, with high feasibility of transferring the results to the media.

Key words: fungicides - benzimidazoles - citrus - microextraction 


\section{RESUM}

L'agroindustria cítrica argentina, que inclou producció, empaque, transport, tractament per fred i producció de sucs concentrats, olis essencials, etc.; constituïx una de les activitats de fonamental importància en l'economia nacional i regional. Els mercats importadors del món i consumidors de productes frescos o industrialitzats en general, han incrementat considerablement les seues exigències respecte als nivells de tolerància de residus d'agroquímics en els productes, la qual cosa demanda controls i estratègies de producció adequades. Dins de l'àmplia gamma de plaguicides d'ús corrent en la producció citrícola, els benzimidazoles constituïxen un grup important de fungicides sistèmics, que són empleats per al control i tractament de malalties en citrus. El contingut de residus d'estos fungicides constituïx un important paràmetre de qualitat a controlar al moment de comercialitzar els fruits, tant per al consum fresc com per al seu ocupació com a matèria primera en la indústria cítrica. Les metodologies analítiques tradicionals per a la determinació de benzimidazoles, són en general complexes, d'elevat cost i temps d'anàlisi; la qual cosa va portar a plantejar com a objectiu del present treball el desenrotllament de metodologies alternatives per a l'anàlisi de fungicides benzimidazólicos en matrius cítriques. La proposta va incloure l'aplicació i optimació de metodologies analítiques per a la determinació de tiofanato, metiltiofanato i thiabendazole per microextracció en fase sòlida i cromatografia gasosa amb detector de nitrogen-fòsfor en fruites, sucs concentrats i productes cítrics fermentats; i la determinació de thiabendazole i carbendazim per extracció en fase sòlida i cromatografia líquida d'alta resolució amb detector d'arreglament de diodes en olis essencials cítrics. En el primer cas es va aplicar microextracció en fase sòlida utilitzant carbowax/dvinilbenceno com polímero de recobriment de la fibra, 10 minuts d'extracció amb agitació magnètica al $2000 \mathrm{rpm}$ i $50 \mathrm{ml}$ de mostra a pH 7. Es va determinar la massa total absorbida a un temps d'equilibri de 720 minuts, les constants de distribució i els coeficients de difusió dels analitos en solucions estàndards i mostres addicionades. El mètode va resultar lineal, precís, d'elevada exactitud i sensibilitat, amb límits de quantificació que van oscil-lar en un rang de $0,20-0,30 \mathrm{ppb}$ per a metiltiofanato, $0,18-0,26$ ppb per a tiofanato i 0,09-0,17 ppb per a thiabendazole; i percentatges de recuperació compresos entre 95 i $98 \%$ per als diferents analitos i matrius. En mostres incògnita es va calibrar amb mostres addiciones a causa de l'existència d'efecte matriu. Es van identificar els analitos extrets per la fibra per mitjà de cromatografia gasosa i espectrometria de 
masses. La metodologia es va aplicar a mostres de empaque i sucs concentrats d'indústria amb adequada reproducibilitat i compatibilitat amb les dades de trazabilitat subministrats. Per a la determinació de thiabendazole i carbendazim en olis essencials cítrics, es va optimar el procés extractiu en fase sòlida utilitzant diol com adsorbent i fase mòbil com eluient, consistent en una mescla $(40: 60 \mathrm{v} / \mathrm{v})$ de KPO4H2 $5 \mathrm{~mm}$ i Acetonitrilo/Metanol, acidulades al 0,01\% amb àcid acètic. Les longituds d'ona seleccionades van ser 303 i $285 \mathrm{~nm}$ per a thiabendazole i carbendazim respectivament. El mètode va resultar lineal, precís, d'elevada exactitud i sensibilitat, amb límits de quantificació de 58 i 68 ppb per a thiabendazole, i 68 i 75 ppb per a carbendazim, en solucions d'estàndards i mostres addicionades respectivament. Els percentatges de recuperació van oscil.lar entre $91-94 \%$ per a thiabendazole i $96-$ $98 \%$ per a carbendazim. En mostres incògnita es va calibrar amb mostres addiciones a causa de l'existència d'efecte matriu. La metodologia es va aplicar a mostres d'olis essencials d'indústria amb adequada reproducibilitat i compatibilitat amb les dades de trazabilitat subministrats, quant a la càrrega residual de fungicides en fruita ingressada en la línia de producció. Les metodologies desenrotllades permeten brindar al sector citrícola una ferramenta de fonamental importància per a l'atenció i control de les problemàtiques vinculades amb la producció, industrialització i comercialització dels seus productes; la qual cosa fa prevore una elevada factibilitat de transferència dels resultats al medi.

Paraules clau: fungicides, benzimidazoles, citrus, microextracció. 


\section{ÍNDICE GENERAL}

INTRODUCCIÓN...................................................... 3 -

Producción citrícola........................................................... - 3 -

Distribución Regional de la Citricultura Argentina ........... - 3 -

Nivel de ocupación ........................................................ - 5 -

Destino de la producción de frutas cítricas....................... - 5 -

Naturaleza, enfermedades y preservación de las

frutas .................................................................... - 6 -

Fungicidas Orgánicos......................................................... - 9 -

Fungicidas sistémicos.............................................. - 10 -

Principales características de algunos fungicidas

sistémicos de interés .............................................. - 13 -

Producción citrícola y plaguicidas ................................ 21 -

Problemática y demanda de soluciones del sector citrícola e industrial ...................................................... - 31 -

Metodologías Analíticas .............................................. - 32 -

Extracción en Fase Sólida (SPE) ................................ - 33 -

Microextracción en fase sólida - SPME ......................... - 38 -

Desarrollo de un método por SPME................................. - 48 -

Selección del absorbente............................................... - 49 -

Selección del modo de extracción ................................. - 50 -

Selección de la técnica de agitación ............................... - 51 -

Selección de técnica de separación y/o detección ........... - 52 - 
Optimización de las condiciones de desorción $-52-$

Optimización del volumen de muestra $-54-$

Determinación del perfil de tiempo de extracción en matriz pura $-56-$

Determinación del tiempo de extracción $56-$

Cálculo de la constante de distribución $-57-$

Determinación del intervalo lineal del método para una matriz pura, en condiciones óptimas de extracción. $59-$

Selección del método de calibración $-59-$

Optimización de las condiciones de extracción para muestras heterogéneas.

Verificación del tiempo de equilibrio, sensibilidad y rango dinámico lineal para muestras de matrices complejas.

DESARROLLO Y APLICACIÓN DE METODOLOGÍAS ANALÍTICAS.

\subsection{DETERMINACIÓN MULTIRESIDUO DE BENZIMIDAZOLES POR CROMATOGRAFÍA GASEOSA CON DETECTOR NITRÓGENO-FÓSFORO (GC/NPD)......... - 77 -}

Generalidades................................................................. 77 -

Materiales y método ....................................................... 78 -

Reactivos ...................................................... 78 -

Equipamiento ..................................................... 78 - 
Preparación de estándares $-78-$

Condiciones cromatográficas......................................... - 79 -

Análisis estadístico ..................................................... - 80 -

Resultados y discusión ................................................... - 82 -

\subsection{DETERMINACIÓN MULTIRESIDUO DE BENZIMIDAZOLES POR MICROEXTRACCIÓN EN FASE SÓLIDA Y CROMATOGRAFÍA GASEOSA CON DETECTOR DE NITRÓGENO-FÓSFORO (SMPE/GC/NPD)}

Generalidades $-93-$

Materiales y método............................................................. 94 -

Reactivos.................................................................. 94

Equipamiento.................................................. - 94 -

Condiciones cromatográficas........................................ - 95 -

Preparación de estándares .............................................. 96 -

Plan de muestreo.................................................... - 98 -

Submuestreo - Preparación de las muestras para el análisis en laboratorio

Preparación de blancos de muestra y muestras adicionadas

Tratamiento previo de las muestras $-102-$

Condiciones de extracción y desorción $-103-$

Desarrollo de la metodología analítica $-106-$

Aplicación de la metodología analítica $-110-$

Análisis estadístico $-110-$

Resultados y discusión $-115-$

Soluciones acuosas estándares de benzimidazoles $-115-$ 
Muestras adicionadas $132-$

Aplicación de la metodología a muestras de empaque e industria

\subsection{DETERMINACIÓN MULTIRESIDUO DE BENZIMIDAZOLES POR MICROEXTRACCIÓN EN FASE SÓLIDA Y CROMATOGRAFÍA GASEOSA CON DETECTOR DE MASA (SMPE/GC/MSD)}

Generalidades ................................................................ - 193 -

Materiales y método ........................................................ 195 -

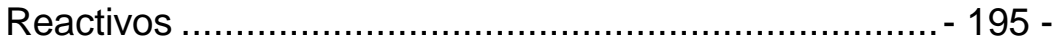

Equipamiento .......................................................... 196 -

Preparación de estándares ......................................... 196 -

Muestreo, submuestreo y preparación de las muestras

Condiciones cromatográficas $198-$

Condiciones de extracción $201-$

Resultados y discusión..................................................... 203 -

Condiciones cromatográficas ..................................... 203 -

Identificación de benzimidazoles por SPME/GC/MSD y PTV modo venteo de solvente y GC/MSD

\subsection{DETERMINACIÓN SIMULTÁNEA DE BENZIMIDAZOLES POR EXTRACCIÓN EN FASE SÓLIDA Y CROMATOGRAFÍA LÍQUIDA DE ALTA RESOLUCIÓN CON DETECTOR DE ARREGLO DE DIODOS - SPE/HPLC/DAD.}

Generalidades $211-$

Materiales y método $212-$ 
Reactivos $212-$

Equipamiento $213-$

Desarrollo metodológico $-213-$

Condiciones cromatográficas $-215-$

Preparación de estándares $-216-$

Plan de muestreo. $-216-$

Preparación de muestras adicionadas $-217-$

Tratamiento previo de las muestras $217-$

Extracción y concentración en fase sólida (SPE) $-218-$

Análisis estadístico $-222-$

Resultados y discusión $-225-$

Condiciones cromatográficas. $225-$

Selección del adsorbente, "clean up" y concentración .. - 226 -

Selección del eluyente $226-$

Linealidad $227-$

Comparación de rectas de regresión - Estándares vs. Aceites esenciales cítricos adicionados $-236-$

Precisión $-238-$

Límites de cuantificación y detección $239-$

Exactitud. $-240-$

Aplicación del método a muestras de aceites esenciales provenientes de industria $-242-$ 



\section{ÍNDICE DE TABLAS}

Tabla 1. Destino de la producción citrícola argentina del año 2009 en toneladas $-6-$

Tabla 2. Sorbentes más comunes y sistemas de preparación $-35-$

Tabla 3. Análisis unidimensional - Respuestas cromatográficas expresadas en alturas de pico Soluciones estándares en etilacetato - Inyección directa - GC-NPD - $n=5, \alpha=0,05$

Tabla 4. Análisis unidimensional - Respuestas cromatográficas expresadas en áreas de pico Soluciones estándares en etilacetato - Inyección directa $-\mathrm{n}=5, \alpha=0,05$. $-85-$

Tabla 5. Interceptos y pendientes - Comparación rectas de regresión - Soluciones de estándares en etilacetato Inyección directa - GC-NPD $-87-$

Tabla 6. Precisión - Valores medios expresados en alturas de pico - Inyección directa $2 \mu l-$ GC-NPD - $\mathrm{n}=5$, $\alpha=0.05$ $-91-$

Tabla 7. Límite de detección y cuantificación - inyección directa $2 \mu \mathrm{l}-$ GC-NPD $-92-$ 
Tabla 8. Comparación de polímeros - Análisis unidimensional -- Respuestas cromatográficas en alturas de pico - Soluciones acuosas estándares de benzimidazoles - SPME/GC/NPD - 10 min extracción $\mathrm{n}=10, \alpha=0,05$

Tabla 9. Perfil de masa absorbida en función del tiempo de extracción - Análisis unidimensional - Respuestas cromatográficas en alturas de pico - Soluciones acuosas estándares de benzimidazoles a $20 \mathrm{ppb}$ - volumen de muestra $50 \mathrm{ml}$ - agitación magnética a $2000 \mathrm{rpm}-\mathrm{n}=5$, $\alpha=0,05$

Tabla 10. Valores medios comparativos de los analitos expresados en alturas de picos para soluciones de 5 ppm por inyección directa de $2 \mu \mathrm{l}$ y soluciones acuosas de 20 ppb con 12 horas de inmersión (SPMECWX/DVB) y agitación magnética a 2000 rpm.

Tabla 11. Determinación de la Constante de Distribución Polímero de recubrimiento/Agua $123-$

Tabla 12. Volumen limitante de muestra y coeficiente de difusión analito/ CWX/DVB - soluciones acuosas de 20 ppb - inmersión 12 h y agitación magnética a 2000 rpm.- 124 -

Tabla 13. Análisis unidimensional - Respuestas cromatográficas expresadas en alturas de pico Soluciones acuosas estándares - CWX/DVB - $50 \mathrm{ml}$ muestra - agitación magnética a $2000 \mathrm{rpm}-\mathrm{n}=10$, $\alpha=0,05$. 
Tabla 14. Análisis unidimensional - Respuestas cromatográficas expresadas en áreas de pico Soluciones acuosas estándares - CWX/DVB - $50 \mathrm{ml}$ muestra - agitación magnética a $2000 \mathrm{rpm}-\mathrm{n}=10$, $\alpha=0,05$

Tabla 15. Precisión - Valores medios expresados en alturas de pico - Soluciones acuosas de estándares a pH 7 CWX/DVB - 10 min de extracción - agitación magnética a $2000 \mathrm{rpm}-\mathrm{n}=10$ y $\alpha=0,05$

Tabla 16. Límite de detección y cuantificación - Soluciones acuosas de estándares benzimidazoles a $\mathrm{pH} 7$ CWX/DVB - 10 min de extracción - agitación magnética a $2000 \mathrm{rpm}-\mathrm{n}=30$ y $\alpha=0,05$ $-132-$

Tabla 17. Perfil de masa absorbida en función del tiempo de extracción - Análisis unidimensional - Valores medios en altura de pico - Soluciones acuosas frutas adicionadas a $20 \mathrm{ppb}$ - volumen de muestra $50 \mathrm{ml}$ agitación magnética a $2000 \mathrm{rpm}-\mathrm{n}=5, \alpha=0,05$

Tabla 18. Valores medios comparativos de los analitos expresados en alturas de picos para soluciones de 5 ppm por Inyección directa de $2 \mu \mathrm{l}$ y frutas adicionadas a 20 ppb - 12 h de inmersión CWX/DVB - agitación magnética a $2000 \mathrm{rpm}$. $-138-$

Tabla 19. Determinación de la Constante de Distribución Polímero de recubrimiento/Agua $-139-$ 
Tabla 20. Volumen limitante de muestra y coeficiente de difusión analito/ CWX/DVB - frutas adicionadas a 20 ppb - inmersión 12 horas y agitación magnética a 2000 rpm.- 140 -

Tabla 21. Análisis comparativo de constantes de distribución y coeficientes de difusión para soluciones acuosas de estándares (ES) y frutas adicionadas (FA) a 20 ppb inmersión 12 horas y agitación magnética $140-$

Tabla 22. Análisis unidimensional - Respuestas cromatográficas en alturas de pico - Soluciones acuosas frutas adicionadas - CWX/DVB - $50 \mathrm{ml}$ muestra agitación magnética a $2000 \mathrm{rpm}-\mathrm{n}=10, \alpha=0,05 \ldots \ldots . . .142$ -

Tabla 23. Interceptos y pendientes - Rectas de regresión Soluciones acuosas de estándares y frutas adicionadas - 148 -

Tabla 24. Precisión - Valores medios en alturas de pico Soluciones acuosas de frutas adicionadas a $\mathrm{pH} 7$ CWX/DVB - 10 min de extracción - agitación magnética a $2000 \mathrm{rpm}-\mathrm{n}=10$ y $\alpha=0,05$. $149-$

Tabla 25. Exactitud del método - Soluciones acuosas de frutas adicionadas $-n=15$ y $\alpha=0,05$ $150-$

Tabla 26. Límite de detección y cuantificación - Soluciones acuosas de frutas adcionadas a $\mathrm{pH} 7-\mathrm{CWX} / \mathrm{DVB}-10$ min de extracción - agitación magnética a 2000 rpm $\mathrm{n}=30$ y $\alpha=0.05$ $151-$

Tabla 27. Perfil de masa absorbida en función del tiempo de extracción - Análisis unidimensional - Valores medios en altura de pico - Soluciones acuosas Jugos cítricos 
adicionados a $20 \mathrm{ppb}$ - volumen de muestra $50 \mathrm{ml}$ agitación magnética a $2000 \mathrm{rpm}-\mathrm{n}=5, \alpha=0,05$ $138-$

Tabla 28. Valores medios comparativos de los analitos expresados en alturas de picos para soluciones de 5 ppm por Inyección directa de $2 \mu$ y jugos adicionados a 20 ppb - 12 h de inmersión CWX/DVB - agitación magnética a $2000 \mathrm{rpm}$.

Tabla 29. Determinación de la Constante de Distribución Polímero de recubrimiento/Agua $-156-$

Tabla 30. Volumen limitante de muestra y coeficiente de difusión analito/ CWX/DVB - jugos adicionados a 20 ppb - inmersión 12 h y agitación magnética a 2000 rpm $-156-$

Tabla 31. Análisis unidimensional - Respuestas cromatográficas en alturas de pico - Soluciones acuosas jugos adicionados - CWX/DVB - $50 \mathrm{ml}$ muestra agitación magnética a $2000 \mathrm{rpm}-\mathrm{n}=10, \alpha=0,05$ $-157-$

Tabla 32. Interceptos y pendientes - Rectas de regresión Soluciones acuosas de estándares y jugos cítricos adicionados

Tabla 33. Precisión - Valores medios expresados en alturas de pico - Soluciones acuosas de jugos adicionados a pH 7 - CWX/DVB - 10 min de extracción $-n=10$ y $\alpha=0,05$ $-164-$

Tabla 34. Exactitud del método - Soluciones acuosas de jugos adicionados $-\mathrm{n}=15$ y $\alpha=0,05$ 
Tabla 35. Límite de detección y cuantificación - Soluciones acuosas de jugos adicionados a pH 7 - CWX/DVB - 10 minutos de extracción - agitación magnética a 2000 rpm $-n=30$ y $\alpha=0,05$ $166-$

Tabla 36. Perfil de masa absorbida en función del tiempo de extracción - Análisis unidimensional - Valores medios en alturas de pico - Soluciones acuosas "Vinos cítricos" adicionados a $20 \mathrm{ppb}$ - volumen de muestra $50 \mathrm{ml}$ agitación magnética a $2000 \mathrm{rpm}-\mathrm{n}=5, \alpha=0,05$. $166-$

Tabla 37. Valores medios comparativos de los analitos expresados en alturas de picos para soluciones de 5 ppm por Inyección directa de $2 \mu \mathrm{l}$ y "vinos cítricos" adicionados a 20 ppb - 12 horas de inmersión CWX/DVB - agitación magnética.

Tabla 38. Determinación de la Constante de Distribución Polímero de recubrimiento/Agua $-170-$

Tabla 39. Volumen limitante de muestra y coeficiente de difusión analito/ CWX/DVB - "Vinos cítricos" adicionados a 20 ppb - inmersión 12 h y agitación magnética a 2000 rpm.

Tabla 40. Análisis unidimensional - Respuestas cromatográficas expresadas en altura de pico Soluciones acuosas "Vinos cítricos" adicionados CWX/DVB - $50 \mathrm{ml}$ muestra - agitación magnética a $2000 \mathrm{rpm}-\mathrm{n}=10, \alpha=0,05$ $-172-$ 
Tabla 41. Interceptos y pendientes - Rectas de regresión Soluciones acuosas de estándares y "Vinos cítricos" adicionados

Tabla 42. Precisión - Valores medios expresados en alturas de pico - Soluciones acuosas de "vinos cítricos" adicionados a pH 7 - CWX/DVB - 10 min de extracción - agitación magnética $-n=10$ y $\alpha=0,05$ $-180-$

Tabla 43. Exactitud del método - Soluciones acuosas de "Vinos cítricos" adicionados $-\mathrm{n}=15$ y $\alpha=0,05$.

Tabla 44. Límite de detección y cuantificación - Soluciones acuosas de "vinos cítricos" adicionados a pH 7 CWX/DVB - 10 min de extracción - agitación magnética a $2000 \mathrm{rpm}-\mathrm{n}=30$ y $\alpha=0,05$

Tabla 45. Concentraciones medias de residuos benzimidazólicos, en $\mathrm{mg} / \mathrm{Kg}$ - Frutas cítricas de empaques - Temporadas agrícolas 2008 y 2009

Tabla 46. Análisis unidimensional de los datos expresados en $\mathrm{mg} / \mathrm{Kg}$ de fruta - Frutas cítricas de empaques $-\mathrm{n}=5$, $\alpha=0,05$ Temporadas agrícolas 2008 y 2009 .

Tabla 47. Análisis unidimensional de los datos expresados en $\mu \mathrm{g} / \mathrm{Kg}$ de jugo concentrado - Jugos cítricos 2009 y $2010-\mathrm{n}=5, \alpha=0,05$.

Tabla 48. Benzimidazoles - GC/MSD - PTV en modo "split/splitles" 
Tabla 49. Rangos de \% de recuperación para diferentes eluyentes - Aceites esenciales adicionados a 0,5 ppm Inyección $30 \mu \mathrm{l}-\mathrm{n}=5$ y $\alpha=0,05$ $227-$

Tabla 50. Análisis unidimensional - Soluciones estándares en fase móvil - Inyección $30 \mu \mathrm{l}-\mathrm{n}=10, \alpha=0,05$ $228-$

Tabla 51. Análisis unidimensional - Valores medios expresados en alturas de pico - Aceite esencial adicionado - Inyección $30 \mu \mathrm{l}-\mathrm{n}=10, \alpha=0,05$. $232-$

Tabla 52. Interceptos y pendientes - Comparación rectas de regresión - Soluciones de estándares y aceites adicionados $238-$

Tabla 53. Precisión - Valores medios de respuestas cromatográficas expresadas en alturas de pico Soluciones estándares de benzimidazoles y aceites esenciales adicionados - Volumen de inyección $30 \mu \mathrm{l}-$ $\mathrm{n}=10$ y $\alpha=0,05$ $239-$

Tabla 54. Límite de detección y cuantificación - Soluciones estándares y aceites adicionados - Volumen de inyección $30 \mu \mathrm{l}-\mathrm{n}=10$ y $\alpha=0,05$. $-240-$

Tabla 55. Exactitud del método - Soluciones acuosas de frutas adicionadas $-\mathrm{n}=35$ y $\alpha=0,05$. $-241-$ 


\section{ÍNDICE DE FIGURAS}

Figura 1. Distribución geográfica de la citricultura argentina ... - 4 -

Figura 2. Fórmula estructural del Thiabendazole $-13-$

Figura 3. Fórmula estructural del Tiofanato $-15-$

Figura 4. Fórmula estructural del Metiltiofanato. $-16-$

Figura 5. Fórmula estructural del Benomil. $-18-$

Figura 6. Fórmula estructural del Carbendazim. $-20-$

Figura 7. Cartuchos para Extracción en Fase Sólida (SPE) .. - 34 -

Figura 8. Etapas del proceso de Extracción en Fase Sólida (SPE) $-37-$

Figura 9. Colector múltiple de vacío y accesorios SPE $-38-$

Figura 10. Jeringa y fibra SPME. $-39-$

Figura 11. Presentación de la configuración del sistema SPME/muestra. $-40-$

Figura 12. Extracción directa - SPME. $-43-$

Figura 13. Efecto del volumen del inyector en la desorción... - 53 Figura 14. Regresión lineal alturas de pico vs. concentración - Soluciones estándares en etilacetato Inyección directa - GC-NPD $-86-$ 
Figura 15. Regresión lineal áreas de pico vs. concentración - Soluciones estándares en etilacetato - Inyección directa - GC-NPD $-86-$

Figura 16. Comparación de rectas de regresión área de pico vs. concentración y altura de pico vs. concentración Soluciones estándares metiltiofanato en etilacetato Inyección directa - GC-NPD $87-$

Figura 17. Regresión lineal - Soluciones estándares metiltiofanato en etilacetato - Inyección directa - GCNPD.

Figura 18. Regresión lineal - Soluciones estándares tiofanato en etilacetato - Inyección directa - GC-NPD ..... 89 -

Figura 19. Regresión lineal - Soluciones estándares thiabendazole en etilacetato - Inyección directa - GCNPD.

Figura 20. Comparación de fibras - Metiltiofanato.

Figura 21. Perfil de masa absorbida en función del tiempo de extracción - Análisis unidimensional - Respuestas cromatográficas en alturas de pico - Soluciones acuosas estándares de benzimidazoles a $20 \mathrm{ppb}$ - volumen de muestra $50 \mathrm{ml}$ - agitación magnética a $2000 \mathrm{rpm}-\mathrm{n}=5$, $\alpha=0,05$.

Figura 22. Cromatograma - Solución acuosa de estándares de benzimidazoles a $10 \mathrm{ppb}$ y $\mathrm{pH} 7$ - CWX/DVB - 10 min de extracción - agitación a 2000 rpm 
Figura 23. Regresión lineal - Soluciones acuosas estándares benzimidazoles a pH 7 - CWX/DVB - 10 min de extracción - agitación magnética a 2000 rpm ..... - 128 -

Figura 24. Regresión lineal - Metiltiofanato - Soluciones acuosas estándares de benzimidazoles a pH 7 CWX/DVB - 10 min de extracción - agitación magnética- 128 -

Figura 25. Regresión lineal - Tiofanato - Soluciones acuosas estándares de benzimidazoles a $\mathrm{pH} \quad 7$ CWX/DVB - 10 min de extracción - agitación magnética- 129 -

Figura 26. Regresión lineal - Thiabendazole - Soluciones acuosas estándares de benzimidazoles a $\mathrm{pH} 7$ CWX/DVB - 10 min de extracción - agitación magnética- 129 -

Figura 27. Perfil de masa absorbida en función del tiempo de extracción - Análisis unidimensional - Valores medios en altura de pico - Soluciones acuosas frutas adicionadas a $20 \mathrm{ppb}$ - volumen de muestra $50 \mathrm{ml}$ agitación magnética a $2000 \mathrm{rpm}-\mathrm{n}=5, \alpha=0,05$ $129-$

Figura 28. Perfiles comparativos de masa absorbida en función del tiempo de extracción para soluciones acuosas de estándares y frutas cítricas adicionadas a 20 ppb - Metiltiofanato $137-$

Figura 29. Perfiles comparativos de masa absorbida en función del tiempo de extracción para soluciones acuosas de estándares y frutas cítricas adicionadas a 20 ppb - Tiofanato. $137-$ 
Figura 30. Perfiles comparativos de masa absorbida en función del tiempo de extracción para soluciones acuosas de estándares y frutas cítricas adicionadas a 20 ppb - Thiabendazole

Figura 31. Cromatograma - Solución acuosa de Fruta adicionada con estándares de benzimidazoles a $10 \mathrm{ppb}$ y pH 7 - CWX/DVB - 10 min de extracción - agitación magnética a $2000 \mathrm{rpm}$

Figura 32. Regresión lineal - Soluciones acuosas de frutas adicionadas a pH 7 - CWX/DVB - 10 min de extracción - agitación magnética a 2000 rpm

Figura 33. Regresión lineal - Metiltiofanato - Soluciones acuosas de frutas adicionadas a $\mathrm{pH} 7-\mathrm{CWX} / \mathrm{DVB}-10$ min de extracción - agitación magnética

Figura 34. Regresión lineal - Tiofanato - Soluciones acuosas de frutas adicionadas a $\mathrm{pH} 7-\mathrm{CWX} / \mathrm{DVB}-10$ min de extracción - agitación magnética

Figura 35. Regresión lineal - Thiabendazole - Soluciones acuosas de frutas adicionadas a $\mathrm{pH} 7-\mathrm{CWX} / \mathrm{DVB}-10$ min de extracción - agitación magnética

Figura 36. Comparación de rectas de regresión Metiltiofanato - Soluciones acuosas de estándares y frutas adicionadas a $\mathrm{pH} 7-\mathrm{CWX} / \mathrm{DVB}-10 \mathrm{~min}$ de extracción - agitación magnética a 2000 rpm.

Figura 37. Comparación de rectas de regresión - Tiofanato - Soluciones acuosas de estándares y frutas 
adicionadas a pH 7 - CWX/DVB - 10 min de extracción - agitación magnética a 2000 rpm

Figura 38. Comparación de rectas de regresión Thiabendazole - Soluciones acuosas de estándares y frutas adicionadas a pH 7 - CWX/DVB - $10 \mathrm{~min}$ de extracción - agitación magnética a 2000 rpm

Figura 39. Perfil de masa absorbida en función del tiempo de extracción - Soluciones acuosas de jugos cítricos adicionados a $20 \mathrm{ppb}$

Figura 40. Regresión lineal - Soluciones acuosas de jugos adicionados a pH 7 - CWX/DVB - 10 min de extracción - agitación magnética a 2000 rpm $159-$

Figura 41. Regresión lineal - Metiltiofanato - Soluciones acuosas de jugos adicionados a pH 7 - CWX/DVB - 10 min de extracción - agitación magnética $159-$

Figura 42. Regresión lineal - Tiofanato - Soluciones acuosas de jugos adicionados a pH 7 - CWX/DVB - 10 min de extracción - agitación magnética $-160-$

Figura 43. Regresión lineal - Thiabendazole - Soluciones acuosas de jugos adicionados a pH $7-C W X / D V B-10$ min de extracción - agitación magnética $160-$

Figura 44. Comparación de rectas de regresión Metiltiofanato - Soluciones acuosas de estándares y Jugos adicionados a pH 7 - CWX/DVB - $10 \mathrm{~min}$ de extracción - agitación magnética a 2000 rpm 
Figura 45. Comparación de rectas de regresión - Tiofanato - Soluciones acuosas de estándares y Jugos adicionados a pH 7 - CWX/DVB - 10 min de extracción - agitación magnética a 2000 rpm

Figura 46. Comparación de rectas de regresión Thiabendazole - Soluciones acuosas de estándares y Jugos adicionados a pH 7 - CWX/DVB - 10 min de extracción - agitación magnética a 2000 rpm. $-162-$

Figura 47. Perfil de masa absorbida en función del tiempo de extracción - Soluciones acuosas de "vinos cítricos" adicionados a $20 \mathrm{ppb}$

Figura 48. Cromatograma - Solución acuosa de "Vino cítrico" adicionado con estándares de benzimidazoles a 10 ppb y pH 7 - CWX/DVB - 10 min de extracción agitación magnética a 2000 rpm $173-$

Figura 49. Regresión lineal - Soluciones acuosas de "vinos cítricos" adicionados a $\mathrm{pH} 7$ - CWX/DVB - $10 \mathrm{~min}$ de extracción - agitación magnética 2000 rpm

Figura 50. Regresión lineal - Metiltiofanato - Soluciones acuosas "Vinos cítricos" adicionados a pH 7 - CWX/DVB - 10 min de extracción - agitación magnética $175-$

Figura 51. Regresión lineal - Tiofanato - Soluciones acuosas "Vinos cítricos" adicionados a pH 7 - CWX/DVB - 10 min de extracción - agitación magnética 
Figura 52. Regresión lineal - Thiabendazole - Soluciones acuosas "Vinos cítricos" adicionados a pH 7 - CWX/DVB - 10 min de extracción - agitación magnética. $176-$

Figura 53. Comparación de rectas de regresión Metiltiofanato - Soluciones acuosas de estándares y "Vinos cítricos" adicionados a pH 7 - CWX/DVB - 10 min de extracción - agitación magnética a 2000 rpm $-177-$

Figura 54. Comparación de rectas de regresión - Tiofanato - Soluciones acuosas de estándares y "Vinos cítricos" adicionados a pH 7 - CWX/DVB - 10 min de extracción - agitación magnética a 2000 rpm

Figura 55. Comparación de rectas de regresión Thiabendazole - Soluciones acuosas de estándares y "Vinos cítricos" adicionados a pH 7 - CWX/DVB - 10 min de extracción - agitación magnética a 2000 rpm $178-$

Figura 56. Cromatograma Metiltiofanato y Tiofanato - Fruta de Empaque - Muestreo 2 - Empaque E3 - Cosecha 2008 - CWX/DVB - GC/NPD $-185-$

Figura 57. Cromatograma Thiabendazole - Fruta de Empaque - Muestreo 1 - Empaque E1 - Cosecha 2009 - CWX/DVB - GC/NPD $185-$

Figura 58. Cromatograma benzimidazoles -Frutas cítricas adicionadas a 50 ppb CWX/DVB - GC/MSD $208-$

Figura 59. Espectro de masas benzimidazoles - TBZ, Tiofanato y Metiltiofanato $-208-$ 
Figura 60. Etapas de un proceso de Extracción en Fase Sólida $220-$

Figura 61. Cromatograma - Solución de estándares a 10 ppm - Inyección $30 \mu \mathrm{l}$. $229-$

Figura 62. Regresión lineal - Soluciones estándares benzimidazoles en fase móvil - Volumen inyección 30 l- 229 -

Figura 63. Regresión lineal - Thiabendazole - Soluciones estándares de benzimidazoles en fase móvil - Volumen de inyección $30 \mu \mathrm{l}$ $230-$

Figura 64. Regresión lineal - Carbendazim - Soluciones estándares de benzimidazoles en fase móvil - Volumen de inyección $30 \mu \mathrm{l}$ $-230-$

Figura 65. Cromatograma - Aceite esencial adicionado a 5 ppm - Volumen Inyección $30 \mu \mathrm{l}$ $230-$

Figura 66. Regresión lineal - Aceites esenciales adicionados - Volumen inyección $30 \mu \mathrm{l}$ $234-$

Figura 67. Regresión lineal - Thiabendazole - Aceites esenciales adicionados - Volumen de inyección $30 \mu \mathrm{l} . .$. - 235 -

Figura 68. Regresión lineal - Carbendazim - Aceites esenciales adicionados - Volumen de inyección $30 \mu \mathrm{l} . .$. - 235 -

Figura 69. Comparación de rectas de regresión Thiabendazole - Soluciones de estándares y aceites adicionados $237-$ 
Figura 70. Comparación de rectas de regresión Carbendazim - Soluciones de estándares y aceites adicionados.................................................................. - 237 - 

CAPÍTULOI

INTRODUCCIÓN 



\section{INTRODUCCIÓN}

\section{Producción citrícola}

La República Argentina constituye un país tradicionalmente citrícola y su producción anual la sitúa entre los primeros del mundo. La agroindustria cítrica, que incluye producción, empaque, transporte, tratamiento por frío y producción de jugos concentrados, aceites, etc.; es una de las actividades agroindustriales más importantes. En el país la citricultura se desarrolla sobre una superficie aproximada de 140.000 hectáreas, de las cuales el 35,4\% corresponde a la naranja, el 25,7 \% a mandarina, el pomelo alcanza el 5,5 \% y el limón aporta el 32,2\% (INTA, 2009). La producción nacional del año 2009, alcanzó a 2.963.283 toneladas distribuidas de la siguiente forma (INTA, 2009): Limón 48,1 \%, Naranja 30,3 \%, Mandarina 13,6 \% y Pomelo $8,0 \%$.

\section{Distribución Regional de la Citricultura Argentina}

La actividad citrícola Argentina se desarrolla principalmente en dos regiones bien definidas (Justo y Rivera, 2007). Una es la región del Noroeste Argentino (NOA) -Tucuman, Jujuy, Salta y Catamarca, que representa el $63 \%$ de la superficie citrícola total, en la que es dominante la producción de limón y pomelo, que 
alcanzan alrededor del $96 \%$ y $86 \%$ de la oferta nacional respectivamente; la segunda es la mesopotámica o región del Nordeste (NEA) - Entre Ríos, Corrientes, Misiones, Buenos Aires y sur de Santa Fe, con importantes áreas cubiertas por naranjos y mandarinos, que aportan aproximadamente el $62 \%$ y $83 \%$ de la producción nacional respectivamente.

En la figura 1 se indica la distribución geográfica de la producción citrícola en el país.

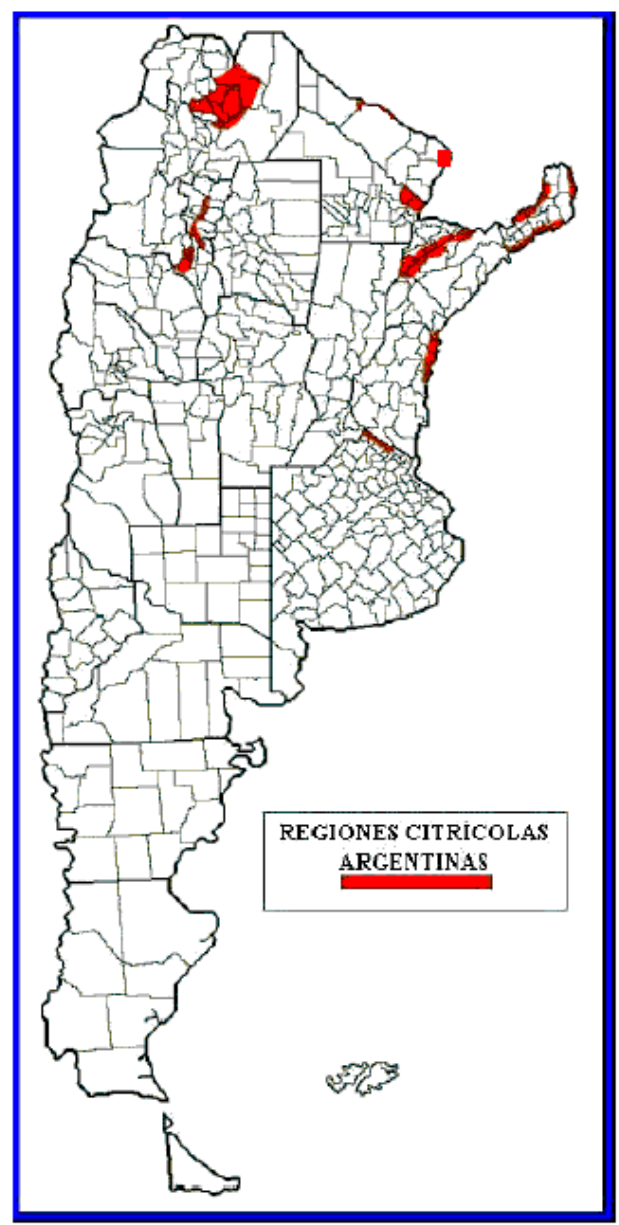

Figura 1. Distribución geográfica de la citricultura argentina Fuente: (SAGPYA, 2004). 
En la provincia de Entre Ríos, la producción de cítricos se encuentra localizada sobre la costa del Río Uruguay en los Departamentos de Concordia, Federación y norte de Colón (Dansa, 2007).

\section{Nivel de ocupación}

Desde el punto de vista ocupacional la producción citrícola, cuyo proceso productivo se basa en cultivos perennes, requiere mano de obra permanente para las labores del campo, por lo que representa una importante fuente laboral. El nivel de ocupación se ve favorecido por los establecimientos de empaques e industrias cítricas que requieren personal, como operarios, técnicos, profesionales, empleados administrativos, personal de transporte, etc.

Según datos provenientes de la Servicio Nacional de Sanidad y Calidad Agroalimentaria (SENASA) y la Federación del Citrus (Federcitrus) el nivel de ocupación generado por la actividad citrícola nacional comprende 5.300 productores, 529 empaques, 79 empaques para la exportación, 16 plantas industriales y la mano de obra ocupada alcanza a unos 100.000 trabajadores (Federcitrus, 2007; SENASA, 2007).

\section{Destino de la producción de frutas cítricas}

La producción citrícola nacional se destina tanto al mercado interno como externo. En cuanto al mercado interno es 
necesario recordar que existe una tradicional sobre oferta en gran parte del año. La industria cítrica nacional abastece el mercado interno normalmente con aproximadamente el $40 \%$ de su producción en materia de jugos (Federcitrus, 2007; SENASA, 2007). El resto de la producción de jugos concentrados y demás productos como aceites esenciales, pellets, cáscara deshidratada, pulpa congelada, limoneno, etc. se envía a los mercados externos. El destino de la producción de cítricos en el país en el año 2010 se muestra en la tabla 1, estimando un 2,5\% de pérdidas en pre y post-cosecha para limón, $15 \%$ para pomelo y $10 \%$ en naranja y mandarina. Con respecto al mercado externo, Argentina exporta frutas a España, Holanda, Bélgica, Rusia, Reino Unido, Polonia, Grecia, Canadá, Rumania, Italia, Filipinas, etc.

Tabla 1. Destino de la producción citrícola argentina del año 2009 en toneladas (Fuente: Federcitrus, 2010)

\begin{tabular}{|c|c|c|c|c|}
\hline Variedad & Industria & $\begin{array}{c}\text { Consumo } \\
\text { Interno }\end{array}$ & $\begin{array}{c}\text { Exportación } \\
\text { en fresco }\end{array}$ & TOTAL \\
\hline Limón & 1.100 .270 & 35.645 & 253.976 & 1.425 .529 \\
\hline Mandarina & 75.328 & 171.716 & 114.345 & 401.543 \\
\hline Naranja & 163.826 & 503.017 & 142.016 & 898.732 \\
\hline Pomelo & 86.841 & 97.295 & 17.721 & 237.479 \\
\hline TOTAL & 1.426 .265 & 807.672 & 528.058 & 2.963 .283 \\
\hline
\end{tabular}

\section{Naturaleza, enfermedades y preservación de las frutas}

El fruto es un organismo vivo, cuyo metabolismo prosigue aún después de su recolección, con la diferencia que separado del árbol, vive a expensas de sus propias y exclusivas reservas. De esta manera va evolucionando hasta la senescencia, con pérdida progresiva de la calidad, debida a varios factores, como 
ser: disminución de peso por transpiración, menor contenido de vitamina C, aparición de alteraciones fisiológicas, enfermedades, daños mecánicos, etc.

La exportación de fruta cítrica está limitada y con pérdidas notables, por varias enfermedades de postcosecha. Se destacan aquellas cuyas infecciones comienzan en la quinta, como Phytophthora citrophthora (podredumbre marrón), que aparece a inicios del período de exportación. Geotrichum candidum a mediados y finales del período de exportación, conjuntamente con Phomopsis citri (podredumbre apicular) (Mazzuz, 1996).

$P$. citrophthora y P. parasítica (podredumbre marrón) se encuentran presentes en los suelos de las quintas. La fruta infectada en el campo generalmente cae; pero en sus primeros estadíos de enfermedad pasan desapercibidas durante la cosecha, produciendo luego la cadena de infección en las frutas sanas en el empaque o estacionamiento. La incidencia de ésta en los galpones alcanza al 7\% de fruta averiada (Stein y Torres Leal, 1991).

G. candidum (podredumbre amarga), es una de las más importantes enfermedades de postcosecha en la mayoría de las áreas citrícolas del mundo. En Argentina la incidencia económica de esta enfermedad es significativa, y se manifiesta a partir de la segunda quincena de julio. No existen fungicidas capaces de controlar eficazmente a ésta, teniendo además carácter evolutivo contagiando a la fruta sana por contacto (Stein y Torres Leal, 1991).

P. citri (podredumbre peduncular), es responsable de pérdidas de frutas cítricas, en áreas de producción con altas 
precipitaciones, durante el período de alargamiento de la fruta y maduración. Esta enfermedad se encuentra latente cuando la fruta está en el campo; después de la recolección, el botón floral empieza a perder vitalidad, hasta que cae y por allí penetra el hongo. Se encuentra presente a través de todo el período de exportación.

Penicillium digitatum (moho verde), cuya infección se realiza en plantas de empaque a lo largo de todo el período de exportación, es el responsable de hasta el $90 \%$ de la fruta averiada en tránsito, en almacenaje y en los mercados a nivel mundial (Eckert y Ogawa, 1985). Los esporos no germinan en la superficie de la fruta hasta que ésta no sufre heridas. Las pérdidas económicas por estos mohos son de dos tipos: por un lado las frutas que se pudren y por otro, la contaminación por esporas a frutas sanas.

Existen resistencias cruzadas por $P$. digitatum y algunas cepas resistentes al Tiabendazol (TBZ). Por otro lado, es necesario destacar el hecho de que Argentina, en lo que respecta a frutas frescas, se encuentra en contraestación y con menores costos comparativos de mano de obra, respecto a países de mayores niveles de ingreso. Pero a su vez, las frutas argentinas presentan la desventaja de la gran distancia a los mercados de destino.

Las enfermedades y desórdenes fisiológicos son fácilmente manejables durante cortos períodos; se tornan problemáticos en los largos períodos de transporte por vía marítima. Desde que la fruta es procesada en plantas de empaque hasta el puerto, transcurren 24 - 48 h de transporte en 
camiones no refrigerados y puede tener demoras de más de una semana hasta ser embarcadas; con viajes de 20 - 30 días hasta su arribo final. Por lo tanto, extender la vida preservando la calidad, es de importancia para el sector productivo, incidiendo esto en sus exportaciones.

La preservación de la fruta puede efectuarse por varios métodos combinados tales como:

- Manejo y control de enfermedades por el buen uso de fitosanitarios, con mínimas dosis y bajos niveles residuales, tanto en pre y postcosecha.

- Frioconservación (control de humedad y temperatura).

- Recubrimientos (ceras y otros).

Como es evidente, se deben buscar estrategias para evitar el desarrollo de resistencia por parte de los patógenos a los fungicidas en uso. Es imprescindible proveer a los empacadores y productores de un sistema de manejo postcosecha eficiente (dosis, tiempo de carencia, etc.) para el control de las enfermedades mencionadas; evitando así la resistencia de los fitosanitarios en uso, con niveles de residuos por debajo de los máximos tolerados por los mercados internacionales.

\section{Fungicidas Orgánicos}

Los fungicidas tienen acción sobre las enfermedades producidas por hongos. Su eficacia en las bacteriosis es mucho menor y no tienen efecto alguno en enfermedades fisiológicas ni 
tampoco en las debidas a virosis y micoplasmosis. Los fungicidas orgánicos se dividen en dos grandes grupos (Barberá, 1989):

1- No sistémicos, llamados también fungistáticos o de contacto.

2- Sistémicos, que se absorben por el vegetal, se incorporan a la savia y son traslocados ejerciendo su acción contra las enfermedades critogámicas.

Entre ambos tipos extremos, existen una serie de gradaciones, pudiéndose hablar de fungicidas dotados de acción penetrante más o menos localizada, o de acción sistémica limitada. Los fungicidas orgánicos no sistémicos han sido los primeros en utilizarse, siendo normalmente preventivos, o sea que deben aplicarse antes de aparecer la enfermedad a fin de evitarla; razón por la cual se los denomina también fungistáticos, ya que inhiben primordialmente la germinación de las esporas del hongo y el desarrollo subsiguiente de la enfermedad. Varios de estos fungicidas orgánicos ostentan propiedades curativas, consiguiendo eliminar la enfermedad o detenerla si se aplican debidamente.

\section{Fungicidas sistémicos}

Esta clase de fungicidas ha alcanzado un amplio desarrollo como consecuencia de la generación de nuevas familias químicas con actividad anticriptogámica. Dentro de este grupo se incluyen además, otros fungicidas que sin ser propiamente sistémicos, se alinean junto a ellos por sus características químicas o por sus 
propiedades penetrantes y cuasi sistémicas. Dentro de este grupo podemos encontrar (Barberá, 1989):

- Benzimidazoles, tales como: tiabendazol o thiabendazole, fuberidazol, benomil, carbendazim, tiofanato, metil-tiofanato.

- Derivados de pirimidina, tales como: dimetirimol, etirimol, bupirimato, fenarimol, nuarimol.

- Derivados triazólicos, tales como: triadimefón, triadimenol, diclorobutazol, bitertanol, fluortrimazol, propiconazol, etaconazol, fluatrifón, penconazol, triciclazol.

- Derivados de piperazina y morfolina, tales como: triforina, tridemorf, dodemorf, fenpropimorf, trimorfamida.

- Anilidas sustituidas, tales como: metalaxil, furalaxil, benalaxil, ofurace, axadixil, fenfuram.

- Benzoanilidas y análogos, tales como: benodanil, piracarbolid, flutolanil, mepronil.

- Carboximidas, tales como: iprodiona, procimidona, vinclozolín, diclozolinato, fluoroimida, miclozolina.

- Derivados fosfóricos, tales como: triamifós, ditalimfós, edifenfós, fosdifén, tolclofós, pirazofós, Kitazin, fosetil-Al.

- Otros derivados, tales como: clobentiazón, probenazol, imazalil, cimoxanil, protiocarb, propamocarb, himexazol.

\section{Benzimidazoles}

Los fungicidas sistémicos derivados del benzimidazol cuentan con representantes utilizados desde hace muchos años, como el thiabendazole que comenzó a utilizarse a mediados de la década de los sesenta. Aplicados al suelo, estos fungicidas, 
poseen una importante persistencia debido a que el anillo benzimidazólico es difícil de romper y su degradación bacteriana es lenta (Barberá, 1989; Pattanasupong et al., 2004; Danaher et al., 2007).

A concentraciones bajas, los benzimidazoles, inhiben la elongación del micelio y a altas actúan sobre la germinación de las esporas. Aunque hace tiempo se conoce que los derivados de benzimidazol interfieren en la mitosis de los hongos, su acción real debida al efecto sobre los microtúbulos, se ha interpretado hace relativamente poco tiempo. La inhibición de la formación de microtúbulos trae, como consecuencia, la ausencia de división celular produciéndose además una desorganización citoplasmática de tipo general (Danaher et al., 2007).

En función de su constitución química, con los derivados benzimidazólicos, pueden formarse dos grupos claramente diferenciados (Barberá, 1989; Veneziano et al., 2004):

1- Derivados tipo Thiabendazole, que comprende a éste y al Fuberidazol.

2- Derivados tipo Benomil o benomilo, que incluye a este fungicida y al Carbendazim, el metil y etil tiofanato, etc.; que poseen estructuras diferentes.

El más antiguo de estos derivados es el Tiabendazol, también conocido como Thiabendazole, Thiobendazole o simplemente TBZ, que antes de ser utilizado como fungicida fue empleado como antihelmíntico en animales, al igual que otros 
benzimidazoles en la actualidad (Balizs, 1999; De Ruyck et al., 2002; Danaher et al., 2003; Dowling et al., 2005).

La propiedad de combatir el Penicillium sp. a bajas concentraciones, hizo que su uso se expandiese rápidamente en el tratamiento post-cosecha de cítricos, manzana, pera y plátano; cultivos en los que diera muy buenos resultados sobre Gloesporium musarum. Además de estas acciones, el thiabendazole, tiene un efecto muy polivalente, lo que hace que se emplee en tratamientos de semillas y suelos, aparte de una serie de aplicaciones foliares, solo o combinado con otros fungicidas (Ito et al., 1998).

Principales características de algunos fungicidas sistémicos de interés

\section{Thiabendazol (TBZ)}

Nomenclatura química: 2-(4-tiazolil)-benzimidazol

CAS Nㅡ: 148-79-8

Clasificación química: benzimidazol

Fórmula química: $\quad \mathrm{C}_{10} \mathrm{H}_{7} \mathrm{~N}_{3} \mathrm{~S}$<smiles>c1ccc2[nH]c(-c3cscn3)nc2c1</smiles>

Figura 2. Fórmula estructural del Thiabendazole

Propiedades fisicoquímicas:

Sólido cristalino, estable a la hidrólisis, luz y calor. 
Peso Molecular: 201,26

Solubilidad en diclorometano: $10 \mathrm{mg} / \mathrm{ml}$

Solubilidad en etilacetato: $15 \mathrm{mg} / \mathrm{ml}$

Solubilidad en metanol: $80 \mathrm{mg} / \mathrm{ml}$

P.E.: $304-305^{\circ} \mathrm{C}$

Acción: sistémica y de contacto

Uso: fungicida

Información general: tiene la facultad de circular por dentro de las plantas, pero su difusión a través de la epidermis de los frutos es considerada reducida. Su espectro de actividad es muy amplio, actúa en forma preventiva y curativa sobre diferentes especies de los géneros Ascochyta, Aspergillius, Cercospor, Fusarium, Penicillium, Phoma, Septoria, Ustilago, Rhizoctonia, Gloesporium, etc. Su acción en citrus: Melanosis, Moho azul, Moho verde, Podredumbre peduncular.

Aplicaciones principales: posee la particularidad de combatir a bajas dosis a diferentes especies de Penicillium, por lo que tiene una importante aplicación en el tratamiento post-cosecha de cítricos, manzanas, pera y plátanos. Además de estas acciones, tiene un efecto muy polivalente, lo que hace que se emplee también en tratamientos de semillas y de suelo.

Información toxicológica

$\mathrm{DL}_{50}$ oral aguda en ratas: hembra $5070 \mathrm{mg} / \mathrm{kg}$, macho $3810 \mathrm{mg} / \mathrm{kg}$ $\mathrm{DL}_{50}$ dérmica aguda: $2000 \mathrm{mg} / \mathrm{kg}$ (conejo)

Límite Máximo de Residuo (mg/Kg): en fruta cítrica entera 10 ppm.

Riesgos ambientales: este producto no presenta riesgo significativo para los peces y fauna silvestre. 


\section{Tiofanato}

Nomenclatura química: dietil-4,4'-(o-fenileno)bis(3-tioalofanato)

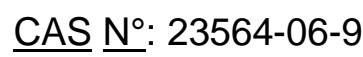

Clasificación química: benzimidazol

Fórmula química: $\quad \mathrm{C}_{14} \mathrm{H}_{18} \mathrm{~N}_{4} \mathrm{O}_{4} \mathrm{~S}_{2}$

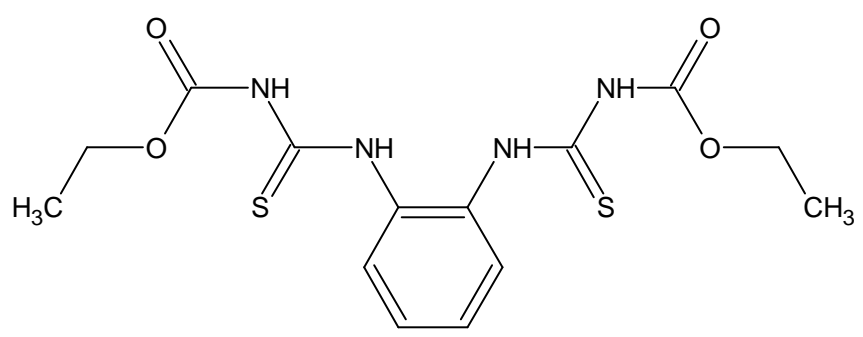

Figura 3. Fórmula estructural del Tiofanato

\section{Propiedades fisicoquímicas:}

Sólido cristalino blanco a marrón pálido.

Peso Molecular: 370,45

P.F.: $195^{\circ} \mathrm{C}$

Densidad: 1.44 a $20^{\circ} \mathrm{C}$

Es estable en medio ácido y se descompone lentamente en bases.

Solubilidad: prácticamente insoluble en agua. Poco soluble en solventes orgánicos. Forma complejos con cobre.

Acción: sistémica

Uso: fungicida

Información general: el tiofanato se convierte lentamente en etil-2benzimidazole carbamato $(E B C)$ que es considerado el agente fungicida activo. EI EBC actúa interfiriendo en la biosíntesis del 
ADN en los hongos, durante el proceso de división celular.

Aplicaciones principales: se emplea en tratamientos de suelos contra diferentes especies de Fusarium, Phyalophora, etc. Se prefiere su uso en tratamientos de suelos por su mayor persistencia respecto al análogo Metil y otros fungicidas.

Información toxicológica:

$\mathrm{DL}_{50}$ oral aguda: $15000 \mathrm{mg} / \mathrm{kg}$

$\mathrm{DL}_{50}$ dérmica aguda: $15000 \mathrm{mg} / \mathrm{kg}$

Riesgos ambientales: estudios indicaron que no es cancerígeno en ratas y acusa una toxicidad moderadamente baja en humanos. Posee muy baja toxicidad en aves. Es moderadamente tóxico para peces e invertebrados acuáticos.

\section{Metiltiofanato}

Nomenclatura química: dimetil-4,4'-(o-fenileno)bis(3-tioalofanato)

CAS Nㅡ: 23564-05-8

Clasificación química: benzimidazol

Fórmula química: $\quad \mathrm{C}_{12} \mathrm{H}_{14} \mathrm{~N}_{4} \mathrm{O}_{4} \mathrm{~S}_{2}$

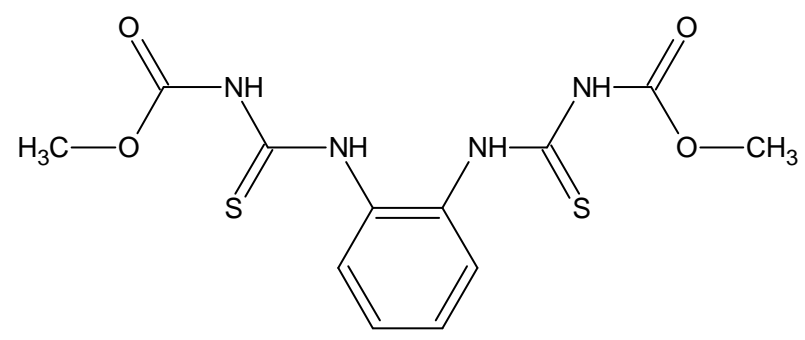

Figura 4. Fórmula estructural del Metiltiofanato

Propiedades fisicoquímicas:

Sólido cristalino, incoloro. 
Peso Molecular: 342,40

Solubilidad: prácticamente insoluble en agua. Soluble en solventes orgánicos como acetona, metanol, cloroformo.

P.F.: $172^{\circ} \mathrm{C}$

Forma complejos con sales de cobre.

Acción: sistémica, preventiva y curativa

Uso: fungicida

Información general: Es de acción rápida e integral, asegurando durante días la preservación de las frutas en condiciones normales de conservación.

Mecanismo de acción: actúa inhibiendo el metabolismo de los hongos y la síntesis de proteínas.

Aplicaciones principales: Se emplea en el tratamiento para varias especies de los géneros Venturia, Monilia, Fusicoccum, Botrytis, Oidiums, Gloesporium, Sphaeropis, Colletotrichum, Septoria, Cercospora, Cercosporella, Rhynchosporium y Phialophora. Se lo usa también en tratamiento de suelos y semillas, y para la desinfección de esquejes y bulbos. Se emplea además para el tratamiento pre-cosecha como en el caso del citrus que se aplica para prevenir la mancha grasienta (Mycosphaerella citri). Se emplea para podredumbre morena de los frutales, sarna de los frutales de caroso y viruela de la púa del duraznero. Además para prevenir la podredumbre gris en frutillas y el mal de los almácigos en hortalizas. Como fungicida de post-cosecha se aplica a frutales de pepita para diversas clases de prodredumbres de los frutos.

Información toxicológica:

$\mathrm{DL}_{50}$ oral aguda en ratas: macho $7500 \mathrm{mg} / \mathrm{kg}$, hembras 6640 $\mathrm{mg} / \mathrm{Kg}$ 
$\mathrm{DL}_{50}$ dérmica aguda en ratas: $>10000 \mathrm{mg} / \mathrm{kg}$

Riesgos ambientales: producto virtualmente no tóxico para abejas, prácticamente no tóxico para aves y moderadamente tóxico para peces.

\section{Benomil}

Nomenclatura química: Metil 1-butilcarbamoil-2-bencimidazolcarbamato

Clasificación química: Benzimidazol

Fórmula química: $\mathrm{C}_{14} \mathrm{H}_{18} \mathrm{~N}_{4} \mathrm{O}_{3}$<smiles>CCCCNC(=O)n1c(NC(=O)OC)nc2ccccc21</smiles>

Figura 5. Fórmula estructural del Benomil

Propiedades fisicoquímicas:

Sólido cristalino

Producto técnico líquido a temperatura normal

Solubilidad en agua: $3,8 \mathrm{mg} / \mathrm{l}$

Soluble en cloroformo y menos en otros disolventes orgánicos.

Acción: Sistémica (preventiva y curativa)

Uso: Fungicida

Información general: se trata de un funguicida sistémico. Su acción es preventiva y curativa, controlando a los hongos patógenos antes de su penetración en las plantas, o bien cuando 
la infección recién se ha producido. Es compatible con todos los plaguicidas, excepto los de reacción alcalina. El uso repetido y exclusivo puede resultar en la selección y desarrollo de razas tolerantes de ciertos patógenos, con la correspondiente disminución en la eficacia del fungicida. Para evitar o disminuir este riesgo, se aconseja no utilizar benomil solo, sino en mezclas o en programas de tratamiento que incluyan otros funguicidas adecuados, de un grupo químico diferente y de un modo de acción distinto.

Aplicaciones principales: se lo utiliza para tratar podredumbre del ajo, hongos del suelo, antracnosis de los citrus, podredumbre de los citrus y otros hongos (Gomyo et al., 1992).

Información toxicológica:

$\mathrm{DL}_{50}$ oral aguda: > $10000 \mathrm{mg} / \mathrm{kg}$ (rata)

$\mathrm{DL}_{50}$ dermal aguda: > $10000 \mathrm{mg} / \mathrm{kg}$ (conejo)

$\mathrm{CL}_{50}$ inhalatoria: $>4 \mathrm{mg} / \mathrm{l}$ (rata)

Riesgos ambientales: ligeramente tóxico para abejas. Moderadamente tóxico para aves. Altamente tóxico para peces.

\section{Carbendazim}

Nomenclatura química: methyl benzimidazol-2-ylcarbamate

CAS Nㅗ: 10605-21-7

Clasificación química: benzimidazol

Fórmula química: $\quad \mathrm{C}_{9} \mathrm{H}_{9} \mathrm{~N}_{3} \mathrm{O}_{2}$ 


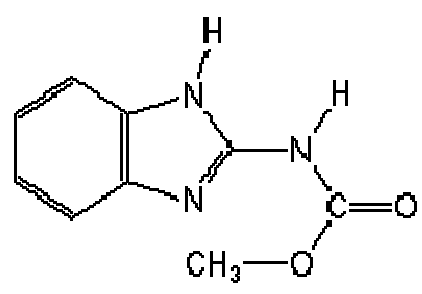

Figura 6. Fórmula estructural del Carbendazim

Propiedades fisicoquímicas:

Sólido cristalino gisáceo.

P.F. $=302-307^{\circ} \mathrm{C}$

Peso Molecular: 191

Solubilidad en agua: $5,8 \mathrm{mg} / \mathrm{l}$

Soluble en dimetilformamida. Poco soluble en disolventes orgánicos. Se descompone por álcalis y forma sales con ácidos.

Acción: sistémica, preventiva y curativa

Uso: fungicida

Información general: fungicida polivalente y sistémico, que se absorbe por lo órganos verdes y las raíces de los vegetales, siendo su persistencia de acción de 2 a 3 semanas. Constituye el principal producto de descomposición de otros fungicidas benzimidazólicos, tales como benomil y metiltiofanato (Boudina et al., 2003). Puede ser usado en mezclas con otros fungicidas, siendo compatible con productos de fuerte acción alcalina.

Aplicaciones principales: se lo emplea para tratamiento contra diversas especies de los géneros Venturia, Monilla, Botrytis, Oidium, Gloesporium, Sphaeropsis, Cocomyces, Phoma, Colletotrichum, etc. En citrus se emplea para combatir la mancha grasienta, melanosis, moho azul y verde, podredumbre peduncular 
y de los frutos, sarna del naranjo agrio, etc. Se ha utilizado también en tratamiento en suelo y semillas.

Información toxicológica:

$\mathrm{DL}_{50}$ oral aguda en ratas: $>6400 \mathrm{mg} / \mathrm{kg}$

$\mathrm{DL}_{50}$ dérmica aguda: $>4000 \mathrm{mg} / \mathrm{kg}$ (conejo)

Riesgos ambientales: prácticamente no tóxico para abejas, moderadamente tóxico para peces y no tóxico para fauna silvestre.

\section{Producción citrícola y plaquicidas}

Los plaguicidas, a nivel mundial, constituyen una problemática polifacética no sólo desde el punto de vista del sector agrícola - industrial, sino de todo el sistema ambiental y también económico. Asimismo, constituye un problema para el hombre como consumidor de productos alimenticios tratados, dada la acumulación de residuos en los mismos, en especial los no biodegradables. Si bien el concepto de calidad abarca muchos aspectos en los productos agrícolas, en especial para los cítricos, es necesario enfocar la calidad en relación a los niveles residuales de los plaguicidas tanto en frutas como en sus productos industriales.

Es primordial lograr un equilibrio entre el uso de plaguicidas y el sector agroindustrial, el mercado interno y de exportación, el ambiente y el consumidor. Para esto, es necesario compatibilizar acciones tendientes a optimizar la producción citrícola regional apuntando a calidad bajo ciertas condiciones básicas, tales como el tratamiento de la plantación en su 
globalidad con menores dosis de plaguicidas. Esto implica, el uso racional de los plaguicidas adecuados y el empleo de dosis mínimas capaces de efectuar el control de las enfermedades y/o plagas.

En este sentido cobra especial importancia contar con la información adecuada respecto a la naturaleza química de los fitosanitarios usados, la forma en que se depositan en la planta, la eliminación progresiva de los residuos en campo y los distintos factores que en ello influyen, los niveles residuales en frutos, la persistencia y penetración en el tejido vegetal y las modificaciones de los mismos; tanto en el momento de la recolección como así también, durante el transporte terrestre y/o marítimo hacia los mercados concentradores en tiempos y condiciones ambientales variadas.

Los plaguicidas son en general sustancias tóxicas y peligrosas para todo el ecosistema, produciendo desequilibrios biológicos, aparición de nuevas plagas, resistencia, fitotoxicidad, etc.; y para el hombre, por consumo de alimentos contaminados tanto de origen vegetal, animal, agua.

El Codex Alimentarius (FAO/OMS, 2007) define como Residuo de plaguicidas a toda/s sustancia/s presente/s en un producto alimenticio, destinado al hombre o a los animales, como consecuencia de la utilización de plaguicidas. Su expresión general es en $\mathrm{mg}$ de plaguicida/Kg de vegetal o partes por millón (ppm).

Esto incluye, no sólo los restos del compuesto o principio activo del mismo, sino todos los productos de reacción, conversión, metabolitos y productos de degradación con 
significado toxicológico, provenientes de sus transformaciones, bien sean de origen biológico y/o ambiental. También son incluidos en esta definición, todos los demás constituyentes de la formulación (inertes, coadyuvantes, impurezas), ya que en determinadas ocasiones pueden presentar toxicidad propia.

La variabilidad de los depósitos se debe a diversos factores, tales como: naturaleza del plaguicida y de la planta sobre la que se aplica, las formas y momento de la aplicación, las condiciones meteorológicas, etc. (Coscolla, 1993). Las características físicoquímicas de la superficie vegetal, la relación superficie/peso en las distintas variedades de frutas cítricas, inciden evidentemente en los niveles residuales.

Aplicación de fungicidas y eliminación progresiva de los residuos

Una vez depositado sobre el vegetal, a partir del momento de la aplicación y a lo largo del tiempo, los residuos van disminuyendo por la acción de diversas causas. Las variaciones de persistencia no sólo se observan entre especies o variedades distintas, sino incluso entre las diferentes partes del tejido vegetal. El crecimiento del vegetal, para el caso de pulverizaciones precosecha, influye en la relación niveles residuales $/ \mathrm{Kg}$ de órgano vegetal, disminuyendo aparentemente los residuos.

Para los frutos cítricos, al tener en su corteza gran densidad de glándulas de aceites esenciales, retienen una parte importante de los plaguicidas, lo mismo que en la capa lipofílica de la piel, pues la mayor parte de los plaguicidas son compuestos no polares (liposolubles) (Coscolla, 1993). Esto tiene ciertas ventajas 
para el consumidor, ya que la penetración en la pulpa estaría disminuida, pero es un inconveniente para el productor, porque extiende la persistencia de los residuos con el consecuente potencial problema legal.

La estructura y tamaño molecular, solubilidad, estabilidad química del principio activo y demás componentes del formulado, condiciones ambientales (temperatura, humedad), son factores de consideración. La influencia del sustrato vegetal en los cítricos, es prácticamente determinante, ya que además de facilitar la penetración, en mayor o menor grado, de gran número de plaguicidas por lipofilia, éstos quedan bloqueados en las celdillas de aceites esenciales de su corteza, pues allí son relativamente estables, lo que contribuye notablemente a su mayor persistencia.

Los procesos degradativos pueden tener lugar, tanto en la superficie del vegetal, como en el interior de sus tejidos, pudiéndose originar metabolitos de baja toxicidad, como de gran significación toxicológica. La evolución de los residuos puede obedecer a dinámicas diferentes. Es evidente además, que las características de las plantas tratadas influyen notablemente, tales como forma y tamaño del órgano vegetal considerado.

El crecimiento del vegetal puede producir una aparente disminución o eliminación de los residuos, ya que al aumentar de tamaño y peso, la relación $\mathrm{mg}$ de residuos/Kg vegetal disminuye, pero no supone necesariamente una eliminación real. Esto no es tan importante en cítricos pues el crecimiento no es rápido, y por lo tanto entran a jugar con mayor importancia otros factores en la posibilidad de disminuir el contenido residual; sin embargo es necesario considerarlo. 
El tipo de formulación aplicada puede ser un factor importante, tanto en la determinación del depósito como en la evolución de los residuos derivados de dicho depósito, al punto tal que aplicando la misma dosis de plaguicidas se pueden tener problemas legales de residuos con un tipo de aplicación y no con otro. Las aplicaciones líquidas formuladas como emulsiones y los "flow" con coadyuvantes especiales para mantener la emulsión en suspensión (tensioactivos, espesantes, etc.), son en general más persistentes que los formulados como polvos mojables, aunque hay excepciones. Las formulaciones de plaguicidas microencapsulados son también, por su capacidad de liberar lentamente el principio activo, los que logran una mayor persistencia de los residuos, inclusive mayor a los líquidos emulsionables.

Las causas ambientales, tales como lluvia y vientos son también factores de influencia. Esta acción es tanto más importante cuanto más próxima tenga lugar tras la aplicación. Las causas físicas (volatilización y solubilización) en la eliminación de los residuos, son muy variables y dependen de la naturaleza del plaguicida (tensión de vapor del mismo) y del medio ambiente (viento, temperatura). La solubilidad en agua (lluvia) es otra de las causas importante en la eliminación o disminución, sin embargo la mayoría de los plaguicidas usados son muy poco solubles en agua.

La degradación química es la vía esencial en la eliminación de los residuos de plaguicidas (Coscolla, 1993). La importancia de esta causa de disipación, depende fundamentalmente de la estructura química, ya que ésta determina su estabilidad. Puede 
deberse esta degradación a reacciones simples tales como: oxidaciones-reducciones, descarboxilaciones, isomerización, hidrólisis, etc., o bien a reacciones bioquímicas más o menos complejas en las que intervienen procesos enzimáticos. Esto puede producirse en la planta o tejido vegetal en quinta y/o en los distintos procesos de industrialización. La velocidad de degradación está influenciada no sólo por la estabilidad química, sino además por la temperatura; siendo ésta muy importante.

La iluminación solar es también otro factor que incide, principalmente sobre los plaguicidas que quedan en la superficie del fruto. En general para los plaguicidas esta propiedad es muy variada. Lo mismo para la degradación en el caso de plaguicidas sistémicos donde los procesos enzimáticos juegan un papel importante.

Sin embargo, el tema central de la problemática de residuos en los cítricos, es la naturaleza de su corteza. Esto, cuando se trata de plaguicidas aplicados sobre la planta; pero por otro lado es necesario tener en cuenta a los plaguicidas que alcanzan al suelo y al ser algunos de éstos sistémicos, se incorporan por raíz y son transportados por la savia a toda la planta.

Las aplicaciones de poscosecha con fungicidas se efectúan tanto en quinta como en empaques en dosis y concentraciones diferentes en función de los objetivos que, en general, es preservar la fruta del ataque de hongos patógenos hasta el momento de su envío a destino, ya sea a empaques o a los mercados internacionales. Es decir que existen dos momentos 
diferenciados en las aplicaciones: en el "drencher" y en la línea de empaque.

El "drencher" (o sistema duchador para "palets" o cajones grandes) consiste en la aplicación por aspersión de 30 segundos a los cajones de frutas recientemente cosechadas a bajas concentraciones de diversos plaguicidas, entre los que se encuentra el TBZ, cuya concentración no supera las 1200 - 1500 ppm (partes por millón) en el líquido de aspersión. Este proceso tiene como fundamento preservar la fruta por un corto período de tiempo hasta su procesamiento final en los empaques o industria, generalmente es aplicado en las mismas quintas o en las duchas de ingreso en los empaques.

Los residuos de TBZ encontrados en las frutas tratadas oscilan en un rango de 0,10 a 0,40 ppm, pudiendo variar además, para iguales dosis y sistema de aplicación, con las diferentes variedades cítricas (Montti et al., 1998; Gerard et al., 2000).

Los tratamientos con fungicidas en la línea de empaques para frutas que deben preservarse por mayor tiempo según su destino, mercado interno y/o mercados internacionales, son efectuados a concentraciones mayores, de 4000 a 5000 ppm, y a dosis reguladas por la velocidad de los rodillos en la línea (80 rpm) de aproximadamente I,2 l/t de fruta. Estas aplicaciones son efectuadas de dos formas diferentes, en soluciones acuosas antes de encerado de las frutas o junto con las ceras al agua, aunque muchos empaques realizan ambas aplicaciones utilizando distintos fungicidas en cada una de ellas.

Las frutas cítricas frescas que ingresan a las plantas de empaque se someten a un proceso de acondicionamiento para su 
comercialización, especialmente en el mercado externo. Para el mercado interno, no siempre se efectúa este proceso, ya que el tiempo entre la comercialización y el consumo es corto.

La eliminación de los residuos de plaguicidas presentes en los frutos por las aplicaciones en quintas, en esta etapa de acondicionamiento, depende de los procesos que en cada empaque se efectúe. El mismo puede sintetizarse de la siguiente manera:

- Lavado y cepillado (desinfección) de la fruta proveniente de quintas: la fruta es lavada con agua, desinfectantes y detergentes específicos, como consecuencia de esto pueden llegar a ser eliminados los residuos de superficie.

- Encerado y adición de fitosanitarios para su conservación.

- Secado y embalaje.

- Frío conservación.

En este proceso, por un lado, se eliminan los residuos de superficie que pueden existir en las frutas pero, por otro lado, se adicionan principalmente fungicidas para evitar la podredumbre de los mismos y prolongar así su conservación durante el tiempo de transporte y asegurar su comercialización. Es necesario identificar la procedencia y procesos que ha sufrido la fruta, ya que existen diferencias en los tratamientos, y por lo tanto éstos inciden en los niveles residuales.

Los plaguicidas de pre y postcosecha están, por lo tanto, presentes en los frutos; de los primeros, debe considerarse en ciertos casos, que pueden persistir y/o penetrar en el tejido vegetal, sumándosele además los de postcosecha con características similares. 


\section{$\underline{\text { Residuos de plaguicidas en productos cítricos industriales }}$}

Es de destacar, que existen factores predominantes que inciden en los niveles residuales de plaguicidas en estos productos, tales como los contenidos residuales en las frutas utilizadas en la industria, las variaciones durante los procesos de transformación, las tecnologías de elaboración para la obtención de los productos industriales (Montti, 1998).

Desde el momento que los frutos cítricos ingresan a la planta, hasta lograr el producto final, debe existir toda una secuencia de acciones tendientes, entre otras, a minimizar el problema de los residuos en los mismos, ya que esto, incide en la calidad y por lo tanto en su comercialización, con beneficios económicos importantes.

Para cada producto, los procesos tecnológicos de elaboración varían y por lo tanto trataremos de enfocar el tema en forma global. Si bien es cierto que un adecuado lavado, con tecnología y productos apropiados, elimina una gran parte de los residuos existentes en la corteza, el problema principal radica en el caso de plaguicidas sistémicos, que no pueden eliminarse por este proceso.

Los jugos cítricos elaborados con frutas tratadas con plaguicidas no sistémicos (no penetran en la pulpa o lo hacen en cantidades insignificantes), estarán generalmente libres de residuos. Ahora bien, si teóricamente el zumo es solamente el líquido contenido en las vesículas de la pulpa, en la práctica contiene a veces también las membranas de dichas vesículas y algunos fragmentos de desecho del albedo y los aceites esenciales. En consecuencia es posible la presencia de residuos 
en los mismos por contaminación con dichos desechos (Coscolla, 1993).

En general, los procesos industriales de extracción incorporan poco aceite de la corteza, incluso se facilita su eliminación por centrifugación o evaporación y los residuos se minimizan en los jugos naturales; los concentrados lógicamente presentan, por efecto de la concentración, niveles más altos a éstos ya que aumenta la proporción en peso de los residuos.

El tratamiento por calor es en general eficaz para eliminar residuos y la degradación puede ser casi total. En el caso de jugos concentrados, con contenidos residuales de plaguicidas, el proceso de conservación por frío al retardar o bloquear las reacciones enzimáticas, retarda también la degradación o disipación natural de los residuos.

En los aceites esenciales, dado que los procesos de obtención a nivel industrial pueden ser diferentes, los niveles residuales pueden ser variables dependiendo del modo en que éstos son extraídos. Si se obtienen por prensado en frío, clarificación y centrifugación, la degradación o pérdida de los residuos en los aceites es prácticamente muy escasa, y por lo tanto serán altos sus niveles residuales. Cuando se lo recupera de las pieles en corriente por destilación al vapor, se favorece la hidrólisis de los plaguicidas y los niveles bajan. De cualquier modo los niveles residuales de plaguicidas en aceites esenciales dependen fundamentalmente de todos los factores antes mencionados para los frutos. 


\section{Problemática y demanda de soluciones del sector} citrícola e industrial

La importancia que se asigna en la actualidad a los residuos de plaguicidas en productos agrícolas, frescos 0 procesados, hace necesaria una atención primordial para operar adecuadamente en las diferentes etapas de producción.

La demanda de información y de factibles soluciones es permanente, no sólo por situaciones puntuales respecto a posibles decomisos de frutas, niveles residuales de plaguicidas en los productos por encima de los límites de tolerancia; sino que es en general una problemática que comienza en las quintas y continúa en todo la cadena de producción y comercialización.

La rentabilidad de una explotación citrícola depende, en gran medida, de la productividad y calidad de la cosecha. Para la fruta de exportación rigen tres grados de selección: superior, elegido y comercial, que se repiten para el mercado interno, incorporando además, el grado común y descarte, siendo el destino de este último la industria.

Esta selección depende de la calidad y sanidad de la fruta. Debemos considerar que los parámetros a tener en cuenta en ésta son varios, tales como: tamaño, aspecto externo, cualidades organolépticas, etc. Además, es importante el contenido residual de biocidas en el valor de comercialización, principalmente en el de exportación, donde las exigencias de control son mayores (Coscolla, 1993).

En este sentido cobra especial relevancia el desarrollo de metodologías analíticas para la determinación y cuantificación de residuos de plaguicidas. El sector citrícola requiere de 
metodologías con adecuado rigor científico que permitan una rápida detección y cuantificación de los residuos al menor costo posible.

\section{Metodologías Analíticas}

El objetivo fundamental de un análisis es proporcionar información confiable sobre la naturaleza y/o composición de las muestras sometidas al mismo.

En general, los métodos cromatográficos se han adaptado muy bien a la determinación de niveles traza de plaguicidas. El importante avance de la tecnología en equipamiento cromatográfico, ha permitido el desarrollo de metodologías analíticas selectivas para la cuantificación de plaguicidas tanto en forma individual como multiresiduos, con importantes mejoras en los sistemas de detección.

Aparejado a este desarrollo, se encuentra también el correspondiente a los métodos de extracción, etapa de fundamental importancia para la adecuada separación del analito desde la matriz de análisis. La tendencia de las mejoras introducidas en los métodos de extracción se encuentra enfocada fundamentalmente en la reducción de la cantidad de solvente orgánico de alta pureza, necesaria para la separación del analito de la matriz.

Así, en la década del '80 la extracción en fase sólida (SPE) introduce mejoras en los métodos de extracción tradicionales, y en los '90 es la microextracción en fase sólida (SPME) la nueva metodología que surge, tendiente a acotar los tiempos de análisis, 
reducir los costos, evitar el uso de solventes y aumentar la sensibilidad del método para la determinación de niveles trazas de contaminantes (Choudhury et. al., 1996; Pawliszyn, 1997).

Cabe destacar que la preparación de las muestras constituye una etapa decisiva en todo método de análisis, en especial en la determinación de microcomponentes (trazas) y en los casos donde la matriz que rodea al analito es muy compleja. La selección del método más apropiado depende de muchos factores, entre los cuales se pueden citar: las propiedades físicas y químicas del analito, concentración de analito en la muestra, naturaleza de la matriz de la muestra, forma en la que se presenta el analito en la muestra, compatibilidad de los medios de solubilización y extracción con el sistema cromatográfico, tipo de detector y compatibilidad con el mismo.

\section{Extracción en Fase Sólida (SPE)}

La extracción en fase sólida (SPE) constituye una técnica cromatográfica de preparación de muestra basada en la adsorción de los analitos en soportes sólidos, que reduce significativamente el tiempo de análisis, los costos y el consumo de disolventes orgánicos.

El principio de esta metodología de extracción es la retención (adsorción) de los solutos sobre un lecho de adsorbente adecuado y posterior elución de los mismos con un reducido volumen de disolvente o mediante aumento de temperatura (Fritz, 1999).

El vasto desarrollo que esta metodología ha experimentado 
en los últimos años, permite actualmente operar con columnas conteniendo los materiales de relleno más variados (Fritz, 1999), como la ilustrada en la figura 7.

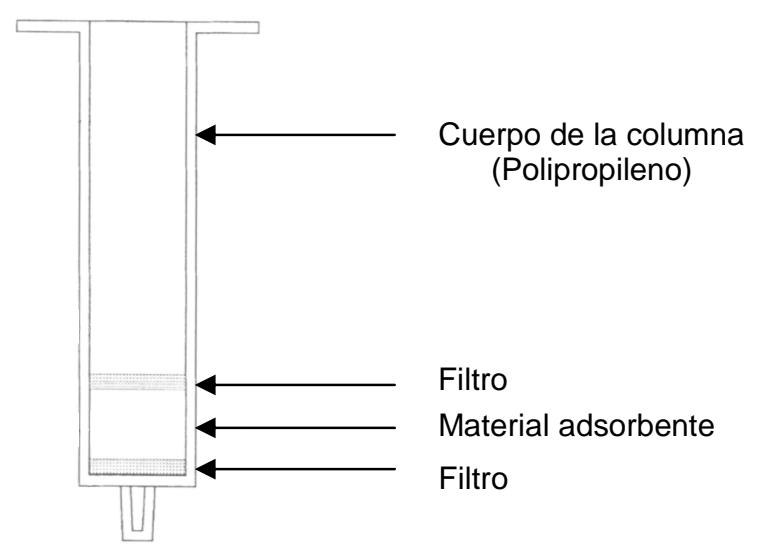

Figura 7. Cartuchos para Extracción en Fase Sólida (SPE)

Estas columnas se rellenan con cantidades variables (desde 100 hasta $500 \mathrm{mg}$ ) de distintos materiales similares a los empleados para el relleno de las columnas de HPLC, de mayor granulometría (típicamente de $40 \mu \mathrm{m}$ ) y con una pequeña distribución de tamaños de partícula.

Los materiales que se emplean para el relleno comprenden desde adsorbentes muy polares como la sílica, hasta muy poco polares como la sílica unida a los grupos $\mathrm{C}_{18}$, pasando también por materiales de intercambio iónico, pudiendo tratarse de fases enlazadas a la sílice o a polímeros como estireno-divinilbenceno.

En general, la capacidad de retención de solutos de una columna de SPE depende del tipo de material de relleno, del tamaño de la columna, del tipo de analito y las condiciones de extracción.

En la tabla 2 se resumen las características de los 
sistemas de preparación de las muestras en las columnas de extracción más comunes:

Tabla 2. Sorbentes más comunes y sistemas de preparación

\begin{tabular}{|c|c|c|c|c|}
\hline $\begin{array}{c}\text { MATERIAL } \\
\text { DE } \\
\text { RELLENO }\end{array}$ & $\begin{array}{l}\text { TIPOS DE } \\
\text { ANALITOS }\end{array}$ & $\begin{array}{l}\text { NATURALEZA } \\
\text { DE LA MATRIZ }\end{array}$ & $\begin{array}{c}\text { ACTIVACION } \\
\text { DE LA } \\
\text { COLUMNA }\end{array}$ & $\begin{array}{l}\text { SOLVENTE } \\
\text { DE ELUCION }\end{array}$ \\
\hline $\mathrm{C}_{18} / \mathrm{C}_{8}$ & $\begin{array}{l}\text { Sustancias } \\
\text { no polares. } \\
\text { Sustancias } \\
\text { ionizables } \\
\text { en su } \\
\text { forma no } \\
\text { ionizada }\end{array}$ & Acuosa & Agua & $\begin{array}{l}\mathrm{MeOH} / \mathrm{AcN} \text { o } \\
\text { mezclas de } \\
\text { éstos con } \\
\text { agua o } \\
\text { buffers de pH } \\
\text { adecuado. }\end{array}$ \\
\hline $\begin{array}{l}\text { Sílice } \\
\text { Diol } \\
\text { CN }\end{array}$ & $\begin{array}{l}\text { Sustancias } \\
\text { polares }\end{array}$ & $\begin{array}{l}\text { Solución en } \\
\text { solventes no } \\
\text { polares } \\
\text { Aceites }\end{array}$ & $\begin{array}{l}\text { Cloroformo } \\
\text { Hexano }\end{array}$ & $\begin{array}{l}\text { Solventes } \\
\text { polares IPA, } \\
\text { MeOH }\end{array}$ \\
\hline Aniónico & $\begin{array}{l}\text { Aniones } \\
\text { Carboxilato } \\
\text { s/ } \\
\text { Sulfonatos }\end{array}$ & $\begin{array}{l}\text { Soluciones } \\
\text { acuosas de } \\
\text { baja fuerza } \\
\text { iónica }\end{array}$ & $\begin{array}{l}\mathrm{MeOH} \\
\text { Buffer }\end{array}$ & $\begin{array}{l}\text { Buffers de } \\
\text { alta fuerza } \\
\text { iónica y pH } \\
\text { adecuado. } \\
\text { Sólo o en } \\
\text { mezclas con } \\
\text { MeOH o AcN. }\end{array}$ \\
\hline Catiónico & $\begin{array}{l}\text { Cationes } \\
\text { Aminas }\end{array}$ & $\begin{array}{l}\text { Soluciones } \\
\text { acuosas de } \\
\text { baja fuerza } \\
\text { iónica }\end{array}$ & $\begin{array}{l}\mathrm{MeOH} \\
\text { Buffer }\end{array}$ & $\begin{array}{l}\text { Buffers de } \\
\text { alta fuerza } \\
\text { iónica y pH } \\
\text { adecuado. } \\
\text { Solo o en } \\
\text { mezclas de } \\
\text { MeOH o AcN }\end{array}$ \\
\hline
\end{tabular}

\section{Metodología de extracción en SPE}

Las condiciones óptimas para la extracción dependen de la naturaleza del analito y de la matriz que lo rodea. La 
determinación de residuos de plaguicidas en aguas mediante SPE requiere la optimización de las variables que afectan tanto a la retención como a la elución de los compuestos. Dicha optimización puede convertirse en una serie de repeticiones de experimentos contradictorios, si no se sigue un plan de optimización que permita controlar y evaluar el efecto de las variables que intervienen en la extracción.

Wells y Michael (1987), proponen un esquema de trabajo basado en un proceso iterativo que permite la optimización progresiva de todas las variables que intervienen en el proceso de extracción. Dicho esquema es el siguiente:

\section{1- Control de la retención}

- Volumen fijo de muestra con una concentración determinada de pesticidas

- Fijar el tipo y cantidad de adsorbente

\section{2- Optimización de la elución. Estudio del efecto del eluyente}

- Comparar la eficacia de diferentes disolventes.

- Estudio del efecto del volumen de eluyente.

3- Optimización de la retención pH de la muestra. Volumen de muestra

- Masa de adsorbente

- Concentración de la muestra

Cualquier procedimiento de SPE, para la preparación de las muestras utiliza los pasos que se describen en la figura 8 (Fritz, 1999).

- Lavado y activación de la columna: esta operación tiene por objeto solvatar los grupos funcionales del material de relleno 
de la columna.

- Aplicación de la muestra: la muestra se aplica en la columna utilizando un caudal determinado, típicamente 1 a $10 \mathrm{ml} / \mathrm{min}$.

- Lavado de la columna: esta operación se refiere a la eliminación de las impurezas retenidas en el paso anterior utilizando un solvente relativamente débil con el cual el analito no eluye.

- Elución del analito: finalmente el analito se eluye con un solvente tal que posea la fuerza de elución apropiada utilizando para ello desde 5 hasta 20 volúmenes de columna.

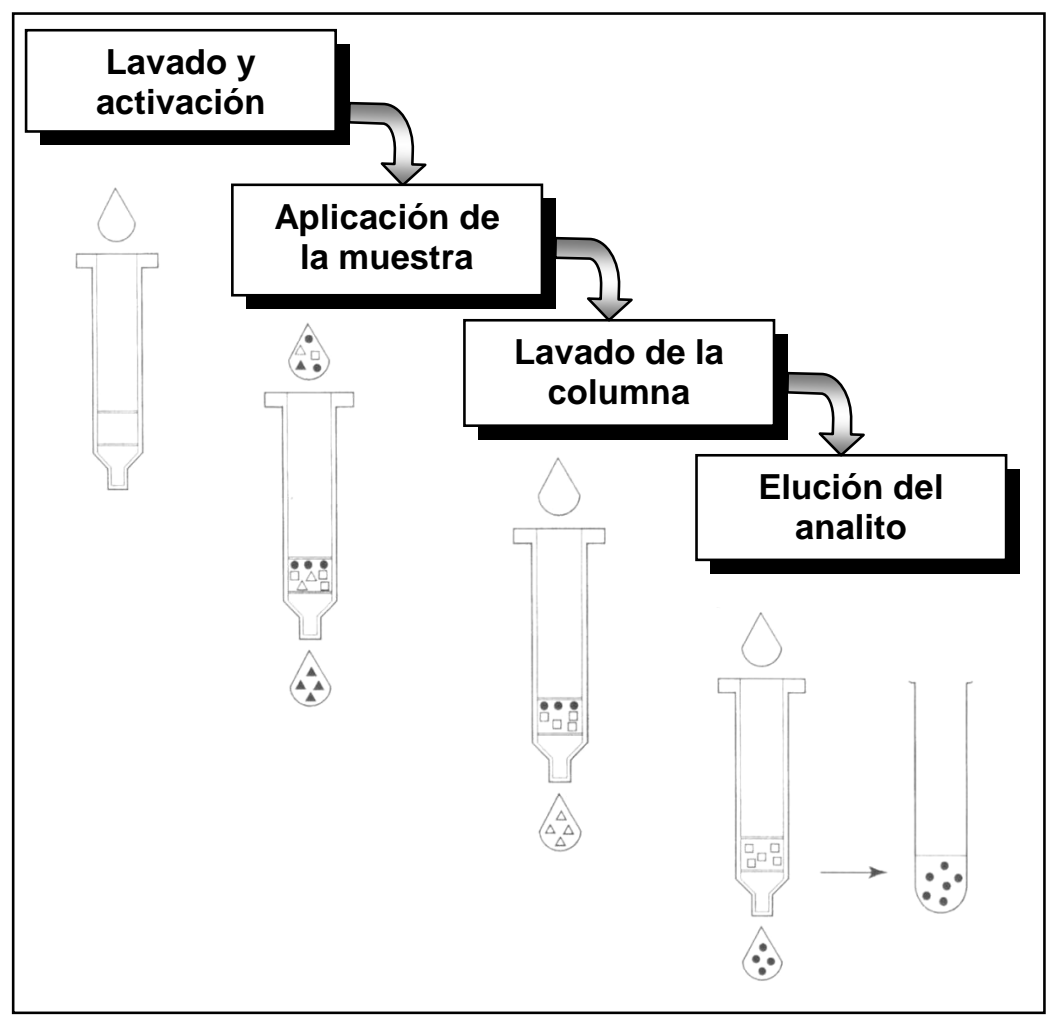

Figura 8. Etapas del proceso de Extracción en Fase Sólida (SPE) 
Si la cantidad de muestras a procesar es muy grande la preparación puede resultar larga y tediosa. Por ello se han diseñado dispositivos en el laboratorio, que pueden efectuar semiautomáticamente todas las operaciones citadas. En estos dispositivos se colocan varias columnas juntas de manera tal que es posible procesar varias muestras en forma simultánea (figura 9).
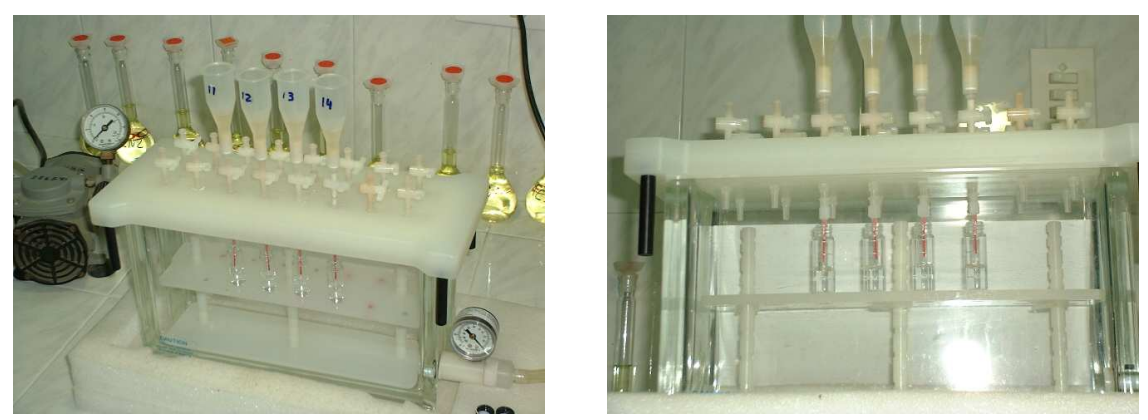

Figura 9. Colector múltiple de vacío ("Vacuum Manifold") y accesorios SPE

\section{Microextracción en fase sólida - SPME}

En SPME el analito es absorbido directamente desde la muestra por una fibra de sílica fundida de pequeño diámetro, recubierta con un polímero sólido o líquido (Fritz, 1999). Esta fibra se encuentra contenida en una jeringa que la protege hasta su introducción en la muestra y posteriormente en el inyector del cromatógrafo (figura 10). El analito particiona en la fase estacionaria, luego es desorbido térmicamente en el inyector del cromatógrafo gaseoso (GC) para su análisis. 
Al estar la fase líquida ligada a la fibra permite una mayor eficiencia en el proceso de extracción, evitando además el uso de solventes orgánicos (Belardi and Pawliszyn, 1989; Arthur and Pawliszyn, 1990). Estos recubrimientos son selectivos, por lo que es necesario una adecuada elección del absorbente en función del peso molecular y polaridad del analito a extraer. La fibra puede utilizarse por inmersión directa en muestras líquidas o en fase gaseosa para la determinación del analito en "headspace" (Kataoka et al., 2000). La misma fibra puede usarse en reiteradas oportunidades hasta tanto lo permita su vida útil.

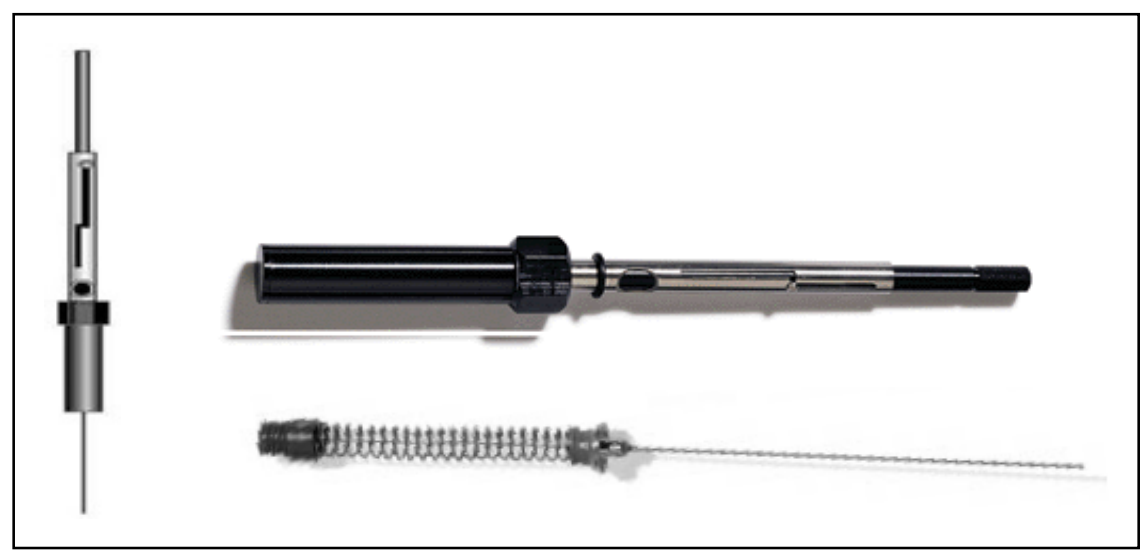

Figura 10. Jeringa y fibra SPME

La geometría cilíndrica simple de esta fibra (figura 11) permite que la extracción pueda optimizarse directamente en muestras reales. El transporte de analito desde la matriz hacia el recubrimiento comienza tan pronto como la fibra es colocada en contacto con la muestra (Kataoka et al., 2000). La extracción se considera completa cuando el analito alcanza el equilibrio entre la muestra y el recubrimiento de la fibra. 
En la práctica esto significa que una vez alcanzado el equilibrio, la cantidad extraída es constante dentro de los límites del error experimental y es independiente de un incremento posterior del tiempo de extracción (Pawliszyn, 1997).

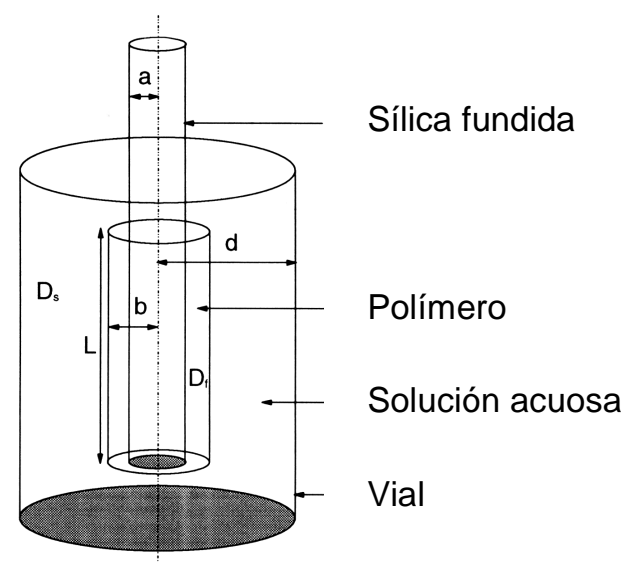

Figura 11. Presentación de la configuración del sistema SPME/muestra.

$a=$ radio de la fibra

$b=$ radio del absorbente

$C=$ radio del vial

$L=$ porción de la fibra recubierta con absorbente

$D_{f}=$ coeficiente de difusión del analito en el absorbente

$D_{s}=$ coeficiente de difusión del analito en el agua

Si se considera que la matriz de la muestra es una fase homogénea simple y que no existe espacio de cabeza en el sistema, la condición de equilibrio puede ser expresada mediante la siguiente ecuación (Pawliszyn, 1997): 


$$
n=\frac{K_{f s .} V_{f} . V_{s} \cdot C_{0}}{K_{f s .} V_{f}+V_{s}}
$$

donde:

$n=$ cantidad extraída por el recubrimiento

$K_{f s}=$ constante de distribución recubrimiento / matriz de la muestra

$V_{f}=$ volumen de recubrimiento

$V_{s}=$ volumen de muestra

$C_{0}=$ concentración inicial de analito en la muestra

Esta ecuación es función de la presencia de otros componentes en la matriz, el volumen de las fases individuales y las constantes de distribución.

En SPME el proceso de extracción del analito puede ser interrumpido y la fibra analizada antes de alcanzar el equilibrio. Sin embargo, para obtener datos reproducibles, se deben controlar cuidadosamente las condiciones de convección constante y el tiempo de extracción. La ecuación (1) muestra una relación directa entre la concentración de muestra y la cantidad de analito extraído, siendo esta relación la base para la cuantificación del mismo.

La ventaja más notable de la SPME radica fundamentalmente en el uso de volúmenes reducidos de muestra, siendo posible su empleo en sistemas vivos. Para pequeños volúmenes de muestra, se puede alcanzar una extracción completa cuando la constante de distribución es razonablemente alta. Cuando el volumen de muestra es muy grande, el término 
$K_{f s} . V_{f}$ es despreciable frente a $V_{s}$, por lo que consecuentemente la ecuación (1) se simplifica, resultando:

$$
n=K_{f s .} V_{f s .} C_{0}
$$

En este caso la cantidad de analito extraído se corresponderá directamente con su concentración en la matriz, siendo independiente del volumen de muestra, lo que hace a la técnica apta para aplicaciones de campo.

\section{Modos de Extracción en SPME}

Existen tres tipos básicos de extracciones que pueden realizarse usando SPME (Pawliszyn, 1997):

- extracción directa: la fibra se inserta directamente en la muestra y los analitos son transportados desde la matriz de la misma a la fase de extracción (figura 12). Para facilitar la extracción rápida, se requiere algún nivel de agitación para transportar los analitos desde la solución a la vecindad de la fibra (Kataoka et al., 2000).

- Headspace: los analitos necesitan ser transportados a través de una barrera de aire antes que puedan alcanzar el recubrimiento. Esta modificación sirve para proteger al mismo recubrimiento de la fibra de los daños causados por interferencias de compuestos de alto peso molecular y otras interferencias presentes en la matriz de la muestra. 
- protección de membrana: consiste en la extracción indirecta por SPME a través de una membrana con el principal propósito de proteger la fibra contra daños.

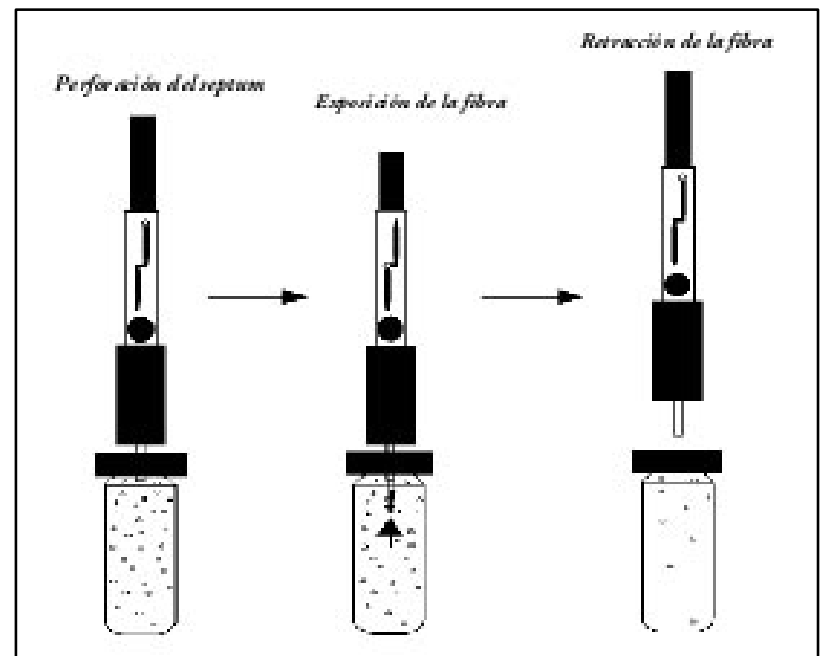

Figura 12. Extracción directa - SPME.

\section{$\underline{\text { Recubrimientos }}$}

Las ecuaciones (1) y (2), indican que la eficiencia del proceso de extracción depende de la constante de distribución $K_{f s}$. Esta constante constituye un parámetro característico que describe las propiedades de un recubrimiento y su selectividad hacia el analito versus los otros componentes de la matriz.

Se pueden desarrollar recubrimientos específicos para un amplio intervalo de aplicaciones. De las ecuaciones se deduce que el volumen del recubrimiento determina la sensibilidad del método, pero un mayor espesor del mismo, provoca un aumento del tiempo de extracción. Por lo tanto es importante utilizar el recubrimiento adecuado para cada aplicación. Han sido 
preparados e investigados varios absorbentes experimentales para un amplio intervalo de aplicaciones (Pawliszyn, 1997). Además de un absorbente polímero líquido tal como PDMS útil para aplicaciones generales, se han desarrollado otros materiales más especializados.

La elección de un recubrimiento apropiado es esencial para el método SPME, dependiendo del peso molecular y polaridad de los analitos que van a ser extraídos; la sensibilidad de cada fibra es distinta. Los distintos tipos de fibras son según Beltran et al. (2000) y Kataoka et al. (2000):

\section{No polares}

- Polidimetilsiloxano (PDMS): $100 \mu \mathrm{m}, 30 \mu \mathrm{m}, 7 \mu \mathrm{m}$

\section{Polares}

- Poliacrilato (PA): $85 \mu \mathrm{m}$

- Carbowax/Divinilbenceno (CW-DVB): $65 \mu \mathrm{m}$

- Carbowax/Resina Templada (CW/TPR): $50 \mu \mathrm{m}$ (solo para HPLC)

\section{Bipolares}

- PDMS/DVB: $65 \mu \mathrm{m}$

- Carboxen/PDMS: $75 \mu \mathrm{m}$

- DVB/carboxen/PDMS: 55/30 $\mu \mathrm{m}$

- PDMS/DVB: $60 \mu \mathrm{m}$ (sólo para HPLC)

\section{Efecto de los parámetros de extracción}

La teoría termodinámica predice los efectos de modificar ciertas condiciones de extracción, sobre la partición y parámetros indicadores para el control de reproducibilidad. La teoría se puede emplear para optimizar las condiciones de extracción con un 
número mínimo de experiencias y, corregir para variaciones en las condiciones de extracción sin necesidad de repetir el test de calibración con las nuevas condiciones. Las condiciones de extracción que afectan la constante de distribución $\left(K_{f s}\right)$ son: temperatura, contenido de sales ("salting"), $\mathrm{pH}$ y solventes orgánicos contenidos en agua (Pawliszyn, 1997; Beltran et al., 2000).

\section{Extracción de los analitos con agitación perfecta}

Es una extracción directa de analitos desde una muestra acuosa homogénea a un polímero líquido que recubre una fibra. Se entiende por agitación perfecta, cuando la muestra se mueve muy rápidamente con respecto a la fibra y todo el analito presente en la misma tiene acceso al absorbente, siendo su concentración uniforme. Es posible que la concentración del analito en la muestra sea constante durante el proceso de extracción, asumiendo un volumen infinito y agitación perfecta. En la práctica para encontrar esta condición, el volumen de la muestra debe ser suficientemente grande para asegurar que la cantidad de analito extraída no cambia, dentro de los límites del error experimental, con el aumento de volumen.

Antes que la fibra se coloque en la solución, no hay analito presente en el absorbente. Inmediatamente después de la inmersión en la muestra, sólo una delgada capa sobre la superficie contiene analito. Con el tiempo, moléculas de analito difunden progresivamente en la profundidad del absorbente y eventualmente se alcanza el equilibrio. En condiciones de perfecta agitación, la velocidad del proceso de absorción está determinada 
sólo por la difusión del analito en el absorbente. Inmediatamente después de la inmersión de la fibra en la solución, hay un rápido incremento de la masa absorbida por la fibra, luego la velocidad de incremento se hace más lenta, y eventualmente alcanza el equilibrio.

El tiempo requerido para alcanzar el equilibrio es infinitamente largo, sin embargo en la práctica, un cambio en la masa extraída puede no ser determinado si este es más pequeño que el error experimental, lo cual es aproximadamente del $5 \%$ (Pawliszyn, 1997). Por lo tanto, se asume que el tiempo de equilibrio se alcanza cuando el $95 \%$ de la cantidad de un analito en equilibrio es extraída desde la muestra.

$$
t_{e}=t_{95 \%}=\frac{(b-a)^{2}}{2 D_{f}}
$$

Usando esta ecuación se puede estimar el tiempo mínimo para alcanzar el equilibrio para el sistema en la práctica, sustituyendo por los datos apropiados el coeficiente de difusión del analito en el absorbente $\left(D_{f}\right)$ y el espesor del absorbente (b - a) (Lord \& Pawliszyn, 2000).

En la práctica hay siempre una capa de agua no agitada alrededor de la fibra, denominada capa límite, de frontera o de Prandtl, cuyo espesor está determinado por las condiciones de agitación y la viscosidad del fluido. Una alta velocidad de agitación resulta en un estrechamiento de esta capa alrededor de la fibra. Después de la inmersión de la fibra en la solución hay un rápido 
incremento en la masa absorbida por la fibra, la cual luego permanece constante cuando el sistema alcanza el equilibrio.

El efecto del tamaño de la capa límite sobre la velocidad de equilibrio es muy visible, ya que una capa límite delgada no afecta significativamente la velocidad de extracción y por lo tanto el tiempo de equilibrio, pero una capa límite relativamente gruesa provoca una importante reducción de la difusión siendo el proceso en la misma la determinante de la velocidad de extracción. Por otra parte, un analito con un valor elevado de $K_{f s}$ tendrá un tiempo para alcanzar el equilibrio elevado, aún con una capa límite delgada característica de agitación rápida (Lord \& Pawliszyn, 2000).

El tiempo de extracción puede disminuirse optimizando la posición de la fibra en el agua agitada. Si la fibra está colocada en el centro de un vial agitado con una barra magnética, el flujo de líquido será simétrico al eje alrededor de la circunferencia de la fibra. La fibra en el vial deberá mantenerse fija, preferiblemente cerca de la posición óptima, cerca de la mitad de la distancia entre el centro del vial y el final de la barra agitadora. En la práctica, es aconsejable la sobreestimación de los tiempos de equilibrio para eliminar extracción aumentada como una función de un mínimo cambio en la posición de la fibra.

\section{Desorción de analitos extraídos}

Después que se completa la extracción, el absorbente conteniendo los analitos se transfiere al inyector de un GC o un HPLC. Durante el proceso de desorción el analito difunde desde el absorbente hacia la corriente del fluido transportador. Por lo tanto 
este proceso es el inverso al de absorción desde una fase acuosa bien agitada, cuando la concentración de analito es cero en la interfase absorbente/fluido.

Para asegurar que esa condición se satisface, se debe generar una velocidad de flujo lineal alta. La velocidad de flujo elevada se requiere para asegurar que el analito desorbido se remueva inmediatamente desde la vecindad del absorbente, de modo de no interactuar con el absorbente y hacer más lento el proceso de desorción.

Al comienzo de la desorción, el analito se remueve desde la capa de absorbente adyacente a la interfase y luego desde las partes más profundas del absorbente. Como en el caso de agitación perfecta, el proceso de desorción se completa a un tiempo $t=(b-a)^{2} / 2 D_{f}$ dado por la ecuación (3) (Lord \& Pawliszyn, 2000). Los valores para la constante de distribución y coeficiente de difusión serán diferentes comparados a la extracción desde una muestra perfectamente agitada por la diferencia de temperatura. La relación anterior indica que el tiempo de desorción es independiente de la constante de distribución $K_{f s}$ e independiente de la concentración inicial en la fibra.

\section{Aspectos relevantes en el desarrollo de un método por SPME}

El desarrollo de un método de extracción por SPME comprende la definición de los parámetros del proceso y su posterior optimización. Las condiciones del proceso extractivo 
comprende las siguientes etapas (Pawliszyn, 1997; Kataoka et al., 2000):

- Selección del recubrimiento de la fibra.

- Selección del modo y condiciones de extracción.

- Selección del método de agitación.

- Determinación del volumen mínimo de muestra.

- Determinación del tiempo óptimo de extracción.

- Selección de las condiciones de desorción.

- Selección del método de separación y detección.

\section{Selección del absorbente}

La naturaleza química del analito, determina el tipo de absorbente a emplear (Pawliszyn, 1997).

El 3-polidimetilsiloxano (PDMS) constituye el adsorbente más empleado (Kataoka et al., 2000), siendo una fase no polar que extrae muy bien analitos no polares. Sin embargo, también puede aplicarse satisfactoriamente a compuestos más polares, particularmente después de optimizar las condiciones de extracción.

Es conveniente utilizar los absorbentes más delgados disponibles que alcancen los límites de detección requeridos. Siempre se debe considerar que, tanto el espesor del absorbente como la constante de distribución, determinan el tiempo de extracción; los mismos parámetros también determinan la sensibilidad del método (Lord \& Pawliszyn, 2000). La decisión acerca del espesor del absorbente se hace después de considerar 
la constante de distribución esperada para los analitos y los requerimientos de sensibilidad del método.

El poliacrilato (PA) es adecuado para compuestos más polares (Beltran et al., 2000), siendo un polímero de baja densidad a temperatura ambiente, con coeficientes de difusión más bajos si se lo compara al PDMS. Los absorbentes con mezcla de fases, tienen propiedades complementarias comparadas al PDMS y PA. Las mezclas que poseen Carbowax en lugar de PDMS, poseen una diferencia de selectividad hacia compuestos polares. Los tiempos de absorción son típicamente más cortos para muestras gaseosas comparadas a PDMS de $100 \mu \mathrm{m}$, ya que los analitos no necesitan difundir a través de la fase de polímero líquido (Beltran et al., 2000).

Un tipo de absorbente óptimo para un rango amplio de compuestos característicos requiere de experimentación con diferentes fibras. El desarrollo de métodos para grupos de analitos, requiere que la consideración primaria esté dada para los analitos más difíciles.

\section{Selección del modo de extracción}

La selección del modo de extracción se hace considerando la matriz de la muestra, volatilidad del analito y su afinidad a la matriz. Para muestras que contienen sustancias capaces de dañar el absorbente o cambiar sus propiedades por absorción, deben elegirse el headspace y el modo con protección de fibra (Lord \& Pawliszyn, 2000). Para matrices limpias, se considera conveniente el muestreo directo. Sin embargo para analitos más volátiles, el 
método de extracción por headspace es más adecuado, debido a que son menores los tiempos de equilibrio. La protección por membrana debería usarse sólo para muestras donde ninguno de los dos anteriores modos puede aplicarse.

\section{Selección de la técnica de agitación}

La eficacia de la técnica de agitación determina los tiempos de equilibrio de las muestras acuosas. Los tiempos de equilibrio para el análisis de muestras gaseosas son rápidos y frecuentemente limitados sólo por la difusión de los analitos en el absorbente. Una situación similar ocurre cuando analitos muy volátiles son analizados por la técnica de headspace.

Cuando se usa barra magnética, se debe asegurar que la velocidad rotacional de la barra sea constante y la base del plato esté térmicamente aislada del vial que contiene la muestra. La agitación magnética es la más comúnmente usada en experiencias de SPME, ya que se encuentra disponible en la mayoría de los laboratorios analíticos y puede emplearse convenientemente en los tres modos de muestreo por SPME.

La extracción es eficiente cuando se aplican velocidades rotacionales elevadas. El tiempo de equilibrio decrece progresivamente a medida que aumenta la velocidad (rpm).

Existen alternativas a la agitación magnética tales como la técnica de vibración de la aguja que usa un motor externo y una leva con el fin de generar un movimiento de agitación de la fibra y el vial, la técnica del vortex el vial se mueve rápidamente con un movimiento circular y la sonicación directa. 


\section{Selección de técnica de separación y/o detección}

La complejidad de la muestra y la selectividad del proceso de extracción, definen los requerimientos para instrumentar la separación y cuantificación. En la mayoría de las aplicaciones, se emplean absorbentes generales como PDMS, con lo que se obtiene una selectividad muy limitada durante el proceso de extracción. Por lo tanto, las demandas sobre técnicas de separación/cuantificación son muy altas.

La mayoría de las aplicaciones para SPME han sido desarrolladas para cromatografía gaseosa (GC) pero más recientemente se han desarrollado interfaces comerciales para cromatografía líquida (HPLC) (Lord \& Pawliszyn, 2000). La complejidad de la mezcla de extracción determina la herramienta de cuantificación apropiada que se necesita. Frecuentemente se requieren espectrómetros de masa como detectores, para muestras complejas ambientales y biológicas.

\section{Optimización de las condiciones de desorción}

Inyectores cromatográficos estandard, tal como el popular "split/splitless" requieren insertos ("Liner") de gran volumen que permitan la expansión del solvente evaporado que ha sido introducido durante la inyección. Un diámetro interno grande (3-5 $\mathrm{mm}$ ) del tubo de vidrio o sílica fundida usados para éste propósito, producen una muy baja velocidad de flujo lineal en el inyector, resultando una transferencia lenta de los analitos volatilizados hacia el frente de la columna GC (figura 13) (Pawliszyn, 1997). El "splits" abierto permite la inyección de una banda aguda, y 
remover el remanente de solventes volatilizados. En la introducción de SPME, no hay solventes presentes y por lo tanto el "splits" es innecesario. En realidad para una óptima sensibilidad, el "splits" necesita estar cerrado durante la desorción para transferir todo el analito en el frente de la columna GC.

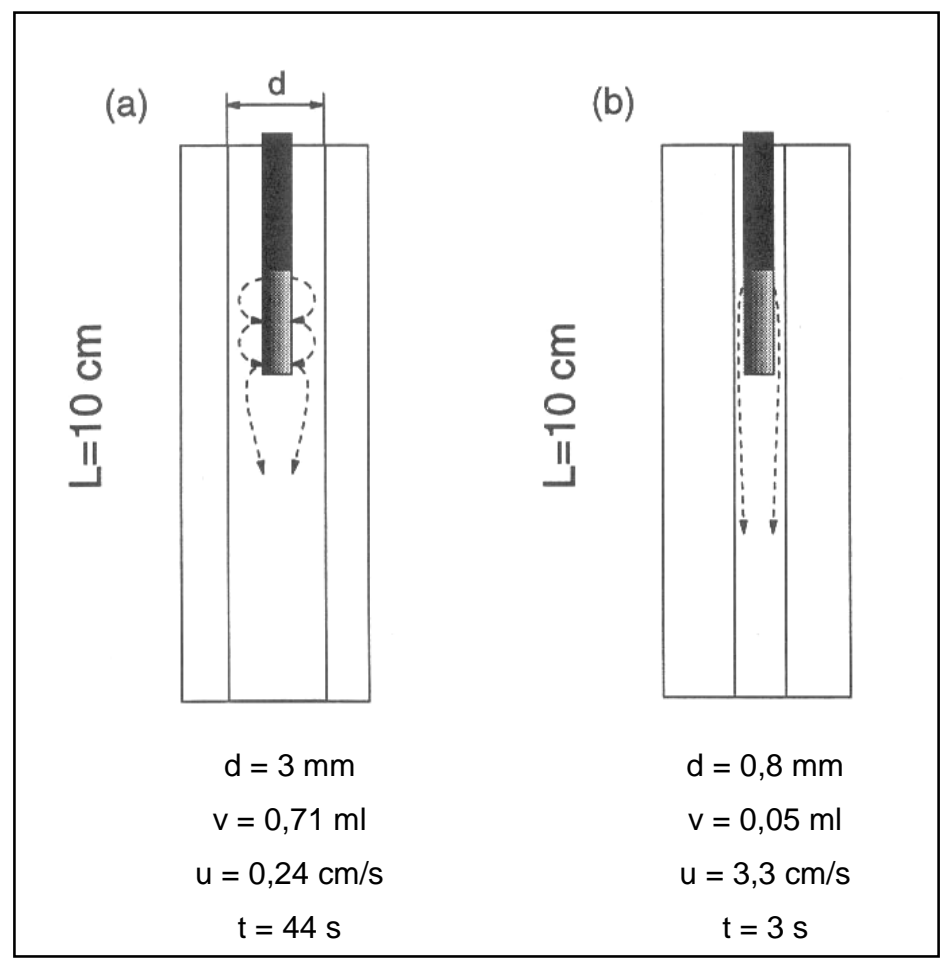

Figura 13. Efecto del volumen del inyector en la desorción.

Habría que enfatizar que el "splits" deber estar cerrado cuando se calibra la respuesta del detector, para asegurar que todos los analitos alcanzan el detector. Para agudizar las bandas de inyección en SPME, los analitos desorbidos deberían removerse rápidamente del inyector. Esto se puede lograr generando una alta velocidad de flujo del gas carrier alrededor del 
absorbente. Ya que la velocidad de flujo volumétrico se fija según la operación óptima de la separación por cromatografía gaseosa (alrededor de $1 \mathrm{ml} / \mathrm{min}$.), el modo práctico de alcanzar alto flujo lineal es reducir el diámetro del insert del inyector, haciéndolo tan ajustado como sea posible al diámetro externo del absorbente de la fibra (figura 13. b).

Para asegurar un calentamiento eficiente y reproducible, la aguja cubierta con el absorbente necesita estar colocada en el centro de la zona caliente, generalmente coincidente con el centro del insert (Lord \& Pawliszyn, 2000). La fibra necesita ser expuesta inmediatamente después que la aguja se introduce en el inserto o "insert", ésta aumenta su temperatura rápidamente y el analito comienza a desorber (Kataoka et al., 2000).

La temperatura del inyector y la velocidad de flujo lineal alrededor de la fibra determinan el tiempo de desorción. Teóricamente los tiempos de desorción son muy cortos ya que el coeficiente de difusión de los analitos en el absorbente se incrementa, y la constante de distribución gas/absorbente disminuye rápidamente con el incremento de temperatura. Los analitos volátiles, son completamente removidos desde el absorbente a las temperaturas normales del inyector.

\section{Optimización del volumen de muestra}

El volumen de muestra será seleccionado en función de la constante de distribución estimada $K_{f s}$. La constante de distribución puede estimarse usando valores de la bibliografía obtenidos para el analito señalado o un compuesto relacionado 
con el absorbente seleccionado. Si esta información no se encontrara disponible, una extracción directa experimental de toda una noche ayudará a calcular la constante.

La sensibilidad del método de SPME es proporcional al número de moles de analito, $n$, extraídos desde la muestra, el cual para un método de extracción directa, esta dado por la ecuación (1). Cuando el volumen de muestra, $V_{s}$ aumenta, también lo hace la cantidad de analito extraído, hasta que $V_{s}$ se hace mucho más grande que el producto $K_{f s} . V_{f}$. En este punto, la sensibilidad del método no se incrementa más con posteriores incrementos de $V_{s}$.

En la práctica, el volumen limitante puede calcularse asumiendo el error de medida, E, generalmente del $5 \%$ (Pawliszyn, 1997):

$$
V_{s}=\frac{100 \cdot K_{f s} \cdot V_{f}}{E}
$$

Por ejemplo, para un error del $5 \%$ se puede estimar que $V_{s}=20 . K_{f s} \cdot V_{f}$

Esto significa que para $K_{f s}$ hasta alrededor de 200 y absorbente de $100 \mu \mathrm{m}$, el vial de $2 \mathrm{ml}$ es suficiente para dar máxima sensibilidad, mientras un vial de $40 \mathrm{ml}$ puede usarse para $K_{f s}$ menor de 4, etc.

Usando volúmenes de muestra más grandes que el valor limitante, no solo se maximiza la sensibilidad, también resulta en una mayor precisión ya que la variación del volumen de muestra no afecta los resultados (Lord \& Pawliszyn, 2000). 


\section{Determinación del perfil de tiempo de extracción en}

\section{matriz pura}

Las experiencias para determinar los parámetros antes indicados se realizan con matriz pura, tal como aire seco o agua pura, a fin lograr un entendimiento básico de la cinética de la transferencia de analito desde la matriz a la fibra al establecer condiciones de agitación.

Los experimentos iniciales confirmarán la capacidad de la extracción del analito por el modo elegido, e indicarán la necesidad de una posterior optimización.

También dará una buena estimación del límite de detección que se espera para la combinación analito/matriz.

El perfil del tiempo de extracción se obtiene preparando un set de viales conteniendo muestras, y luego extrayéndolas por tiempos progresivamente más largos.

La masa extraída se determina por un método seleccionado y un procedimiento de calibración adecuado, el que típicamente involucrará la inyección de $1 \mu \mathrm{l}$ de analito marcado, mezclado en un solvente que no interfiere (Lord \& Pawliszyn, 2000).

\section{Determinación del tiempo de extracción}

El tiempo de equilibrio se define como el tiempo después del cual la cantidad de analito extraído permanece constante y corresponde, dentro del error experimental, a la cantidad extraída al tiempo de extracción infinito. 
La determinación de la cantidad extraída al equilibrio permite calcular la constante de distribución. Cuando los tiempos de equilibrio son demasiado largos para una aplicación dada, se pueden elegir tiempos de extracción más cortos para la cuantificación (Lord \& Pawliszyn, 2000).

\section{Cálculo de la constante de distribución}

La constante de distribución de un analito dado para una matriz pura define la sensibilidad del método. No es necesario calcular la constante de distribución absorbente/matriz de la muestra de la fibra $\left(K_{f s}\right)$, si la calibración está basada en estándares isotópicamente marcados o adición de estándar. Esto es cierto aún con calibración externa, con matriz y volumen de headspace idénticos cuando se usan en un standard y en una muestra. Sin embargo, es aconsejable determinar $K_{f s}$ ya que este valor da más información acerca de la experiencia y ayuda a la optimización del método.

El valor de la constante de distribución absorbente/matriz $\left(K_{f s}\right)$ se puede utilizar para predecir la distribución de los analitos en el sistema. Esta información permite calcular el volumen de headspace, el volumen de muestra y el espesor de absorbente requerido para alcanzar la sensibilidad deseada. Cambios en $K_{f s}$ causados por variaciones de las condiciones de extracción tales como: temperatura, volumen de muestra, $\mathrm{pH}$ y contenido de sal; pueden estimarse teóricamente usando los principios indicados anteriormente. La constante de distribución, para el modo de extracción directa puede calcularse despejando $K_{f s}$ en la ec. (1): 


$$
K_{f s}=\frac{n \cdot V_{s}}{V_{f}\left(C_{0} \cdot V_{s}-n\right)}
$$

donde $n$ es la cantidad de analito particionando en el absorbente.

Es importante considerar el volumen de muestra cuando se calcula el valor de $K_{f s}$.

Para estimar correctamente la constante de distribución por encima de 1000 con 0,1 mm de espesor de fibra PDMS, se necesitan utilizar volúmenes de muestra mayores de $2 \mathrm{ml}$ (Pawliszyn, 1997). Para $K_{f s}$ más grandes, $1.10^{6}$ por ejemplo, e hidrocarburos de alto peso molecular en agua o aire, el volumen de muestra necesario debe ser al menos de $35 \mathrm{ml}$ (Lord \& Pawliszyn, 2000). Si la constante de distribución es baja y el volumen total de la muestra es elevado, el valor de $K_{f s}$ puede estimarse mediante:

$$
K_{f s}=\frac{n}{C_{0} \cdot V_{f}}
$$

Sin embargo, deben tomarse precauciones extremas cuando se utiliza esta ecuación, ya que se asume que después de la extracción, la concentración de analito no cambia significativamente en la muestra. 
Determinación del intervalo lineal del método para una matriz pura, en condiciones óptimas de extracción

Establecidos y optimizados los parámetros de extracción, es necesario luego determinar el intervalo lineal del método. Esta determinación también permitirá la estimación de los límites de detección. Los absorbentes de SPME incluyen polímeros líquidos como PDMS, que tienen un muy amplio rango lineal. Para adsorbentes sólidos, tal como Carbowax / DVB o PDMS / DVB, el rango lineal es más pequeño a causa de un número ilimitado de sitios de adsorción sobre la superficie, pero aún así tiene un rango lineal de varias órdenes de magnitud para analitos típicos (Pawliszyn, 1997).

\section{Selección del método de calibración}

Los procedimientos estándar utilizados para calibración con otras técnicas de extracción pueden adaptarse a SPME. EI blanco de fibra verificará que ni el instrumento, ni la aguja, se encuentran contaminados por el analito o un compuesto que interfiera. Generalmente el absorbente de la fibra se "limpia" por desorción en el inyector.

Cuando la matriz es simple, como aire o agua limpia, las constantes de distribución son muy similares a la de la matriz pura (Lord \& Pawliszyn, 2000).

Procedimientos especiales de calibración, tales como adiciones isotópicamente marcadas o adición de estándar, deben utilizarse para muestras más complejas (Lord \& Pawliszyn, 2000). 
En estos métodos se supone que el analito señalado se comporta similarmente al adicionado durante la extracción. Esta constituye una presunción adecuada cuando se analizan muestras homogéneas. Sin embargo, esto no debería ser cierto para muestras heterogéneas, a menos que las condiciones de extracción sean tales que el analito nativo sea extraído cuantitativamente de la matriz.

\section{Optimización de las condiciones de extracción para muestras heterogéneas}

Optimizar el proceso de extracción del analito nativo desde la matriz es difícil ya que, la asociación analito/matriz generalmente es desconocida. Cada vez que se considera un nuevo tipo de matriz compleja, se debe realizar una investigación para encontrar las condiciones óptimas de extracción, las cuales permitirán la más rápida y completa extracción y partición de analitos nativos.

La optimización de los parámetros de extracción se considera completa, cuando las recuperaciones de analitos presentes en una muestra nativa igualan a aquellas introducidas con una adición. Esta verificación se realiza basada en los resultados de extracción obtenidos para material estándar de referencia certificado, o por comparación con métodos de extracción estándar. Cuando esta condición es alcanzada, la cuantificación se realiza comparando las cantidades extraídas de analitos nativos y adicionados. 
Verificación del tiempo de equilibrio, sensibilidad $y$ rango dinámico lineal para muestras de matrices complejas

La presencia de una matriz de muestra puede cambiar no solo la constante de distribución sino también el tiempo de equilibrio. En casos donde la matriz tiene fases adicionales, por ejemplo una muestra acuosa con materia sólida particulada, la cinética de extracción del analito debería determinar en conjunto la velocidad de extracción. Para operar a sensibilidad óptima, el tiempo de extracción necesita estar ajustado en concordancia.

Es útil confirmar experimentalmente el rango lineal con la matriz real. Esto asegura que las condiciones de separación son satisfactorias y que no existen interferencias con el analito señalado (Lord \& Pawliszyn, 2000). 

CAPÍTULO II ObJetivos 



\section{OBJETIVOS}

Los benzimidazoles constituyen un grupo importante de fungicidas sistémicos que son utilizados para el control de enfermedades en cítricos. Sus características fisicoquímicas y capacidad de penetrar el tejido vegetal, hacen factible su presencia en los frutos y productos industrializados al momento de su comercialización.

Los mercados importadores del mundo y consumidores de productos frescos o industrializados, han incrementado considerablemente sus exigencias respecto a los niveles de tolerancia de residuos de agroquímicos, lo que demanda controles y estrategias de producción adecuadas.

Las metodologías analíticas tradicionales para la determinación de benzimidazoles son en su mayoría complejas, de elevado costo y tiempo de análisis. Lo que hace prever la necesidad de desarrollar metodologías alternativas tendientes a incrementar la sensibilidad, resolución y especificidad analítica, a la vez de reducir el uso de solventes contaminantes, costo y tiempo analítico.

Con el fin de brindar al sector citrícola una herramienta de fundamental importancia para la atención y control de las problemáticas relacionadas a la producción, industrialización y comercialización de sus productos; se plantea como objetivo general del trabajo el desarrollo de metodologías alternativas 
para el análisis de fungicidas benzimidazólicos en matrices cítricas.

La propuesta incluye la aplicación y optimización de metodologías para la determinación de multiresiduos de benzimidazoles por:

1- Microextracción en fase sólida y cromatografía Gaseosa SPME/GC.

2- Extracción en fase sólida y cromatografía líquida de alta resolución - SPE/HPLC.

\section{Objetivos específicos}

Teniendo en cuenta las características propias de cada metodología, con el fin de alcanzar el objetivo general, se plantean objetivos específicos para cada una de ellas.

1- Microextracción en fase sólida y cromatografía Gaseosa SPME/GC.

- Identificar los fungicidas benzimidazólicos factibles de ser analizados por esta metodología.

- Validar el sistema cromatográfico por inyección directa de los analitos.

- Seleccionar y adoptar el recubrimiento adecuado de la fibra en función de las propiedades de los analitos. 
- Seleccionar el modo de extracción de los analitos de las muestras.

- Evaluar y adoptar la técnica de agitación más eficiente.

- Establecer los parámetros y cinética del proceso de extracción.

- Optimizar las condiciones cromatográficas y establecer los parámetros de desorción de los analitos.

- Determinar y optimizar el perfil de tiempo de extracción en soluciones acuosas de estándares y muestras adicionadas.

- Determinar el tiempo de equilibrio y el volumen mínimo de muestra.

- Calcular las constantes de distribución analito-absorbente y coeficientes de difusión de los analitos.

- Determinar el rango lineal del método y seleccionar la metodología de calibración.

- Determinar la recuperación o exactitud, precisión, límites de detección y cuantificación del método. 
- Desarrollar y optimizar la SPME para matrices cítricas tales como frutas, jugos y productos fermentados.

- Aplicar la metodología desarrollada en muestras provenientes de empaques y/o industria cítrica.

- Identificar por espectrometría de masas los analitos extraidos por la fibra (SPME/GC/MSD) y optimizar los parámetros del inyector de vaporización de temperatura programada (PTV) en modo split/splitless y venteo de solvente para la determinación por GC/MSD.

\section{2- Extracción en fase sólida y cromatografía líquida de alta} resolución - SPE/HPLC.

- Optimizar las condiciones cromatográficas: seleccionar el tipo de columna, longitud de onda, composición de la fase móvil, temperatura de columna, velocidad de flujo, volumen de inyección.

- Determinar las condiciones óptimas de extracción, clean up y concentración: selección del adsorbente, acondicionamiento de la columna, definición de las condiciones de operación para la extracción, selección del eluyente, conservación del eluato. 
- Determinar el rango lineal del método y seleccionar la metodología de calibración.

- Establecer la precisión, exactitud y sensibilidad (límites de detección y cuantificación) del método.

- Optimizar la SPE para matrices cítricas.

- Aplicar la metodología desarrollada en muestras provenientes de empaques y/o la industria cítrica. 

CAPÍTULO III

DESARROLLO Y APLICACIÓN DE METODOLOGÍAS ANALÍtICAS 



\section{DESARROLLO Y APLICACIÓN DE METODOLOGÍAS ANALÍTICAS}

El desarrollo metodológico, conforme lo indicado en el capítulo anterior, comprendió la optimización de metodologías para la determinación de multiresiduos de benzimidazoles por:

1- Microextracción en fase sólida y cromatografía Gaseosa SPME/GC.

2- Extracción en fase sólida y cromatografía líquida de alta resolución - SPE/HPLC.

En cada caso el desarrollo metodológico implicó la ejecución, en etapas, de actividades tendientes a definir las condiciones de extracción y cuantificación de los analitos factibles de ser determinados por cada metodología.

Las diferentes etapas en cada caso se han organizado en función de una mayor claridad del proceso metodológico llevado adelante, aunque la práctica experimental real implica un devenir continuo que muchas veces dista del orden cronológico en que los distintos pasos se presentan.

En este sentido, se presenta el desarrollo metodológico y los resultados, organizados conforme la siguiente estructura: 
1. Microextracción en fase sólida y cromatografía Gaseosa SPME/GC.

1.1 Determinación Multiresiduo de Benzimidazoles por Cromatografía Gaseosa con Detector Nitrógeno-Fósforo GC/NPD.

1.2 Determinación Multiresiduo de Benzimidazoles por Microextracción en Fase sólida y Cromatografía Gaseosa con Detector Nitrógeno-Fósforo - SPME/GC/NPD.

1.3 Determinación Multiresiduo de Benzimidazoles por Microextracción en Fase sólida y Cromatografía Gaseosa con Detector de Masa - SPME/GC/MSD.

2 Extracción en fase sólida y cromatografía líquida de alta resolución - SPE/HPLC.

2.1 Determinación Simultánea de Benzimidazoles por Extracción en Fase Sólida y Cromatografía Líquida de Alta Resolución. 
1. Microextracción en Fase Sólida $y$ Cromatografía Gaseosa - SPME/GC 



\subsection{DETERMINACIÓN MULTIRESIDUO DE BENZIMIDAZOLES POR CROMATOGRAFIA GASEOSA CON DETECTOR NITRÓGENO- FÓSFORO (GC/NPD)}

\section{Generalidades}

El desarrollo de la metodología por microextracción y cromatografía gaseosa (SPME/GC) implica como etapas previas la definición de los analitos posibles de analizar por esta técnica cromatográfica, la identificación de los picos y determinación de los tiempos de retención, la determinación de la relación entre la concentración de los analitos y las respuestas cromatográficas, la definición y optimización de las condiciones cromatográficas; es decir, la validación previa del sistema cromatográfico (Navarro et al., 2002; Stajnbaher, 2003; Ouyang et al., 2005).

Con este fin se realiza, en primera instancia, el desarrollo metodológico para la determinación por inyección directa de los siguientes fungicidas benzimidazólicos: thiabendozole (TBZ), metiltiofanato y tiofanato. 


\section{Materiales y método}

\section{Reactivos}

Metanol, hexano, acetona y etilacetato (Merck) calidad cromatográfica.

Estándares certificados de thiabendazole, metiltifanato y tiofanato (Accu Standard Inc.).

\section{Equipamiento}

Se utilizó un cromatógrafo gaseoso Modelo 5890 Serie II, con sistema de inyección capilar "split/splitless", equipado con Inyector automático Hewlett Packard Modelo 6890 Series y estación de trabajo ("Chem station") HP, Versión A.03.34 y detector de nitrógeno-fósforo (NPD). Columna Agilent HP - 5MS $0,25 \mathrm{~mm} \times 30 \mathrm{~m} \times 0,25 \mu \mathrm{m}$. Inserto o "Liner" de $900 \mu \mathrm{l}-78,5 \times$ $6,5 \mathrm{~mm}$.

\section{Preparación de estándares}

Se prepararon estándares individuales y mezclas de estándares en diferentes solventes a fin de determinar los tiempos de retención individuales e identificación de picos en la mezcla.

A fin de seleccionar el solvente óptimo para la determinación analítica, se utilizaron los siguientes: metanol, hexano, acetona y etilacetato (Stajnbaher, 2003; Mastovska y Lehotay, 2004; Albero, 2005; Ouyang et al., 2005). 
En función de las distintas condiciones y respuestas cromatográficas, en alturas y áreas de picos, se seleccionó como solvente para la preparación de estándares el etilacetato.

Los estándares de los analitos en dicho solvente se prepararon por quintuplicado a diferentes concentraciones: 10,0 7,5 - 6,0 - 5,0 - 4,0 - 2,5 y 2,0 mg/l o partes por millón (ppm); a fin de trazar las curvas de linealidad respectivas.

Para determinar precisión se prepararon quintuplicados de soluciones estándares de los analitos a 2,5 - 5,0 y 7,5 ppm, y para determinar límites, quintuplicados de soluciones estándares a 2,0 $-2,5$ y 4,0 ppm.

\section{Condiciones cromatográficas}

A fin de establecer una referencia metodológica que permitiera evaluar en forma comparativa las metodologías por inyección directa y SPME, se llevaron adelante numerosas pruebas a fin de establecer las condiciones cromatográficas óptimas.

Las modificaciones en las distintas pruebas realizadas se basaron fundamentalmente en las temperaturas del inyector y rampas de temperaturas del horno, a fin de lograr la mayor separación de los analitos y adecuadas respuestas cromatográficas.

Establecidas las condiciones cromatográficas, el desarrollo metodológico implicó la determinación de la curva de regresión lineal, intervalos de confianza, precisión y límites de detección y cuantificación. 


\section{Análisis estadístico}

El procesamiento estadístico de los datos obtenidos se realizó mediante versión de prueba del software Statgraphics Centurión XV.

\section{$\underline{\text { Análisis Unidimensional }}$}

Los parámetros estadísticos correspondientes al análisis unidimensional de los datos incluyen las medidas de tendencia central, de variabilidad y de forma; los coeficientes de asimetría y curtosis estandarizados determinan si la muestra procede de una distribución normal.

\section{Regresión Lineal}

En el análisis de regresión lineal se determinó la independencia y normalidad de los residuos a partir de los estadísticos Durbin Watson y Kolmogorov para un nivel de confianza del $95 \%$. Se estableció la ecuación de la recta y el estadístico $R^{2}$ que indica la relación entre las variables (respuestas cromatográficas vs. concentración).

\section{Precisión}

La precisión es un parámetro estadístico que determina la dispersión de las medidas alrededor de su valor medio, que se expresa matemáticamente como la desviación estándar estimada analíticamente o más comúnmente por la desviación estándar relativa o coeficiente de variación (Miller y Miller, 1993). El método 
se considera preciso cuando el coeficiente de variación porcentual no supera el 1,5-2\% (AOAC, 1990).

Se determinó precisión del sistema a partir de los datos de las respuestas cromatográficas expresadas en alturas de pico, para $n=5$ y $\alpha=0,05$; en condiciones repetitivas y reproducibles. Mediante test de Student se determinó el intervalo de confianza de la media.

\section{Límites de detección y cuantificación}

Los límites se estimaron a partir de la curva de regresión para bajas concentraciones de los analitos y 15 determinaciones individuales ( $\left.n^{\prime}\right)$. De dicha curva se determinó la pendiente $(b)$ y por extrapolación a concentración cero, se obtuvo un estimado de la respuesta del blanco $\left(Y_{b l}\right)$.

A partir de la desviación estándar correspondiente a cada concentración, se determinó la recta correspondiente y por extrapolación se estimó la desviación estándar del blanco $\left(S_{b 1}\right)$.

Los límites de detección y cuantificación se calcularon a partir de las ecuaciones (7) y (8), en las cuales se considera 3 y 10 veces la desviación estándar del blanco respectivamente.

$$
\begin{aligned}
& \text { Límite de detección }=\frac{Y_{b l}+3 S_{b l}}{b} \cdot \frac{1}{\sqrt{n^{\prime}}} \\
& \text { Límite de Cuantificación }=\frac{Y_{b l}+10 S_{b l}}{b} \cdot \frac{1}{\sqrt{n^{\prime}}}
\end{aligned}
$$


Donde:

$n^{\prime}=$ número de determinaciones individuales.

$b=$ pendiente de la curva de regresión a bajas concentraciones de los analitos.

$Y_{b l}=$ estimado de la respuesta del blanco a concentración cero.

$S_{b l}=$ estimado de la desviación estándar del blanco a concentración cero.

\section{Resultados y discusión}

Se establecieron las condiciones cromatográficas para la determinación por inyección directa de soluciones mezcla de estándares benzimidazólicos, siendo las mismas las siguientes:

Velocidad gas carrier $\left(\mathrm{N}_{2}\right) 1,5 \mathrm{ml} / \mathrm{min}$, flujo del gas auxiliar $\left(\mathrm{N}_{2}\right) 30 \mathrm{ml} / \mathrm{min}$, flujo de $\mathrm{H}_{2} 4 \mathrm{ml} / \mathrm{min}$ y flujo de aire $100-110 \mathrm{ml} / \mathrm{min}$, temperatura inyector $250^{\circ} \mathrm{C}$ con $1 \mathrm{~min}$ de "splitless", temperatura inicial de columna $80 \stackrel{\circ}{ } \mathrm{C}$ durante $2 \mathrm{~min}$, rampa de $40 \stackrel{\circ}{\circ} / \mathrm{min}$ hasta temperatura final de $280 \stackrel{\circ}{\circ}$ durante $6 \mathrm{~min}$, temperatura del detector NPD $300^{\circ} \mathrm{C}$. Columna Agilent HP - 5MS 0,25 mm x $30 \mathrm{~m}$ x 0,25 $\mu \mathrm{m}$. "Liner" de $900 \mu \mathrm{l}-78,5$ x 6,5 mm. Volumen de inyección $2 \mu \mathrm{l}$.

De los diferentes solventes evaluados para la preparación de estándares, metanol, hexano, acetona y etilacetato (o acetato de etilo); se seleccionó este último en función de las respuestas cromatográficas expresadas en alturas y áreas de pico. 
Establecidas las condiciones cromatográficas se identificaron los tiempos de retención para cada analito individual y en soluciones mezcla de estándares. Los tiempos de retención medios (RT), tanto en solución individual como en la solución mezcla, de los benzimidazoles analizados fueron: Metiltiofanato $R T=3,316$; Tiofanato RT = 3,681 y Thiabendazole $R T=9,078$.

El análisis estadístico de los datos correspondientes a las respuestas cromatográficas expresadas en alturas y áreas de pico para las distintas soluciones estándares de los analitos en etilacetato a $10,0-7,5-6,0-5,0-4,0-2,5$ y 2,0 ppm, se muestra en la tablas 3 y 4 .

Se determinó para cada analito la curva de regresión lineal, intervalos de confianza, precisión y límites de detección y cuantificación. Los resultados del análisis unidimensional, indicaron para todas las concentraciones de los analitos una distribución normal de las observaciones. El análisis de regresión lineal permitió establecer la ecuación de la recta (respuestas cromatográficas en alturas y áreas de pico vs. concentración), el coeficiente de correlación y el estadístico $\mathrm{R}^{2}$ para cada analito. En las figuras 14 y 15 se indican las curvas de regresión correspondientes. 
Tabla 3. Análisis unidimensional - Respuestas cromatográficas expresadas en alturas de pico - Soluciones estándares en etilacetato - Inyección directa - GC-

\begin{tabular}{|c|c|c|c|c|c|c|c|}
\hline \multirow{3}{*}{$\begin{array}{c}\text { Analito } \\
\begin{array}{c}\text { Concentración } \\
\text { ppm }\end{array} \\
\end{array}$} & \multicolumn{7}{|c|}{$N P D-n=5, \alpha=0,05$} \\
\hline & \multicolumn{7}{|c|}{ Metiltiofanato - Alturas } \\
\hline & 10,0 & 7,5 & 6,0 & 5,0 & 4,0 & 2,5 & 2,0 \\
\hline Altura Media & 250079 & 187778 & 149649 & 124883 & 100156 & 63455 & 50722 \\
\hline $\begin{array}{l}\text { Desviación } \\
\text { Estándar }\end{array}$ & 433 & 576 & 841 & 729 & 781 & 475 & 435 \\
\hline RSD \% & 0,17 & 0,31 & 0,56 & 0,58 & 0,78 & 0,75 & 0,86 \\
\hline $\begin{array}{l}\text { Intervalos de } \\
\text { confianza +/- }\end{array}$ & 537 & 715 & 1044 & 906 & 970 & 590 & 540 \\
\hline Analito & \multicolumn{7}{|c|}{ Tiofanato - Alturas } \\
\hline $\begin{array}{c}\text { Concentración } \\
\text { ppm }\end{array}$ & 10,0 & 7,5 & 6,0 & 5,0 & 4,0 & 2,5 & 2,0 \\
\hline Altura Media & 316453 & 237704 & 190583 & 159108 & 127125 & 79300 & 64021 \\
\hline $\begin{array}{l}\text { Desviación } \\
\text { Estándar }\end{array}$ & 523 & 627 & 627 & 628 & 633 & 636 & 670 \\
\hline RSD \% & 0,17 & 0,26 & 0,33 & 0,39 & 0,50 & 0,80 & 1,05 \\
\hline $\begin{array}{l}\text { Intervalos de } \\
\text { confianza +/- }\end{array}$ & 650 & 779 & 778 & 780 & 785 & 789 & 832 \\
\hline Analito & \multicolumn{7}{|c|}{ Thiabendazole - Alturas } \\
\hline $\begin{array}{c}\text { Concentración } \\
\text { ppm }\end{array}$ & 10,0 & 7,5 & 6,0 & 5,0 & 4,0 & 2,5 & 2,0 \\
\hline Altura Media & 476951 & 362184 & 290885 & 240404 & 191328 & 119913 & 95008 \\
\hline $\begin{array}{l}\text { Desviación } \\
\text { Estándar }\end{array}$ & 597 & 738 & 849 & 977 & 984 & 992 & 1031 \\
\hline RSD \% & 0,13 & 0,20 & 0,29 & 0,41 & 0,51 & 0,83 & 1,09 \\
\hline $\begin{array}{l}\text { Intervalos de } \\
\text { confianza +/- }\end{array}$ & 742 & 917 & 1054 & 1213 & 1222 & 1232 & 1280 \\
\hline
\end{tabular}


Tabla 4. Análisis unidimensional - Respuestas cromatográficas expresadas en áreas de pico - Soluciones estándares en etilacetato - Inyección directa $-n=5$,

\begin{tabular}{|c|c|c|c|c|c|c|c|}
\hline \multirow{2}{*}{$\begin{array}{c}\text { Analito } \\
\begin{array}{c}\text { Concentración } \\
\text { ppm }\end{array} \\
\end{array}$} & \multicolumn{7}{|c|}{ Metiltiofanato - Areas } \\
\hline & 10 & 7,5 & 6 & 5 & 4 & 2,5 & 2 \\
\hline Area Media & 437776 & 328226 & 262072 & 218764 & 175691 & 110908 & 88857 \\
\hline $\begin{array}{c}\text { Desviación } \\
\text { Estándar }\end{array}$ & 340 & 352 & 355 & 357 & 364 & 382 & 383 \\
\hline RSD \% & 0,08 & 0,11 & 0,14 & 0,16 & 0,21 & 0,34 & 0,43 \\
\hline $\begin{array}{l}\text { Intervalos de } \\
\text { confianza +/- }\end{array}$ & 422 & 437 & 441 & 443 & 452 & 474 & 475 \\
\hline Analito & \multicolumn{7}{|c|}{ Tiofanato - Areas } \\
\hline $\begin{array}{c}\text { Concentración } \\
\text { ppm }\end{array}$ & 10 & 7,5 & 6 & 5 & 4 & 2,5 & 2 \\
\hline Area Media & 554492 & 416047 & 333065 & 278205 & 222985 & 140008 & 112140 \\
\hline $\begin{array}{l}\text { Desviación } \\
\text { Estándar }\end{array}$ & 406 & 432 & 453 & 454 & 476 & 486 & 488 \\
\hline RSD \% & 0,07 & 0,10 & 0,14 & 0,16 & 0,21 & 0,35 & 0,44 \\
\hline $\begin{array}{l}\text { Intervalos de } \\
\text { confianza +/- }\end{array}$ & 504 & 536 & 563 & 564 & 590 & 604 & 606 \\
\hline Analito & \multicolumn{7}{|c|}{ Thiabendazole - Areas } \\
\hline $\begin{array}{c}\text { Concentración } \\
\text { ppm }\end{array}$ & 10 & 7,5 & 6 & 5 & 4 & 2,5 & 2 \\
\hline Area Media & 843737 & 639009 & 510821 & 424940 & 339831 & 210599 & 168030 \\
\hline $\begin{array}{c}\text { Desviación } \\
\text { Estándar }\end{array}$ & 283 & 293 & 329 & 353 & 385 & 421 & 425 \\
\hline RSD \% & 0,03 & 0,05 & 0,06 & 0,08 & 0,11 & 0,20 & 0,25 \\
\hline $\begin{array}{l}\text { Intervalos de } \\
\text { confianza +/- }\end{array}$ & 351 & 364 & 409 & 439 & 478 & 523 & 527 \\
\hline
\end{tabular}

La tabla 5 muestra en forma comparativa los valores de pendientes e interceptos de las distintas rectas de regresión expresadas en areas y alturas de pico para los diferentes analitos. 


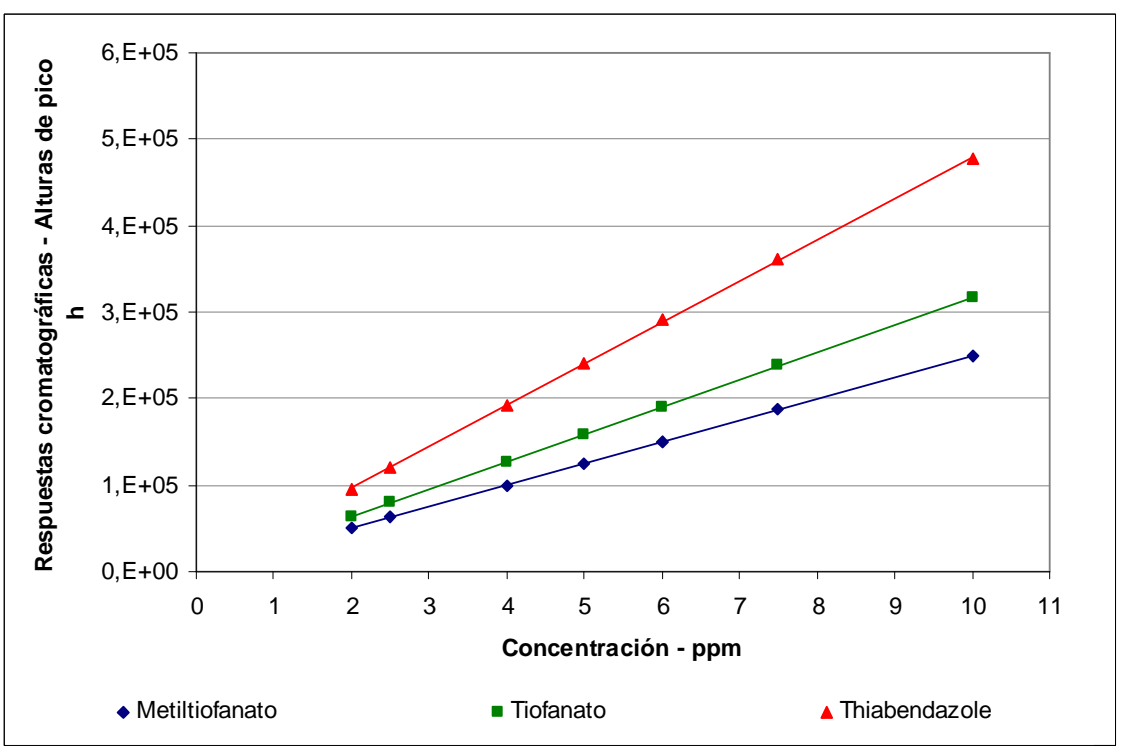

Figura 14. Regresión lineal alturas de pico vs. concentración - Soluciones estándares en etilacetato - Inyección directa - GC-NPD

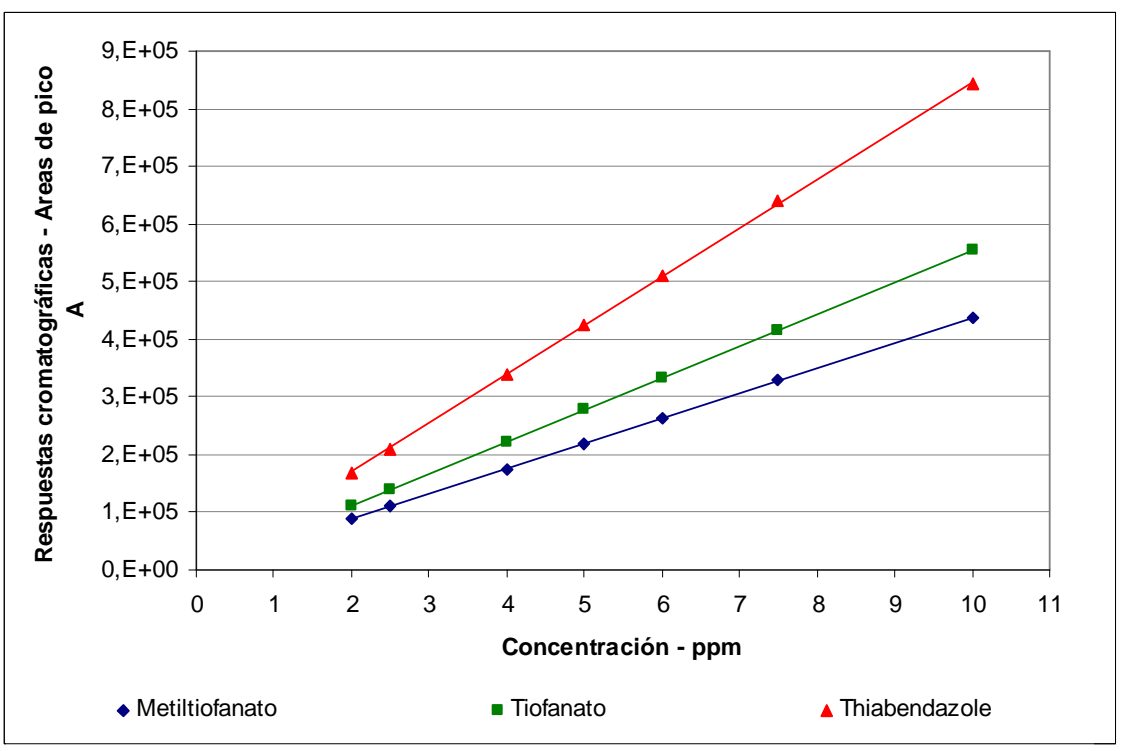

Figura 15. Regresión lineal áreas de pico vs. concentración - Soluciones estándares en etilacetato - Inyección directa - GC-NPD 
Tabla 5. Interceptos y pendientes - Comparación rectas de regresión Soluciones de estándares en etilacetato - Inyección directa - GC-NPD

\begin{tabular}{|c|c|c|c|c|c|c|}
\cline { 2 - 7 } \multicolumn{1}{c|}{} & \multicolumn{2}{c|}{ Metiltiofanato } & \multicolumn{2}{c|}{ Tiofanato } & \multicolumn{2}{c|}{ Thiabendazole } \\
\cline { 2 - 7 } & Intercepto & Pendiente & Intercepto & Pendiente & Intercepto & Pendiente \\
\hline $\begin{array}{c}\text { Altura de } \\
\text { pico }\end{array}$ & 738 & 24907 & 770 & 31592 & 452 & 47933 \\
\hline $\begin{array}{c}\text { Area de } \\
\text { pico }\end{array}$ & 1433 & 43575 & 1762 & 55260 & 351 & 85700 \\
\hline
\end{tabular}

El análisis estadístico de los datos permitió establecer que existen diferencias significativas entre las pendientes e interceptos de las curvas de regresión expresadas en áreas y alturas de pico vs. concentración para los distintos analitos con un nivel de confianza del $99 \%$.

La figura 16 muestra, a modo de ejemplo, la comparación de rectas de regresión expresadas en áreas y alturas de pico vs concentración para el metiltiofanato.

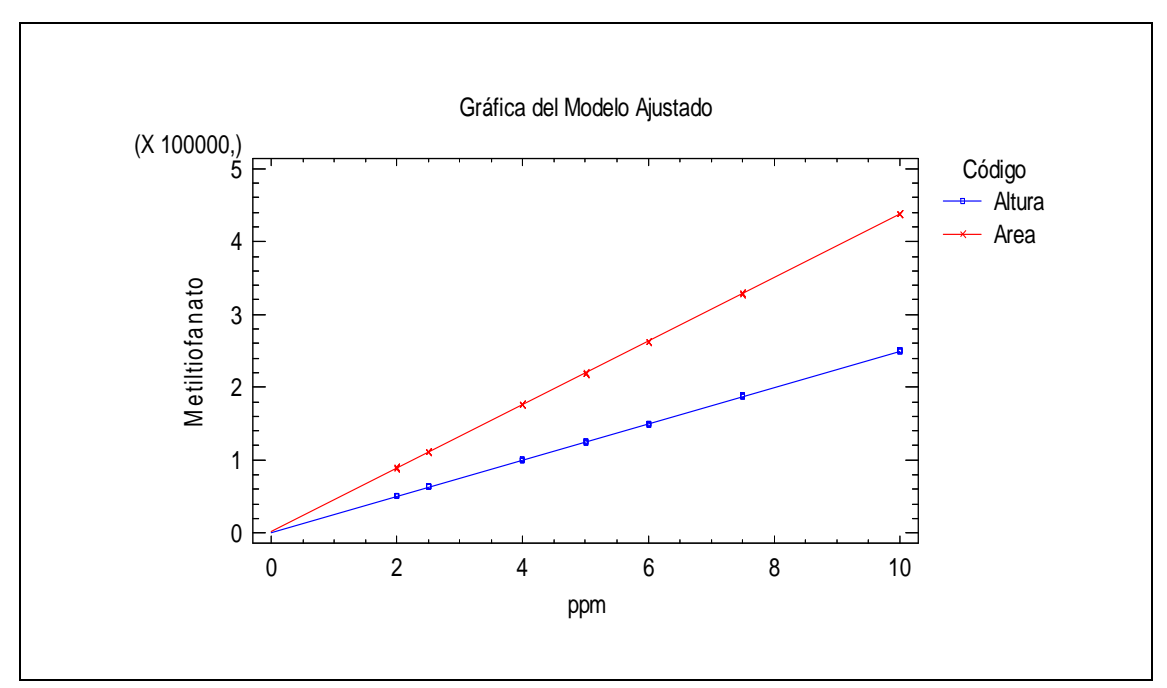

Figura 16. Comparación de rectas de regresión área de pico vs. concentración y altura de pico vs. concentración - Soluciones estándares metiltiofanato en etilacetato - Inyección directa - GC-NPD

$$
-87-
$$


Dado que los resultados para los distintos analitos no presentan diferencias significativas en los coeficientes de correlación de las ecuaciones del modelo ajustado utilizando áreas o alturas de pico, se presentan a continuación los resultados en alturas de pico vs. concentración.

Las figuras 17, 18 y 19 muestran las rectas de regresión para cada analito con indicación de los límites de confianza y de predicción correspondientes.

Las ecuaciones del modelo ajustado para cada analito fueron:

$\mathrm{h}_{\text {Metilitiofanato }}=738+24907 \mathrm{ppm}$ Metilitiofanato

Coeficiente de Correlación $=0,999948$

$R^{2}=99,9897 \%$

$\mathrm{h}_{\text {Tiofanato }}=770+31592 \mathrm{ppm}$ Tiofanato

Coeficiente de Correlación $=0,999972$

$R^{2}=99,9945 \%$

$\mathrm{h}_{\text {Thiabendazole }}=452+47932 \mathrm{ppm}$ Thiabendazole

Coeficiente de Correlación $=0,999872$

$R^{2}=99,9744 \%$

Donde:

$\mathrm{h}=$ respuestas cromatográficas expresadas en alturas de pico.

ppm = concentración expresada en partes por millón o mg/l 


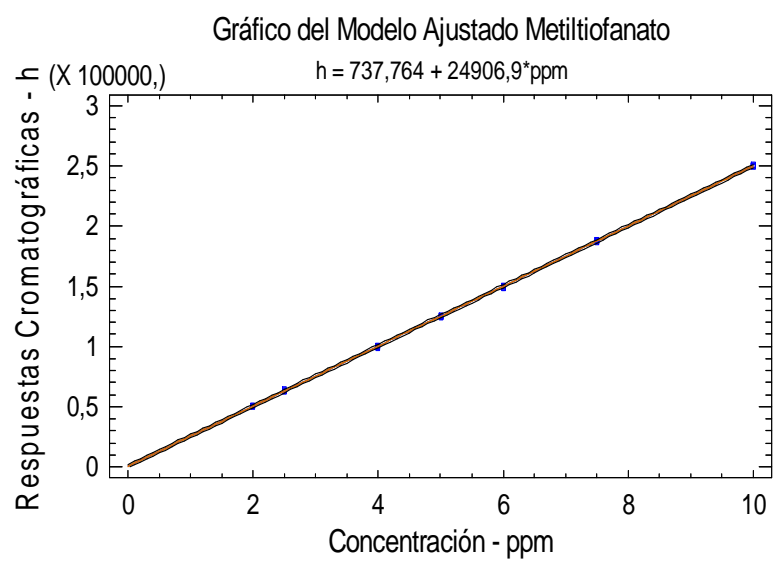

Figura 17. Regresión lineal - Soluciones estándares metiltiofanato en etilacetato - Inyección directa - GC-NPD

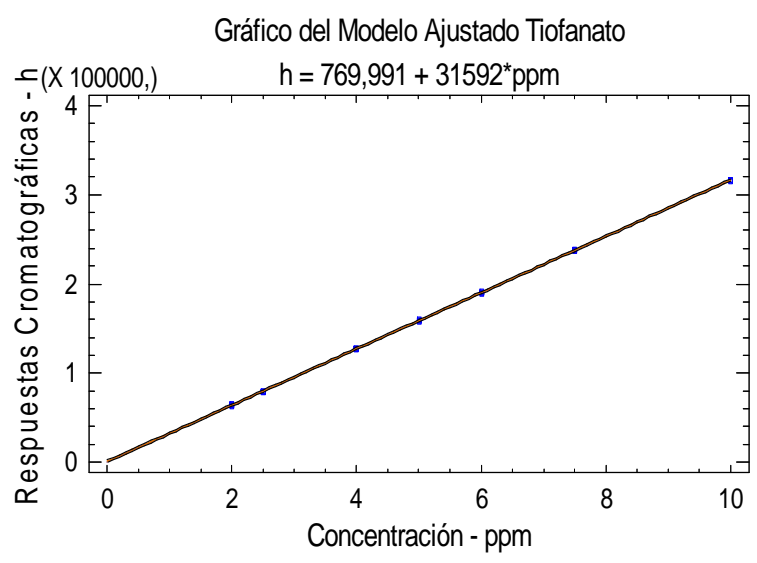

Figura 18. Regresión lineal - Soluciones estándares tiofanato en etilacetato Inyección directa - GC-NPD 


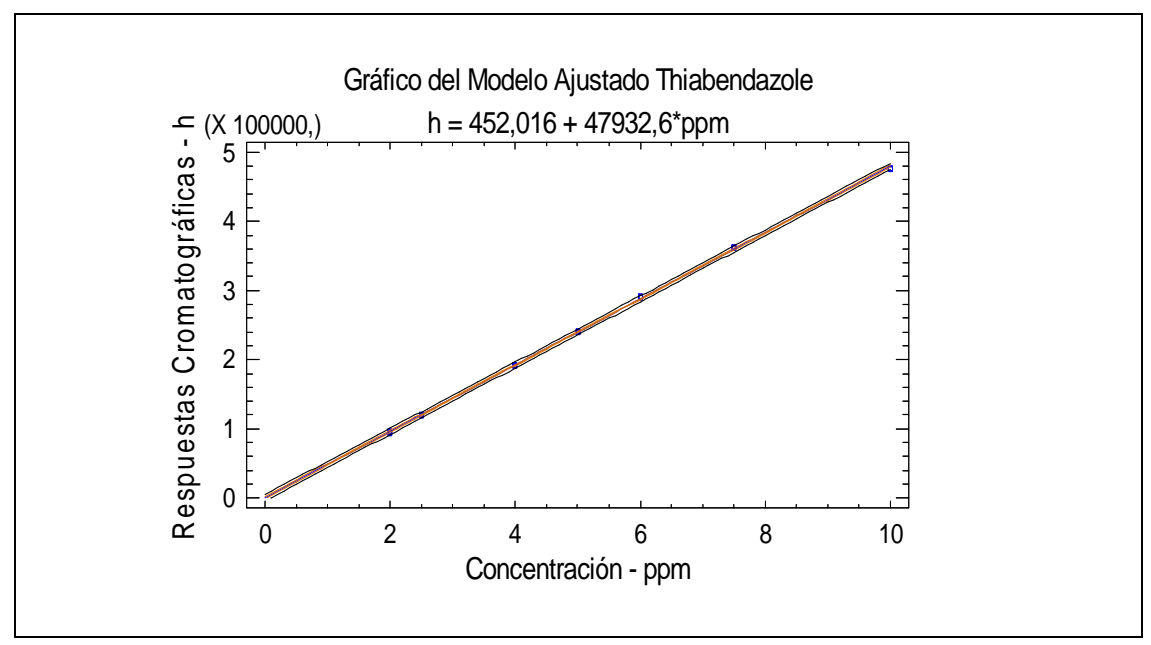

Figura 19. Regresión lineal - Soluciones estándares thiabendazole en etilacetato - Inyección directa - GC-NPD

Puesto que el valor-P del análisis de varianza (ANOVA) para todos los analitos resultó menor que 0,05; se estableció que existe en todos los casos una relación estadísticamente significativa entre las respuestas cromatográficas (alturas de pico) y la concentración (ppm) con un nivel de confianza del 95,0\%.

El estadístico $R^{2}$ y el coeficiente de correlación muestran para los distintos analitos el ajuste lineal entre las variables. En todos los casos se establecieron los valores predichos de las respuestas cromatográficas para el modelo ajustado y los residuos correspondientes. Se determinó para cada uno la independencia y normalidad de los residuos a partir de los estadísticos Durbin Watson y Kolmogorov para un nivel de confianza del $95 \%$. Mediante el estadístico de Durbin-Watson (DW) se examinaron los residuos correspondientes a los diferentes analitos a fin de determinar la existencia de una correlación significativa basada en el orden de los datos. El valor-P en todos los casos resultó mayor 
que 0,05 estableciéndose la independencia de los residuos.

Dado que el valor-P más pequeño del test de bondad de ajuste para residuos (Kolmogorov) resultó menor a 0,05 para todos los analitos, se estableció que los residuos proceden de una distribución normal con un nivel de confianza de al menos el $95 \%$.

Se determinó precisión del sistema a partir de los datos de las respuestas cromatográficas expresadas en alturas de pico correspondientes a soluciones de estándares a 2,5 - 5 y 7,5 ppm, para $n=5$ y $\alpha=0,05$; en condiciones repetitivas y reproducibles.

En cada caso se determinó desviación estándar, coeficiente de variación porcentual (RSD \%) y mediante test de Student los intervalos de confianza de la media. Los resultados se indican en la tabla 6.

Tabla 6. Precisión - Valores medios expresados en alturas de pico - Inyección directa $2 \mu \mathrm{l}-\mathrm{GC}-\mathrm{NPD}-\mathrm{n}=5, \alpha=0.05$

\begin{tabular}{|c|c|c|c|c|}
\hline \multirow{2}{*}{ Analitos } & \multicolumn{4}{|c|}{ Soluciones estándares a 2,5 ppm } \\
\cline { 2 - 5 } & Promedio & $\begin{array}{c}\text { Desviación } \\
\text { estándar }\end{array}$ & RSD \% & $\begin{array}{c}\text { Intervalo de } \\
\text { confianza }\end{array}$ \\
\hline Metiltiofanato & 63455 & 475 & 0,75 & \pm 590 \\
\hline Tiofanato & 79300 & 636 & 0,80 & \pm 789 \\
\hline Thiabendazole & 119913 & 992 & 0,83 & \pm 1232 \\
\hline \multirow{2}{*}{ Analitos } & \multicolumn{4}{|c|}{ Soluciones estándares a 5 ppm } \\
\cline { 2 - 5 } & Promedio & $\begin{array}{c}\text { Desviación } \\
\text { estándar }\end{array}$ & RSD \% & $\begin{array}{c}\text { Intervalo de } \\
\text { confianza }\end{array}$ \\
\hline Metiltiofanato & 124883 & 729 & 0,58 & \pm 906 \\
\hline Tiofanato & 159108 & 628 & 0,39 & \pm 780 \\
\hline Thiabendazole & 240404 & 977 & 0,41 & \pm 1213 \\
\hline \multirow{2}{*}{ Analitos } & \multicolumn{4}{|c|}{ Soluciones estándares a 7,5 ppm } \\
\cline { 2 - 5 } & Promedio & $\begin{array}{c}\text { Desviación } \\
\text { estándar }\end{array}$ & RSD \% & $\begin{array}{c}\text { Intervalo de } \\
\text { confianza }\end{array}$ \\
\hline Metiltiofanato & 187778 & 576 & 0,31 & \pm 715 \\
\hline Tiofanato & 237704 & 627 & 0,26 & \pm 779 \\
\hline Thiabendazole & 362184 & 738 & 0,20 & \pm 917 \\
\hline
\end{tabular}


Como puede observarse en dicha tabla los coeficientes de variación porcentual para los diferentes analitos, a las distintas concentraciones, resultan menores a 1,5 - $2 \%$ (AOAC, 1990), por lo que es posible deducir que el método es preciso en las condiciones establecidas.

Los límites de detección y cuantificación fueron determinados a partir de quintuplicados de soluciones estándares de los analitos a las siguientes concentraciones: $2-2,5$ y 4 ppm.

Mediante las ecuaciones (7) y (8), se calcularon los límites correspondientes a cada analito. Los resultados se muestran en la tabla 7, expresados en términos de concentración en ppm de la solución y masa inyectada en ng, para un intervalo de confianza del $95 \%$.

Tabla 7. Límite de detección y cuantificación - inyección directa $2 \mu$ l - GC-NPD

\begin{tabular}{|l|c|c|c|c|}
\hline \multirow{2}{*}{ Analitos } & \multicolumn{2}{|c|}{ Límite de detección } & \multicolumn{2}{c|}{ Límite de cuantificación } \\
\cline { 2 - 5 } & ppm & $\mathbf{n g}$ & $\mathbf{p p m}$ & $\mathbf{n g}$ \\
\hline Metiltiofanato & 0,018 & 36 & 0,022 & 44 \\
\hline Tiofanato & 0,021 & 42 & 0,061 & 122 \\
\hline Thiabendazole & 0,013 & 26 & 0,050 & 100 \\
\hline
\end{tabular}

El análisis de los resultados obtenidos permite indicar que el sistema presenta una adecuada precisión y sensibilidad para las condiciones establecidas, mostrando una estrecha correlación entre las respuestas cromatográficas y la concentración o masa inyectada de los analitos en cuestión. 


\subsection{DETERMINACIÓN MULTIRESIDUO DE BENZIMIDAZOLES POR MICROEXTRACCIÓN EN FASE SÓLIDA Y CROMATOGRAFÍA GASEOSA CON DETECTOR DE NITRÓGENO- FÓSFORO (SMPE/GC/NPD)}

\section{Generalidades}

Definidos los analitos factibles de analizar mediante cromatografía gaseosa con detector NPD y optimizadas las condiciones cromatográficas para la determinación por inyección directa; se procedió al desarrollo y optimización de la metodología de extracción por SPME.

La selección de la metodología de extracción se fundó en las ventajas comparativas que la SPME presenta frente a otros métodos extractivos tradicionales (Beltran et al., 2000; Lord \& Pawliszyn, 2000; Sjaak y Pawliszyn, 2004; Dietz et al., 2006; Sauret-Szczepansky et al., 2006). El desarrollo metodológico del proceso de extracción por SPME, comprendió las siguientes etapas (Pawliszyn, 1997; Kataoka et al., 2000; Lambropoulou et al., 2000; Ouyang et al., 2005):

- Selección del recubrimiento de la fibra.

- Selección del modo y condiciones de extracción.

- Selección del método de agitación.

- Determinación del volumen mínimo de muestra. 
- Determinación del tiempo óptimo de extracción.

- Selección de las condiciones de desorción.

Asimismo se optimizó el sistema de separación y detección para las nuevas condiciones de operación.

Las experiencias comprendieron el tratamiento de diferentes matrices de análisis tales como soluciones mezcla de estándares, muestras adicionadas y muestras provenientes de empaques e industrias de la región.

\section{Materiales y método}

\section{Reactivos}

Estándares certificados de thiabendazole (Pestanal), metiltifanato y tiofanato (Accu Standard Inc.).

Hidróxido de sodio, ácido clorhídrico y cloruro de sodio (Anedra). Metanol calidad cromatográfica (Merck). Agua grado 1.

\section{Equipamiento}

Se utilizó un cromatógrafo gaseoso Modelo 5890 Serie II, con sistema de inyección capilar "split/splitless", equipado con Inyector automático Hewlett Packard Modelo 6890 Series y "Chem station" HP. Versión A.03.34 y detector de nitrógeno-fósforo (NPD). Columna Agilent HP - 5MS 0,25 mm x $30 \mathrm{~m} \times 0,25 \mu \mathrm{m}$. Inserto o "Liner" de 0,75 mm de diámetro interno. 
Para la obtención de agua grado 1 se utilizó un equipo $\mathrm{E}$. Pure - Barnstead.

Para la agitación de las soluciones se utilizó un agitador magnético Mistral Large Magnestir II - Lab Line Mod 1170-1 con sistema para mantener la temperatura constante, y baño de ultrasonido NEY-Dental International con controles ajustables.

Se emplearon fibras de sílica fundida recubierta con polidimetilxilosano (PDMS), poliacrilato (PA) y carbowax/ divinilbenceno (CW/DVB) (Beltran et al., 2000; Lambropoulou et al., 2000; Zimmermann et al., 2006); marca Supelco de 100, 85 y $65 \mu \mathrm{m}$ respectivamente. Se empleó como soporte de la fibra una Jeringa SPME marca Supelco y un soporte de muestreo manual SPME para 8 viales de $4 \mathrm{ml}$ y un adaptador para viales de mayor volumen.

Balanza analítica Ohaus, Freezer electrolux, Centrífugas Gelec 130-D y Gelec G-142-D. Procesadora Ultracomb.

Filtros de papel Double Ring 101 y fritz 0,45 $\mu \mathrm{m}$ Alltech.

Colector al vacío (“Vacuum Manifold”) Alltech.

\section{Condiciones cromatográficas}

Se llevaron adelante numerosas pruebas para establecer las condiciones óptimas de extracción y desorción. Las modificaciones en los distintos métodos evaluados se basaron fundamentalmente en variaciones de $\mathrm{pH}$ de las soluciones acuosas, tiempos de extracción y desorción, grado de salinización, naturaleza del absorbente, temperaturas del inyector y rampas de temperaturas del horno, etc. (Lord \& Pawliszyn, 2000; Ouyang et 
al., 2005); a fin de lograr la mayor separación de los analitos y adecuadas respuestas cromatográficas. En función de las experiencias efectuadas, se establecieron las siguientes condiciones cromatográficas:

Velocidad gas carrier $\left(\mathrm{N}_{2}\right)$ 1,5 ml/min, flujo del gas auxiliar $\left(\mathrm{N}_{2}\right) 30 \mathrm{ml} / \mathrm{min}$, flujo de $\mathrm{H}_{2} 4 \mathrm{ml} / \mathrm{min}$ y flujo de aire $100-110 \mathrm{ml} / \mathrm{min}$, temperatura inyector $250 \stackrel{\circ}{\circ}$ con 3 minutos de "splitless", temperatura inicial de columna $80{ }^{\circ} \mathrm{C}$ durante $3,5 \mathrm{~min}$, rampa de $55^{\circ} \mathrm{C} / \mathrm{min}$ hasta temperatura final de $280^{\circ} \mathrm{C}$ durante $8,5 \mathrm{~min}$, temperatura del detector $300^{\circ} \mathrm{C}$. Columna Agilent HP - 5MS 0,25 $\mathrm{mm}$ x $30 \mathrm{~m}$ x 0,25 $\mu \mathrm{m}$. "Liner" de 0,75 mm de diámetro interno.

\section{Preparación de estándares}

La preparación de las soluciones acuosas, constituye una etapa de fundamental importancia para lograr una óptima transferencia de los analitos al polímero de recubrimiento.

La pureza del agua está garantizada ya que se trata de agua grado 1, por lo que las modificaciones del medio acuoso se redujeron a variaciones de $\mathrm{pH}$ y grado de salinización.

Con el fin de verificar el efecto del medio para cada analito en particular, se prepararon soluciones individuales de cada uno a distintos valores de $\mathrm{pH}$, tales como:

a)- soluciones acuosas de 0,02 ppm de TBZ a pH 5, 7 y 9 .

b)- soluciones acuosas de 0,02 ppm de metiltiofanato a pH 5, 7 y

9.

c)- soluciones acuosas de 0,02 ppm de tiofanato a pH 5, 7 y 9 . 
Para cada una de estas soluciones se estableció un tiempo de extracción de $10 \mathrm{~min}$, con los diferentes polímeros de recubrimiento: poliacrilato de $85 \mu \mathrm{m}$ (PA), polidimetilsiloxano de $100 \mu \mathrm{m}$ (PDMS) y cabowax/ divinilbenceno de $65 \mu \mathrm{m}$ (CW/DVB).

A fin de evaluar la incidencia del grado de salinización del medio sobre el proceso extractivo, se adicionó a soluciones acuosas de estándares un 10, 20 y $30 \%$ de $\mathrm{NaCl}$.

Seleccionadas las condiciones óptimas del medio, se prepararon estándares individuales y mezclas de estándares en soluciones acuosas a $50 \mathrm{ppb}$ (partes por billón $0 \mu \mathrm{g} / \mathrm{l}$ ), a fin de determinar los tiempos de retención individuales e identificar los picos en la mezcla.

Para la selección del polímero de recubrimiento se prepararon 10 soluciones acuosas individuales de cada analito y mezcla de los mismos a $20 \mathrm{ppb}$.

Las soluciones acuosas de mezcla de estándares a 20 ppb se emplearon para determinar el perfil de concentración, masa y número total de moles absorbidos, constante de distribución, volumen mínimo de muestra y coeficiente de difusión.

Se prepararon 10 soluciones de mezcla de estándares a $10,20,30,40$, y $50 \mathrm{ppb}$ a fin de trazar las curvas de linealidad respectivas. Los estándares para determinar precisión se prepararon a 20,40 y 50 ppb.

Se prepararon soluciones acuosas de mezcla de estándares a 10, 20 y 30 ppb; para determinar los límites de detección y cuantificación. 


\section{Plan de muestreo}

Las muestras involucradas en el plan de muestreo fueron:

- Fruta: naranja valencia

- Jugo concentrado de naranja

- "Vino cítrico" de naranja: producto obtenido por fermentación alcohólica de jugo de naranja

- Fruta de empaque: naranja valencia

- Jugos concentrados de naranja

Considerando que se pretende la optimización de la Microextracción en Fase Sólida (SPME) como parte del desarrollo de la metodología analítica para la determinación de plaguicidas benzimidazólicos en matrices cítricas, fue necesario en principio establecer las condiciones tanto cromatográficas, como de extracción y desorción de los analitos seleccionados, en matrices acuosas y en soluciones acuosas modificadas.

Una vez establecidos los parámetros operativos del proceso de extracción de los analitos por SPME, las condiciones de desorción en el inyector del cromatógrafo y las correspondientes condiciones cromatográficas para su detección; se llevaron adelante experiencias para la aplicación de las metodologías desarrolladas en matrices complejas tales como: frutas cítricas, jugos concentrados y "vinos cítricos". Se detallan a continuación los aspectos metodológicos relacionados al muestreo y preparación de las muestras. 


\section{Muestreo de los lotes}

Los muestreos se efectuaron en función del tipo de muestra y enfoque analítico a evaluar. Se llevaron a cabo muestreos de: frutas cítricas, jugos concentrados y "vinos cítricos". La recolección y manejo de las muestras se llevó a cabo en función de la naturaleza de las mismas y enfoque analítico. La recolección de muestras de frutas y jugos concentrados se efectuó con la colaboración de profesionales de la industria y del Instituto Nacional de Tecnología Agropecuaria (INTA Concordia).

En función de los datos de trazabilidad de frutas y jugos concentrados libres de tratamientos con los plaguicidas evaluados, el plan de muestreo involucró establecer el tamaño de muestra, el cual se estableció en 25 unidades para fruta y $250 \mathrm{ml}$ para jugos concentrados (Codex Alimentarius, 1999), los cuales se efectuaron por triplicado.

Las muestras de "vino cítrico" fueron provistas por el grupo de investigación del laboratorio de Microbiología y Biotecnología de la Facultad de Ciencias de la Alimentación. Se tomaron dos unidades de $750 \mathrm{ml}$ correspondientes a la misma producción, cuya trazabilidad indicó ausencia de estos analitos. Según los datos suministrados por el laboratorio indicado, las muestras correspondieron a un lote con las siguientes características fisicoquímicas: $\mathrm{pH}=3,65$; Brix $=8,5$; acidez $=1,14 \%$ ácido cítrico; azúcares totales $=0,43 \mathrm{~g} / 100 \mathrm{ml}$; azúcares reductores = $0,41 \mathrm{~g} / 100 \mathrm{ml}$; etanol $=8,28 \mathrm{~g} / 100 \mathrm{ml}$; vitamina $\mathrm{C}=22,05 \mathrm{~g} / 100 \mathrm{ml}$.

Para frutas tratadas de empaque el plan de muestreo consistió en 3 muestreos en forma aleatoria de 3 empaques de la 
región durante las temporadas agrícolas 2008 y 2009. Para cada muestreo del lote se tomaron, a intervalos de 120 minutos en la línea de empaque, muestras de 25 unidades.

Las muestras de jugo concentrado de naranja provenientes de industrias de la región, fueron tomadas al azar a partir de muestras recibidas en carácter de servicios, en el Laboratorio de Investigación de Residuos de Plaguicidas en Alimentos de la Facultad de Ciencias de la Alimentación. Las mismas se reciben por triplicado en un volumen de $100 \mathrm{ml}$ al laboratorio, Brix $=60-$ 65 , seleccionándose para el análisis un total de 35 muestras y sus correspondientes réplicas.

\section{Submuestreo - Preparación de las muestras para el análisis en laboratorio}

Es fundamental que la preparación de la muestra del laboratorio para ser analizada, sea la más representativa del lote del cual fue tomada. El método de submuestreo adoptado, fue el de preparación de una muestra de laboratorio compuesta. Es decir que a partir de porciones o unidades individuales representativas, se combinaron para formar una mezcla homogénea o muestra compuesta.

Para frutas frescas en general, se preparó la muestra compuesta a partir de la totalidad de los elementos correspondientes a una muestra (tamaño muestreal) en el momento su recepción. Las mismas se trituraron en procesadora hasta obtener una mezcla homogénea y se combinaron para formar una muestra compuesta. 
La muestra compuesta fue fraccionada, rotulada y conservada en freezer hasta su posterior tratamiento para el análisis en el laboratorio. Para el análisis se tomaron porciones de la muestra compuesta, efectuándose previamente la reconstitución y homogeneización.

Para jugos concentrados y vino el submuestreo fue en una primera instancia de unidades múltiples, para posible control de fluctuación de valores entre las unidades múltiples y la variabilidad del lote. En función de las experiencias, se continuó con el método de muestras compuestas. Cada tipo de material que se ha preparado para el análisis ha requerido exigencias propias.

El almacenaje de las submuestras se efectuó por duplicado y en función de las recomendaciones globales y específicas, tanto para el tipo de envases, como lavado o acondicionamiento previo de los mismos, temperatura, etc.

\section{Preparación de blancos de muestra $y$ muestras adicionadas}

Matrices complejas, tales como frutas cítricas, jugos concentrados y "vinos cítricos"; libres de plaguicidas benzimidazólicos, fueron seleccionadas para establecer los blanco de muestra y ser posteriormente adicionadas con los estándares respectivos.

Muestras adicionadas con mezclas de estándares a 20 ppb se emplearon para determinar el perfil de concentración, masa y número total de moles absorbidos, constante de distribución, volumen mínimo de muestra y coeficiente de difusión. 
Las muestras de las diferentes matrices fueron adicionadas con soluciones mezcla de estándares previamente al proceso extractivo. Las diferentes matrices fueron adicionadas a las siguientes concentraciones: $10,20,30,40$ y $50 \mathrm{ppb}$ a fin de determinar linealidad; 20, 40 y 50 ppb para precisión; y 10, 20 y 30 ppb para determinar límites de detección y cuantificación.

\section{Tratamiento previo de las muestras}

Para todas las matrices se toman para el análisis porciones de la muestra compuesta, efectuándose previamente la reconstitución y homogeneización. Cada tipo de material preparado para el análisis ha requerido exigencias propias.

\section{Frutas cítricas}

Se pesan aproximadamente $5 \mathrm{~g}$ de muestra compuesta, se adiciona agua grado 1 hasta un volumen próximo a $100 \mathrm{ml}$. Se agita vigorosamente y se sonifica durante $5 \mathrm{~min}$. La mezcla se distribuye en sendos tubos y se centrifuga a $4000 \mathrm{rpm}$ durante 10 min. El sobrendante se filtra a través de papel de filtro. El filtrado se lleva a un volumen final de $100 \mathrm{ml}$ ajustando el $\mathrm{pH}$ a 7 con solución de $\mathrm{NaOH}$ 0,1 N. Posteriormente el volumen de muestra a ser sometida al proceso extractivo se filtra a través de membrana (fritz) de 0,45 $\mu \mathrm{m}$. 


\section{Jugos concentrados}

Los jugos concentrados de naranja de aproximadamente 65 Brix son diluidos con agua Grado 1 en una relac ión de $5 \mathrm{~g}$ en $100 \mathrm{ml}$ aproximadamente. Se agita vigorosamente y se sonifica durante $5 \mathrm{~min}$. Posteriormente la mezcla se filtra a través de papel de filtro. El filtrado se lleva a un volumen final de $100 \mathrm{ml}$ ajustando el pH a 7 con solución de $\mathrm{NaOH} \mathrm{0,1} \mathrm{N}$. Finalmente el volumen de muestra a ser sometida al proceso extractivo se filtra a través de membrana de 0,45 $\mu \mathrm{m}$.

\section{"Vinos cítricos"}

La muestra se diluye con agua Grado 1 en una relación de 5:100 v/v ajustando el $\mathrm{pH}$ a 7 con solución de $\mathrm{NaOH} \mathrm{0,1} \mathrm{N}$. Se agita y filtra a través de membrana de 0,45 $\mu \mathrm{m}$. En todos los casos la adición de soluciones mezcla de estándares de los analitos a evaluar se efectúa previa a la preparación de la solución acuosa.

\section{Condiciones de extracción y desorción}

Selección del absorbente o polímero de recubrimiento de la fibra de sílica fundida - Método SPME

A los fines de seleccionar el polímero y las condiciones óptimas de extracción de los analitos en cuestión, se efectuaron ensayos con los siguientes polímeros de recubrimiento (Lambropoulou et al., 2000): 
- Polidimetilsiloxano (PDMS) de $100 \mu \mathrm{m}$.

- Poliacrilato (PA) de $85 \mu \mathrm{m}$.

- Carbowax/Divinilbenceno (CW/DVB) de $65 \mu \mathrm{m}$.

Los polímeros a evaluar se seleccionaron en función de las propiedades fisicoquímicas de los analitos y de la naturaleza de los respectivos recubrimientos. La selección del polímero más adecuado requirió el establecimiento previo de ciertos parámetros inherentes al proceso de extracción, tales como: método de extracción directa por inmersión de la fibra en la solución acuosa, tiempo de extracción, sistema de agitación y concentración de los analitos. Para ello se efectuaron 10 extracciones a partir de soluciones mezcla de benzimidazoles a 20 ppb, con un volumen de muestra de $50 \mathrm{ml}$, con agitación magnética a 2000 rpm y tiempos de inmersión de $10 \mathrm{~min}$; para cada uno de los polímeros evaluados. Concluida esta etapa se procedió a determinar los restantes parámetros operativos.

\section{Selección del modo de extracción}

Se seleccionó el modo de extracción directo considerando la matriz de las muestras, la volatilidad de los analitos y su afinidad individual a la matriz.

\section{Selección de la técnica de agitación}

Teniendo en cuenta que la eficacia de la técnica de agitación determina los tiempos de equilibrio de las muestras acuosas, y que se requiere agitación para facilitar el transporte de masa entre lo profundo de la muestra y la fibra (Lord \& Pawliszyn, 
2000), se seleccionó el modo de agitación magnética de la muestra. Se tuvo especial cuidado en mantener constante la velocidad rotacional de la barra magnética y la base del plato térmicamente aislada del vial que contenía la muestra. Considerando que la extracción es eficiente cuando se aplican velocidades rotacionales elevadas y que el tiempo de equilibrio decrece progresivamente a medida que aumenta la velocidad (Pawliszyn, 1997), se seleccionó una velocidad de agitación de 2000 rpm.

Determinación del Perfil de masa absorbida en función del tiempo de extracción para soluciones acuosas: determinación de constantes de distribución, volumen de muestra y coeficientes de difusión de los analitos en el absorbente.

Las condiciones de extracción para la determinación del perfil de masa absorbida en función del tiempo se establecieron en función de experiencias previas. Siendo para la fibra seleccionada la extracción directa a partir de soluciones mezcla de benzimidazoles a $20 \mathrm{ppb}$, con un volumen de muestra de $50 \mathrm{ml}$, con agitación magnética a 2000 rpm y tiempos de inmersión de $10,20,30,40,45,50,120,240,360$ y $720 \mathrm{~min}$.

Considerando que se ha alcanzado el equilibrio del sistema a 720 min, la masa total absorbida para cada analito se determinó a partir de las respuestas cromatográficas obtenidas a dicho tiempo de extracción, de la curva de calibración por inyección directa y de las especificaciones de la fibra seleccionada.

En función de los pesos moleculares de los analitos evaluados se determinó el número total de moles absorbidos. A 
partir de este valor se calculó la constante de distribución de los mismos en el polímero de recubrimiento y el volumen mínimo de muestra, a partir de las ecuaciones (4) $V_{s}=100 . K_{f s} . V_{f} / E$ y (5) $K_{f s}=n \cdot V_{s} / V_{f}\left(C_{0} \cdot V_{s}-n\right)$.

El coeficiente de difusión de los analitos en el absorbente se determinó a partir de la curva del perfil para un $95 \%$ de masa absorbida considerando un error del $5 \%$, despejando $D_{f}$ en la ecuación (3) $t_{e}=t_{95 \%}=(b-a)^{2} / 2 D_{f}$.

A los fines prácticos se estableció para la determinación de todos los parámetros estadísticos, un tiempo de extracción para el análisis de $10 \mathrm{~min}$ (Montti et al., 2000).

\section{Selección del tiempo óptimo de desorción}

El tiempo óptimo de desorción de los analitos se determinó en forma experimental mediante ensayos a diferentes tiempos de exposición del absorbente en el puerto de inyección, para una temperatura y diámetro del insert adecuados según las especificaciones para SPME.

\section{Desarrollo de la metodología analítica}

\section{Soluciones acuosas de estándares}

Definidas las condiciones cromatográficas, la metodología de extracción, etc.; se efectuaron ensayos preliminares a fin de establecer las condiciones del medio acuoso en el proceso 
extractivo con los diferentes polímeros. De estos ensayos y experiencias previas se estableció un valor del $\mathrm{pH}=7$ del medio. Respecto a la incidencia del medio salino en el proceso extractivo, se efectuaron ensayos a diferentes concentraciones de $\mathrm{NaCl}$, observándose ligeras modificaciones de las respuestas cromatográficas de escasa relevancia frente a posibles factores que afectan la vida útil de la fibra $y / 0$ incrementan las interferencias en el proceso extractivo. Considerando que el agregado de otros reactivos al medio puede sumar interferencias y que una factible formación de microcristales en el puerto de inyección puede producir pérdidas del recubrimiento de la fibra, se optó como única modificación del medio la variación del $\mathrm{pH}$ hasta la neutralidad.

La selección del polímero de recubrimiento involucró la determinación de las respuestas cromatográficas correspondientes a soluciones acuosas de mezcla de estándares de 20 ppb a pH = 7, con agitación magnética a 2000 rpm y tiempo de inmersión de 10 min para cada polímero con $n=10$ y $\alpha=0,05$.

En función del análisis estadístico de los datos y de los valores medios de las respuestas cromatográficas de los analitos se consideró como polímero de recubrimiento más adecuado el Carbowax/Divinilbenceno (CW/DVB) de $65 \mu \mathrm{m}$.

Establecidos los parámetros del proceso extractivo por SPME, se trazó el perfil de masa absorbida en función del tiempo de extracción para soluciones acuosas del modo explicitado. Considerando que se alcanza el equilibrio del sistema a los 720 min de extracción, se determinó la masa total absorbida para cada analito a partir de las respuestas cromatográficas obtenidas 
a dicho tiempo de extracción, de la curva de calibración por inyección directa y de las especificaciones de la fibra seleccionada (Montti et al., 2000; Kooijman et al., 2004; Zimmermann et al., 2006).

Espesor del polímero $=\mathrm{b}-\mathrm{a}=65 \mu \mathrm{m}=0,0065 \mathrm{~cm}$

Longitud del polímero de recubriendo en la fibra $=L=1 \mathrm{~cm}$

Volumen del recubrimiento $=V_{f}=\pi(b-a)^{2} L=0,13 \mu \mathrm{l}$

A partir de los pesos moleculares de los analitos evaluados se calculó el número total de moles absorbidos $(n)$, la constante de distribución $\left(K_{f s}\right)$ de los mismos en el polímero de recubrimiento y el volumen mínimo de muestra $\left(V_{s}\right)$, a partir de las ecuaciones (4) y (5), de la siguiente forma:

$$
V_{s}=\frac{100 \cdot K_{f s} \cdot V_{f}}{E} \quad \text { y } \quad K_{f s}=\frac{n \cdot V_{s}}{V_{f}\left(C_{0} \cdot V_{s}-n\right)}
$$

$P M_{\text {metilitiofanato }}=342,7$
$P M_{\text {tiofanato }}=370,45$
$P M_{\text {thiabendazole }}=201,26$

El coeficiente de difusión de los analitos en el absorbente se determinó a partir de la curva del perfil para un $95 \%$ de masa absorbida considerando un error $(E)$ del $5 \%$, despejando $D_{f}$ en la ecuación (3):

$$
t_{e}=t_{95 \%}=\frac{(b-a)^{2}}{2 D_{f}}
$$


A los fines prácticos se estableció para la determinación de todos los parámetros estadísticos, un tiempo de extracción para el análisis de $10 \mathrm{~min}$.

Las etapas subsiguientes del desarrollo metodológico comprendieron la determinación de la curva de regresión lineal, intervalos de confianza, precisión y límites de detección y cuantificación para soluciones estándares.

\section{Muestras adicionadas}

La metodología desarrollada para soluciones estándares fue aplicada con similar procedimiento a muestras adicionadas. El desarrollo metodológico implicó la determinación del perfil de masa absorbida en función del tiempo de extracción, la curva de regresión lineal e intervalos de confianza, comparación de las rectas de regresión estándar vs. muestras adicionadas, precisión, recuperación y límites de detección y cuantificación del método. La comparación de las rectas de regresión estándar vs. muestras adicionadas se efectuó a fin de establecer la existencia o no de efecto matriz, lo cual determina la metodología de calibración del método.

Respecto a recuperación, se evaluaron las respuestas cromatográficas de quintuplicados de muestras adicionadas a 3 concentraciones diferentes: 10,30 y 50 ppb. 


\section{Aplicación de la metodología analítica}

Una vez efectuado el análisis estadístico de los resultados correspondientes a la metodología optimizada, se consideró su aplicación a muestras provenientes de empaques e industrias. Las muestras fueron tomadas y procesadas del modo descrito en el muestreo y tratamiento previo para frutas cítricas y jugos concentrados.

\section{Análisis estadístico}

El procesamiento estadístico de los datos obtenidos se realizó mediante vesión de prueba del software Statgraphics Centurión XV.

\section{Soluciones estándares}

Comparación de fibras

Los parámetros estadísticos correspondientes al análisis unidimensional de los datos incluyen las medidas de tendencia central, de variabilidad y de forma; los coeficientes de asimetría y curtosis estandarizados permiten determinar si los datos para cada muestra poseen una distribución normal.

Se efectuaron los análisis unidimensionales de los datos de las observaciones correspondientes a las respuestas cromatográficas de soluciones de estándares para $\mathrm{n}=10 \mathrm{y}$ $\alpha=0,05$; a $20 \mathrm{ppb}, \mathrm{pH}=7 ; 10 \mathrm{~min}$ de extracción para cada polímero de recubrimiento evaluado. 
Mediante prueba- $t$ se compararon las medias de las respuestas cromatográficas obtenidas con las diferentes fibras y mediante prueba- $F$ se compararon las varianzas correspondientes. Las distribuciones de las muestras de datos se compararon mediante test de Kolmogorov-Smirnov.

\section{Perfil de masa absorbida vs. tiempo de extracción}

Se realizó el análisis unidimensional de los datos correspondientes a soluciones estándares a 20 ppb para cada tiempo de extracción en las condiciones optimizadas, a fin de establecer la normalidad de las observaciones. Se trazaron las curvas correspondientes y determinaron los parámetros: masa total absorbida, constantes de distribución, volumen mínimo de la muestra y coeficiente de difusión.

\section{$\underline{\text { Regresión Lineal }}$}

En el análisis de regresión lineal se determinó la independencia y normalidad de los residuos a partir de los estadísticos Durbin Watson y Kolmogorov para un nivel de confianza del $95 \%$. Se estableció la ecuación de la recta para soluciones estándares a diferentes concentraciones y la relación entre las variables a través del estadístico $R^{2}$.

\section{Precisión}

Se determinó precisión a partir de los datos de las respuestas cromatográficas expresadas en alturas de pico, para soluciones estándares, $n=10$ y $\alpha=0,05$; en condiciones 
repetitivas y reproducibles. Mediante test de Student se determinó el intervalo de confianza de la media.

\section{Límites de detección y cuantificación}

Los límites de detección y cuantificación se determinaron para la metodología SPME de soluciones estándares del mismo modo que el descrito para inyección directa, a partir de las ecuaciones $(7)$ y $(8)$, en las que se considera 3 y 10 veces la desviación estándar del blanco respectivamente.

\section{$\underline{\text { Muestras adicionadas }}$}

Las diferentes matrices acuosas de muestras adicionadas, obtenidas a partir de frutas cítricas, jugos concentrados y "vinos cítricos"; fueron procesadas estadísticamente de forma similar que para las soluciones estándares en las condiciones de extracción establecidas.

\section{Análisis Unidimensional}

Los parámetros estadísticos correspondientes al análisis unidimensional de los datos obtenidos de las diferentes muestras adicionadas, se determinaron a fin de establecer la normalidad de las observaciones.

Perfil de masa absorbida en función del tiempo (a una o dos concentraciones diferentes) - incluye análisis unidimensional y curvas

A fin de determinar la masa total absorbida, constantes de distribución, volumen mínimo de la muestra y coeficiente de $-112-$ 
difusión para soluciones acuosas de muestras adicionadas a 20 ppb, se trazó el perfil de masa absorbida en función del tiempo. Estos perfiles se compararon gráficamente con los correspondientes a soluciones estándares.

\section{$\underline{\text { Regresión Lineal }}$}

Se trazó la curva de regresión lineal para las diferentes muestras adicionadas y determinaron los parámetros estadísticos correspondientes.

\section{Comparación de rectas de regresión}

Para cada matriz adicionada con soluciones mezcla de estándares se efectuó la comparación de rectas de regresión, y del análisis estadístico, test ANOVA, se determinaron si existen diferencias significativas entre los puntos de corte y pendientes de las curvas correspondientes a soluciones estándares y muestras adicionadas con un $99 \%$ de nivel de confianza.

\section{Precisión}

Se determinó la precisión del método para las diferentes muestras adicionadas, $\mathrm{n}=10$ y $\alpha=0,05$; y establecieron los intervalos de confianza correspondientes.

\section{$\underline{\text { Recuperación }}$}

Para cada matriz se prepararon por quintuplicado muestras adicionadas a 3 concentraciones diferentes a fin de determinar la recuperación o exactitud del método para $n=15$ y $\alpha=0,05$. Se determinaron los parámetros estadísticos correspondientes y 
mediante test de Student, se evaluó si existen diferencias significativas entre la recuperación media y el $100 \%$.

\section{Límites de detección y cuantificación}

Se determinaron los límites de detección y cuantificación del método correspondiente a cada matriz adicionada a partir de las ecuaciones ( 7 y $(8)$, en las cuales se considera 3 y 10 veces la desviación estándar del blanco respectivamente.

$$
\begin{aligned}
& \text { Límite de detección }=\frac{Y_{b l}+3 S_{b l}}{b} \cdot \frac{1}{\sqrt{n^{\prime}}} \\
& \text { Límite de Cuantificación }=\frac{Y_{b l}+10 S_{b l}}{b} \cdot \frac{1}{\sqrt{n^{\prime}}}
\end{aligned}
$$

\section{Muestras provenientes de empaques e industria}

Se procesaron por quintuplicado las muestras de frutas cítricas y jugos cítricos concentrados provenientes de empaques e industria respectivamente. A partir de las curvas de calibración correspondientes, se determinaron en todos los casos los valores medios de las respuestas cromatográficas y concentración de los analitos en las muestras, expresados en $\mathrm{mg} / \mathrm{Kg} \circ \mu \mathrm{g} / \mathrm{Kg}$ de fruta 0 jugo concentrado. Se determinó además para cada muestra la desviación, coeficiente de variación e intervalo de confianza. 


\section{Resultados y discusión}

\section{Soluciones acuosas estándares de benzimidazoles}

\section{$\underline{\text { Condiciones cromatográficas }}$}

Se llevaron adelante numerosas pruebas para establecer las condiciones óptimas de extracción y desorción. Las modificaciones en los distintos métodos evaluados se basaron fundamentalmente en variaciones de $\mathrm{pH}$ de las soluciones acuosas, tiempos de extracción y desorción, grado de salinización, naturaleza del absorbente, temperaturas del inyector y rampas de temperaturas del horno, etc.; a fin de lograr la mayor separación de los analitos y adecuadas respuestas cromatográficas.

Las modificaciones de las condiciones cromatográficas incluyeron el cambio de "inlet" (Pawliszyn, 1997), la definición del tiempo de desorción - 3 minutos de "splitless" - a fin de lograr la desorción total de los analitos en el puerto de inyección y, por lo tanto, el aumento del tiempo inicial de permanencia del horno a $80{ }^{\circ} \mathrm{C}$ (Ouyang et al., 2005). Las condiciones cromatográficas optimizadas se detallan a continuación:

Velocidad gas carrier $\left(\mathrm{N}_{2}\right) 1,5 \mathrm{ml} / \mathrm{min}$, flujo del gas auxiliar $\left(\mathrm{N}_{2}\right) 30 \mathrm{ml} / \mathrm{min}$, flujo de $\mathrm{H}_{2} 4 \mathrm{ml} / \mathrm{min}$ y flujo de aire $100-110 \mathrm{ml} / \mathrm{min}$, temperatura inyector $250 \stackrel{\circ}{\circ}$ con 3 min de "splitless", temperatura inicial de columna $80{ }^{\circ} \mathrm{C}$ durante $3,5 \mathrm{~min}$, rampa de $55^{\circ} \mathrm{C} /$ minuto hasta temperatura final de $280 \stackrel{\circ}{\mathrm{C}}$ durante $8,5 \mathrm{~min}$, temperatura del detector $300 \stackrel{\circ}{\circ}$. Columna Agilent HP - 5MS 0,25 mm x $30 \mathrm{~m}$ x $0,25 \mu \mathrm{m}$. "Liner" de 0,75 mm de diámetro interno. 


\section{$\underline{\text { Condiciones de extracción }}$}

Las soluciones acuosas individuales a distintos valores de $\mathrm{pH}$, sometidas al proceso extractivo con los diferentes polímeros de recubrimiento (poliacrilato - PA de $85 \mu \mathrm{m}$, polidimetilsiloxano PDMS de $100 \mu \mathrm{m}$ y cabowax/divinilbenceno - CWX/DVB de $65 \mu \mathrm{m})$, fueron:

a)- soluciones acuosas de 0,02 ppm de TBZ a pH 5, 7 y 9 .

b)- soluciones acuosas de 0,02 ppm de metiltiofanato a pH 5, 7 y 9.

c)- soluciones acuosas de $0,02 \mathrm{ppm}$ de tiofanato a pH 5, 7 y 9 .

Los resultados obtenidos para un tiempo de extracción de 10 min con agitación magnética a 2000 rpm, indicaron que el PA, a los diferentes $\mathrm{pH}$ de las soluciones no logra respuestas cromatográficas relevantes para los distintos analitos.

El metiltiofanato y el tiofanato a $\mathrm{pH} 7$ logran ser extraídos con PDMS, pero este polímero no es adecuado para la extracción de TBZ. El CW/DVB resultó ser el absorbente que mejor extrae al TBZ tanto a pH 9 como a $\mathrm{pH} 7$.

Los resultados obtenidos con soluciones mezcla de estándares a los mismos $\mathrm{pH}$ fueron concordantes con los observados para los analitos individuales, por lo que se estableció como polímero de recubrimiento de la fibra al CW/DVB de $65 \mu$ y un $\mathrm{pH} 7$ de las soluciones acuosas.

Los resultados de los ensayos a diferentes concentraciones de $\mathrm{NaCl}(10,20$ y $30 \%)$, mostraron ligeros incrementos de las respuestas cromatográficas los que fueron consideradas de escasa relevancia frente a otros factores que 
pueden afectar la vida útil de la fibra o incrementar las interferencias en el proceso extractivo.

En función de lo explicitado se optó como única modificación del medio, la variación del pH hasta la neutralidad.

Establecidas las condiciones óptimas del medio, se prepararon estándares individuales y mezclas de estándares en soluciones acuosas a $50 \mathrm{ppb}$, a fin de determinar los tiempos de retención individuales e identificar los picos en la mezcla.

Los tiempos de retención medios (RT), tanto en solución individual como en la solución mezcla, de los benzimidazoles analizados fueron: Metiltiofanato $R T=5,117$; Tiofanato $R T=6,941$ y Thiabendazole RT $=11,001$.

La selección del polímero de recubrimiento, en función de lo explicitado, involucró el análisis estadístico de las respuestas cromatográficas obtenidas a partir de soluciones acuosas remezcla de estándares a 20 ppb, para PDMS y CWX/DVB en las condiciones de extracción establecidas.

En la tabla 8 se detallan los resultados del análisis unidimensional de las observaciones correspondientes a 10 extracciones de soluciones mezcla de benzimidazoles a 20 ppb, $\mathrm{pH}=7$, volumen de muestra de $50 \mathrm{ml}$, agitación magnética a 2000 rpm y tiempos de inmersión de 10 min.

En todos los casos el análisis unidimensional de los datos indicó una distribución normal de las observaciones.

La prueba-t de comparación de medias entre las muestras correspondientes a ambas fibras, reveló que existen diferencias estadísticamente significativas entre las medias de las dos 
muestras, para todos los analitos con un nivel de confianza del $95,0 \%$.

Tabla 8. Comparación de polímeros - Análisis unidimensional -- Respuestas cromatográficas en alturas de pico - Soluciones acuosas estándares de benzimidazoles - SPME/GC/NPD - 10 min extracción $-\mathrm{n}=10, \alpha=0,05$

\begin{tabular}{|c|c|c|c|c|c|c|}
\hline Analito & \multicolumn{2}{|c|}{ Metiltiofanato } & \multicolumn{2}{c|}{ Tiofanato } & \multicolumn{2}{c|}{ Thiabendazole } \\
\hline Fibra & PDMS & CWX/DVB & PDMS & CWX/DVB & PDMS & CWX/DVB \\
\hline Altura Media & 75335 & 64970 & 90540 & 79447 & 7082 & 117931 \\
\hline $\begin{array}{c}\text { Desviación } \\
\text { Estándar }\end{array}$ & 341 & 255 & 278 & 212 & 29 & 287 \\
\hline RSD \% & 0,45 & 0,39 & 0,31 & 0,27 & 0,41 & 0,24 \\
\hline $\begin{array}{c}\text { Intervalos de } \\
\text { confianza +/- }\end{array}$ & 244 & 182 & 199 & 152 & 21 & 205 \\
\hline
\end{tabular}

El test de comparación de desviaciones estándares indicó que no existen diferencias estadísticamente significativas entre las desviaciones estándares de las dos muestras para metiltiofanato y tiofanato, sin embargo existen diferencias significativas entre las desviaciones estándares de las dos muestras para TBZ, con un nivel de confianza del 95,0\%.

El valor-P del test de Kolmogorov-Smirnov de comparación de las distribuciones de las dos muestras, menor que 0,05 para todos los analitos, indicó que existen diferencias estadísticamente significativas entre ambas distribuciones para un nivel de confianza del $95,0 \%$.

La figura 20 muestra los gráficos obtenidos en el análisis estadístico de los datos correspondientes a la comparación de fibras para uno de los analitos evaluados. 


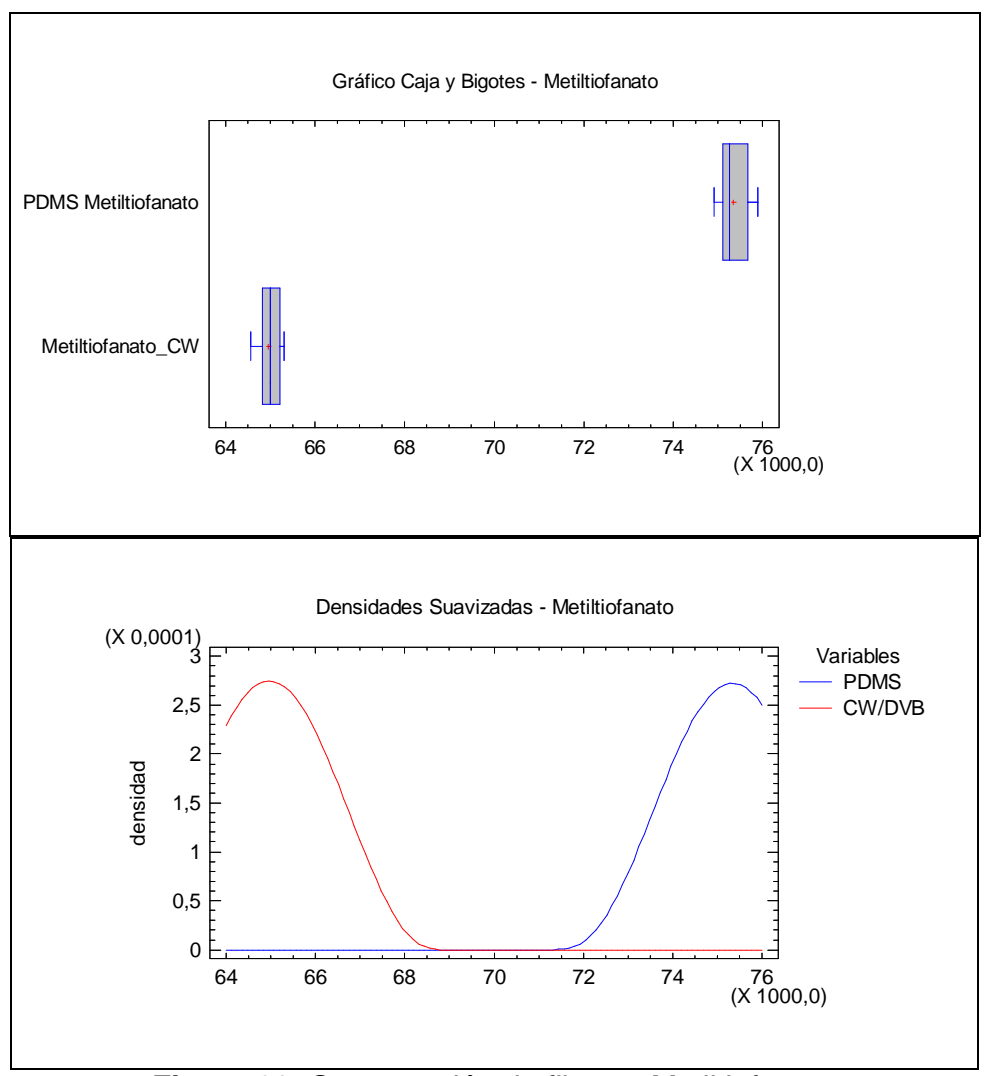

Figura 20. Comparación de fibras - Metiltiofanato

Como puede apreciarse en la tabla 8, las respuestas cromatográficas obtenidas cuando se emplea como polímero el PDMS, son ligeramente superiores a las obtenidas con CWX/DVB para el metiltiofanato y el tiofanato. Para TBZ, en cambio, las respuestas cromatográficas son sensiblemente superiores cuando se emplea el CWX/DVB como polímero de recubrimiento.

En función de los resultados se adoptaron como condiciones de extracción la neutralidad del medio y el CWX/DVB como polímero de recubrimiento, de modo tal de lograr la 
adecuada extracción del thiabendazole que es el fungicida de mayor uso para el tratamiento de frutas en la región.

Perfil de masa absorbida, número total de moles, constante de distribución, volumen mínimo de muestra y coeficiente de difusión

El análisis unidimensional de los datos obtenidos a partir de quintuplicados de soluciones acuosas mezcla de estándares a 20 ppb, para $50 \mathrm{ml}$ de muestra, agitación a 2000 rpm y tiempos de inmersión de 10, 20, 30, 40, 45, 50, 120, 240, 360 y 720 min; indicó en todos los casos una distribución normal de las observaciones. Los resultados del análisis unidimensional y el perfil de masa total absorbida en función del tiempo, para cada analito, se muestran en la tabla 9 y figura 21 respectivamente.

Considerando que se ha alcanzado el equilibrio del sistema a $720 \mathrm{~min}$, la masa total absorbida para cada analito se determinó a partir de las respuestas cromatográficas obtenidas a dicho tiempo de extracción, de la curva de calibración por inyección directa y de las especificaciones de la fibra seleccionada. Los resultados se indican en la tabla 10.

Teniendo en cuenta las especificaciones del CWX/DVB y los pesos moleculares de los analitos evaluados, los cuales son:

Espesor del polímero $=(b-a)=65 \mu m=0,0065 \mathrm{~cm}$

Longitud del polímero de recubriendo en la fibra $=L=1 \mathrm{~cm}$

Volumen del recubrimiento $=V_{f}=\pi(b-a)^{2} L=0,13 \mu l$

$$
\begin{aligned}
& P M_{\text {metilitiofanato }}=342,70 \\
& P M_{\text {tiofanato }}=370,45 \\
& P M_{\text {thiabendazole }}=201,26
\end{aligned}
$$




\begin{tabular}{|c|c|c|c|c|c|c|c|c|c|c|c|c|c|c|c|c|c|}
\hline 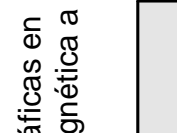 & ని & $\mid \begin{array}{l}0 \\
0 \\
0 \\
0 \\
0\end{array}$ & 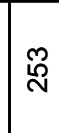 & \begin{tabular}{|l|}
$\infty$ \\
0 \\
0 \\
0
\end{tabular} & $\frac{\nabla}{m}$ & & ลิ & 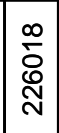 & 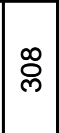 & $\mid \begin{array}{c} \pm \\
0 \\
0\end{array}$ & 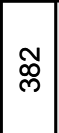 & & ลิ & \begin{tabular}{|l|}
$\frac{6}{0}$ \\
$\frac{0}{6}$ \\
\end{tabular} & $\stackrel{\infty}{\sim}$ & $\begin{array}{l} \pm \\
0 \\
0\end{array}$ & o \\
\hline זٓ & \&্ల & 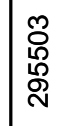 & $\stackrel{\mathfrak{R}}{N}$ & $\begin{array}{l}8 \\
0 \\
0\end{array}$ & 胥 & & : & \begin{tabular}{|l}
$\hat{N}$ \\
$\stackrel{N}{N}$ \\
$\stackrel{N}{N}$
\end{tabular} & $\frac{\hat{m}}{\mathrm{~m}}$ & $\mid \begin{array}{l}5 \\
0 \\
0\end{array}$ & 志 & & : & $\mid$\begin{tabular}{|c|}
$\widetilde{N}$ \\
0 \\
0 \\
0 \\
\end{tabular} & Б्ల & $\begin{array}{l}\mathscr{0} \\
0\end{array}$ & $\begin{array}{l}\mathscr{q} \\
\mathscr{q}\end{array}$ \\
\hline$\frac{1}{\varepsilon}$ & I & 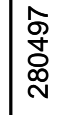 & న్ & 음 & ర్ల & & I & 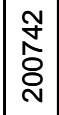 & 胥 & $\frac{1}{0}$ & $\hat{\mathscr{Y}}$ & & 帝 & 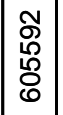 & 点 & $\begin{array}{l}\mathscr{8} \\
0\end{array}$ & $\bar{q}$ \\
\hline 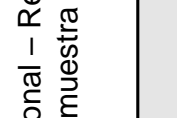 & ิㅗ & Nิ & ठ্् & $\begin{array}{l}L \\
\frac{L}{0} \\
0\end{array}$ & 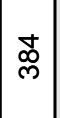 & & 오 & 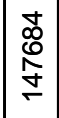 & 㕆 & $\begin{array}{l}\mathbb{N} \\
0 \\
0\end{array}$ & \begin{tabular}{|l|}
0 \\
$\mathscr{\Im}$
\end{tabular} & & 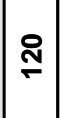 & 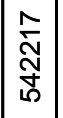 & ণ్లి & $\begin{array}{l}\hat{0} \\
0\end{array}$ & 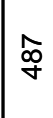 \\
\hline$\stackrel{\complement}{\Phi}$ & 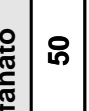 & 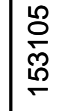 & $\frac{n}{m}$ & $\mid \begin{array}{l}\bar{N} \\
\overline{0} \\
\end{array}$ & হ్্ా & $\frac{\circ}{\pi}$ & in & 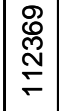 & $\begin{array}{l}\dot{y} \\
\text { D }\end{array}$ & $\mid \begin{array}{c}\tilde{m} \\
0 \\
0\end{array}$ & 守 & 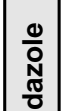 & 80 & \begin{tabular}{|l|}
$\tilde{d}$ \\
$\tilde{e}$ \\
$\hat{g}$ \\
$\dot{\xi}$
\end{tabular} & \% & $\begin{array}{l}8 \\
0 \\
0\end{array}$ & 운 \\
\hline $\begin{array}{ll}1 & 0 \\
0 & 0 \\
2 & 0 \\
0\end{array}$ & \begin{tabular}{|l|l|l}
$\bar{E}$ & \\
\end{tabular} & 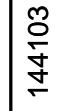 & $\infty$ & \begin{tabular}{|l}
3 \\
\multirow{2}{*}{} \\
0
\end{tabular} & 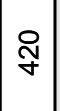 & $\stackrel{ㅎ ㅡ}{ }$ & \& & 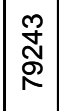 & \begin{tabular}{|l|}
$\mathscr{D}$ \\
$\mathbb{m}$
\end{tabular} & $\left|\begin{array}{l|}g \\
g \\
0\end{array}\right|$ & \begin{tabular}{|l|}
$\mathscr{\infty}$ \\
$\stackrel{\infty}{+}$ \\
\end{tabular} & 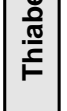 & \& & \begin{tabular}{|l|}
$\mathscr{8}$ \\
0 \\
0 \\
$\frac{\sigma}{\sigma}$
\end{tabular} & 莳 & $\frac{0}{\circ}$ & i \\
\hline $\begin{array}{ll}0 & 10 \\
0 & 11 \\
0 & =\end{array}$ & $q$ & 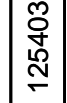 & $\underset{\infty}{\infty}$ & \begin{tabular}{|l|}
$\mathbb{2}$ \\
$\mathbb{Z}$ \\
0
\end{tabular} & 占 & & q & \begin{tabular}{|l|} 
\\
0 \\
$o$ \\
$\infty$ \\
$\infty$
\end{tabular} \mid & 命 & $\mid \begin{array}{l}\hat{a} \\
\dot{g} \\
0\end{array}$ & $\stackrel{\infty}{\stackrel{\infty}{\leftarrow}}$ & & q & $\left|\begin{array}{|l|}0 \\
o \\
o \\
0 \\
e\end{array}\right|$ & $\frac{N}{\square}$ & $\bar{\sigma}$ & $\frac{N}{n}$ \\
\hline $\begin{array}{l}\overline{\frac{c}{5}} \\
\frac{\bar{a}}{N} \\
\overline{0}\end{array}$ & 이 & \begin{tabular}{|l|} 
\\
$\mathscr{్}$ \\
$\tilde{్}$ \\
$\varnothing$
\end{tabular} & 点 & $\begin{array}{l}\hat{m} \\
0 \\
0\end{array}$ & $\hat{f}$ & & ర్ల & \begin{tabular}{|c|}
$\hat{0}$ \\
0 \\
$\stackrel{0}{0}$ \\
$\infty$
\end{tabular} & $\frac{\pi}{6}$ & $\left|\begin{array}{c}\tilde{N} \\
\tilde{O} \\
0\end{array}\right|$ & \begin{tabular}{|l|}
$\infty$ \\
\hdashline \\
\end{tabular} & & 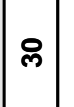 & $\begin{array}{l}\frac{8}{0} \\
\frac{\rho}{m} \\
\frac{m}{m}\end{array}$ & q & $\frac{⿱}{\Delta}$ & f \\
\hline $\begin{array}{l}0 \\
0 \\
\frac{0}{0} \\
\frac{0}{0}\end{array}$ & ฉి & \begin{tabular}{|c|}
$\tilde{\Xi}$ \\
0 \\
$\infty$ \\
1
\end{tabular} & 电 & 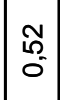 & 号 & & จิ & 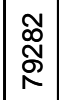 & $\stackrel{\sim}{\widetilde{J}}$ & $\cong$ & $\stackrel{f}{\underline{\tau}}$ & & กิ & $\begin{array}{l}\bar{\sigma} \\
\bar{\phi} \\
\bar{d}\end{array}$ & $\stackrel{\mathscr{P}}{\mathscr{\sigma}}$ & $\begin{array}{l}\stackrel{\mathfrak{N}}{\mathrm{O}} \\
\mathbf{0}\end{array}$ & 恕 \\
\hline $\begin{array}{l}0 \\
0 \\
0 \\
\mathbb{8} \\
\mathbb{1}\end{array}$ & $\circ$ & \begin{tabular}{|l|}
$\bar{\delta}$ \\
$\stackrel{8}{0}$ \\
$\overline{0}$
\end{tabular} & $\bar{\sigma}$ & $\begin{array}{l}\widetilde{0} \\
0 \\
0\end{array}$ & $\begin{array}{l}\stackrel{\infty}{+} \\
\end{array}$ & & 웅 & 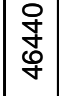 & 导 & $\begin{array}{l}\hat{\delta} \\
0 \\
0\end{array}$ & 命 & & 우 & 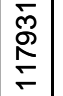 & $\hat{\tilde{D}}$ & $\begin{array}{l}\mathscr{9} \\
\stackrel{1}{*} \\
0\end{array}$ & $\ddot{\theta}$ \\
\hline 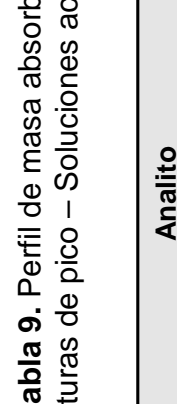 & 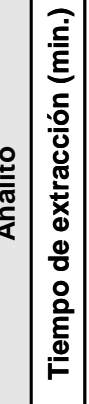 & 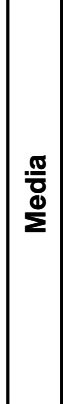 & 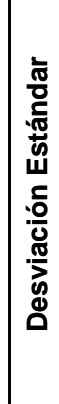 & 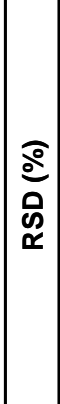 & 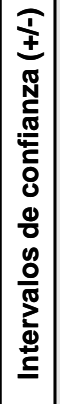 & \begin{tabular}{|l|} 
\\
0 \\
$\frac{2}{7}$ \\
$\frac{5}{4}$ \\
\end{tabular} & 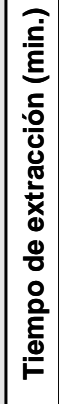 & 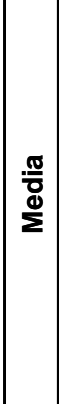 & 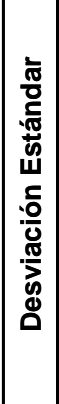 & 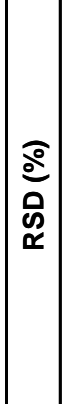 & 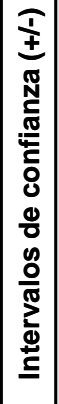 & 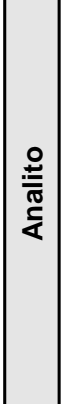 & 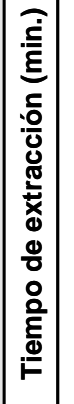 & & 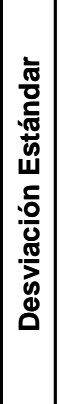 & 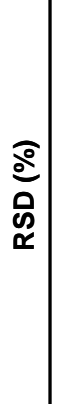 & 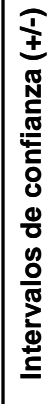 \\
\hline
\end{tabular}




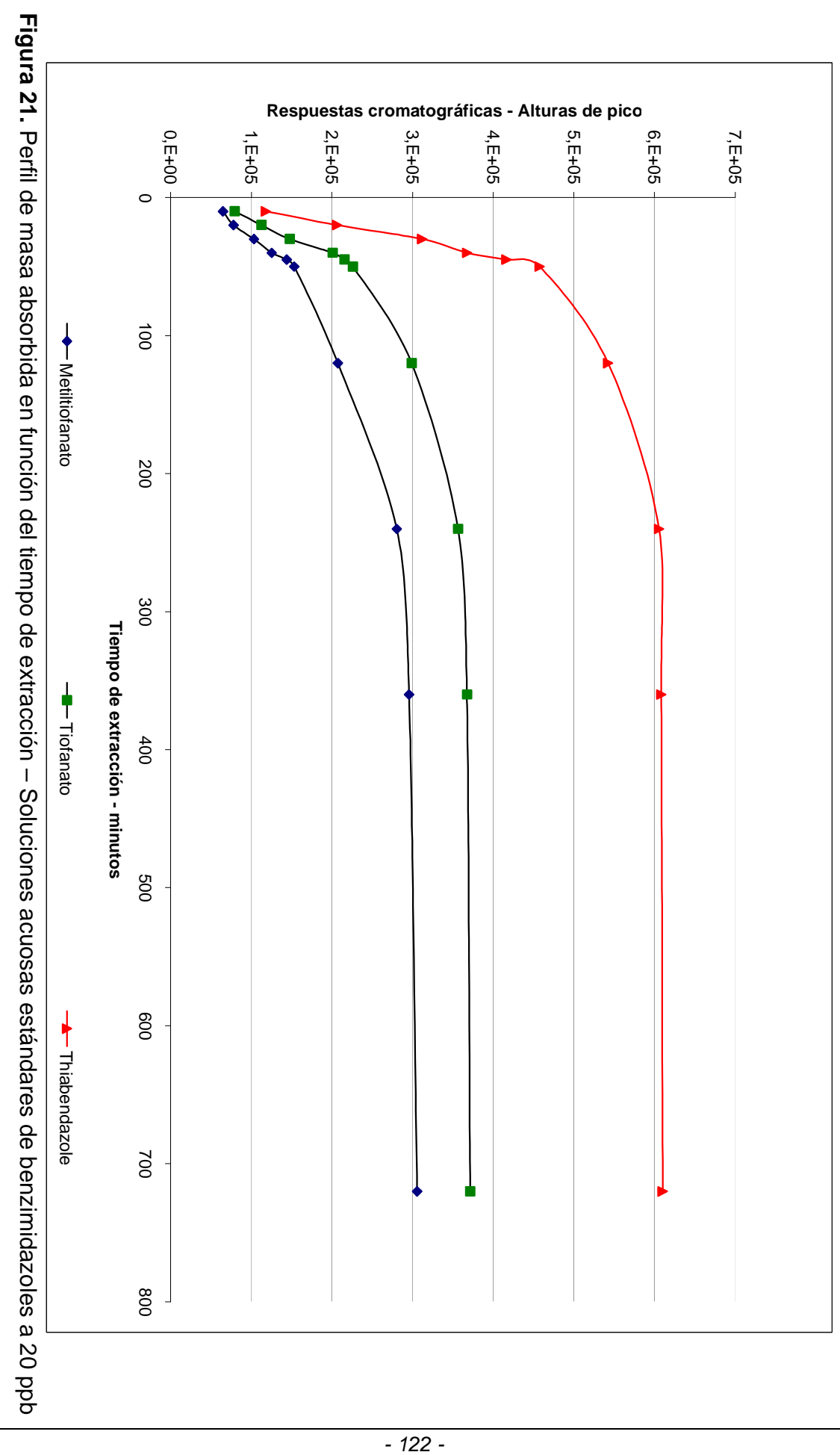


Tabla 10. Valores medios comparativos de los analitos expresados en alturas de picos para soluciones de $5 \mathrm{ppm}$ por inyección directa de $2 \mu \mathrm{l}$ y soluciones acuosas de 20 ppb con 12 horas de inmersión (SPME- CWX/DVB) y agitación

\begin{tabular}{|c|c|c|c|c|}
\hline \multirow{2}{*}{ Analito } & \multicolumn{3}{|c|}{$\begin{array}{r}\text { Inyección Directa } \\
2 \mu \mathrm{l} \text { de } 5 \mathrm{ppm}\end{array}$} & \multicolumn{2}{|c|}{$\begin{array}{c}\text { SPME- CWX/DVB } \\
20 \mathrm{ppb} 720 \text { minutos }\end{array}$} \\
\cline { 2 - 5 } & $\begin{array}{c}\text { Promedio } \\
\text { respuesta }\end{array}$ & $\begin{array}{c}\text { masa } \\
\text { inyectada } \\
\text { (ng) }\end{array}$ & $\begin{array}{c}\text { Promedio } \\
\text { respuesta }\end{array}$ & $\begin{array}{c}\text { masa } \\
\text { absorbida } \\
\text { (ng) }\end{array}$ \\
\hline Metiltiofanato & 124883 & 10 & 305506 & 24,47 \\
\hline Tiofanato & 159108 & 10 & 371297 & 23,46 \\
\hline Thiabendazole & 240404 & 10 & 610045 & 25,44 \\
\hline
\end{tabular}

Se calculó el número total de moles absorbidos $(n)$, la constante de distribución $\left(K_{f s}\right)$ de los mismos en el polímero de recubrimiento y el volumen mínimo de muestra $\left(V_{s}\right)$, a partir de las ecuaciones (4) $V_{s}=100 . K_{f s} . V_{f} / E$ y (5) $K_{f s}=n \cdot V_{s} / V_{f}\left(C_{0} . V_{s}-n\right)$.

En la tabla 11 se indican los resultados obtenidos.

Tabla 11. Determinación de la Constante de Distribución Polímero de

\begin{tabular}{|c|c|c|c|c|}
\hline Analitos & $\begin{array}{c}\text { Masa } \\
\text { molecular } \\
\text { (ng) }\end{array}$ & $\begin{array}{c}\text { Número de } \\
\text { moles } \\
\text { absorbidos }\end{array}$ & $\begin{array}{c}\boldsymbol{C}_{\boldsymbol{o}} \\
\text { (moles/ml) }\end{array}$ & $\boldsymbol{K}_{\boldsymbol{f s}}$ \\
\hline Metiltiofanato & $3,42710^{11}$ & $7,1410^{-11}$ & $5,8410^{-11}$ & 9455 \\
\hline Tiofanato & $3,704510^{11}$ & $6,3310^{-11}$ & $5,4010^{-11}$ & 9053 \\
\hline Thiabendazole & $2,012610^{11}$ & $1,2610^{-10}$ & $9,9410^{-11}$ & 9837 \\
\hline
\end{tabular}

El coeficiente de difusión de los analitos en el absorbente se determinó a partir de la curva del perfil para un $95 \%$ de masa absorbida considerando un error $(E)$ del $5 \%$, despejando $D_{f}$ en la ecuación (3) $t_{e}=t_{95 \%}=(b-a)^{2} / 2 D_{f}$. 
Los tiempos correspondientes a un $95 \%$ de masa absorbida ( $\left.t_{95 \%}\right)$ para los distintos analitos fueron: Metiltiofanato $t_{95 \%}=290 \mathrm{~min}$, Tiofanato $t_{95 \%}=229 \mathrm{~min}$, Thiabendazole $t_{95 \%}=181$ min. Los resultados correspondientes se muestran en la tabla 12.

A los fines prácticos se estableció para la determinación de todos los parámetros estadísticos, un tiempo de extracción para el análisis de $10 \mathrm{~min}$.

Tabla 12. Volumen limitante de muestra y coeficiente de difusión analito/ CWX/DVB - soluciones acuosas de 20 ppb - inmersión 12 h y agitación

\begin{tabular}{|c|c|c|c|c|}
\hline Analitos & $K_{f s}$ & $\begin{array}{c}V_{s} \\
(\mathrm{ml})\end{array}$ & $\begin{array}{c}\text { Tiempo } \\
t_{95 \%}(\mathrm{~min})\end{array}$ & $\begin{array}{c}D_{f} \\
\left(\mathrm{~cm}^{2} / \mathrm{seg}\right) \\
\end{array}$ \\
\hline Metiltiofanato & 9455 & 25,1 & 290 & $1,2110^{-9}$ \\
\hline Tiofanato & 9053 & 24,0 & 229 & $1,5410^{-9}$ \\
\hline Thiabendazole & 9837 & 26,1 & 181 & $1,9510^{-9}$ \\
\hline
\end{tabular}

\section{Linealidad}

Los resultados obtenidos a partir de 10 muestras de soluciones mezcla de estándares a 10, 20, 30, 40 y 50 ppb se detallan en las tablas 13 y 14 . En las mismas se indican las respuestas cromatográficas expresadas en alturas y áreas de pico respectivamente.

El análisis unidimensional indicó para todas las concentraciones de los analitos una distribución normal de las observaciones. 
Tabla 13. Análisis unidimensional - Respuestas cromatográficas expresadas en alturas de pico - Soluciones acuosas estándares - CWX/DVB - $50 \mathrm{ml}$ muestra agitación magnética a $2000 \mathrm{rpm}-\mathrm{n}=10, \alpha=0,05$

\begin{tabular}{|c|c|c|c|c|c|}
\hline Analito & \multicolumn{5}{|c|}{ Metiltiofanato - Alturas } \\
\hline Concentración (ppb) & 10 & 20 & 30 & 40 & 50 \\
\hline Altura Media & 31775 & 64970 & 95913 & 127949 & 160966 \\
\hline Desviación Estándar & 308 & 255 & 224 & 176 & 164 \\
\hline RSD \% & 0,97 & 0,39 & 0,23 & 0,14 & 0,10 \\
\hline Intervalo de confianza +/- & 220 & 182 & 160 & 126 & 117 \\
\hline Analito & \multicolumn{5}{|c|}{ Tiofanato - Alturas } \\
\hline Concentración (ppb) & 10 & 20 & 30 & 40 & 50 \\
\hline Altura Media & 41156 & 79447 & 121287 & 161012 & 202005 \\
\hline Desviación Estándar & 303 & 212 & 202 & 196 & 178 \\
\hline RSD \% & 0,74 & 0,27 & 0,17 & 0,12 & 0,09 \\
\hline Intervalo de confianza +/- & 217 & 152 & 145 & 140 & 127 \\
\hline Analito & \multicolumn{5}{|c|}{ Thiabendazole - Alturas } \\
\hline Concentración (ppb) & 10 & 20 & 30 & 40 & 50 \\
\hline Altura Media & 58606 & 117931 & 176300 & 233572 & 294164 \\
\hline Desviación Estándar & 293 & 287 & 281 & 273 & 261 \\
\hline RSD \% & 0,50 & 0,24 & 0,16 & 0,12 & 0,09 \\
\hline Intervalo de confianza +/- & 210 & 205 & 201 & 196 & 187 \\
\hline
\end{tabular}


Tabla 14. Análisis unidimensional - Respuestas cromatográficas expresadas en áreas de pico - Soluciones acuosas estándares - CWX/DVB - $50 \mathrm{ml}$ muestra agitación magnética a $2000 \mathrm{rpm}-\mathrm{n}=10, \alpha=0,05$

\begin{tabular}{|c|c|c|c|c|c|}
\hline Analito & \multicolumn{5}{|c|}{ Metiltiofanato - Áreas } \\
\hline Concentración (ppb) & 10 & 20 & 30 & 40 & 50 \\
\hline Altura Media & 55933 & 113195 & 167651 & 224141 & 281481 \\
\hline Desviación Estándar & 330 & 310 & 294 & 255 & 252 \\
\hline RSD \% & 0,59 & 0,27 & 0,18 & 0,11 & 0,09 \\
\hline Intervalo de confianza +/- & 236 & 222 & 210 & 182 & 180 \\
\hline Analito & \multicolumn{5}{|c|}{ Tiofanato - Áreas } \\
\hline Concentración (ppb) & 10 & 20 & 30 & 40 & 50 \\
\hline Altura Media & 71047 & 139307 & 210093 & 280670 & 350954 \\
\hline Desviación Estándar & 303 & 298 & 275 & 253 & 221 \\
\hline RSD \% & 0,43 & 0,21 & 0,13 & 0,09 & 0,06 \\
\hline Intervalo de confianza +/- & 217 & 213 & 197 & 181 & 158 \\
\hline Analito & \multicolumn{5}{|c|}{ Thiabendazole - Áreas } \\
\hline Concentración (ppb) & 10 & 20 & 30 & 40 & 50 \\
\hline Altura Media & 104132 & 203738 & 307961 & 412181 & 513765 \\
\hline Desviación Estándar & 339 & 312 & 291 & 277 & 233 \\
\hline RSD \% & 0,33 & 0,15 & 0,09 & 0,07 & 0,05 \\
\hline Intervalo de confianza +/- & 243 & 223 & 208 & 199 & 167 \\
\hline
\end{tabular}

En la figura 22 se muestra, a modo de ejemplo, el cromatograma obtenido para una muestra de solución estándar a $10 \mathrm{ppb}$ en el cual pueden observarse los tiempos de retensión para cada analito y la definición de los picos correspondientes. 


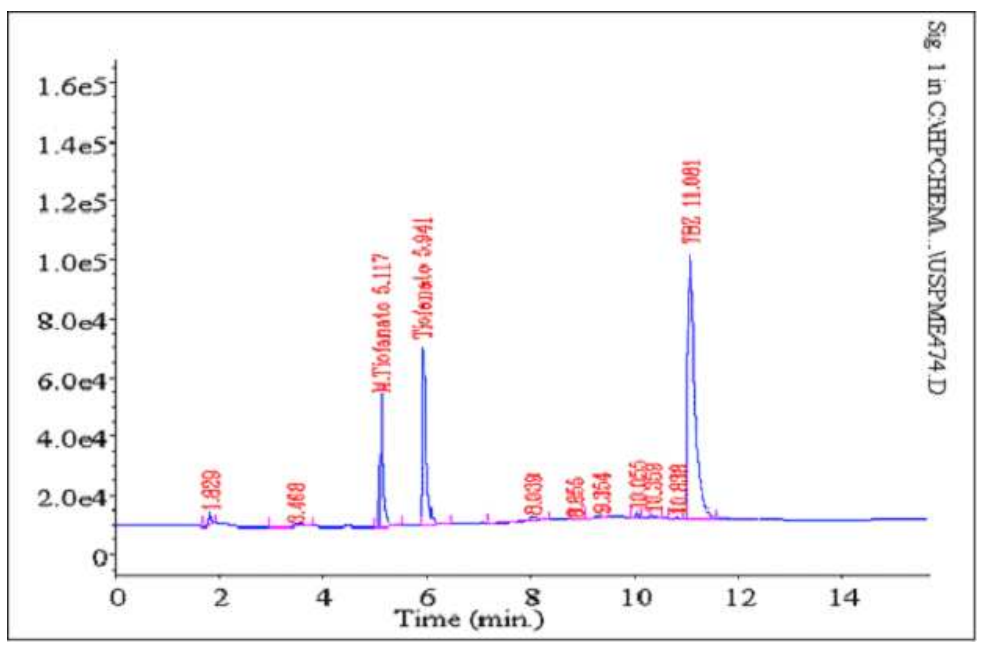

Figura 22. Cromatograma - Solución acuosa de estándares de benzimidazoles a 10 ppb y pH 7 - CWX/DVB - 10 min de extracción - agitación a 2000 rpm

Del mismo modo que en el caso de inyección de directa, se compararon las rectas de regresión obtenidas con alturas y áreas de pico. El análisis estadístico de los datos permitió establecer que existen diferencias estadísticamente significativas entre las pendientes e interceptos de las curvas de regresión expresadas en áreas y alturas de pico vs. concentración para los distintos analitos con un nivel de confianza del $99 \%$.

Los coeficientes de correlación de las ecuaciones del modelo ajustado utilizando áreas o alturas de pico, en cambio, no presentan diferencias estadísticamente significativas para los distintos analitos, por lo que en adelante las respuestas cromatográficas se expresan en alturas de pico.

Las curvas de regresión lineal correspondientes a soluciones de estándares a las concentraciones y condiciones establecidas se muestran en la figura 23.

Las figuras 24, 25 y 26 muestran las rectas de regresión 
para cada analito con indicación de los límites de confianza y de predicción correspondientes.

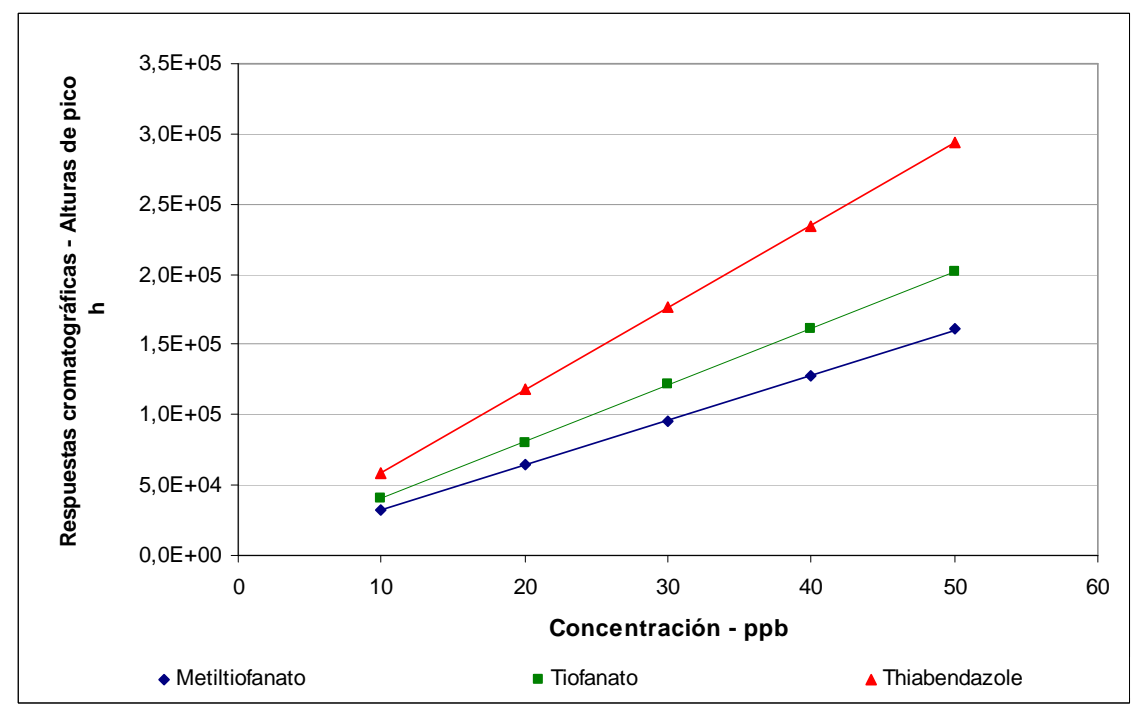

Figura 23. Regresión lineal - Soluciones acuosas estándares benzimidazoles a pH 7 - CWX/DVB - 10 min de extracción - agitación magnética a 2000 rpm

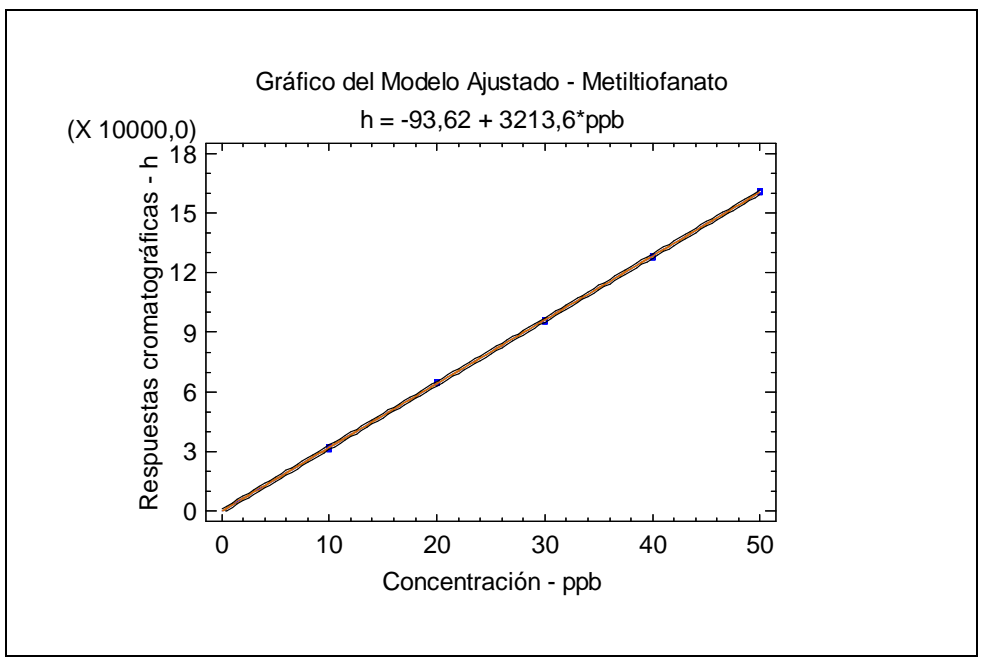

Figura 24. Regresión lineal - Metiltiofanato - Soluciones acuosas estándares de benzimidazoles a pH 7 - CWX/DVB - 10 min de extracción - agitación magnética 


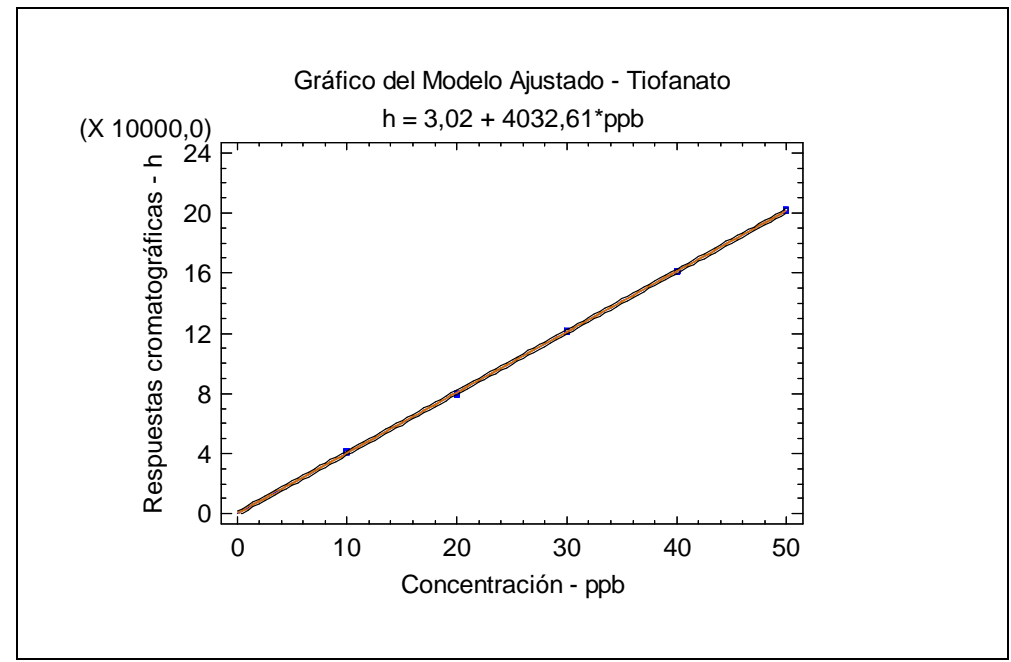

Figura 25. Regresión lineal - Tiofanato - Soluciones acuosas estándares de benzimidazoles a pH 7 - CWX/DVB - 10 min de extracción - agitación magnética

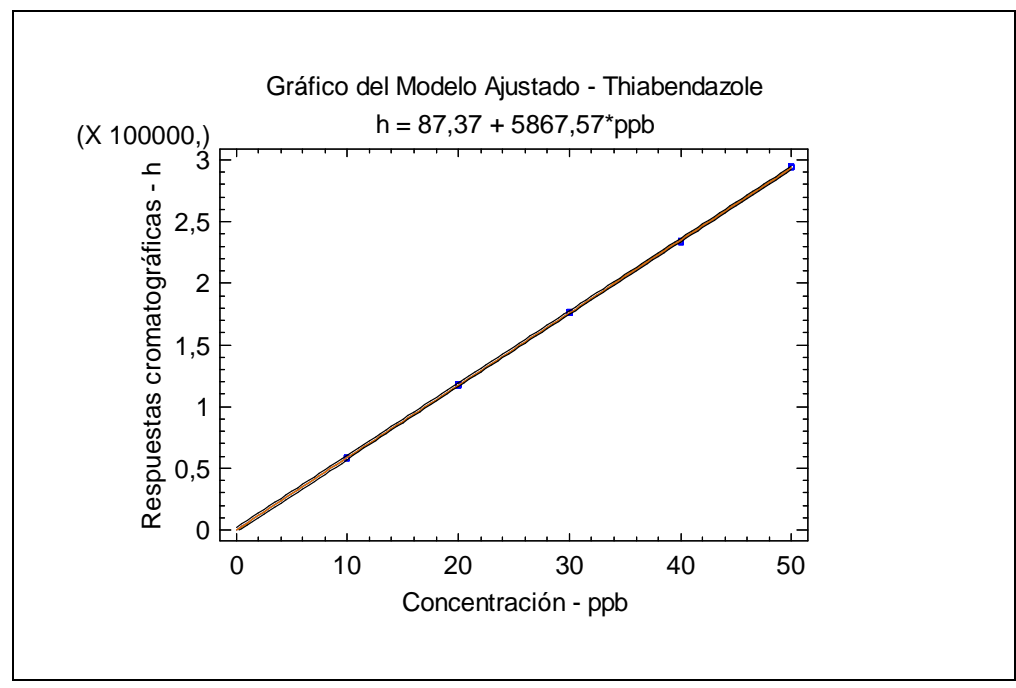

Figura 26. Regresión lineal - Thiabendazole - Soluciones acuosas estándares de benzimidazoles a pH 7 - CWX/DVB - 10 min de extracción - agitación magnética 
Las ecuaciones del modelo ajustado para cada analito fueron:

$\mathrm{h}_{\text {Metilitiofanato }}=-94+3214 \mathrm{ppb}$ Metilitiofanato

Coeficiente de Correlación $=0,999928$

$R^{2}=99,9855 \%$

$\mathrm{h}_{\text {Tiofanato }}=3+4033 \mathrm{ppb}$ Tiofanato

Coeficiente de Correlación $=0,999917$

$R^{2}=99,9835 \%$

$\mathrm{h}_{\text {Thiabendazole }}=87+5868 \mathrm{ppb}$ Thiabendazole

Coeficiente de Correlación $=0,999962$

$R^{2}=99,9924 \%$

Donde:

$\mathrm{h}=$ respuestas cromatográficas expresadas en alturas de pico.

$\mathrm{ppb}=$ concentración expresada en partes por billón $\circ \mu \mathrm{g} / \mathrm{l}$.

El análisis de varianza (ANOVA) indicó que existe en todos los casos una relación estadísticamente significativa entre las respuestas cromatográficas (alturas de pico) y la concentración (ppb) con un nivel de confianza del 95,0\%.

El estadístico $R^{2}$ y el coeficiente de correlación muestran para los distintos analitos un ajuste lineal entre las variables.

En todos los casos se establecieron los valores predichos de las respuestas cromatográficas para el modelo ajustado y los residuos correspondientes. 
Los estadísticos Durbin Watson y Kolmogorov permitieron establecer la independencia de los residuos y una distribución normal de los mismos para un nivel de confianza del $95 \%$.

\section{Precisión}

Se determinó precisión a partir de los datos de las respuestas cromatográficas expresadas en alturas de pico correspondientes a soluciones mezcla de estándares a 20, 40 y $50 \mathrm{ppb}$, para $\mathrm{n}=10$ y $\alpha=0,05$; en condiciones repetitivas $\mathrm{y}$ reproducibles. En cada caso se determinó desviación estándar, coeficiente de variación porcentual (RSD \%) y mediante test de Student los intervalos de confianza de la media. Los resultados se muestran en la tabla 15.

Tabla 15. Precisión - Valores medios expresados en alturas de pico Soluciones acuosas de estándares a pH 7 - CWX/DVB - 10 min de extracción agitación magnética a $2000 \mathrm{rpm}-\mathrm{n}=10$ y $\alpha=0,05$

\begin{tabular}{|l|c|c|c|c|}
\hline \multirow{2}{*}{ Analitos } & \multicolumn{4}{|c|}{ Soluciones estándares a 20 ppb } \\
\cline { 2 - 5 } & Promedio & $\begin{array}{c}\text { Desviación } \\
\text { estándar }\end{array}$ & RSD \% & $\begin{array}{c}\text { Intervalo de } \\
\text { confianza }\end{array}$ \\
\hline Metiltiofanato & 64970 & 255 & 0,39 & \pm 182 \\
\hline Tiofanato & 79447 & 212 & 0,27 & \pm 152 \\
\hline Thiabendazole & 117931 & 287 & 0,24 & \pm 205 \\
\hline \multirow{3}{*}{ Analitos } & \multicolumn{4}{|c|}{ Soluciones estándares a 40 ppb } \\
\cline { 2 - 5 } & Promedio & $\begin{array}{c}\text { Desviación } \\
\text { estándar }\end{array}$ & RSD \% & $\begin{array}{c}\text { Intervalo de } \\
\text { confianza }\end{array}$ \\
\hline Metiltiofanato & 127949 & 176 & 0,14 & \pm 126 \\
\hline Tiofanato & 161012 & 196 & 0,12 & \pm 140 \\
\hline Thiabendazole & 233572 & 273 & 0,12 & \pm 196 \\
\hline \multirow{2}{*}{ Analitos } & \multicolumn{5}{|c|}{ Soluciones estándares a 50 ppb } \\
\cline { 2 - 5 } & Promedio & $\begin{array}{c}\text { Desviación } \\
\text { estándar }\end{array}$ & RSD \% & $\begin{array}{c}\text { Intervalo de } \\
\text { confianza }\end{array}$ \\
\hline Metiltiofanato & 160966 & 164 & 0,10 & \pm 117 \\
\hline Tiofanato & 202005 & 178 & 0,09 & \pm 127 \\
\hline Thiabendazole & 294164 & 261 & 0,09 & \pm 187 \\
\hline
\end{tabular}

$-131-$ 
Los resultados obtenidos permiten establecer que el método es preciso para el rango de concentraciones analizados para un nivel de confianza de al menos el $95 \%$.

\section{Límites de detección y cuantificación}

La sensibilidad del método fue determinada a partir de 10 muestras de soluciones acuosas mezcla de estándares de los analitos a 10,20 y $30 \mathrm{ppb}$.

En la tabla 16 se indican los límites correspondientes a cada analito expresados en ppb $\circ \mu \mathrm{g} / \mathrm{l}$ de la solución para un intervalo de confianza del $95 \%$.

Tabla 16. Límite de detección y cuantificación - Soluciones acuosas de estándares benzimidazoles a pH 7 - CWX/DVB - 10 min de extracción agitación magnética a $2000 \mathrm{rpm}-\mathrm{n}=30$ y $\alpha=0,05$

\begin{tabular}{|l|c|c|}
\hline \multicolumn{1}{|c|}{ Analitos } & $\begin{array}{c}\text { Límite de detección } \\
\mathbf{p p b}\end{array}$ & $\begin{array}{c}\text { Límite de cuantificación } \\
\mathbf{p p b}\end{array}$ \\
\hline Metiltiofanato & 0,09 & 0,20 \\
\hline Tiofanato & 0,07 & 0,18 \\
\hline Thiabendazole & 0,03 & 0,09 \\
\hline
\end{tabular}

Los resultados indican que el método es sensible para la determinación de benzimidazoles en soluciones acuosas por microextracción en fase sólida y cromatografía gaseosa

\section{Muestras adicionadas}

La metodología analítica optimizada para soluciones acuosas de benzimidazoles fue aplicada para la extracción de estos analitos en matrices cítricas tales como: frutas cítricas, jugos 
cítricos concentrados y "vinos cítricos". Se detallan a continuación los resultados correspondientes para las diferentes matrices.

\section{Frutas cítricas}

Como se ha explicitado en el plan de muestreo las frutas cítricas corresponden a la variedad naranja Valencia.

Las muestras fueron procesadas según la metodología descripta: muestras acuosas obtenidas a partir de $5 \mathrm{~g}$ de fruta homogeneizada, neutralizadas a $\mathrm{pH} 7$ adicionadas con soluciones mezcla de estándares previamente al proceso extractivo.

Los resultados de frutas adicionadas a 10, 20, 30, 40 y $50 \mathrm{ppb}$; neutralizadas a pH 7, con extracción de 10 min por inmersión de la fibra CWX/DVB de $65 \mu \mathrm{m}$, agitación magnética a 2000 rpm; se analizaron estadísticamente.

A partir de muestras adicionadas con estándares individuales y mezcla de estándares a 50 ppb, se determinaron los tiempos de retención individuales e identificación de picos en la mezcla.

Los tiempos de retención medios (RT) de los benzimidazoles analizados, para muestras adicionadas con estándares individuales y mezcla de estándares fueron: Metiltiofanato $R T=5,124$; Tiofanato $R T=5,944$ y Thiabendazole $\mathrm{RT}=11,050$.

Se determinó el perfil de masa absorbida en función del tiempo de extracción, la curva de regresión lineal e intervalos de confianza, comparación de las rectas de regresión estándar vs. 
muestras adicionadas, precisión, recuperación y límites de detección y cuantificación del método.

Perfil de masa absorbida, número total de moles, constante de distribución, volumen mínimo de muestra y coeficiente de difusión - Frutas cítricas adicionadas.

El análisis unidimensional de los datos obtenidos a partir de quintuplicados de soluciones acuosas de frutas adicionadas con mezcla de benzimidazoles a $20 \mathrm{ppb}$, volumen de muestra de 50 ml, agitación magnética a 2000 rpm y tiempos de inmersión de 10, 20, 30, 40, 45, 50, 120, 240, 360 y 720 min; indicó en todos los casos una distribución normal de las observaciones. Los resultados obtenidos se detallan en la tabla 17.

El perfil de masa total absorbida en función del tiempo, para cada analito, se muestra en la figura 27. En las figuras 28,29 y 30 se comparan los perfiles correspondientes a soluciones acuosas de estándares y frutas adicionadas para cada uno de los analitos. 


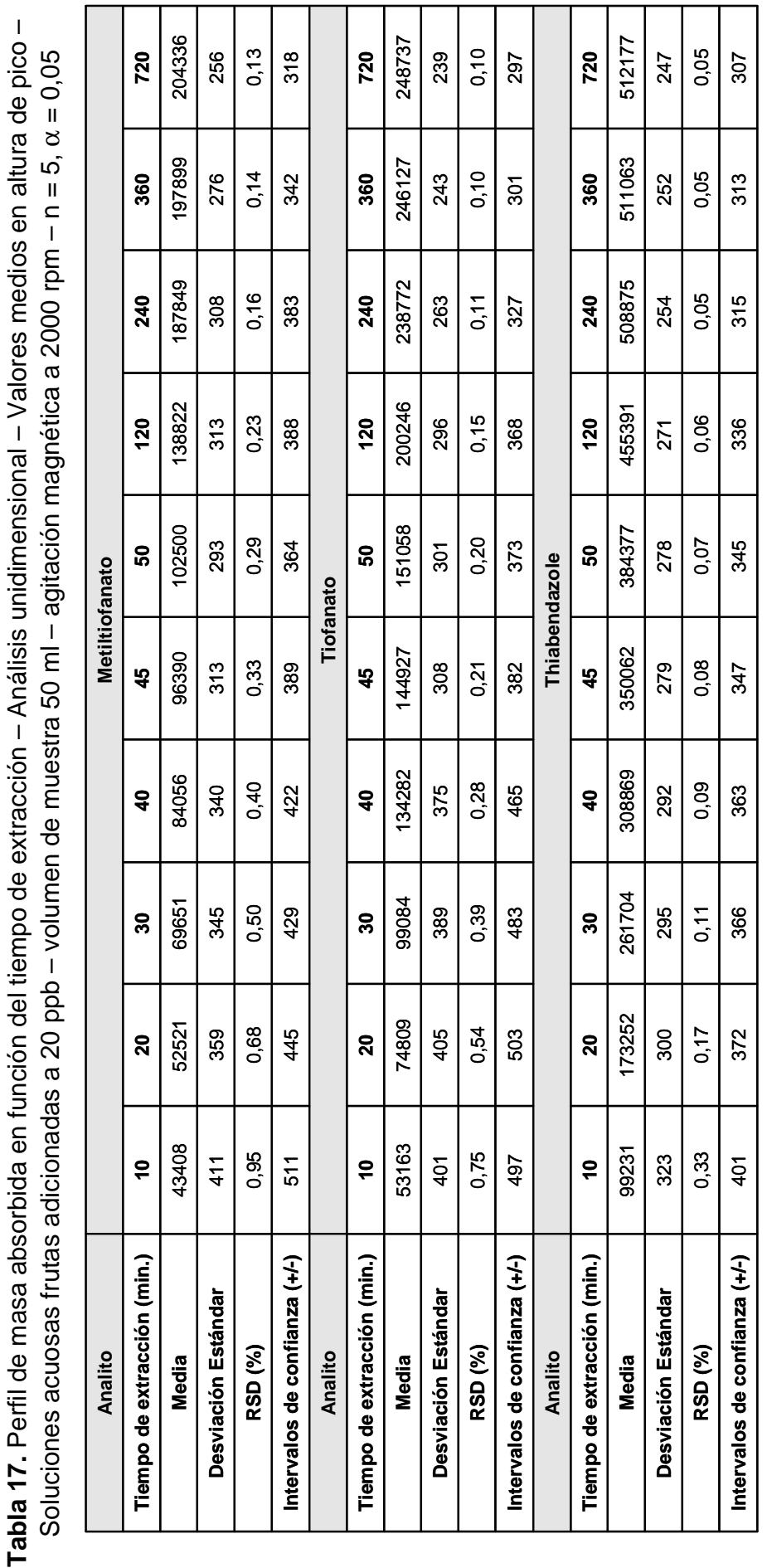


Desarrollo y Aplicación de Metodologías Analíticas

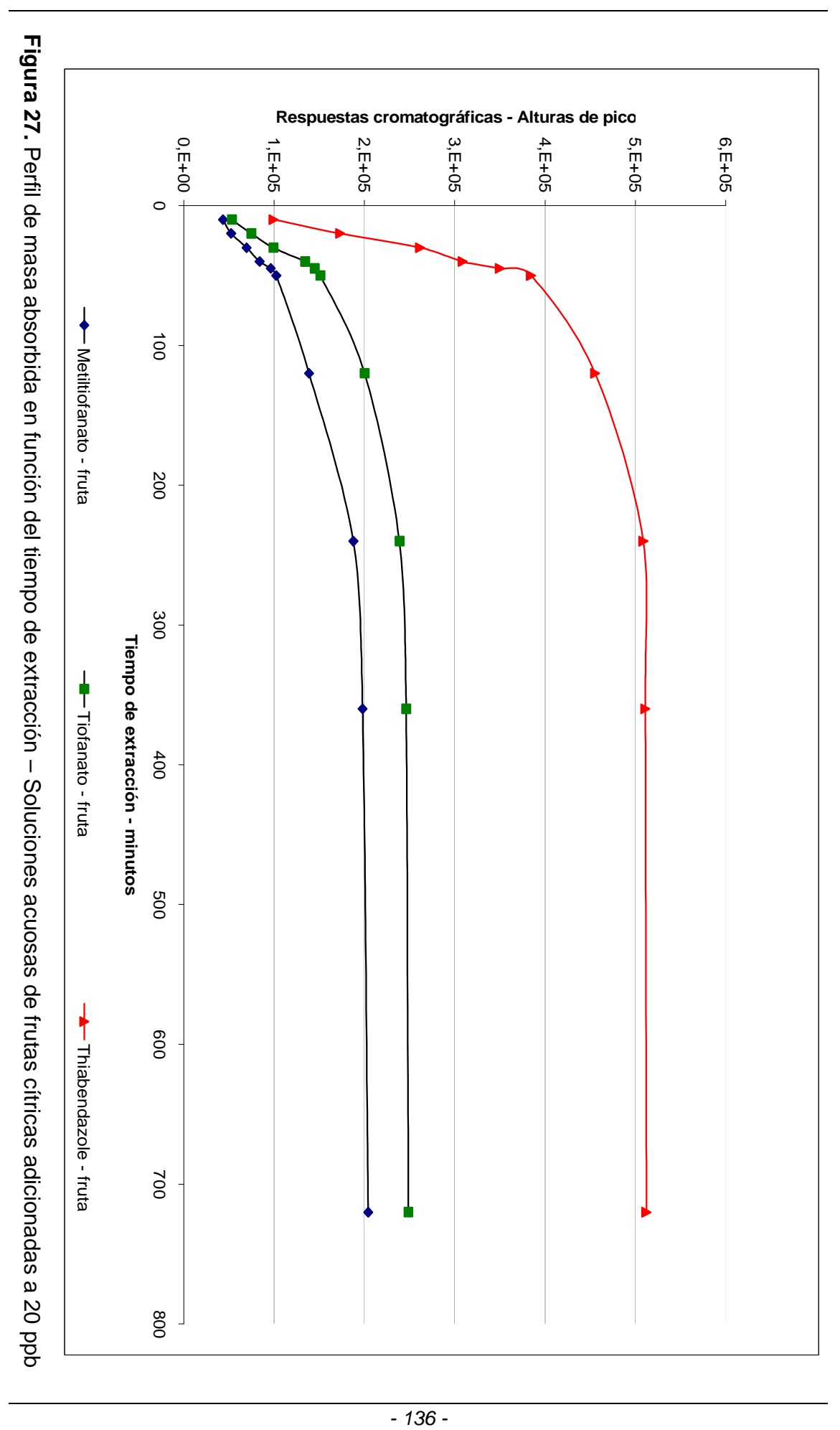




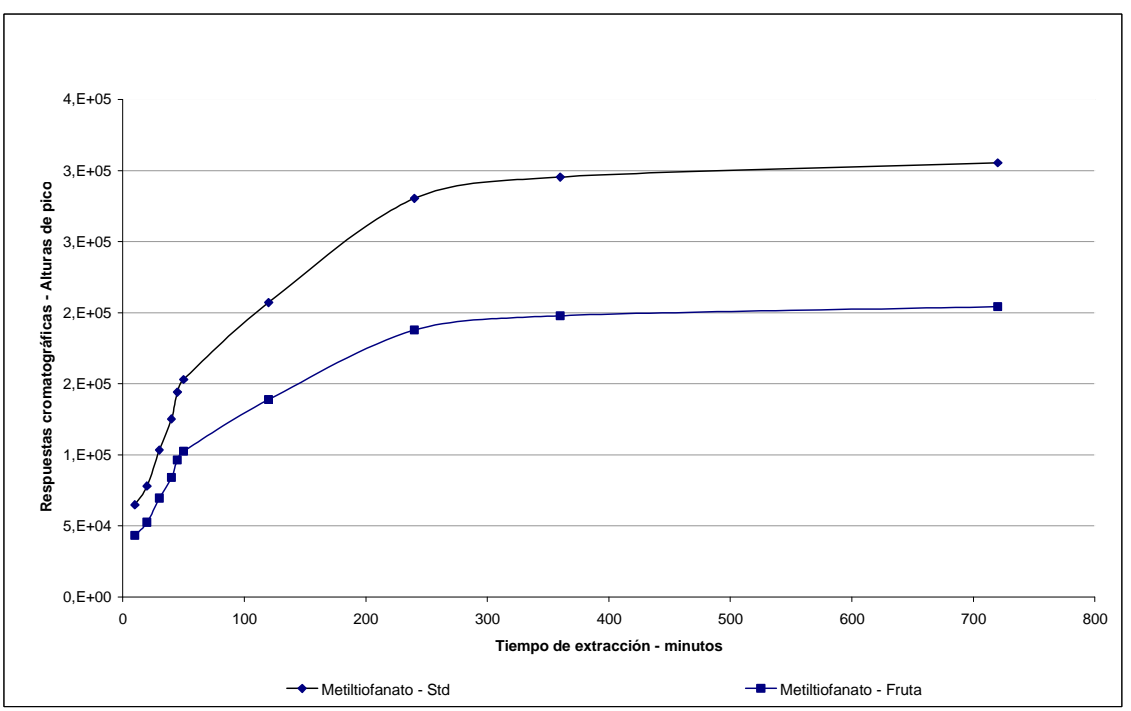

Figura 28. Perfiles comparativos de masa absorbida en función del tiempo de extracción para soluciones acuosas de estándares y frutas cítricas adicionadas a $20 \mathrm{ppb}$ - Metiltiofanato

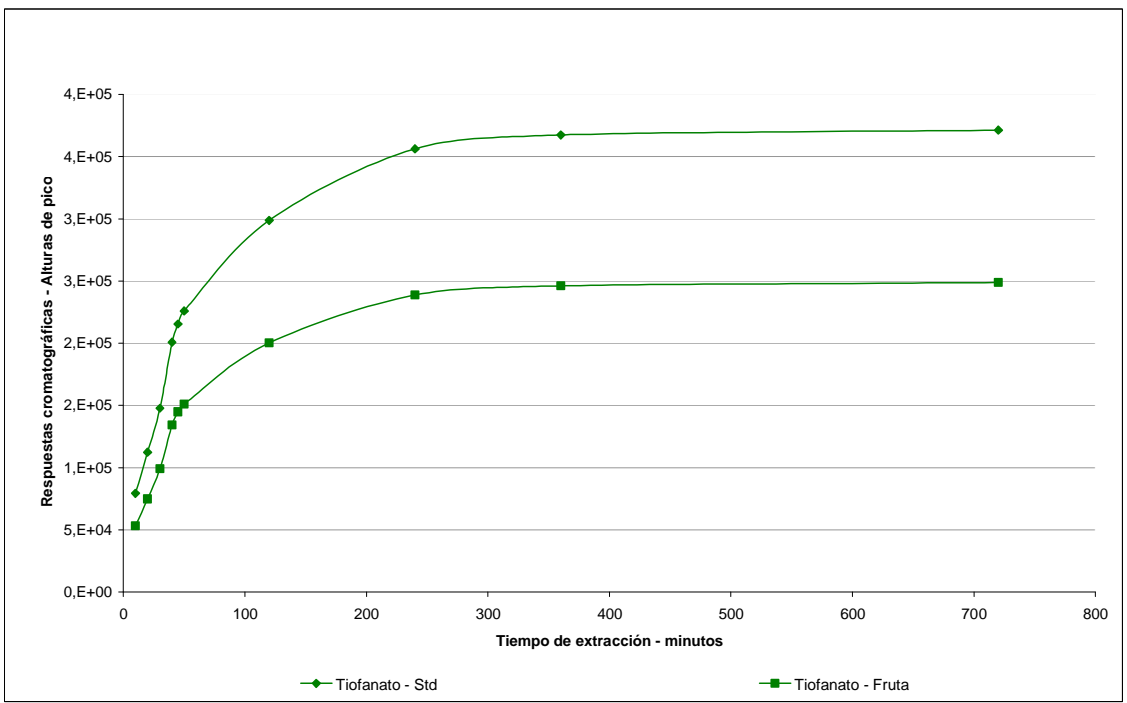

Figura 29. Perfiles comparativos de masa absorbida en función del tiempo de extracción para soluciones acuosas de estándares y frutas cítricas adicionadas a $20 \mathrm{ppb}$ - Tiofanato 


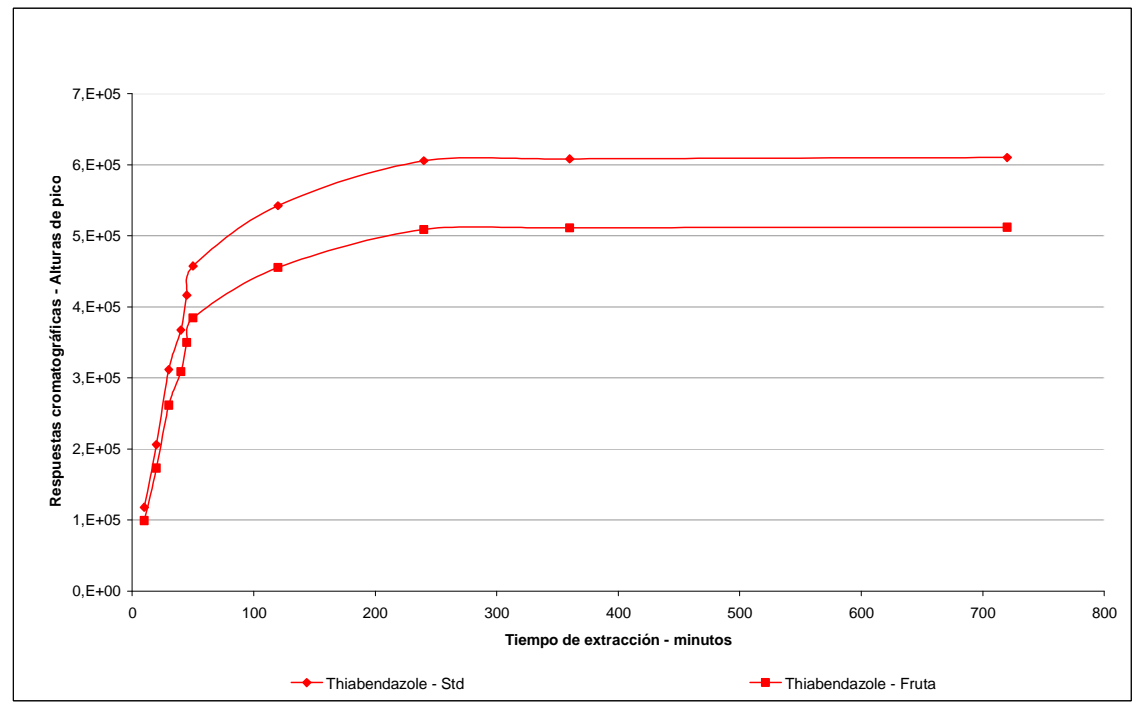

Figura 30. Perfiles comparativos de masa absorbida en función del tiempo de extracción para soluciones acuosas de estándares y frutas cítricas adicionadas a $20 \mathrm{ppb}$ - Thiabendazole

Considerando que se ha alcanzado el equilibrio del sistema a $720 \mathrm{~min}$, la masa total absorbida para cada analito se determinó a partir de las respuestas cromatográficas obtenidas a dicho tiempo de extracción, de la curva de calibración por inyección directa y de las especificaciones de la fibra seleccionada. Los resultados se indican en la tabla 18.

Tabla 18. Valores medios comparativos de los analitos expresados en alturas de picos para soluciones de 5 ppm por Inyección directa de $2 \mu \mathrm{l}$ y frutas adicionadas a 20 ppb - 12 h de inmersión CWX/DVB - agitación magnética a 2000 rpm.

\begin{tabular}{|c|c|c|c|c|}
\hline \multirow{2}{*}{ Analito } & \multicolumn{2}{|c|}{$\begin{array}{r}\text { Inyección Directa } \\
2 \mu \mathrm{l} \text { de } 5 \mathrm{ppm}\end{array}$} & \multicolumn{2}{|c|}{$\begin{array}{r}\text { SPME- CWX/DVB } \\
20 \mathrm{ppb} 720 \mathrm{~min}\end{array}$} \\
\cline { 2 - 5 } & $\begin{array}{c}\text { Promedio } \\
\text { respuesta }\end{array}$ & $\begin{array}{c}\text { masa } \\
\text { inyectada } \\
\text { (ng) }\end{array}$ & $\begin{array}{c}\text { Promedio } \\
\text { respuesta }\end{array}$ & $\begin{array}{c}\text { masa } \\
\text { absorbida } \\
\text { (ng) }\end{array}$ \\
\hline Metiltiofanato & 124883 & 10 & 204336 & 16,35 \\
\hline Tiofanato & 159108 & 10 & 248737 & 15,70 \\
\hline Thiabendazole & 240404 & 10 & 512177 & 21,35 \\
\hline
\end{tabular}


Teniendo en cuenta las especificaciones del CWX/DVB y los pesos moleculares de los analitos evaluados, del mismo modo que para soluciones estándares, se calculó número total de moles absorbidos $(n)$, constante de distribución $\left(K_{f s}\right)$ de los mismos en el polímero de recubrimiento y volumen mínimo de muestra $\left(V_{s}\right)$, a partir de las ecuaciones (5) $K_{f s}=n . V_{s} / V_{f}\left(C_{0} . V_{s}-n\right)$ y (4) $V_{s}=100 . K_{f s} \cdot V_{f} / E$. Los resultados se indican en la tabla 19.

Tabla 19. Determinación de la Constante de Distribución Polímero de recubrimiento/Agua

\begin{tabular}{|c|c|c|c|c|}
\hline Analitos & $\begin{array}{c}\text { Masa } \\
\text { molecular } \\
(\mathbf{n g})\end{array}$ & $\begin{array}{c}\text { Número de } \\
\text { moles } \\
\text { absorbidos }\end{array}$ & $\begin{array}{c}\boldsymbol{C}_{\boldsymbol{o}} \\
\text { (moles/mI) }\end{array}$ & $\boldsymbol{K}_{\mathbf{f s}}$ \\
\hline Metiltiofanato & $3,42710^{11}$ & $4,7710^{-11}$ & $5,8410^{-11}$ & 6264 \\
\hline Tiofanato & $3,704510^{11}$ & $4,2410^{-11}$ & $5,4010^{-11}$ & 6011 \\
\hline Thiabendazole & $2,012610^{11}$ & $1,0610^{-10}$ & $9,9410^{-11}$ & 8223 \\
\hline
\end{tabular}

El coeficiente de difusión de los analitos en el absorbente se determinó a partir de la curva del perfil para un $95 \%$ de masa absorbida considerando un error $(E)$ del $5 \%$, despejando $D_{f}$ en la ecuación (3) $t_{e}=t_{95 \%}=(b-a)^{2} / 2 D_{f}$.

Los tiempos correspondientes a un $95 \%$ de masa absorbida ( t $\left._{95 \%}\right)$ para los distintos analitos fueron:

$$
\begin{aligned}
& \text { Metiltiofanato } t_{95 \%}=290 \mathrm{~min} \\
& \text { Tiofanato } t_{95 \%}=224 \mathrm{~min} \\
& \text { Thiabendazole } t_{95 \%}=179 \mathrm{~min}
\end{aligned}
$$

Los resultados correspondientes se muestran en la tabla 20. 
Tabla 20. Volumen limitante de muestra y coeficiente de difusión analito/ CWX/DVB - frutas adicionadas a 20 ppb - inmersión 12 horas y agitación magnética a $2000 \mathrm{rpm}$.

\begin{tabular}{|c|c|c|c|c|}
\hline Analitos & $\boldsymbol{K}_{\boldsymbol{f s}}$ & $\begin{array}{c}\boldsymbol{V}_{\boldsymbol{f}} \\
(\mathbf{m l})\end{array}$ & $\begin{array}{c}\text { Tiempo } \\
\mathbf{t}_{\mathbf{9 5}}(\mathbf{m i n})\end{array}$ & $\begin{array}{c}\boldsymbol{D}_{\boldsymbol{f}} \\
\left(\mathbf{c m}^{2} / \mathbf{s e g}\right)\end{array}$ \\
\hline Metiltiofanato & 6264 & 16,6 & 290 & $1,2110^{-9}$ \\
\hline Tiofanato & 6011 & 15,9 & 224 & $1,5710^{-9}$ \\
\hline Thiabendazole & 8223 & 21,8 & 179 & $1,9710^{-9}$ \\
\hline
\end{tabular}

A los fines prácticos se estableció para la determinación de los restantes parámetros estadísticos, un tiempo de extracción para el análisis de $10 \mathrm{~min}$. En la tabla 21 se muestran los resultados comparativos correspondientes a soluciones acuosas de estándares y frutas adicionadas.

Tabla 21. Análisis comparativo de constantes de distribución y coeficientes de difusión para soluciones acuosas de estándares (ES) y frutas adicionadas (FA) a

\begin{tabular}{|c|c|c|c|c|c|c|c|c|}
\hline \multirow{3}{*}{ Analitos } & \multicolumn{2}{|c|}{$\boldsymbol{K}_{\boldsymbol{f s}}$} & \multicolumn{2}{c|}{$\begin{array}{c}\boldsymbol{V}_{\boldsymbol{f}} \\
(\mathbf{m l})\end{array}$} & $\begin{array}{c}\text { Tiempo } \\
\mathbf{t}_{\mathbf{9 5}} \%(\mathbf{m i n})\end{array}$ & $\begin{array}{c}\boldsymbol{D}_{\boldsymbol{f}}\left(\mathbf{1 0} \mathbf{1 0}^{-9}\right) \\
\left(\mathbf{c m}^{\mathbf{2}} \mathbf{s e g}\right)\end{array}$ \\
\cline { 2 - 9 } & ES & FA & ES & FA & ES & FA & ES & FA \\
\hline Metiltiofanato & 9455 & 6264 & 25,1 & 16,6 & 290 & 290 & 1,21 & 1,21 \\
\hline Tiofanato & 9053 & 6011 & 24,0 & 15,9 & 229 & 224 & 1,54 & 1,57 \\
\hline Thiabendazole & 9837 & 8223 & 26,1 & 21,8 & 181 & 179 & 1,95 & 1,97 \\
\hline
\end{tabular}

Como puede observarse las constantes de distribución de los distintos analitos, son menores para frutas adicionadas. Respecto a los valores comparativos de los coeficientes de difusión, puede apreciarse que en frutas existe un ligero incremento del valor de $D_{f}$ para Tiofanato y TBZ, manteniendo el mismo valor para el metiltiofanato. 


\section{Linealidad - Frutas cítricas adicionadas}

Los resultados obtenidos a partir de 10 muestras de soluciones acuosas de frutas adicionadas con mezcla de estándares a 10, 20, 30, 40, y 50 ppb se detallan en la tabla 22. En todos los casos el análisis unidimensional a las concentraciones evaluadas, indicó una distribución normal de las observaciones.

La figura 31 muestra el cromatograma obtenido para una muestra de fruta adicionada con solución de estándares a 10 ppb, en la cual se observan los tiempos de retensión correspondientes a cada analito.

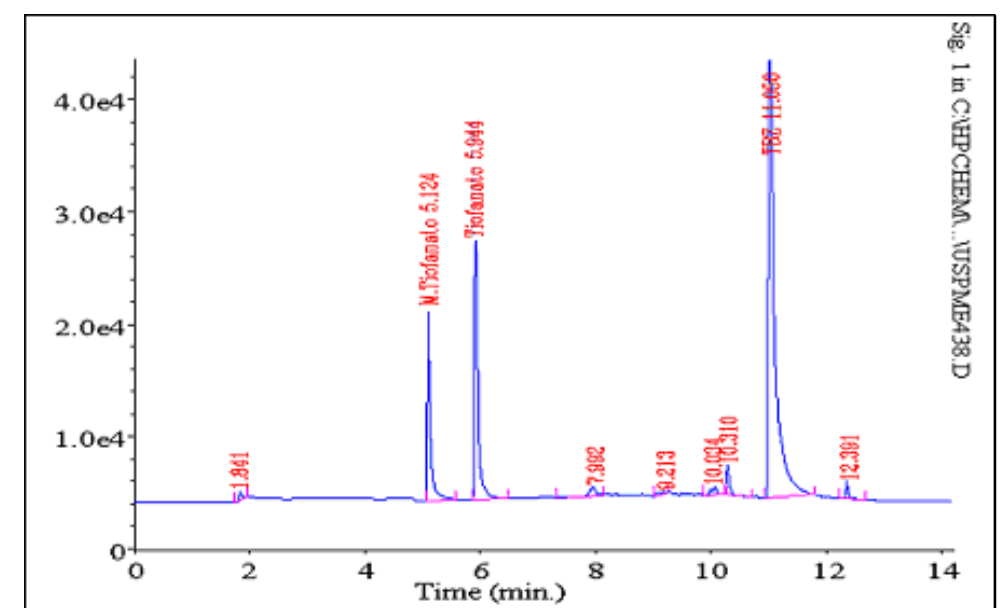

Figura 31. Cromatograma - Solución acuosa de Fruta adicionada con estándares de benzimidazoles a $10 \mathrm{ppb}$ y pH $7-\mathrm{CWX} / \mathrm{DVB}-10 \mathrm{~min}$ de extracción - agitación magnética a 2000 rpm

Las curvas de regresión lineal correspondientes a soluciones acuosas de frutas adicionadas a las concentraciones y condiciones establecidas se muestran en la figura 32. Las figuras 33, 34 y 35 muestran las rectas de regresión para cada analito con 
indicación de los límites de confianza y de predicción correspondientes.

Tabla 22. Análisis unidimensional - Respuestas cromatográficas en alturas de pico - Soluciones acuosas frutas adicionadas - CWX/DVB - $50 \mathrm{ml}$ muestra agitación magnética a $2000 \mathrm{rpm}-\mathrm{n}=10, \alpha=0,05$

\begin{tabular}{|c|c|c|c|c|c|}
\hline Analito & \multicolumn{5}{|c|}{ Metiltiofanato } \\
\hline Concentración (ppb) & 10 & 20 & 30 & 40 & 50 \\
\hline Altura Media & 21286 & 43471 & 64273 & 85762 & 107794 \\
\hline Desviación Estándar & 312 & 282 & 261 & 230 & 204 \\
\hline RSD \% & 1,46 & 0,65 & 0,41 & 0,27 & 0,19 \\
\hline Intervalo de confianza +/- & 223 & 202 & 187 & 165 & 146 \\
\hline Analito & \multicolumn{5}{|c|}{ Tiofanato } \\
\hline Concentración (ppb) & 10 & 20 & 30 & 40 & 50 \\
\hline Altura Media & 27645 & 53135 & 81354 & 107762 & 135282 \\
\hline Desviación Estándar & 313 & 294 & 247 & 214 & 188 \\
\hline RSD \% & 1,13 & 0,55 & 0,30 & 0,20 & 0,14 \\
\hline Intervalo de confianza +/- & 224 & 210 & 177 & 153 & 134 \\
\hline Analito & \multicolumn{5}{|c|}{ Thiabendazole } \\
\hline Concentración (ppb) & 10 & 20 & 30 & 40 & 50 \\
\hline Altura Media & 48726 & 99123 & 147050 & 198500 & 245069 \\
\hline Desviación Estándar & 280 & 245 & 242 & 204 & 114 \\
\hline RSD \% & 0,57 & 0,25 & 0,16 & 0,10 & 0,05 \\
\hline Intervalo de confianza +/- & 200 & 175 & 173 & 146 & 81 \\
\hline
\end{tabular}




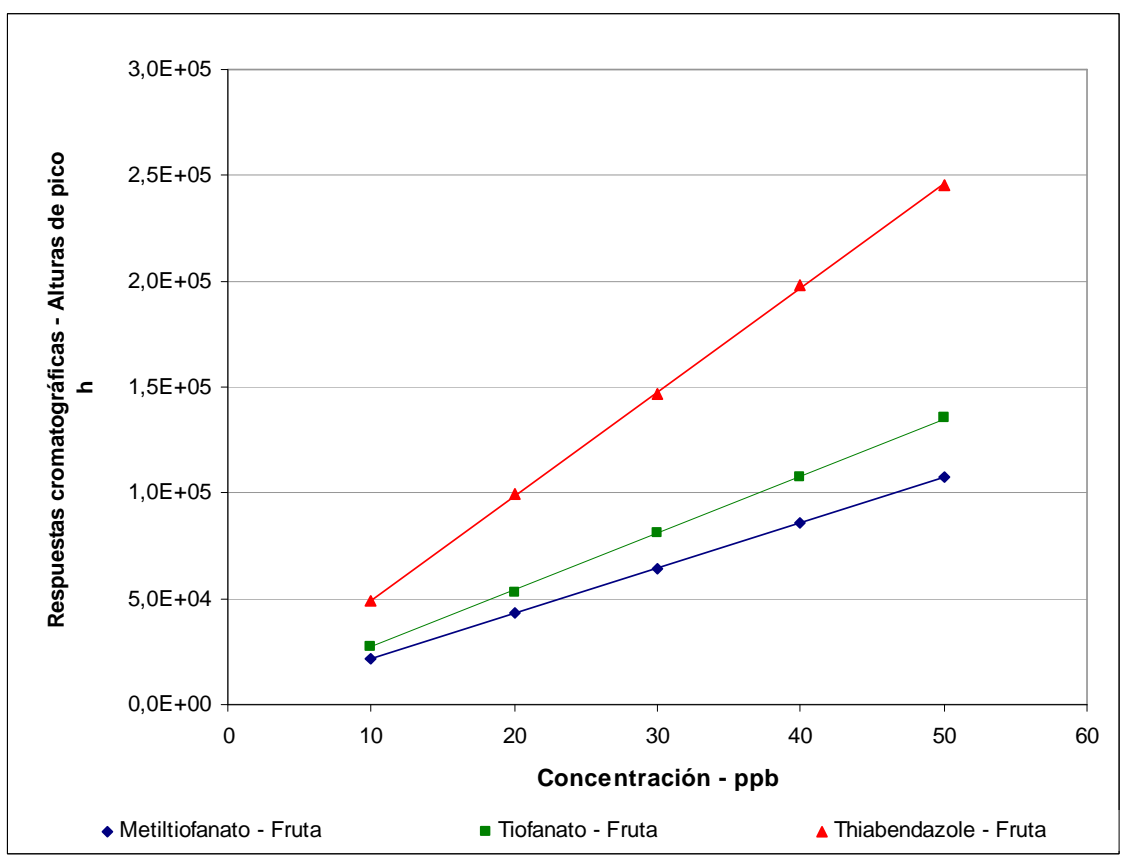

Figura 32. Regresión lineal - Soluciones acuosas de frutas adicionadas a pH 7 CWX/DVB - 10 min de extracción - agitación magnética a 2000 rpm

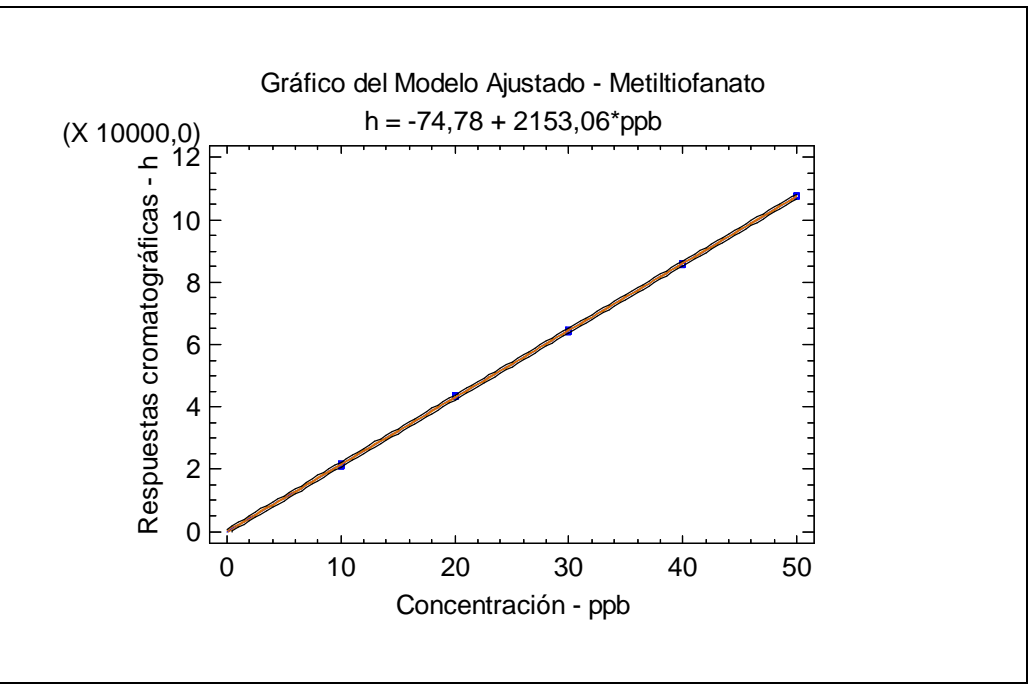

Figura 33. Regresión lineal - Metiltiofanato - Soluciones acuosas de frutas adicionadas a pH 7 - CWX/DVB - 10 min de extracción - agitación magnética 


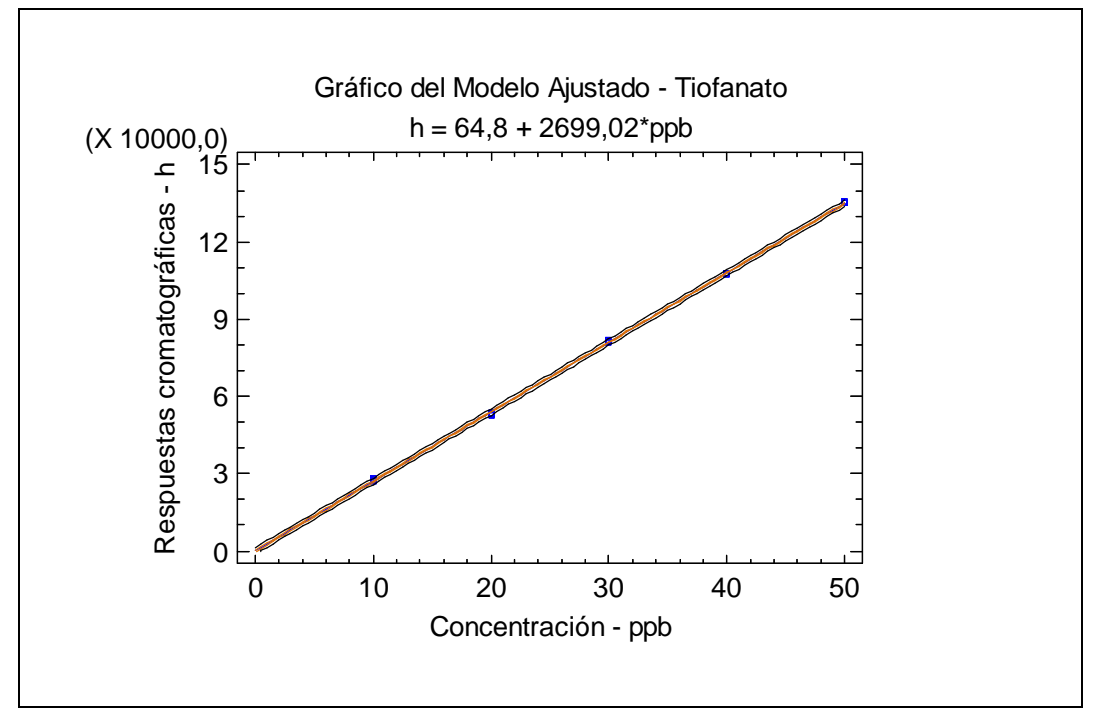

Figura 34. Regresión lineal - Tiofanato - Soluciones acuosas de frutas adicionadas a pH 7 - CWX/DVB - 10 min de extracción - agitación magnética

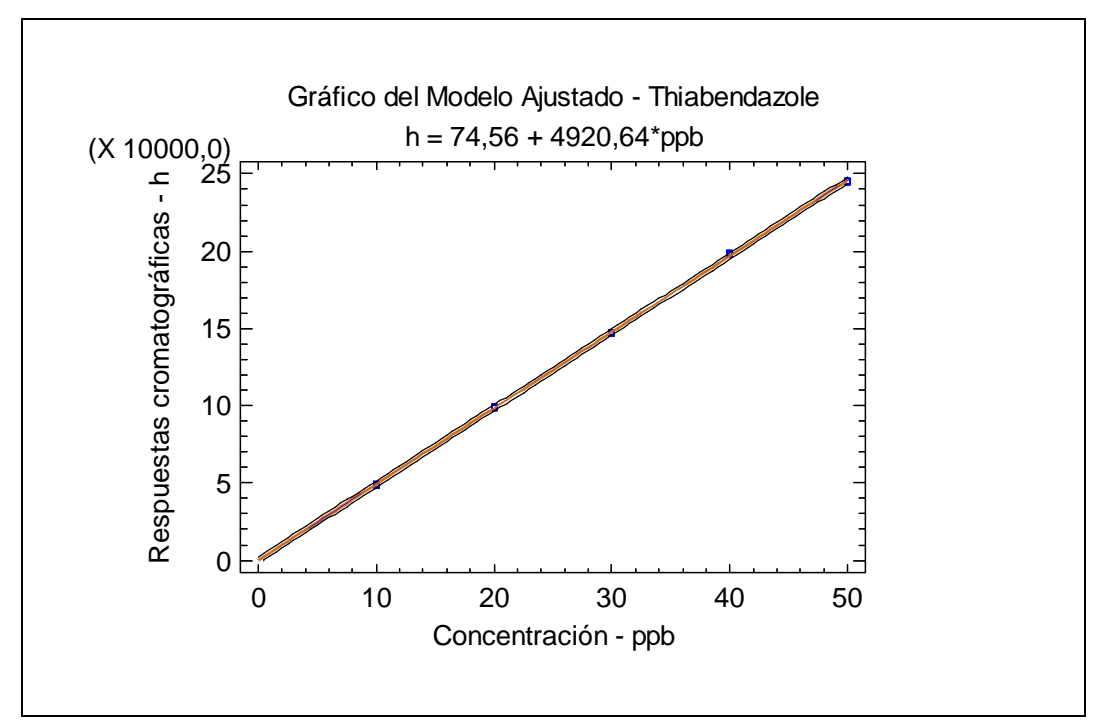

Figura 35. Regresión lineal - Thiabendazole - Soluciones acuosas de frutas adicionadas a pH 7 - CWX/DVB - 10 min de extracción - agitación magnética 
Las ecuaciones del modelo ajustado para cada analito fueron:

$\mathrm{h}_{\text {Metilitiofanato }}=-75+2153 \mathrm{ppb}$ Metilitiofanato

Coeficiente de Correlación $=0,999918$

$\mathrm{R}^{2}=99,9837 \%$

$\mathrm{h}_{\text {Tiofanato }}=65+2699 \mathrm{ppb}$ Tiofanato

Coeficiente de Correlación $=0,999883$

$R^{2}=99,9765 \%$

$\mathrm{h}_{\text {Thiabendazole }}=75+4921 \mathrm{ppb}$ Thiabendazole

Coeficiente de Correlación $=0,999897$

$R^{2}=99,9794 \%$

Donde:

$\mathrm{h}=$ respuestas cromatográficas expresadas en alturas de pico.

$\mathrm{ppb}=$ concentración expresadas en partes por billón $\circ \mu \mathrm{g} / \mathrm{l}$

El análisis de varianza (ANOVA) indicó que existe en todos los casos una relación estadísticamente significativa entre las respuestas cromatográficas (alturas de pico) y la concentración (ppb) con un nivel de confianza del 95,0\%. El estadístico $\mathrm{R}^{2}$ y el coeficiente de correlación muestran para los distintos analitos un ajuste lineal entre las variables. En todos los casos se establecieron los valores predichos de las respuestas cromatográficas para el modelo ajustado y los residuos correspondientes. 
Los estadísticos Durbin Watson y Kolmogorov permitieron establecer la independencia de los residuos y una distribución normal de los mismos para un nivel de confianza del $95 \%$.

Comparación de rectas de regresión - Estándares vs. Frutas cítricas adicionadas

Se realizó el análisis comparativo de las rectas de regresión correspondiente a soluciones acuosas de estándares y frutas adicionadas a fin de establecer si existe efecto matriz y definir la metodología de calibración del método. Las gráficas comparativas de las rectas de regresión para cada analito, se muestran en las figuras 36,37 y 38 .

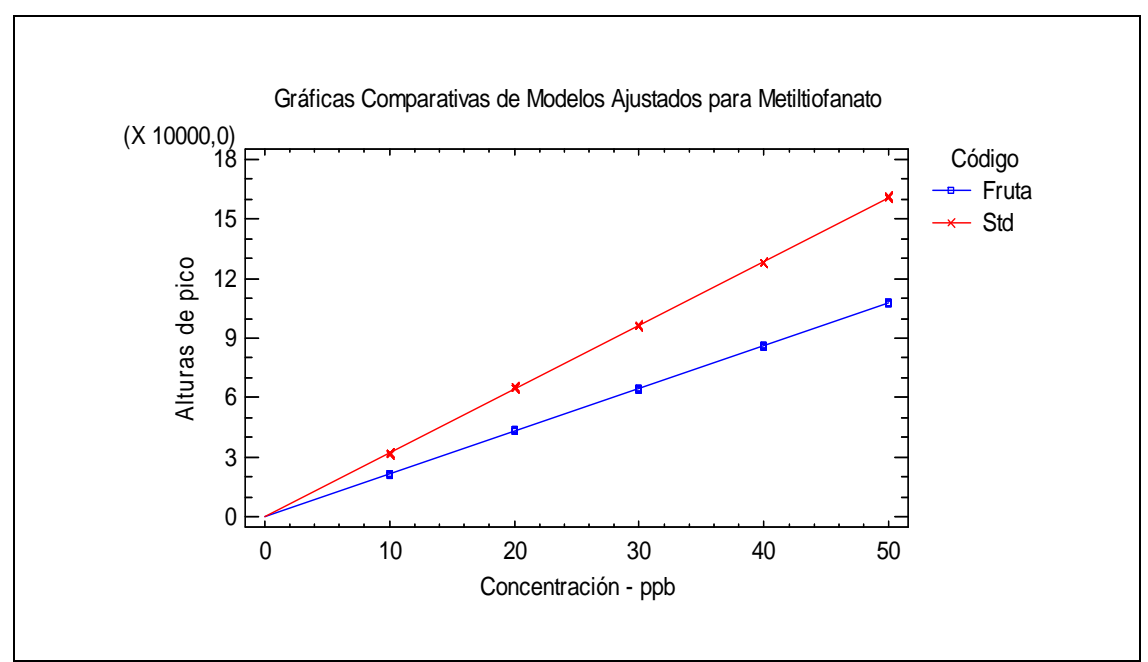

Figura 36. Comparación de rectas de regresión - Metiltiofanato - Soluciones acuosas de estándares y frutas adicionadas a pH 7 - CWX/DVB - 10 min de extracción - agitación magnética a 2000 rpm 


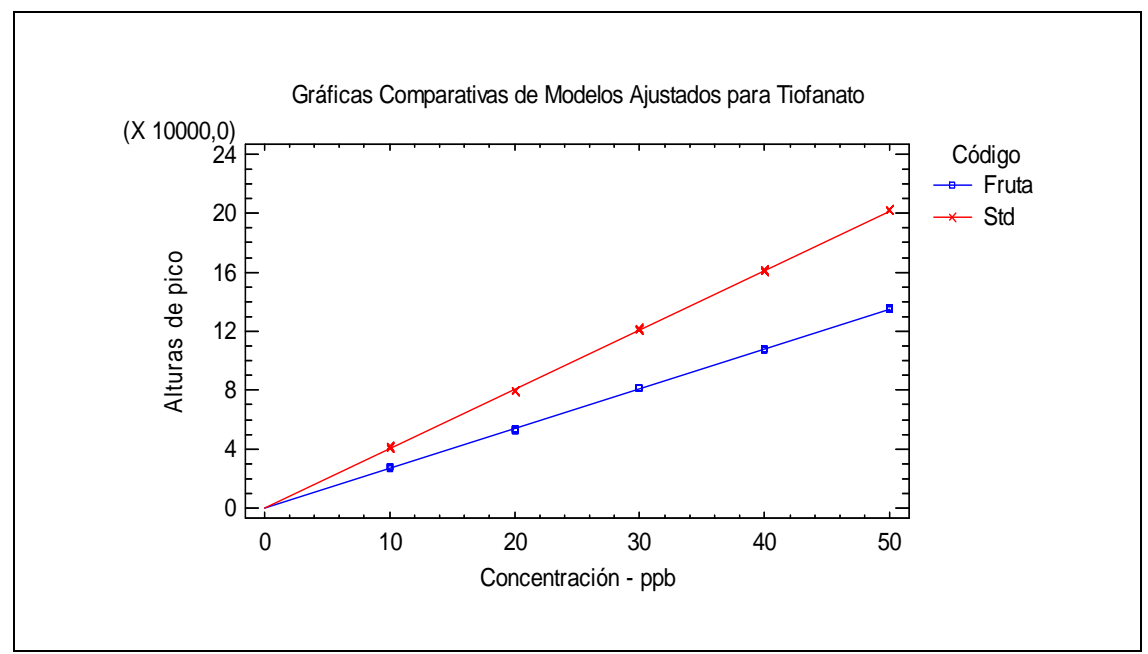

Figura 37. Comparación de rectas de regresión - Tiofanato - Soluciones acuosas de estándares y frutas adicionadas a pH 7-CWX/DVB - $10 \mathrm{~min}$ de extracción - agitación magnética a 2000 rpm

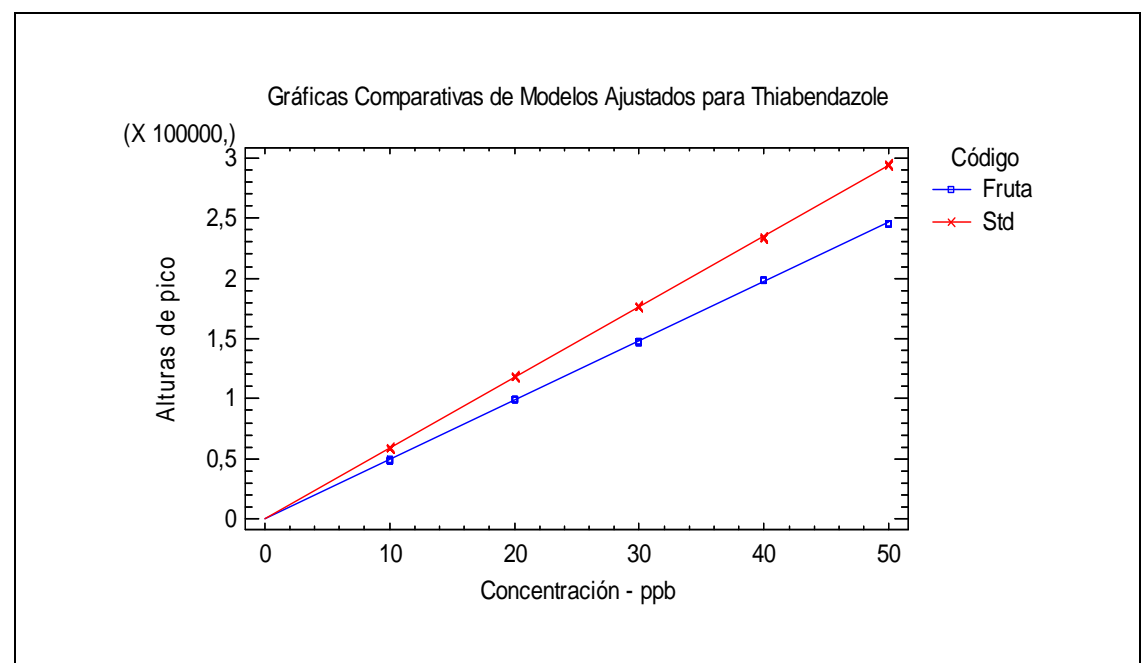

Figura 38. Comparación de rectas de regresión - Thiabendazole - Soluciones acuosas de estándares y frutas adicionadas a pH 7 - CWX/DVB - 10 min de extracción - agitación magnética a 2000 rpm 
En la tabla 23 se detallan, para cada analito, las pendientes y ordenadas al origen de las rectas de regresión correspondientes a soluciones de estándares y muestras adicionadas.

Tabla 23. Interceptos y pendientes - Rectas de regresión - Soluciones acuosas de estándares y frutas adicionadas

\begin{tabular}{|c|c|c|c|c|c|c|}
\hline \multirow{2}{*}{ Matriz } & \multicolumn{2}{|c|}{ Metiltiofanato } & \multicolumn{2}{c|}{ Tiofanato } & \multicolumn{2}{c|}{ Thiabendazole } \\
\cline { 2 - 7 } & Intercepto & Pendiente & Intercepto & Pendiente & Intercepto & Pendiente \\
\hline $\begin{array}{c}\text { Soluciones } \\
\text { estándares }\end{array}$ & -94 & 3214 & 3 & 4033 & 87 & 5868 \\
\hline $\begin{array}{c}\text { Frutas } \\
\text { adicionadas }\end{array}$ & -75 & 2153 & 65 & 2699 & 75 & 4921 \\
\hline
\end{tabular}

Mediante test ANOVA se determinó si existen diferencias significativas entre los puntos de corte y pendientes de las curvas correspondientes a soluciones estándares y frutas adicionadas.

El valor-P tanto para los interceptos como para las pendientes fue menor que 0,01 para todos los analitos, lo cual indicó la existencia de diferencias estadísticamente significativas entre los puntos de corte y pendientes de las rectas correspondientes a soluciones estándares y frutas adicionadas con un nivel de confianza del 99\%.

Los resultados demuestran la existencia de efecto matriz, por lo que, en todos los casos en los que se determine benzimidazoles en frutas cítricas aplicando esta metodología, es necesario efectuar calibración previa con muestras adicionadas.

\section{$\underline{\text { Precisión - Frutas cítricas adicionadas }}$}

Se determinó precisión a partir de los datos de las respuestas cromatográficas expresadas en alturas de pico 
correspondientes a soluciones acuosas de frutas adicionadas a 20, 40 y $50 \mathrm{ppb}$, para $\mathrm{n}=10$ y $\alpha=0,05$, en condiciones repetitivas y reproducibles. En cada caso se determinó desviación estándar, coeficiente de variación porcentual (RSD \%) y mediante test de Student los intervalos de confianza de la media. Los resultados del análisis estadístico de los datos se muestran en la tabla 24.

Tabla 24. Precisión - Valores medios en alturas de pico - Soluciones acuosas de frutas adicionadas a pH 7 - CWX/DVB - 10 min de extracción - agitación magnética a $2000 \mathrm{rpm}-\mathrm{n}=10$ y $\alpha=0,05$

\begin{tabular}{|c|c|c|c|c|}
\hline \multirow[b]{2}{*}{ Analitos } & \multicolumn{4}{|c|}{ Soluciones acuosas de frutas adicionadas a $20 \mathrm{ppb}$} \\
\hline & Promedio & $\begin{array}{c}\text { Desviación } \\
\text { estándar }\end{array}$ & RSD \% & $\begin{array}{c}\text { Intervalo de } \\
\text { confianza }\end{array}$ \\
\hline Metiltiofanato & 43471 & 282 & 0,65 & \pm 202 \\
\hline Tiofanato & 53135 & 294 & 0,55 & \pm 210 \\
\hline Thiabendazole & 99123 & 245 & 0,25 & \pm 175 \\
\hline \multirow[b]{2}{*}{ Analitos } & \multicolumn{4}{|c|}{ Soluciones acuosas de frutas adicionadas a $40 \mathrm{ppb}$} \\
\hline & Promedio & $\begin{array}{c}\text { Desviación } \\
\text { estándar }\end{array}$ & RSD \% & $\begin{array}{c}\text { Intervalo de } \\
\text { confianza }\end{array}$ \\
\hline Metiltiofanato & 85762 & 230 & 0,27 & \pm 165 \\
\hline Tiofanato & 107762 & 214 & 0,20 & \pm 153 \\
\hline Thiabendazole & 198500 & 204 & 0,10 & \pm 146 \\
\hline \multirow[b]{2}{*}{ Analitos } & \multicolumn{4}{|c|}{ Soluciones acuosas de frutas adicionadas a $50 \mathrm{ppb}$} \\
\hline & Promedio & $\begin{array}{c}\text { Desviación } \\
\text { estándar }\end{array}$ & RSD \% & $\begin{array}{c}\text { Intervalo de } \\
\text { confianza }\end{array}$ \\
\hline Metiltiofanato & 107794 & 204 & 0,19 & \pm 146 \\
\hline Tiofanato & 135282 & 188 & 0,14 & \pm 134 \\
\hline Thiabendazole & 245069 & 114 & 0,05 & \pm 81 \\
\hline
\end{tabular}

Los resultados obtenidos permiten establecer que el método es preciso para el intervalo de concentraciones analizado a un nivel de confianza del $95 \%$. 
$\underline{\text { Recuperación - Frutas cítricas adicionadas }}$

La exactitud del método se determinó para cada analito a partir de quintuplicados de muestras adicionadas a 10, $30 \mathrm{y}$ $50 \mathrm{ppb}$.

El análisis estadístico de los resultados para todas las observaciones indicó que no existen diferencias significativas entre las medias de las recuperaciones a las diferentes concentraciones de los analitos para un nivel de confianza del $95 \%$. Los resultados se muestran en la tabla 25.

Tabla 25. Exactitud del método - Soluciones acuosas de frutas adicionadas $\mathrm{n}=15$ y $\alpha=0,05$

\begin{tabular}{|l|c|c|c|c|}
\hline \multirow{2}{*}{ Analitos } & \multicolumn{5}{|c|}{\begin{tabular}{c} 
Soluciones acuosas de frutas adicionadas a 10 ppb \\
\cline { 2 - 5 }
\end{tabular}} & $\begin{array}{c}\text { Recuperación } \\
\text { media \% }\end{array}$ & $\begin{array}{c}\text { Desviación } \\
\text { estándar }\end{array}$ & RSD \% & $\begin{array}{c}\text { Intervalo de } \\
\text { confianza }\end{array}$ \\
\hline Metiltiofanato & 96,17 & 1,35 & 1,40 & $\pm 0,75$ \\
\hline Tiofanato & 96,07 & 1,67 & 1,74 & $\pm 0,92$ \\
\hline Thiabendazole & 98,51 & 2,41 & 2,45 & $\pm 1,34$ \\
\hline \multirow{2}{*}{ Analitos } & Soluciones acuosas de frutas adicionadas a 30 ppb \\
\cline { 2 - 5 } & $\begin{array}{c}\text { Recuperación } \\
\text { media \% }\end{array}$ & $\begin{array}{c}\text { Desviación } \\
\text { estándar }\end{array}$ & RSD \% & $\begin{array}{c}\text { Intervalo de } \\
\text { confianza }\end{array}$ \\
\hline Metiltiofanato & 96,19 & 0,76 & 0,79 & $\pm 0,42$ \\
\hline Tiofanato & 96,99 & 1,01 & 1,04 & $\pm 0,56$ \\
\hline Thiabendazole & 98,66 & 1,33 & 1,35 & $\pm 0,74$ \\
\hline \multirow{2}{*}{ Analitos } & Soluciones acuosas de frutas adicionadas a 50 ppb \\
\cline { 2 - 6 } & $\begin{array}{c}\text { Recuperación } \\
\text { media \% }\end{array}$ & $\begin{array}{c}\text { Desviación } \\
\text { estándar }\end{array}$ & RSD \% & $\begin{array}{c}\text { Intervalo de } \\
\text { confianza }\end{array}$ \\
\hline Metiltiofanato & 95,59 & 1,36 & 1,42 & $\pm 0,75$ \\
\hline Tiofanato & 96,29 & 0,61 & 0,64 & $\pm 0,34$ \\
\hline Thiabendazole & 97,80 & 1,10 & 1,13 & $\pm 0,61$ \\
\hline
\end{tabular}

Se determinaron los parámetros estadísticos correspondientes y mediante test de Student, se estableció que no existen diferencias significativas entre la recuperación media y el 
$100 \%$ para un nivel de confianza del $95 \%$.

Límites de detección y cuantificación - Frutas cítricas adicionadas

La sensibilidad del método fue determinada a partir de 10 muestras de soluciones acuosas de frutas adicionadas a 10, $20 \mathrm{y}$ $30 \mathrm{ppb}$. En la tabla 26 se indican los límites correspondientes a cada analito expresados en ppb de la solución para un intervalo de confianza del $95 \%$.

Tabla 26. Límite de detección y cuantificación - Soluciones acuosas de frutas adcionadas a pH 7 - CWX/DVB - 10 min de extracción - agitación magnética a $2000 \mathrm{rpm}-\mathrm{n}=30$ y $\alpha=0.05$

\begin{tabular}{|l|c|c|}
\hline \multicolumn{1}{|c|}{ Analitos } & $\begin{array}{c}\text { Límite de detección } \\
\text { ppb }\end{array}$ & $\begin{array}{c}\text { Límite de cuantificación } \\
\text { ppb }\end{array}$ \\
\hline Metiltiofanato & 0,17 & 0,30 \\
\hline Tiofanato & 0,13 & 0,26 \\
\hline Thiabendazole & 0,07 & 0,14 \\
\hline
\end{tabular}

Los resultados indican que el método es sensible para la determinación de benzimidazoles en frutas adicionadas por microextracción en fase sólida y cromatografía gaseosa.

\section{Jugos cítricos concentrados}

Tal como se ha explicitado en el plan de muestreo, los jugos cítricos concentrados de naranja de aproximadamente 65Brix fueron diluidos con agua en una relación 5:100 p/v, neutralizados a $\mathrm{pH} 7$ y adicionados con soluciones mezcla de estándares de benzimidazoles previo al proceso extractivo.

A partir de muestras adicionadas con estándares individuales y mezcla de estándares a 50 ppb, se determinaron los 
tiempos de retención individuales e identificación de picos en la mezcla.

Los tiempos de retención medios (RT) de los benzimidazoles analizados, para muestras adicionadas con estándares individuales y mezcla fueron: Metiltiofanato $\mathrm{RT}=5,111$; Tiofanato $\mathrm{RT}=6,103$ y Thiabendazole $\mathrm{RT}=11,012$.

Los resultados obtenidos a partir de las muestras acuosas de jugos cítricos adicionados a 10, 20, 30, 40 y 50 ppb; neutralizadas a $\mathrm{pH} 7, \mathrm{y}$ sometidas al proceso extractivo descrito fueron analizados estadísticamente.

Se determinó el perfil de masa absorbida en función del tiempo de extracción, la curva de regresión lineal e intervalos de confianza, comparación de las rectas de regresión estándar vs. muestras adicionadas, precisión, recuperación y límites de detección y cuantificación del método.

Perfil de masa absorbida, número total de moles, constante de distribución, volumen mínimo de muestra y coeficiente de difusión - Jugos cítricos adicionados

Del mismo modo que para frutas cítricas adicionadas, se determinó el perfil de masa absorbida (figura 39) a partir de quintuplicados de soluciones acuosas de jugos cítricos adicionados con mezcla de benzimidazoles a $20 \mathrm{ppb}$, volumen de muestra de $50 \mathrm{ml}$, agitación magnética a 2000 rpm y tiempos de inmersión de 10, 20, 30, 40, 45, 50, 120, 240, 360 y 720 min.

El análisis unidimensional de los datos obtenidos indicó en todos los casos una distribución normal de las observaciones. Los resultados obtenidos se muestran en la en la tabla 27. 


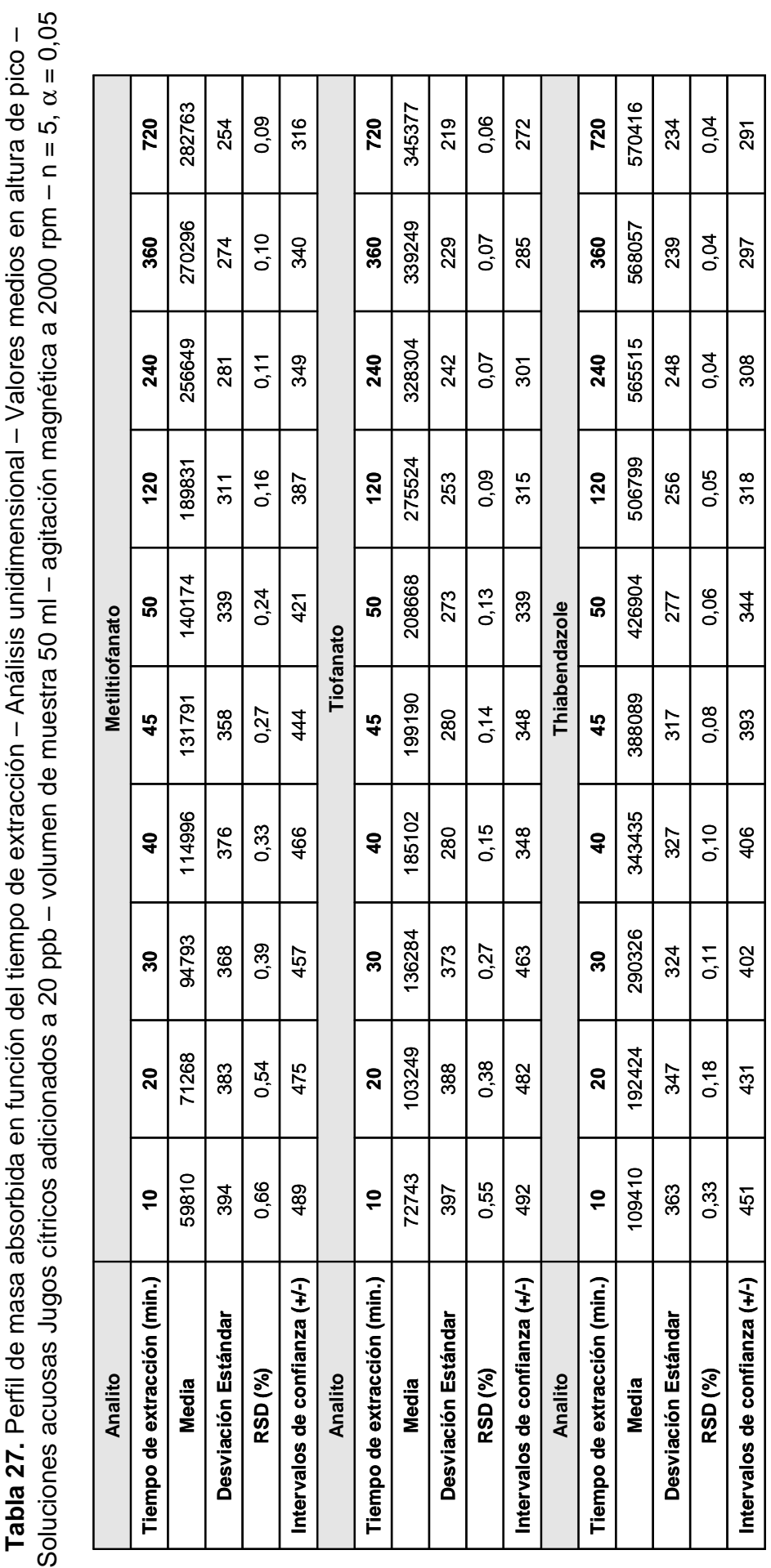

$-153-$ 
Desarrollo y Aplicación de Metodologías Analíticas

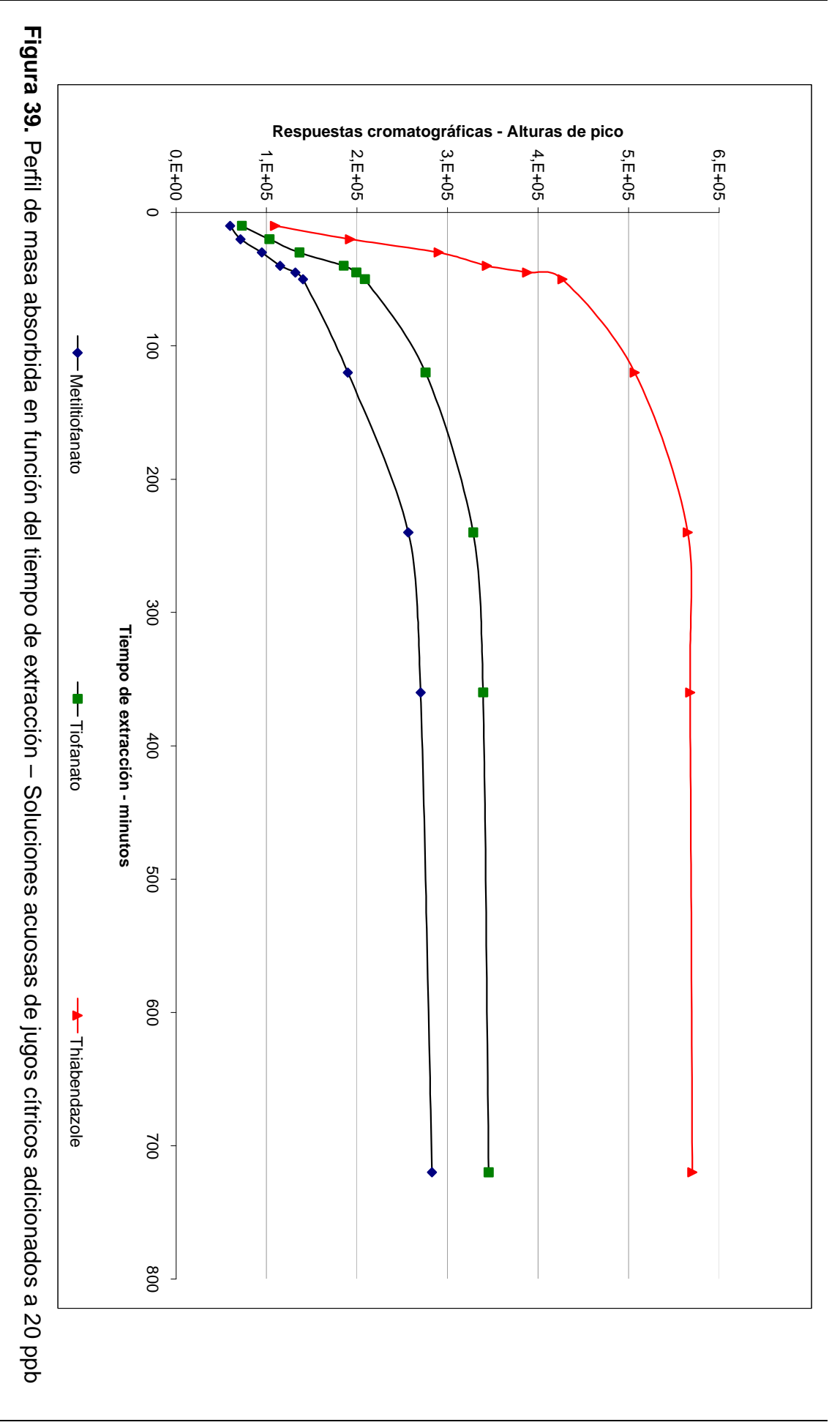

$-154-$ 
Considerando que se ha alcanzado el equilibrio del sistema a 720 min, la masa total absorbida para cada analito se determinó a partir de las respuestas cromatográficas obtenidas a dicho tiempo de extracción, de la curva de calibración por inyección directa y de las especificaciones de la fibra seleccionada. Los resultados se indican en la tabla 28.

Tabla 28. Valores medios comparativos de los analitos expresados en alturas de picos para soluciones de 5 ppm por Inyección directa de $2 \mu$ y jugos adicionados a 20 ppb - 12 h de inmersión CWX/DVB - agitación magnética a 2000 rpm.

\begin{tabular}{|c|c|c|c|c|}
\hline \multirow{2}{*}{ Analito } & \multicolumn{2}{|c|}{$\begin{array}{c}\text { Inyección Directa } \\
2 \mu \mathrm{l} \text { de } 5 \mathrm{ppm}\end{array}$} & \multicolumn{2}{c|}{$\begin{array}{c}\text { SPME- CWX/DVB } \\
20 \mathrm{ppb} 720 \text { minutos }\end{array}$} \\
\cline { 2 - 5 } & $\begin{array}{c}\text { Promedio } \\
\text { respuesta }\end{array}$ & $\begin{array}{c}\text { masa } \\
\text { inyectada } \\
\text { (ng) }\end{array}$ & $\begin{array}{c}\text { Promedio } \\
\text { respuesta }\end{array}$ & $\begin{array}{c}\text { masa } \\
\text { absorbida } \\
\text { (ng) }\end{array}$ \\
\hline Metiltiofanato & 124883 & 10 & 282763 & 22,65 \\
\hline Tiofanato & 159108 & 10 & 345377 & 21,82 \\
\hline Thiabendazole & 240404 & 10 & 570416 & 23,78 \\
\hline
\end{tabular}

Teniendo en cuenta las especificaciones del CWX/DVB y los pesos moleculares de los analitos evaluados, del mismo modo que para soluciones estándares y frutas adicionadas, se calculó número total de moles absorbidos $(n)$, constante de distribución $\left(K_{f s}\right)$ de los mismos en el polímero de recubrimiento y volumen mínimo de muestra $\left(V_{s}\right)$, a partir de las ecuaciones (5) $K_{f s}=n . V_{s} / V_{f}\left(C_{0} . V_{s}-n\right)$ y (4) $V_{s}=100 . K_{f s} . V_{f} / E$. Los resultados se indican en la tabla 29.

El coeficiente de difusión de los analitos en el absorbente se determinó a partir de la curva del perfil para un $95 \%$ de masa absorbida considerando un error $(E)$ del $5 \%$, despejando $D_{f}$ en la ecuación (3) $t_{e}=t_{95 \%}=(b-a)^{2} / 2 D_{f}$. 
Tabla 29. Determinación de la Constante de Distribución Polímero de recubrimiento/Agua

\begin{tabular}{|c|c|c|c|c|}
\hline Analitos & $\begin{array}{c}\text { Masa } \\
\text { molecular } \\
\text { (ng) }\end{array}$ & $\begin{array}{c}\text { Número de } \\
\text { moles } \\
\text { absorbidos }\end{array}$ & $\begin{array}{c}\boldsymbol{C}_{\boldsymbol{o}} \\
\text { (moles/mI) }\end{array}$ & $\boldsymbol{K}_{\text {fs }}$ \\
\hline Metiltiofanato & $3,42710^{11}$ & $6,6110^{-11}$ & $5,8410^{-11}$ & 8733 \\
\hline Tiofanato & $3,704510^{11}$ & $5,8910^{-11}$ & $5,4010^{-11}$ & 8406 \\
\hline Thiabendazole & $2,012610^{11}$ & $1,1810^{-10}$ & $9,9410^{-11}$ & 9181 \\
\hline
\end{tabular}

Los tiempos correspondientes a un $95 \%$ de masa absorbida ( $\left.\mathrm{t}_{95 \%}\right)$ para los distintos analitos fueron:

Metiltiofanato $\mathrm{t}_{95 \%}=328 \mathrm{~min}$

Tiofanato $t_{95 \%}=233 \mathrm{~min}$

Thiabendazole $t_{95 \%}=179 \mathrm{~min}$

Los resultados correspondientes se muestran en la tabla 30.

Tabla 30. Volumen limitante de muestra y coeficiente de difusión analito/ CWX/DVB - jugos adicionados a 20 ppb - inmersión 12 h y agitación magnética

\begin{tabular}{|c|c|c|c|c|}
\hline Analitos & $\boldsymbol{K}_{\boldsymbol{f s}}$ & $\begin{array}{c}\text { a } 2000 \mathrm{rpm} . \\
\left(\boldsymbol{V}_{\boldsymbol{f}}\right.\end{array}$ & $\begin{array}{c}\text { Tiempo } \\
\left.\mathbf{t}_{\mathbf{9 5}} \text { ( } \mathbf{m i n}\right)\end{array}$ & $\begin{array}{c}\boldsymbol{D}_{\boldsymbol{f}} \\
\left(\mathbf{c m}^{2} / \mathbf{s e g}\right)\end{array}$ \\
\hline Metiltiofanato & 8733 & 23,2 & 328 & $1,0710^{-9}$ \\
\hline Tiofanato & 8406 & 22,3 & 233 & $1,5110^{-9}$ \\
\hline Thiabendazole & 9181 & 24,4 & 179 & $1,9710^{-9}$ \\
\hline
\end{tabular}

A los fines prácticos se estableció para la determinación de los restantes parámetros estadísticos, un tiempo de extracción para el análisis de $10 \mathrm{~min}$.

\section{Linealidad - Jugos cítricos adicionados}

Los resultados obtenidos a partir de 10 muestras de soluciones acuosas de Jugos adicionados con mezcla de estándares a 10, 20, 30, 40, y 50 ppb se detallan en la tabla 31. 
Tabla 31. Análisis unidimensional - Respuestas cromatográficas en alturas de pico - Soluciones acuosas jugos adicionados - CWX/DVB - $50 \mathrm{ml}$ muestra agitación magnética a $2000 \mathrm{rpm}-\mathrm{n}=10, \alpha=0,05$

\begin{tabular}{|c|c|c|c|c|c|}
\hline Analito & \multicolumn{5}{|c|}{ Metiltiofanato } \\
\hline Concentración (ppb) & 10 & 20 & 30 & 40 & 50 \\
\hline Altura Media & 29233 & 59772 & 88240 & 117713 & 148088 \\
\hline Desviación Estándar & 265 & 257 & 246 & 166 & 149 \\
\hline RSD \% & 0,91 & 0,43 & 0,28 & 0,14 & 0,10 \\
\hline Intervalo de confianza +/- & 203 & 168 & 147 & 116 & 108 \\
\hline Analito & \multicolumn{5}{|c|}{ Tiofanato } \\
\hline Concentración (ppb) & 10 & 20 & 30 & 40 & 50 \\
\hline Altura Media & 37864 & 72336 & 111584 & 147666 & 185189 \\
\hline Desviación Estándar & 279 & 276 & 186 & 167 & 132 \\
\hline RSD \% & 0,74 & 0,38 & 0,17 & 0,11 & 0,07 \\
\hline Intervalo de confianza +/- & 199 & 198 & 133 & 119 & 94 \\
\hline Analito & \multicolumn{5}{|c|}{ Thiabendazole } \\
\hline Concentración (ppb) & 10 & 20 & 30 & 40 & 50 \\
\hline Altura Media & 54183 & 109005 & 160648 & 214886 & 270988 \\
\hline Desviación Estándar & 296 & 262 & 257 & 251 & 218 \\
\hline RSD \% & 0,55 & 0,24 & 0,16 & 0,12 & 0,08 \\
\hline Intervalo de confianza +/- & 212 & 188 & 184 & 180 & 156 \\
\hline
\end{tabular}

El análisis unidimensional indicó una distribución normal de las observaciones para cada analito a las distintas concentraciones. Las curvas de regresión lineal correspondientes a soluciones acuosas de jugos adicionados a las concentraciones y condiciones establecidas se muestran en la figura 40. 
Las ecuaciones del modelo ajustado para cada analito fueron:

$\mathrm{h}_{\text {Metiltiofanato }}=-86+2957 \mathrm{ppb}$ Metilitifanato

Coeficiente de Correlación $=0,999928$

$R^{2}=99,9855 \%$

$\mathrm{h}_{\text {Tiofanato }}=-66+3700 \mathrm{ppb}$ Tiofanato

Coeficiente de Correlación $=0,999847$

$R^{2}=99,9694 \%$

$\mathrm{h}_{\text {Thiabendazole }}=95+5395 \mathrm{ppb}$ Thiabendazole

Coeficiente de Correlación $=0,999908$

$R^{2}==99,9816 \%$

Donde:

$\mathrm{h}=$ respuestas cromatográficas expresadas en alturas de pico.

$\mathrm{ppb}=$ concentración expresadas en partes por billón $0 \mu \mathrm{g} / \mathrm{l}$

Las figuras 41,42 y 43 muestran las rectas de regresión para cada analito con indicación de los límites de confianza y de predicción correspondientes.

El análisis de varianza (ANOVA) indicó que existe en todos los casos una relación estadísticamente significativa entre las respuestas cromatográficas (alturas de pico) y la concentración (ppb) con un nivel de confianza del 95,0\%.

El estadístico $R^{2}$ y el coeficiente de correlación muestran para los distintos analitos un ajuste lineal entre las variables. 


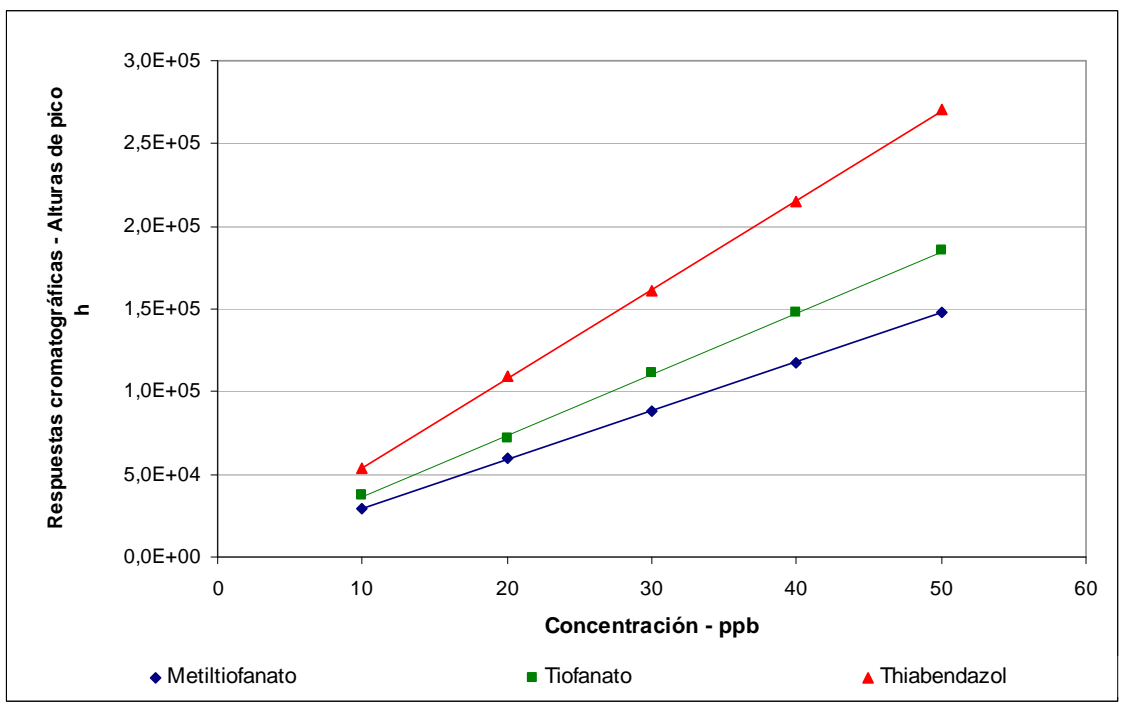

Figura 40. Regresión lineal - Soluciones acuosas de jugos adicionados a pH 7 CWX/DVB - 10 min de extracción - agitación magnética a 2000 rpm

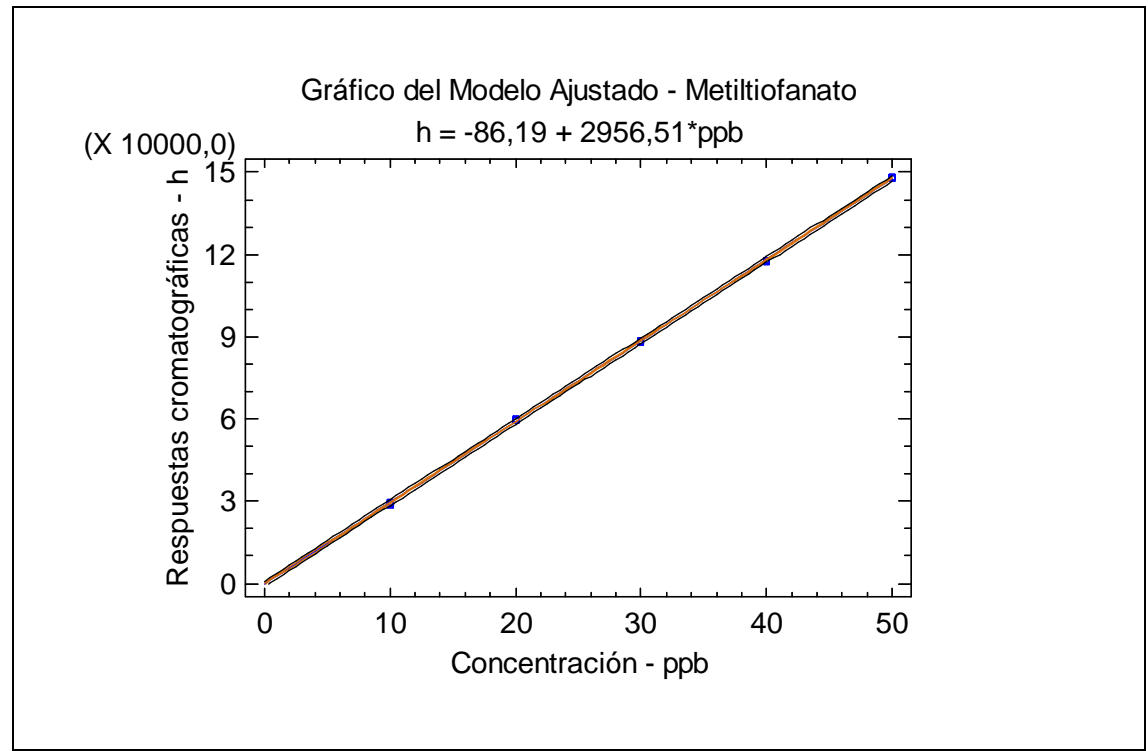

Figura 41. Regresión lineal - Metiltiofanato - Soluciones acuosas de jugos adicionados a pH 7 - CWX/DVB - 10 min de extracción - agitación magnética 


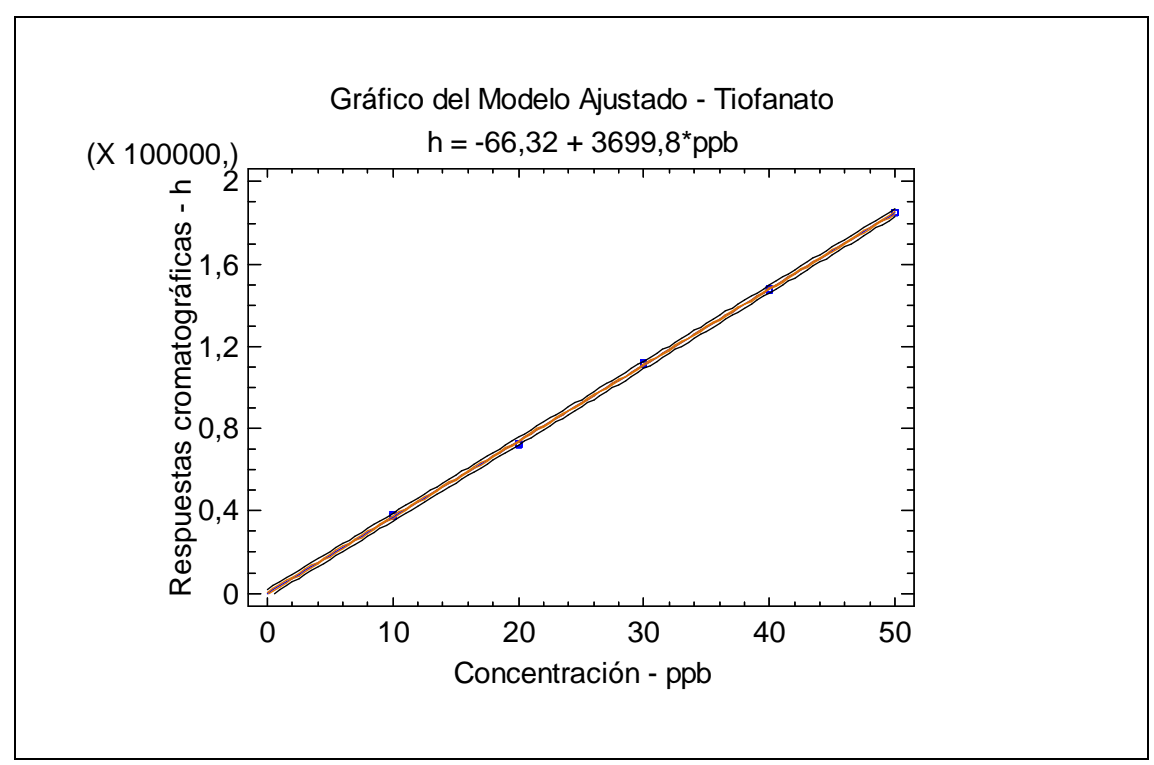

Figura 42. Regresión lineal - Tiofanato - Soluciones acuosas de jugos adicionados a pH 7 - CWX/DVB - 10 min de extracción - agitación magnética

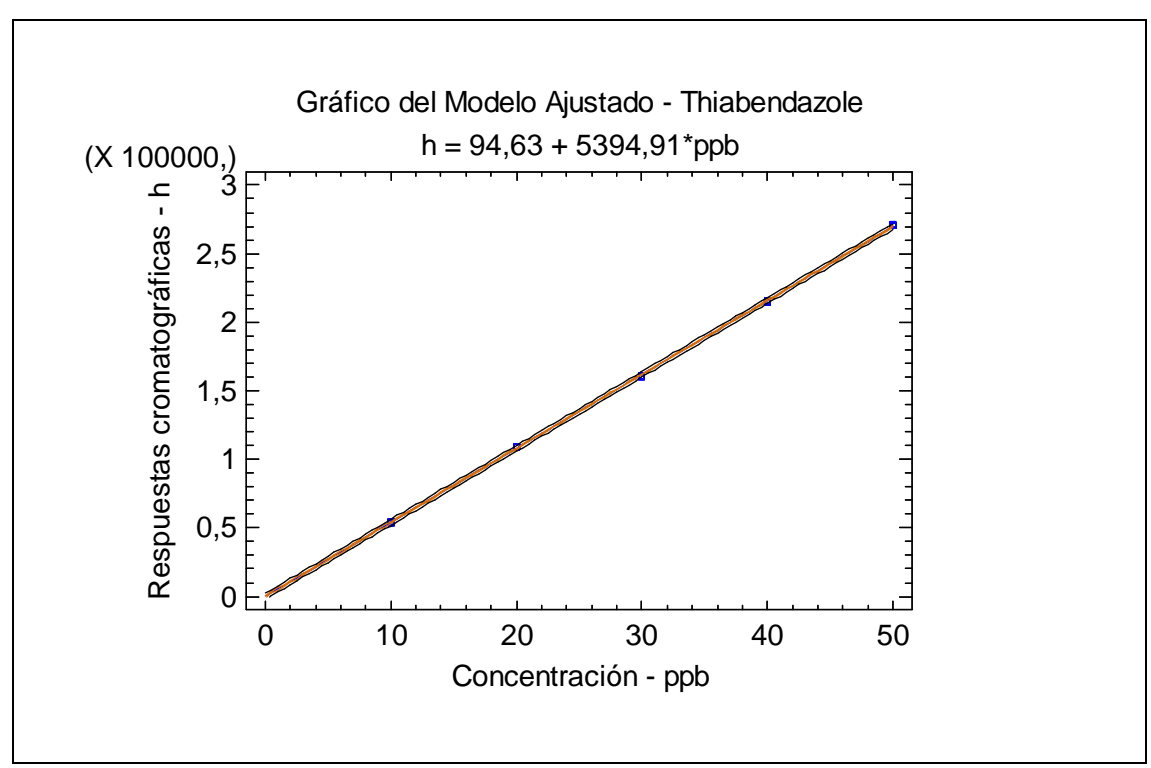

Figura 43. Regresión lineal - Thiabendazole - Soluciones acuosas de jugos adicionados a pH 7 - CWX/DVB - 10 min de extracción - agitación magnética 
En todos los casos se establecieron los valores predichos de las respuestas cromatográficas para el modelo ajustado y los residuos correspondientes.

Los estadísticos Durbin Watson y Kolmogorov permitieron establecer la independencia de los residuos y una distribución normal de los mismos para un nivel de confianza del $95 \%$.

Comparación de rectas de regresión - Estándares vs. jugos cítricos adicionados

Se realizó el análisis comparativo de las rectas de regresión correspondiente a soluciones acuosas de estándares y jugos adicionadas a fin de establecer si existe efecto matriz y definir la metodología de calibración del método. Las gráficas comparativas de las rectas de regresión para cada analito se muestran en las figuras 44,45 y 46 .

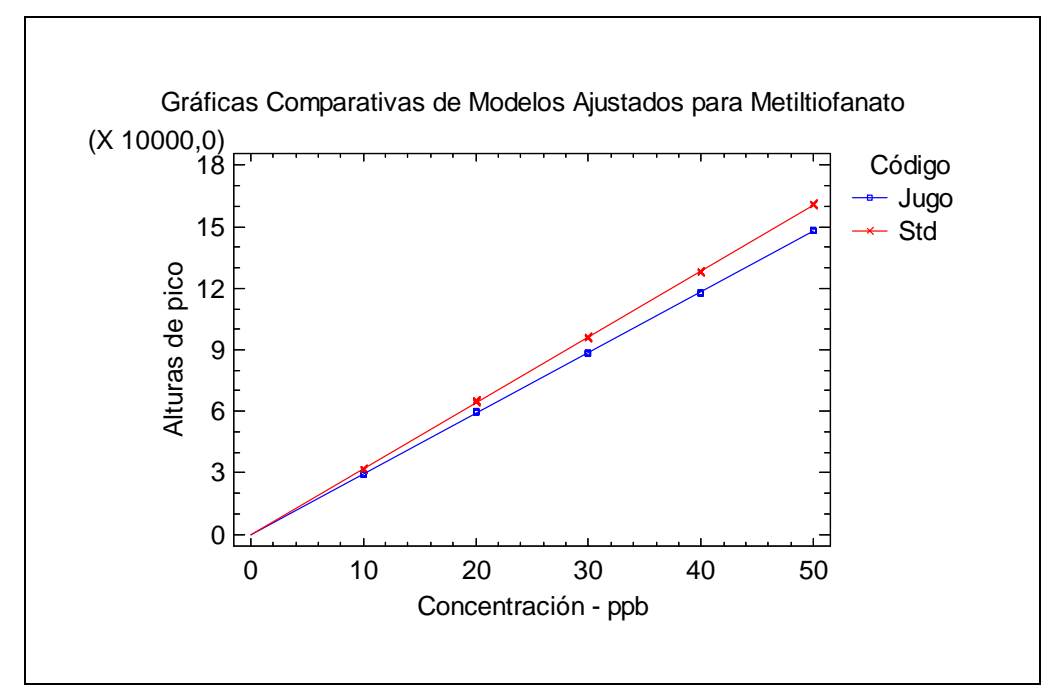

Figura 44. Comparación de rectas de regresión - Metiltiofanato - Soluciones acuosas de estándares y Jugos adicionados a pH 7 - CWX/DVB - 10 min de extracción - agitación magnética a 2000 rpm

$$
-161-
$$


Gráficas Comparativas de Modelos Ajustados para Tiofanato (X 10000,0

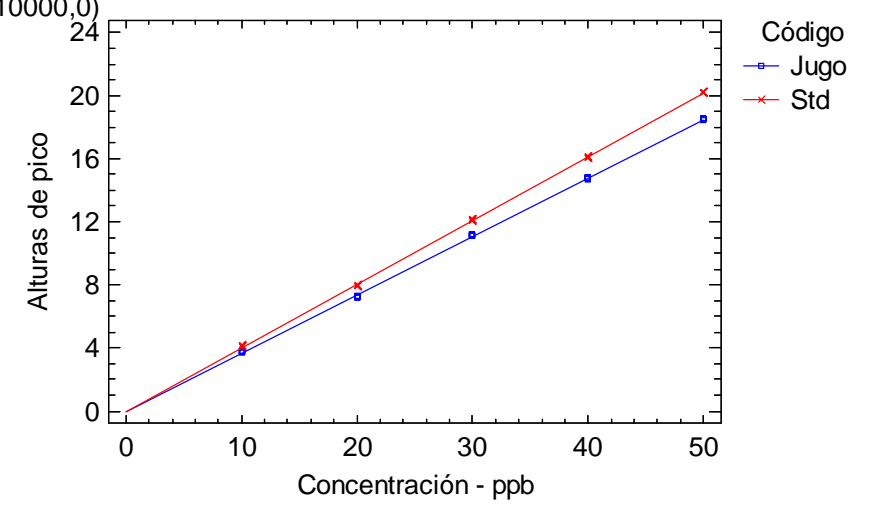

Figura 45. Comparación de rectas de regresión - Tiofanato - Soluciones acuosas de estándares y Jugos adicionados a pH 7 - CWX/DVB - $10 \mathrm{~min}$ de extracción - agitación magnética a 2000 rpm

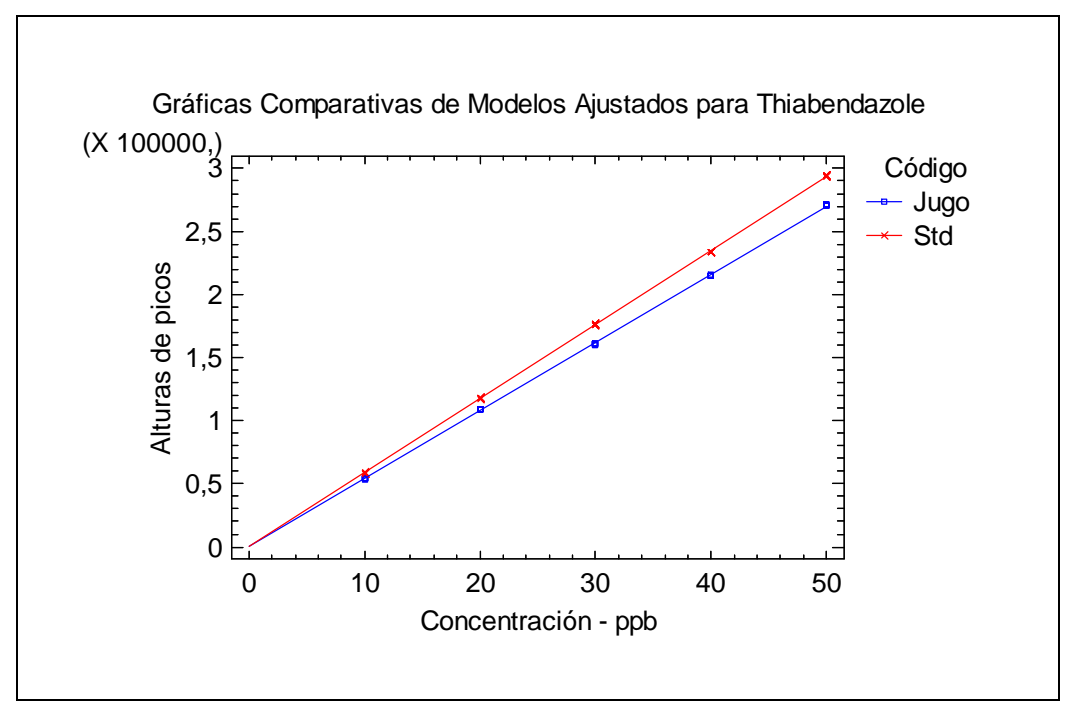

Figura 46. Comparación de rectas de regresión - Thiabendazole - Soluciones acuosas de estándares y Jugos adicionados a pH 7 - CWX/DVB - $10 \mathrm{~min}$ de extracción - agitación magnética a 2000 rpm 
En la tabla 32 se detallan para cada analito las pendientes y ordenadas al origen de las rectas de regresión correspondientes a soluciones de estándares y muestras adicionadas.

Tabla 32. Interceptos y pendientes - Rectas de regresión - Soluciones acuosas de estándares y jugos cítricos adicionados

\begin{tabular}{|c|c|c|c|c|c|c|}
\hline \multirow{2}{*}{ Matriz } & \multicolumn{2}{|c|}{ Metiltiofanato } & \multicolumn{2}{c|}{ Tiofanato } & \multicolumn{2}{c|}{ Thiabendazole } \\
\cline { 2 - 7 } & Intercepto & Pendiente & Intercepto & Pendiente & Intercepto & Pendiente \\
\hline $\begin{array}{c}\text { Soluciones } \\
\text { estándares }\end{array}$ & -94 & 3214 & 3 & 4033 & 87 & 5868 \\
\hline $\begin{array}{c}\text { Jugos } \\
\text { adicionados }\end{array}$ & -86 & 2957 & -66 & 3700 & 95 & 5395 \\
\hline
\end{tabular}

En el test ANOVA el valor-P resultó en todos los casos menor a 0,01 ; lo cual indicó la existencia de diferencias estadísticamente significativas entre los puntos de corte y pendientes de las curvas correspondientes a soluciones estándares y jugos adicionados, para todos los analitos con un $99 \%$ de nivel de confianza.

Los resultados demuestran que el efecto matriz es relevante, por lo que se deduce que para la determinación de benzimidazoles en jugos cítricos mediante esta metodología, es necesario efectuar calibración previa con muestras adicionadas.

\section{$\underline{\text { Precisión - Jugos cítricos adicionados }}$}

Se determinó precisión a partir de los datos de las respuestas cromatográficas expresadas en alturas de pico correspondientes a soluciones acuosas de jugos adicionados a 20,40 y 50 ppb, para $n=10$ y $\alpha=0,05$; en condiciones repetitivas y reproducibles. En cada caso se determinó desviación estándar, 
coeficiente de variación porcentual (RSD \%) y mediante test de Student los intervalos de confianza de la media.

Los resultados obtenidos, tabla 33, permiten establecer que el método es preciso para el intervalo de concentraciones analizado a un nivel de confianza del $95 \%$.

Tabla 33. Precisión - Valores medios expresados en alturas de pico Soluciones acuosas de jugos adicionados a pH $7-\mathrm{CWX} / \mathrm{DVB}-10 \mathrm{~min}$ de extracción $-n=10$ y $\alpha=0,05$

\begin{tabular}{|l|c|c|c|c|}
\hline \multirow{2}{*}{ Analitos } & \multicolumn{4}{|c|}{ Soluciones acuosas de jugos adicionados a $20 \mathrm{ppb}$} \\
\cline { 2 - 5 } & Promedio & $\begin{array}{c}\text { Desviación } \\
\text { estándar }\end{array}$ & RSD \% & $\begin{array}{c}\text { Intervalo de } \\
\text { confianza }\end{array}$ \\
\hline Metiltiofanato & 59772 & 257 & 0,43 & \pm 168 \\
\hline Tiofanato & 72336 & 276 & 0,38 & \pm 198 \\
\hline Thiabendazole & 109005 & 262 & 0,24 & \pm 188 \\
\hline \multirow{2}{*}{ Analitos } & Soluciones acuosas de jugos adicionados a $40 \mathrm{ppb}$ \\
\cline { 2 - 5 } & Promedio & $\begin{array}{c}\text { Desviación } \\
\text { estándar }\end{array}$ & RSD \% & $\begin{array}{c}\text { Intervalo de } \\
\text { confianza }\end{array}$ \\
\hline Metiltiofanato & 117713 & 166 & 0,14 & \pm 116 \\
\hline Tiofanato & 147666 & 167 & 0,11 & \pm 119 \\
\hline Thiabendazole & 214886 & 251 & 0,12 & \pm 180 \\
\hline \multirow{2}{*}{ Analitos } & Soluciones acuosas de jugos adicionados a 50 ppb \\
\cline { 2 - 5 } & Promedio & $\begin{array}{c}\text { Desviación } \\
\text { estándar }\end{array}$ & RSD \% & $\begin{array}{c}\text { Intervalo de } \\
\text { confianza }\end{array}$ \\
\hline Metiltiofanato & 148088 & 149 & 0,10 & \pm 108 \\
\hline Tiofanato & 185189 & 132 & 0,07 & \pm 94 \\
\hline Thiabendazole & 270988 & 218 & 0,08 & \pm 156 \\
\hline
\end{tabular}

\section{$\underline{\text { Recuperación - Jugos cítricos adicionados }}$}

La exactitud del método se determinó para cada analito a partir de quintuplicados de muestras adicionadas a 10, 30 y $50 \mathrm{ppb}$.

El análisis estadístico para todas las observaciones indicó que no existen diferencias significativas entre las medias de las 
recuperaciones a las diferentes concentraciones de los analitos. Los resultados se muestran en la tabla 34.

Tabla 34. Exactitud del método - Soluciones acuosas de jugos adicionados $\mathrm{n}=15$ y $\alpha=0,05$

\begin{tabular}{|l|c|c|c|c|}
\hline \multirow{2}{*}{ Analitos } & \multicolumn{4}{|c}{ Soluciones acuosas de jugos adicionados a 10 ppb } \\
\cline { 2 - 5 } & $\begin{array}{c}\text { Recuperación } \\
\text { media \% }\end{array}$ & $\begin{array}{c}\text { Desviación } \\
\text { estándar }\end{array}$ & RSD \% & $\begin{array}{c}\text { Intervalo de } \\
\text { confianza }\end{array}$ \\
\hline Metiltiofanato & 94,94 & 1,34 & 1,41 & $\pm 0,74$ \\
\hline Tiofanato & 95,46 & 1,24 & 1,30 & $\pm 0,68$ \\
\hline Thiabendazole & 97,62 & 1,16 & 1,19 & $\pm 0,64$ \\
\hline \multirow{2}{*}{ Analitos } & Soluciones acuosas de jugos adicionados a 30 ppb \\
\cline { 2 - 5 } & $\begin{array}{c}\text { Recuperación } \\
\text { media \% }\end{array}$ & $\begin{array}{c}\text { Desviación } \\
\text { estándar }\end{array}$ & RSD \% & $\begin{array}{c}\text { Intervalo de } \\
\text { confianza }\end{array}$ \\
\hline Metiltiofanato & 95,19 & 1,32 & 1,38 & $\pm 0,73$ \\
\hline Tiofanato & 96,56 & 1,26 & 1,30 & $\pm 0,70$ \\
\hline Thiabendazole & 97,92 & 0,56 & 0,58 & $\pm 0,31$ \\
\hline \multirow{2}{*}{ Analitos } & Soluciones acuosas de jugos adicionados a 50 ppb \\
\cline { 2 - 5 } & $\begin{array}{c}\text { Recuperación } \\
\text { media \% }\end{array}$ & $\begin{array}{c}\text { Desviación } \\
\text { estándar }\end{array}$ & RSD \% & $\begin{array}{c}\text { Intervalo de } \\
\text { confianza }\end{array}$ \\
\hline Metiltiofanato & 95,02 & 1,29 & 1,36 & $\pm 0,71$ \\
\hline Tiofanato & 96,07 & 0,71 & 0,74 & $\pm 0,39$ \\
\hline Thiabendazole & 97,71 & 1,01 & 1,03 & $\pm 0,56$ \\
\hline
\end{tabular}

Se determinaron los parámetros estadísticos correspondientes y mediante test de Student, se estableció que no existen diferencias significativas entre la recuperación media y el $100 \%$ para un nivel de confianza del $95 \%$.

Límites de detección y cuantificación - Jugos cítricos adicionados

La sensibilidad del método fue determinada a partir de 10 muestras de soluciones acuosas de jugos adicionados a 10, 20 y $30 \mathrm{ppb}$. En la tabla 35 se indican los límites correspondientes a cada analito expresados en ppb de la solución para un intervalo de confianza del $95 \%$. 
Tabla 35. Límite de detección y cuantificación - Soluciones acuosas de jugos adicionados a pH 7 - CWX/DVB - 10 minutos de extracción - agitación

\begin{tabular}{|l|c|c|}
\multicolumn{1}{|c|}{ Analitos } & $\begin{array}{c}\text { Límite de detección } \\
\text { ppb }\end{array}$ & $\begin{array}{c}\text { Límite de cuantificación } \\
\text { ppb }\end{array}$ \\
\hline Metiltiofanato & 0,11 & 0,24 \\
\hline Tiofanato & 0,09 & 0,20 \\
\hline Thiabendazole & 0,06 & 0,12 \\
\hline
\end{tabular}

Los resultados indican que el método es sensible para la determinación de benzimidazoles en jugos cítricos adicionados por microextracción en fase sólida y cromatografía gaseosa

\section{"Vinos cítricos"}

Según se ha explicitado en el plan de muestreo, los "vinos cítricos" de naranja se diluyeron con agua en una relación de 5:100 v/v ajustando el $\mathrm{pH}$ a 7 . En todo los casos, y previo al proceso extractivo, las muestras se adicionaron con soluciones mezcla de estándares de benzimidazoles.

Los tiempos de retención medios (RT) de los benzimidazoles analizados, para muestras adicionadas con estándares individuales y mezcla de estándares fueron: Metiltiofanato $R T=5,102$; Tiofanato $R T=5,992$ y Thiabendazole $\mathrm{RT}=11,073$.

Los resultados obtenidos a partir de las muestras acuosas de "vinos cítricos" adicionados a 10, 20, 30, 40 y 50 ppb; neutralizadas a $\mathrm{pH} 7, \mathrm{y}$ sometidas al proceso extractivo descrito: 10 minutos de inmersión de la fibra CWX/DVB de $65 \mu \mathrm{m}$ y agitación magnética a 2000 rpm; fueron analizados estadísticamente. 
Se determinó el perfil de masa absorbida en función del tiempo de extracción, la curva de regresión lineal e intervalos de confianza, comparación de las rectas de regresión estándar vs. muestras adicionadas, precisión, recuperación y límites de detección y cuantificación del método.

Perfil de masa absorbida, número total de moles, constante de distribución, volumen mínimo de muestra y coeficiente de difusión - Jugos cítricos adicionados

Se determinó el perfil de masa absorbida a partir de quintuplicados de soluciones acuosas de "vinos cítricos" adicionados con solución mezcla de benzimidazoles a 20 ppb, volumen de muestra de $50 \mathrm{ml}$, agitación magnética a 2000 rpm y tiempos de inmersión de 10, 20, 30, 40, 45, 50, 120, 240, 360 y $720 \mathrm{~min}$. Los resultados se detallan en la tabla 36.

El análisis unidimensional de los datos obtenidos indicó en todos los casos una distribución normal de las observaciones.

El perfil de masa total absorbida en función del tiempo, para cada analito, se muestra en la figura 47. 


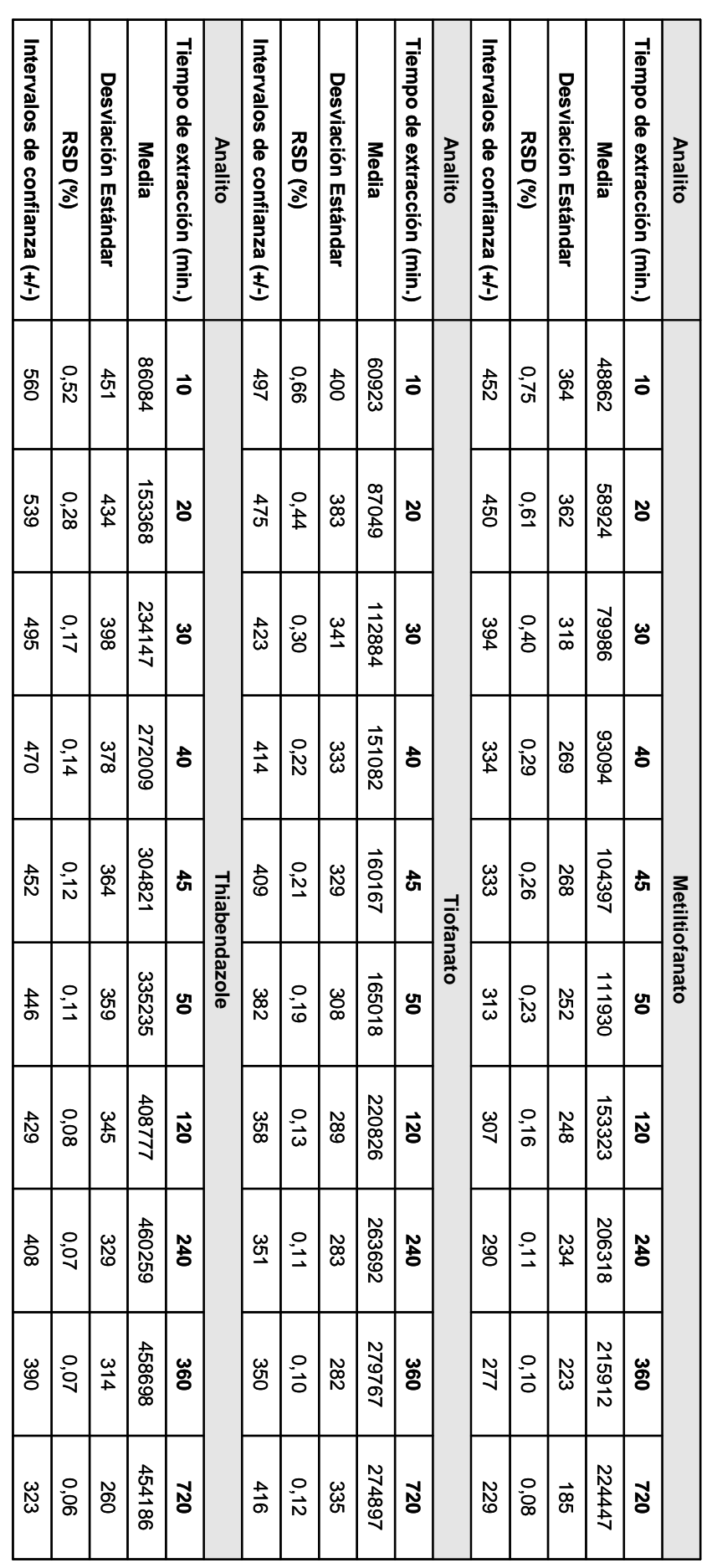

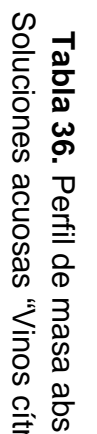

궁. 웅.

은.

올 공

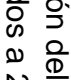

응

음 홍

응 응

을

응 윽

उำ

变

잉 $\frac{\omega}{\omega}$.

근 들.

을. 공

옹. 응.

3

흉

高

공

응 응

흑 옥

$1 \stackrel{0}{د}$

II

응 $\frac{0}{8}$

으으. 


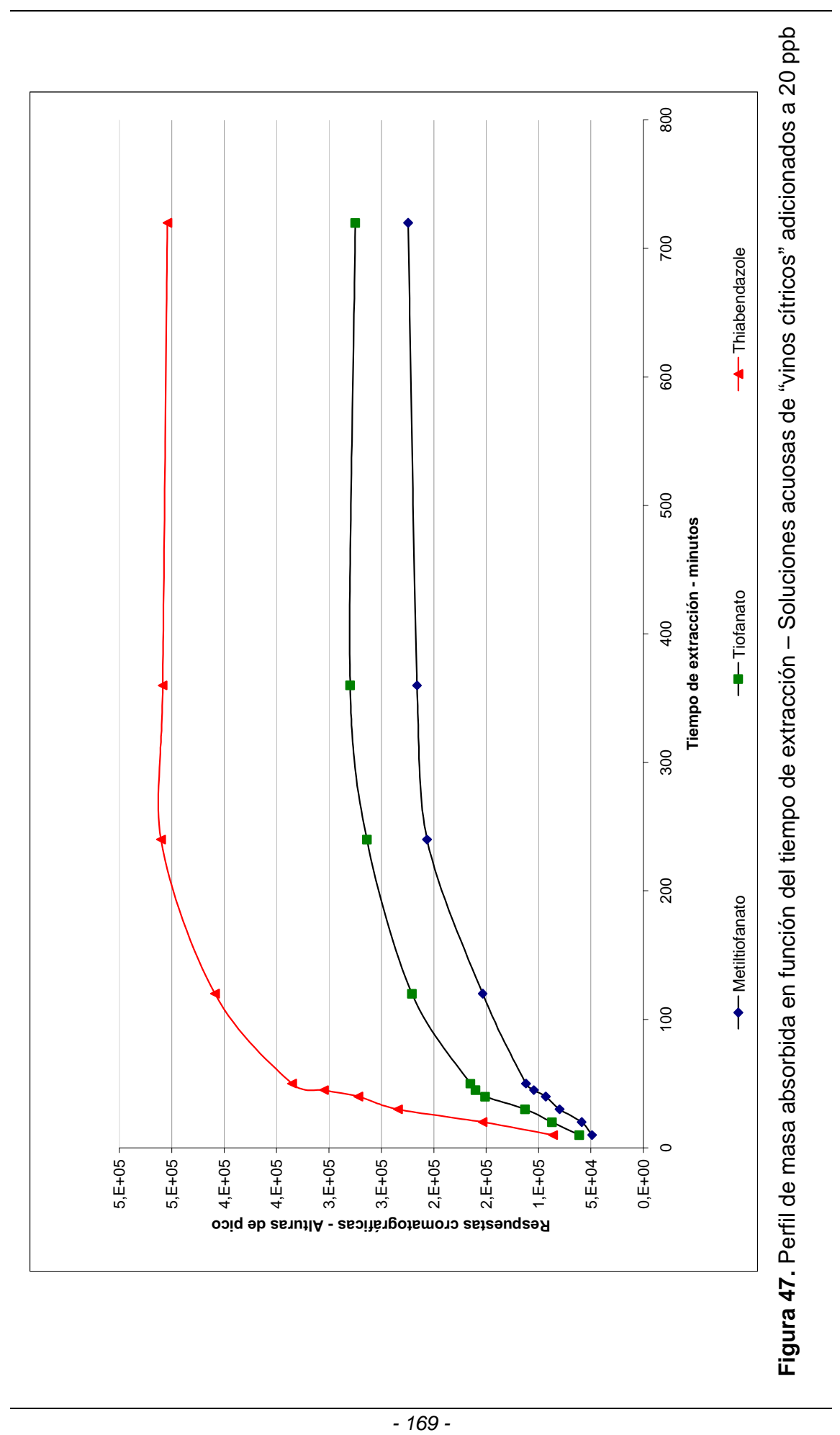


Haciendo las mismas consideraciones que en los casos anteriores se determinó la masa total absorbida para cada analito. Los resultados se muestran en la tabla 37.

Tabla 37. Valores medios comparativos de los analitos expresados en alturas de picos para soluciones de 5 ppm por Inyección directa de $2 \mu$ y "vinos cítricos" adicionados a 20 ppb - 12 horas de inmersión CWX/DVB - agitación magnética

\begin{tabular}{|c|c|c|c|c|}
\hline \multirow{2}{*}{ Analito } & \multicolumn{2}{|c|}{$\begin{array}{r}\text { Inyección Directa } \\
2 \mu \mathrm{lde} 5 \mathrm{ppm}\end{array}$} & \multicolumn{2}{|c|}{$\begin{array}{c}\text { SPME- CWX/DVB } \\
20 \mathrm{ppb} 720 \text { minutos }\end{array}$} \\
\cline { 2 - 5 } & $\begin{array}{c}\text { Promedio } \\
\text { respuesta }\end{array}$ & $\begin{array}{c}\text { masa } \\
\text { inyectada } \\
\text { (ng) }\end{array}$ & $\begin{array}{c}\text { Promedio } \\
\text { respuesta }\end{array}$ & $\begin{array}{c}\text { masa } \\
\text { absorbida } \\
\text { (ng) }\end{array}$ \\
\hline Metiltiofanato & 124883 & 10 & 224447 & 17,96 \\
\hline Tiofanato & 159108 & 10 & 274897 & 17,35 \\
\hline Thiabendazole & 240404 & 10 & 454186 & 18,93 \\
\hline
\end{tabular}

Teniendo en cuenta las especificaciones del CWX/DVB y los pesos moleculares de los analitos evaluados, del mismo modo que en los casos anteriores, se calculó el número total de moles absorbidos $(n)$, constante de distribución $\left(K_{f s}\right)$ de los mismos en el polímero de recubrimiento y volumen mínimo de muestra $\left(V_{s}\right)$, a partir de las ecuaciones (5) $K_{f s}=n . V_{s} / V_{f}\left(C_{0} . V_{s}-n\right)$ y (4) $V_{s}=100 . K_{f s} . V_{f} / E$. Los resultados se indican en la tabla 38.

Tabla 38. Determinación de la Constante de Distribución Polímero de recubrimiento/Agua

\begin{tabular}{|c|c|c|c|c|}
\hline Analitos & $\begin{array}{c}\text { Masa } \\
\text { molecular } \\
\text { (ng) }\end{array}$ & $\begin{array}{c}\text { Número de } \\
\text { moles } \\
\text { absorbidos }\end{array}$ & $\begin{array}{c}\boldsymbol{C}_{\boldsymbol{o}} \\
\text { (moles/l) }\end{array}$ & $\boldsymbol{K}_{\boldsymbol{f s}}$ \\
\hline Metiltiofanato & $3,42710^{11}$ & $5,2410^{-11}$ & $5,8410^{-11}$ & 6894 \\
\hline Tiofanato & $3,704510^{11}$ & $4,6810^{-11}$ & $5,4010^{-11}$ & 6656 \\
\hline Thiabendazole & $2,012610^{11}$ & $9,4110^{-11}$ & $9,9410^{-11}$ & 7273 \\
\hline
\end{tabular}


El coeficiente de difusión de los analitos en el absorbente se determinó a partir de la curva del perfil para un $95 \%$ de masa absorbida considerando un error $(E)$ del $5 \%$, despejando $D_{f}$ en la ecuación (3) $t_{e}=t_{95 \%}=(b-a)^{2} / 2 D_{f}$.

Los tiempos correspondientes a un $95 \%$ de masa absorbida $\left(t_{95 \%}\right)$ para los distintos analitos fueron:

$$
\begin{aligned}
& \text { Metiltiofanato } t_{95 \%}=290 \mathrm{~min} \\
& \text { Tiofanato } t_{95 \%}=229 \mathrm{~min} \\
& \text { Thiabendazole } t_{95 \%}=163 \mathrm{~min}
\end{aligned}
$$

Los resultados correspondientes se muestran en tabla 39.

Tabla 39. Volumen limitante de muestra y coeficiente de difusión analito/ CWX/DVB - "Vinos cítricos" adicionados a 20 ppb - inmersión 12 h y agitación

\begin{tabular}{|c|c|c|c|c|}
\hline Analitos & $\boldsymbol{K}_{\boldsymbol{f s}}$ & $\begin{array}{c}\boldsymbol{V}_{\boldsymbol{f}} \\
\mathbf{( m )}\end{array}$ & $\begin{array}{c}\text { Tiempo } \\
\mathbf{t}_{\mathbf{9 5}} \mathbf{( \mathbf { m i n } )}\end{array}$ & $\begin{array}{c}\boldsymbol{D}_{\boldsymbol{f}} \\
\left(\mathbf{c m}^{\mathbf{2}} / \mathbf{s e g}\right)\end{array}$ \\
\hline Metiltiofanato & 6894 & 18,3 & 290 & $1,2110^{-9}$ \\
\hline Tiofanato & 6656 & 17,7 & 229 & $1,5410^{-9}$ \\
\hline Thiabendazole & 7273 & 19,3 & 163 & $2,1610^{-9}$ \\
\hline
\end{tabular}

A los fines prácticos se estableció para la determinación de los restantes parámetros estadísticos, un tiempo de extracción para el análisis de 10 min.

\section{Linealidad - "Vinos cítricos" adicionados}

Los resultados obtenidos a partir de 10 muestras de soluciones acuosas de "Vinos cítricos" adicionados con mezcla de estándares a 10, 20, 30, 40, y 50 ppb se detallan en la tabla 40. 
Tabla 40. Análisis unidimensional - Respuestas cromatográficas expresadas en altura de pico - Soluciones acuosas "Vinos cítricos" adicionados - CWX/DVB $50 \mathrm{ml}$ muestra - agitación magnética a $2000 \mathrm{rpm}-\mathrm{n}=10, \alpha=0,05$

\begin{tabular}{|c|c|c|c|c|c|}
\hline Analito & \multicolumn{5}{|c|}{ Metiltiofanato } \\
\hline Concentración (ppb) & 10 & 20 & 30 & 40 & 50 \\
\hline Altura Media & 23831 & 48727 & 71934 & 95961 & 120724 \\
\hline Desviación Estándar & 231 & 191 & 168 & 132 & 123 \\
\hline RSD \% & 0,97 & 0,39 & 0,23 & 0,14 & 0,10 \\
\hline Intervalo de confianza +/- & 165 & 137 & 120 & 94 & 88 \\
\hline Analito & \multicolumn{5}{|c|}{ Tiofanato } \\
\hline Concentración (ppb) & 10 & 20 & 30 & 40 & 50 \\
\hline Altura Media & 31690 & 61174 & 93391 & 123979 & 155543 \\
\hline Desviación Estándar & 233 & 163 & 156 & 151 & 137 \\
\hline RSD \% & 0,74 & 0,27 & 0,17 & 0,12 & 0,09 \\
\hline Intervalo de confianza +/- & 167 & 117 & 111 & 108 & 98 \\
\hline Analito & \multicolumn{5}{|c|}{ Thiabendazole } \\
\hline Concentración (ppb) & 10 & 20 & 30 & 40 & 50 \\
\hline Altura Media & 42782 & 86090 & 128699 & 170507 & 214740 \\
\hline Desviación Estándar & 214 & 209 & 205 & 200 & 191 \\
\hline RSD \% & 0,50 & 0,24 & 0,16 & 0,12 & 0,09 \\
\hline Intervalo de confianza +/- & 153 & 150 & 147 & 143 & 136 \\
\hline
\end{tabular}

El análisis unidimensional indicó una distribución normal de las observaciones para todos los analitos a las diferentes concentraciones evaluadas.

La figura 48 muestra el cromatograma obtenido para una muestra de "vino cítrico" adicionado con solución de estándares a 10 ppb en el cual se puede apreciar la separación de los analitos en función de sus tiempos de retensión. 


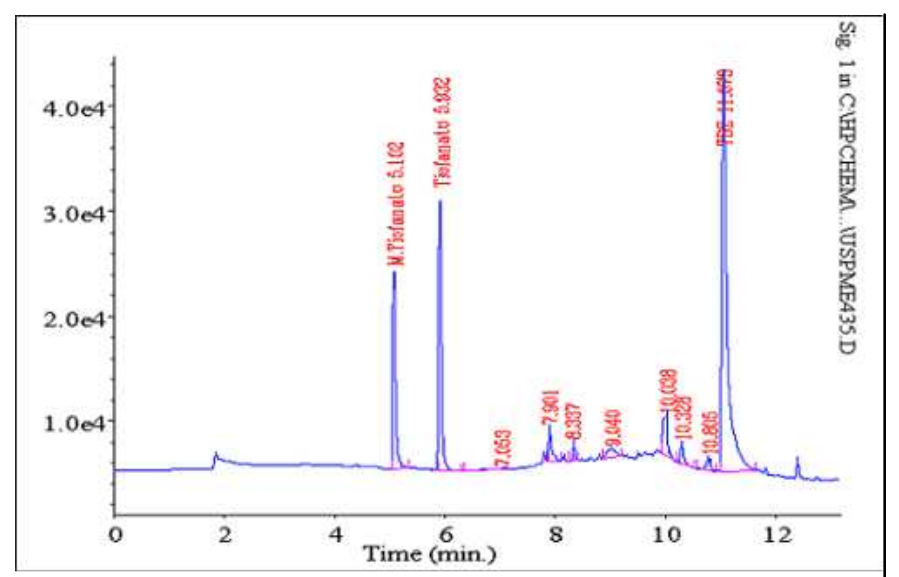

Figura 48. Cromatograma - Solución acuosa de "Vino cítrico" adicionado con estándares de benzimidazoles a $10 \mathrm{ppb}$ y pH 7 - CWX/DVB - $10 \mathrm{~min}$ de extracción - agitación magnética a 2000 rpm

Las curvas de regresión lineal correspondientes a soluciones acuosas de "vinos cítricos" adicionadas a las concentraciones y condiciones establecidas se muestran en la figura 49.

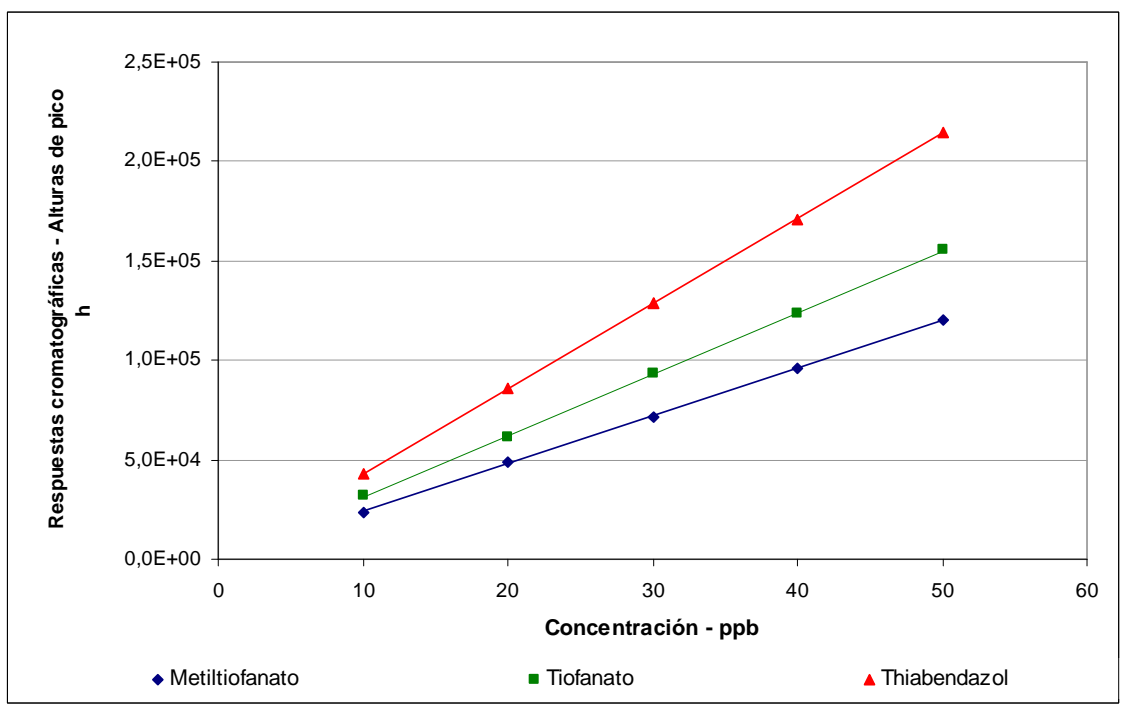

Figura 49. Regresión lineal - Soluciones acuosas de "vinos cítricos" adicionados a pH 7 - CWX/DVB - 10 min de extracción - agitación magnética 2000 rpm 
Las ecuaciones del modelo ajustado para cada analito fueron:

$\mathrm{h}_{\text {Metilitiofanato }}=-70+2410 \mathrm{ppb}$ Metilitiofanato

Coeficiente de Correlación $=0,999928$

$R^{2}=99,9855 \%$

$\mathrm{h}_{\text {Tiofanato }}=2+3105 \mathrm{ppb}$ Tiofanato

Coeficiente de Correlación $=0,999917$

$R^{2}=99,9835 \%$

$\mathrm{h}_{\text {Thiabendazole }}=64+4283 \mathrm{ppb}$ Thiabendazole

Coeficiente de Correlación $=0,999962$

$R^{2}=99,9924 \%$

Donde:

$\mathrm{h}=$ respuestas cromatográficas expresadas en alturas de pico.

$\mathrm{ppb}=$ concentración expresadas en partes por billón 0 $\mu \mathrm{g} / \mathrm{l}$

Las figuras 50,51 y 52 muestran las rectas de regresión para cada analito con indicación de los límites de confianza y de predicción correspondientes. 


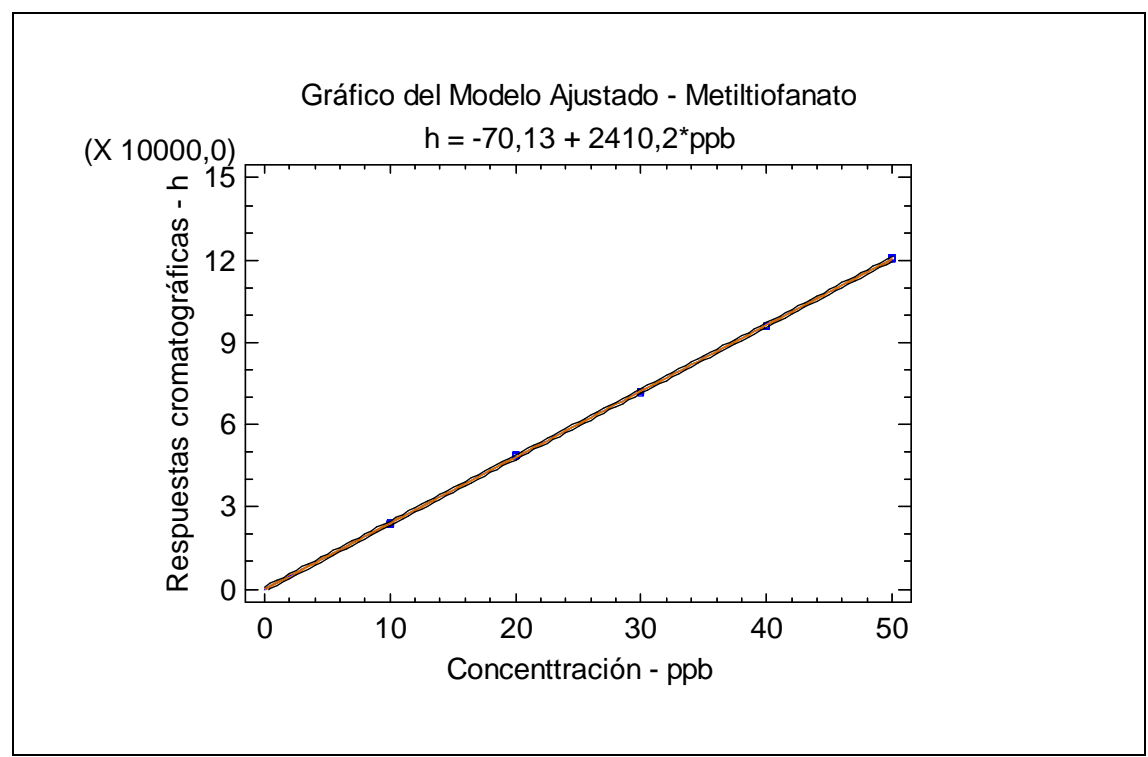

Figura 50. Regresión lineal - Metiltiofanato - Soluciones acuosas "Vinos cítricos" adicionados a pH 7 - CWX/DVB - 10 min de extracción - agitación magnética

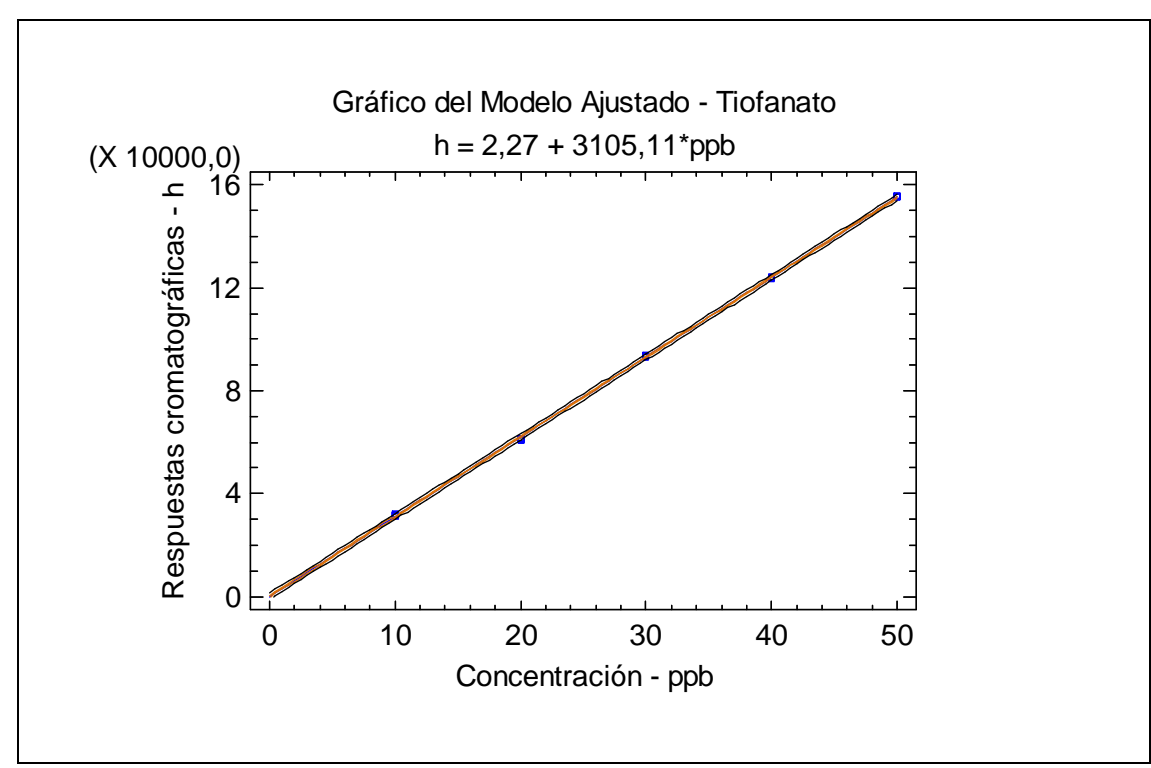

Figura 51. Regresión lineal - Tiofanato - Soluciones acuosas "Vinos cítricos" adicionados a pH 7 - CWX/DVB - 10 min de extracción - agitación magnética 


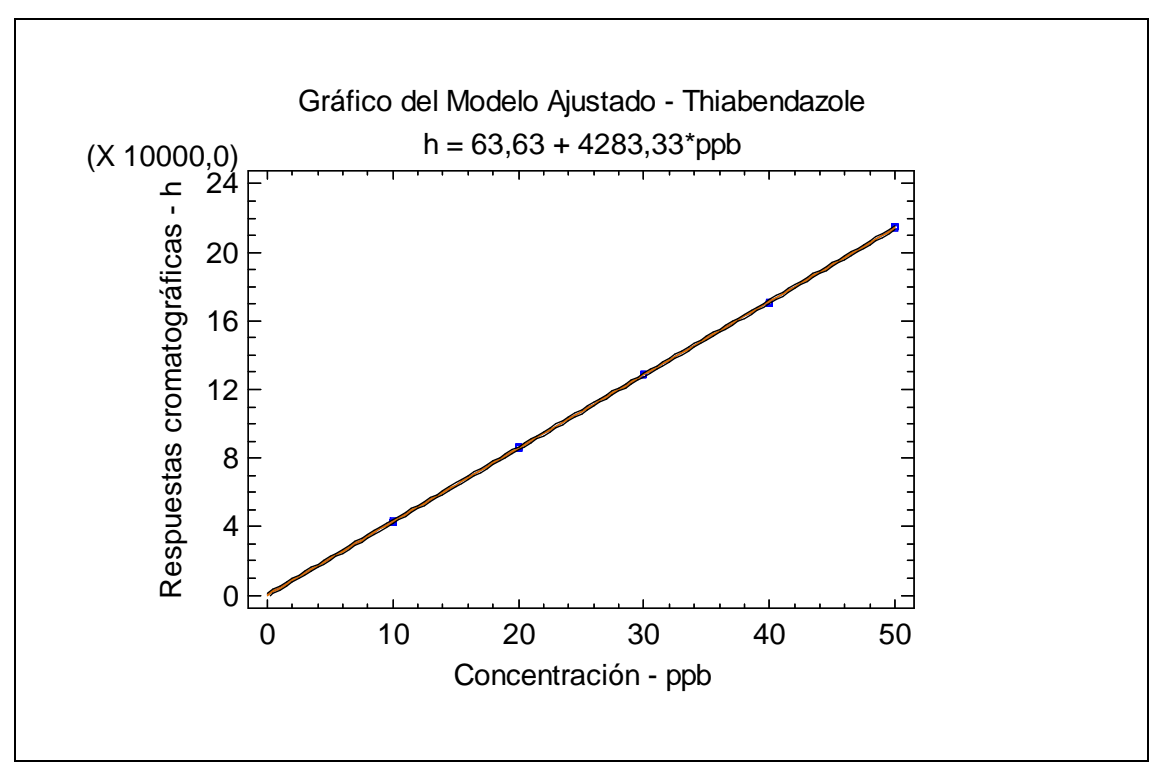

Figura 52. Regresión lineal - Thiabendazole - Soluciones acuosas "Vinos cítricos" adicionados a pH 7 - CWX/DVB - 10 min de extracción - agitación magnética

El análisis de varianza (ANOVA) indicó que existe en todos los casos una relación estadísticamente significativa entre las respuestas cromatográficas (alturas de pico) y la concentración (ppb) con un nivel de confianza del 95,0\%.

El estadístico $R^{2}$ y el coeficiente de correlación muestran para los distintos analitos un ajuste lineal entre las variables.

En todos los casos se establecieron los valores predichos de las respuestas cromatográficas para el modelo ajustado y los residuos correspondientes.

Los estadísticos Durbin Watson y Kolmogorov permitieron establecer la independencia de los residuos y una distribución normal de los mismos para un nivel de confianza del $95 \%$. 
Comparación de rectas de regresión - Estándares vs. "vinos cítricos" adicionados

Se realizó el análisis comparativo de las rectas de regresión correspondiente a soluciones acuosas de estándares y "vinos cítricos" adicionadas a fin de establecer si existe efecto matriz y definir la metodología de calibración del método.

Las gráficas comparativas de las rectas de regresión para cada analito se muestran en las figuras 53,54 y 55 . En la tabla 41 se detallan para cada analito las pendientes y ordenadas al origen de las rectas de regresión correspondientes a soluciones de estándares y muestras adicionadas.

Gráficas Comparativas de Modelos Ajustados para Metiltiofanato (X 10000,0)

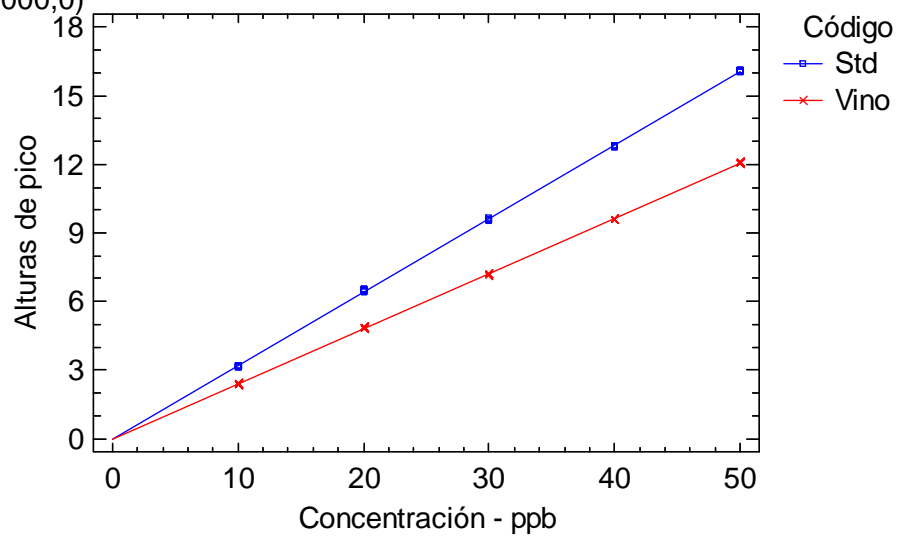

Figura 53. Comparación de rectas de regresión - Metiltiofanato - Soluciones acuosas de estándares y "Vinos cítricos" adicionados a pH 7 - CWX/DVB - 10 min de extracción - agitación magnética a 2000 rpm 


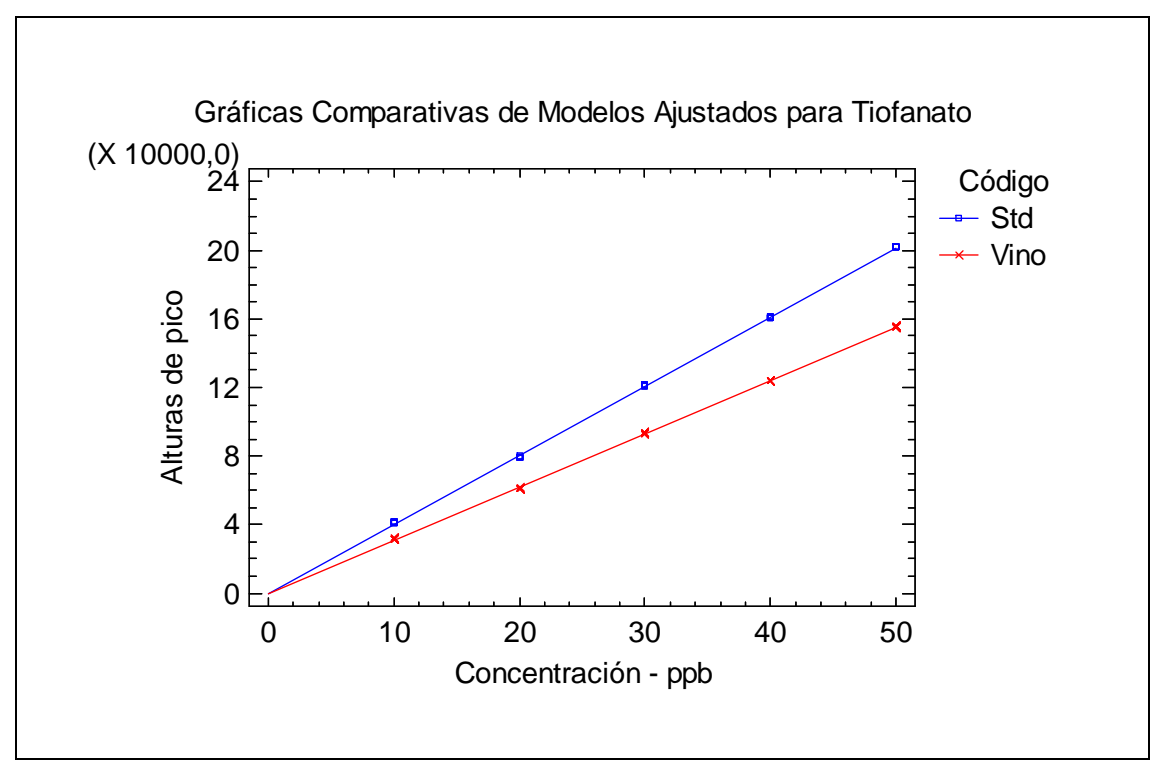

Figura 54. Comparación de rectas de regresión - Tiofanato - Soluciones acuosas de estándares y "Vinos cítricos" adicionados a pH 7 - CWX/DVB - 10 min de extracción - agitación magnética a 2000 rpm

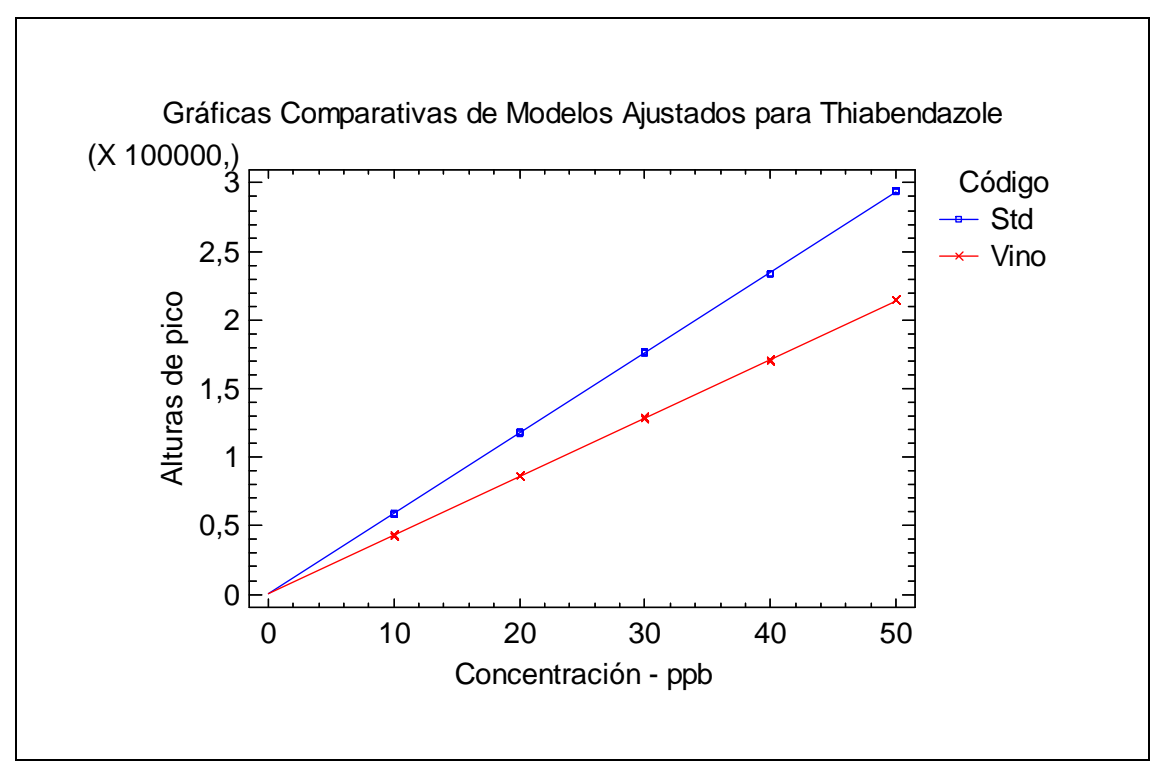

Figura 55. Comparación de rectas de regresión - Thiabendazole - Soluciones acuosas de estándares y "Vinos cítricos" adicionados a pH 7 - CWX/DVB - 10 min de extracción - agitación magnética a 2000 rpm 
Tabla 41. Interceptos y pendientes - Rectas de regresión - Soluciones acuosas de estándares y "Vinos cítricos" adicionados

\begin{tabular}{|c|c|c|c|c|c|c|}
\hline \multirow{2}{*}{ Matriz } & \multicolumn{2}{|c|}{ Metiltiofanato } & \multicolumn{2}{c|}{ Tiofanato } & \multicolumn{2}{c|}{ Thiabendazole } \\
\cline { 2 - 7 } & Intercepto & Pendiente & Intercepto & Pendiente & Intercepto & Pendiente \\
\hline $\begin{array}{c}\text { Soluciones } \\
\text { estándares }\end{array}$ & -94 & 3214 & 3 & 4033 & 87 & 5868 \\
\hline $\begin{array}{c}\text { "Vinos } \\
\begin{array}{c}\text { Cítricos" } \\
\text { adicionados }\end{array}\end{array}$ & -70 & 2410 & 2 & 3105 & 64 & 4283 \\
\hline
\end{tabular}

Mediante test ANOVA, dado que el Valor-P resultó menor que 0,01 en todos los casos, se determinó que existen diferencias estadísticamente significativas entre los puntos de corte y pendientes de las curvas correspondientes a soluciones estándares y "vinos cítricos" adicionados, para todos los analitos con un $99 \%$ de nivel de confianza.

Los resultados demuestran efecto matriz relevante, por lo que para la determinación de benzimidazoles en "vinos cítricos" mediante esta metodología, es necesario efectuar calibración previa con muestras adicionadas.

\section{$\underline{\text { Precisión - "vinos cítricos" adicionados }}$}

Se determinó precisión a partir de los datos de las respuestas cromatográficas expresadas en alturas de pico correspondientes a soluciones acuosas de "vinos cítricos" adicionados a 20, 40 y $50 \mathrm{ppb}$, para $n=10$ y $\alpha=0,05$; en condiciones repetitivas y reproducibles. En cada caso se determinó desviación estándar, coeficiente de variación porcentual (RSD \%) y mediante test de Student los intervalos de confianza de la media. 
Los resultados obtenidos para cada analito y concentración, se muestran en la tabla 42. Los mismos permiten establecer que el método es preciso para el intervalo de concentraciones analizado a un nivel de confianza del $95 \%$.

Tabla 42. Precisión - Valores medios expresados en alturas de pico Soluciones acuosas de "vinos cítricos" adicionados a pH $7-C W X / D V B-10 \mathrm{~min}$ de extracción - agitación magnética $-\mathrm{n}=10$ y $\alpha=0,05$

\begin{tabular}{|l|c|c|c|c|}
\hline \multirow{2}{*}{ Analitos } & \multicolumn{4}{|c|}{ Soluciones acuosas de vinos adicionados a 20 ppb } \\
\cline { 2 - 5 } & Promedio & $\begin{array}{c}\text { Desviación } \\
\text { estándar }\end{array}$ & RSD \% & $\begin{array}{c}\text { Intervalo de } \\
\text { confianza }\end{array}$ \\
\hline Metiltiofanato & 48727 & 191 & 0,39 & \pm 137 \\
\hline Tiofanato & 61174 & 163 & 0,27 & \pm 117 \\
\hline Thiabendazole & 86090 & 209 & 0,24 & \pm 150 \\
\hline \multirow{3}{*}{ Analitos } & Soluciones acuosas de vinos adicionados a $40 \mathrm{ppb}$ \\
\cline { 2 - 5 } & Promedio & $\begin{array}{c}\text { Desviación } \\
\text { estándar }\end{array}$ & RSD \% & $\begin{array}{c}\text { Intervalo de } \\
\text { confianza }\end{array}$ \\
\hline Metiltiofanato & 95961 & 132 & 0,14 & \pm 94 \\
\hline Tiofanato & 123979 & 151 & 0,12 & \pm 108 \\
\hline Thiabendazole & 170507 & 200 & 0,12 & \pm 143 \\
\hline \multirow{3}{*}{ Analitos } & Soluciones acuosas de vinos adicionados a 50 ppb \\
\cline { 2 - 5 } & Promedio & $\begin{array}{c}\text { Desviación } \\
\text { estándar }\end{array}$ & RSD \% & $\begin{array}{c}\text { Intervalo de } \\
\text { confianza }\end{array}$ \\
\hline Metiltiofanato & 120724 & 123 & 0,10 & \pm 88 \\
\hline Tiofanato & 155543 & 137 & 0,09 & \pm 98 \\
\hline Thiabendazole & 214740 & 191 & 0,09 & \pm 136 \\
\hline
\end{tabular}

\section{$\underline{\text { Recuperación - "vinos cítricos" adicionados }}$}

La exactitud se determinó para cada analito a partir de quintuplicados de muestras adicionadas a 10, 30 y 50 ppb.

El análisis estadístico de los resultados para todas las observaciones indicó que no existen diferencias significativas entre las medias de las recuperaciones a las diferentes concentraciones de los analitos. Los resultados se muestran en la tabla 43. 
Tabla 43. Exactitud del método - Soluciones acuosas de "Vinos cítricos" adicionados $-n=15$ y $\alpha=0,05$

\begin{tabular}{|c|c|c|c|c|}
\hline \multirow[b]{2}{*}{ Analitos } & \multicolumn{4}{|c|}{ Soluciones acuosas de vinos adicionados a $10 \mathrm{ppb}$} \\
\hline & $\begin{array}{c}\text { Recuperación } \\
\text { media \% }\end{array}$ & $\begin{array}{c}\text { Desviación } \\
\text { estándar }\end{array}$ & RSD \% & $\begin{array}{c}\text { Intervalo de } \\
\text { confianza }\end{array}$ \\
\hline Metiltiofanato & 95,52 & 0,77 & 0,80 & $\pm 0,42$ \\
\hline Tiofanato & 97,35 & 0,79 & 0,82 & $\pm 0,44$ \\
\hline Thiabendazole & 94,83 & 1,25 & 1,31 & $\pm 0,69$ \\
\hline \multirow{2}{*}{ Analitos } & \multicolumn{4}{|c|}{ Soluciones acuosas de vinos adicionados a 30 ppb } \\
\hline & $\begin{array}{c}\text { Recuperación } \\
\text { media \% }\end{array}$ & $\begin{array}{c}\text { Desviación } \\
\text { estándar }\end{array}$ & RSD \% & $\begin{array}{c}\text { Intervalo de } \\
\text { confianza }\end{array}$ \\
\hline Metiltiofanato & 94,83 & 1,25 & 1,31 & $\pm 0,69$ \\
\hline Tiofanato & 96,04 & 0,90 & 0,94 & $\pm 0,50$ \\
\hline Thiabendazole & 97,45 & 0,80 & 0,82 & $\pm 0,44$ \\
\hline \multirow[b]{2}{*}{ Analitos } & \multicolumn{4}{|c|}{ Soluciones acuosas de vinos adicionados a 50 ppb } \\
\hline & $\begin{array}{c}\text { Recuperación } \\
\text { media \% }\end{array}$ & $\begin{array}{c}\text { Desviación } \\
\text { estándar }\end{array}$ & RSD \% & $\begin{array}{c}\text { Intervalo de } \\
\text { confianza }\end{array}$ \\
\hline Metiltiofanato & 95,13 & 0,77 & 0,81 & $\pm 0,42$ \\
\hline Tiofanato & 96,17 & 0,77 & 0,80 & $\pm 0,43$ \\
\hline Thiabendazole & 97,11 & 0,63 & 0,65 & $\pm 0,35$ \\
\hline
\end{tabular}

Se determinaron los parámetros estadísticos correspondientes y mediante test de Student, se estableció que no existen diferencias significativas entre la recuperación media y el $100 \%$ para un nivel de confianza del $95 \%$.

Límites de detección y cuantificación - "vinos cítricos" adicionados

La sensibilidad del método fue determinada a partir de 10 muestras de soluciones acuosas de "vinos cítricos" adicionados a 10, 20 y $30 \mathrm{ppb}$. En la tabla 44 se indican los límites correspondientes a cada analito expresados en ppb $\circ \mu \mathrm{g} / \mathrm{l}$ de la solución para un intervalo de confianza del $95 \%$.

Los resultados indican que el método es sensible para la determinación de benzimidazoles en "vinos cítricos" adicionados por microextracción en fase sólida y cromatografía gaseosa 
Tabla 44. Límite de detección y cuantificación - Soluciones acuosas de "vinos cítricos" adicionados a pH 7 - CWX/DVB - 10 min de extracción - agitación

\begin{tabular}{|l|c|c|}
\multicolumn{2}{|c|}{ magnética a $2000 \mathrm{rpm}-\mathrm{n}=30$ y $\alpha=0,05$} \\
\hline Analitos & $\begin{array}{c}\text { Límite de detección } \\
\mathbf{p p b}\end{array}$ & $\begin{array}{c}\text { Límite de cuantificación } \\
\mathbf{p p b}\end{array}$ \\
\hline Metiltiofanato & 0,15 & 0,29 \\
\hline Tiofanato & 0,11 & 0,23 \\
\hline Thiabendazole & 0,08 & 0,17 \\
\hline
\end{tabular}

\section{Aplicación de la metodología a muestras de empaque e industria}

Optimizada la metodología para la determinación de multiresiduos de benzimidazoles por SPME/GC/NPD, se aplicó la misma a muestras provenientes de empaque e industria.

\section{Futas cítricas de empaque}

Frutas tratadas en empaque, correspondientes a la variedad naranja valencia, fueron procesadas por quintuplicado y analizadas del modo descrito.

Tal como se indica en el plan de muestreo, se realizaron 3 muestreos, identificados como 1,2 y 3 ; en forma aleatoria de 3 empaques de la región, identificados como E1, E2 y E3. Los muestreos se efectuaron durante las temporadas agrícolas 2008 y 2009. Para cada muestreo del lote se tomaron, a intervalos de 120 minutos en la línea de empaque, muestras de 25 unidades.

Se prepararon las muestras de laboratorio a partir de la totalidad de las unidades individuales, las cuales en el momento de su recepción se trituraron en procesadora hasta obtener una 
mezcla homogénea y se combinaron para formar una muestra compuesta.

La muestra compuesta fue fraccionada, rotulada y conservada en freezer hasta su posterior tratamiento para el análisis en el laboratorio.

Se efectuó la reconstitución y homogeneización de la muestra compuesta y se tomaron para el análisis por quintuplicado porciones de aproximadamente $5 \mathrm{~g}$, a los cuales se adicionó agua grado 1 hasta un volumen próximo a $100 \mathrm{ml}$. Las mezclas se agitaron y sonificaron por 5 minutos y luego centrifugaron a 4000 rpm durante 10 minutos. Cada sobrenadante se filtró a través de papel de filtro y el filtrado se llevó a un volumen final de $100 \mathrm{ml}$ ajustando el $\mathrm{pH}$ a 7 con solución de $\mathrm{NaOH} 0,1 \mathrm{~N}$ y posterior filtrado con membrana de $0,45 \mu \mathrm{m}$ de poro.

Teniendo en cuenta los niveles habituales de residuos de los plaguicidas analizados en la matriz de análisis y los correspondientes Límites Máximos Permitidos de Residuos (LMRs), se efectúan diluciones de las muestras a fin de lograr que las concentraciones de las mismas se encuentren comprendidas en el intervalo lineal de calibración con frutas adicionadas.

Las muestras se sometieron al proceso de extracción descrito y las respuestas cromatográficas obtenidas en alturas de pico se procesaron estadísticamente.

A partir de las curvas de calibración correspondientes, se determinaron en todos los casos los valores de concentración de los analitos en las soluciones acuosas. La concentración de los 
mismos en las muestras se determinó considerando el peso de fruta procesada $(5 \mathrm{~g})$ y las diluciones correspondientes.

En la tabla 45 se detallan las concentraciones medias de residuos, en $\mathrm{mg} / \mathrm{Kg}$ obtenidas para las diferentes muestras de cada empaque en las temporadas agrícolas evaluadas.

Tabla 45. Concentraciones medias de residuos benzimidazólicos, en mg/Kg Frutas cítricas de empaques - Temporadas agrícolas 2008 y 2009.

\begin{tabular}{|c|l|c|c|c|c|c|c|}
\hline \multirow{3}{*}{ Muestreo } & \multirow{2}{*}{ Analito } & \multicolumn{3}{|c|}{ Año 2008 } & \multicolumn{3}{c|}{ Año 2009 } \\
\cline { 3 - 8 } & & E1 & E2 & E3 & E1 & E2 & E3 \\
\hline \multirow{3}{*}{$\mathbf{1}$} & Metiltiofanato & 1,70 & $\mathrm{~N} / \mathrm{D}$ & 2,10 & 1,80 & $\mathrm{~N} / \mathrm{D}$ & $\mathrm{N} / \mathrm{D}$ \\
\cline { 2 - 8 } & Tiofanato & $\mathrm{N} / \mathrm{D}$ & $\mathrm{N} / \mathrm{D}$ & $\mathrm{N} / \mathrm{D}$ & $\mathrm{N} / \mathrm{D}$ & $\mathrm{N} / \mathrm{D}$ & $\mathrm{N} / \mathrm{D}$ \\
\cline { 2 - 8 } & Thiabendazole & 3,53 & 3,19 & $\mathrm{~N} / \mathrm{D}$ & 3,96 & 4,46 & 4,95 \\
\hline \multirow{3}{*}{$\mathbf{2}$} & Metiltiofanato & $\mathrm{N} / \mathrm{D}$ & $\mathrm{N} / \mathrm{D}$ & 1,79 & $\mathrm{~N} / \mathrm{D}$ & $\mathrm{N} / \mathrm{D}$ & 1,70 \\
\cline { 2 - 8 } & Tiofanato & $\mathrm{N} / \mathrm{D}$ & $\mathrm{N} / \mathrm{D}$ & 1,61 & $\mathrm{~N} / \mathrm{D}$ & $\mathrm{N} / \mathrm{D}$ & $\mathrm{N} / \mathrm{D}$ \\
\cline { 2 - 8 } & Thiabendazole & 4,00 & 4,62 & $\mathrm{~N} / \mathrm{D}$ & 4,35 & 4,25 & 3,75 \\
\hline \multirow{3}{*}{3} & Metiltiofanato & 1,70 & $\mathrm{~N} / \mathrm{D}$ & 1,70 & $\mathrm{~N} / \mathrm{D}$ & $\mathrm{N} / \mathrm{D}$ & $\mathrm{N} / \mathrm{D}$ \\
\cline { 2 - 8 } & Tiofanato & $\mathrm{N} / \mathrm{D}$ & $\mathrm{N} / \mathrm{D}$ & $\mathrm{N} / \mathrm{D}$ & $\mathrm{N} / \mathrm{D}$ & $\mathrm{N} / \mathrm{D}$ & $\mathrm{N} / \mathrm{D}$ \\
\cline { 2 - 8 } & Thiabendazole & 3,33 & 3,82 & 4,32 & 5,19 & 3,93 & 4,64 \\
\hline
\end{tabular}

$\mathrm{N} / \mathrm{D}=$ no detecta

E1, E2, E3 = Empaques 1, 2 y 3, respectivamente

En las figuras 56 y 57 se muestran los cromatogramas correspondientes a dos muestras de diferentes empaques y temporadas agrícolas. En los mismos pueden observarse los picos correspondientes a los analitos detectados en las muestras correspondientes.

Se realizó para cada muestra y analito el análisis unidimensional de los datos correspondientes a las concentraciones expresadas en $\mathrm{mg} / \mathrm{Kg}$ de fruta, para $\mathrm{n}=5 \mathrm{y}$ $\alpha=0,05$ y se determinó en cada caso la desviación estándar, 
coeficiente de variación e intervalo de confianza. Los resultados se muestran en la tabla 46.

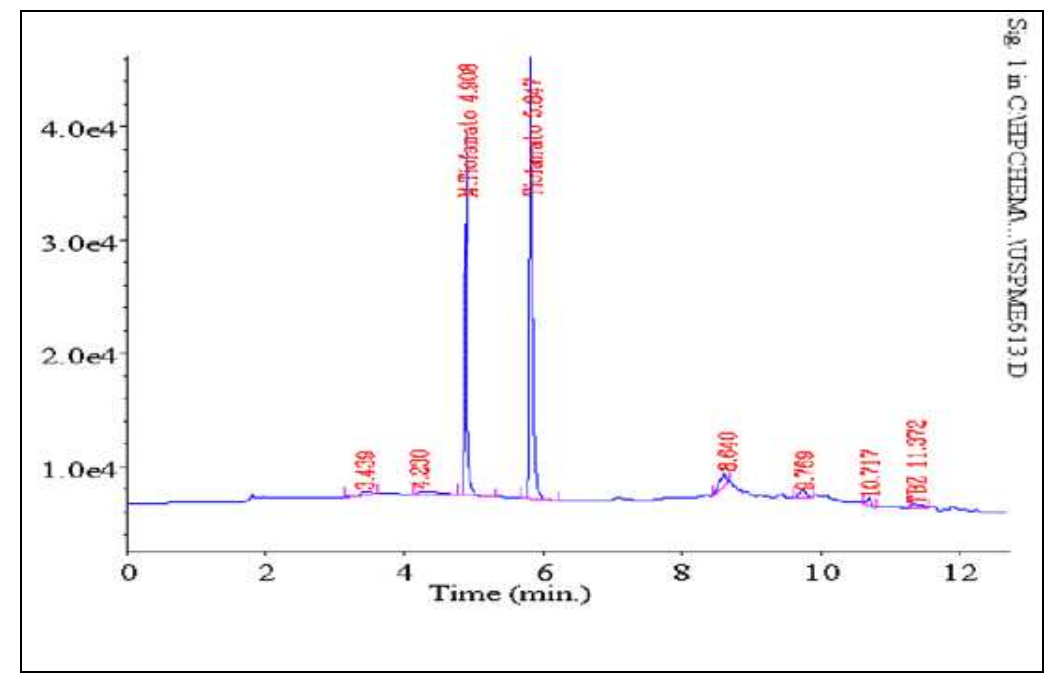

Figura 56. Cromatograma Metiltiofanato y Tiofanato - Fruta de Empaque Muestreo 2 - Empaque E3 - Cosecha 2008 - CWX/DVB - GC/NPD

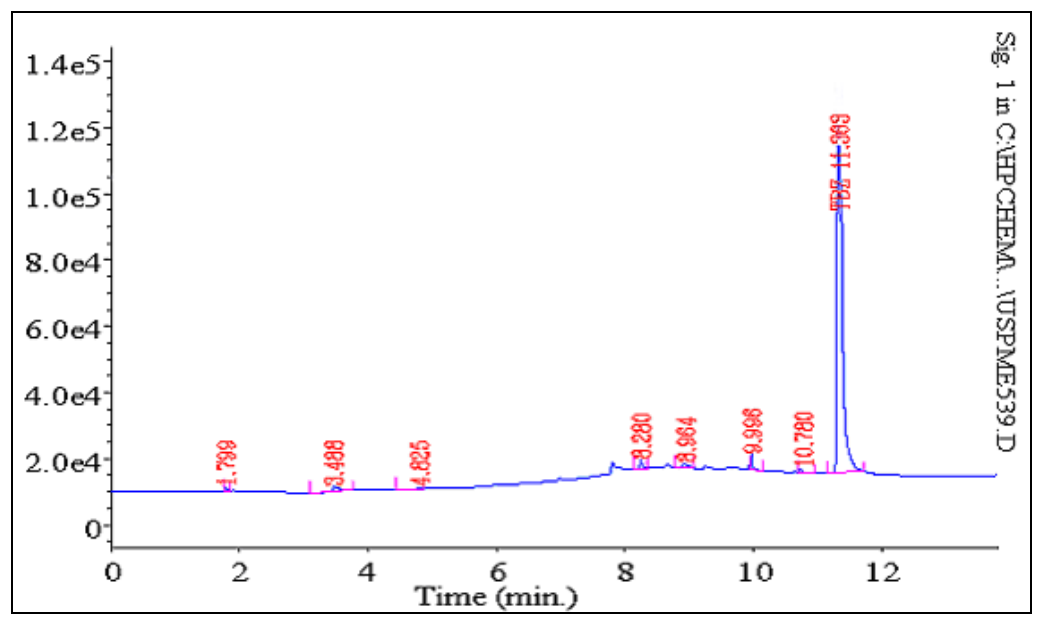

Figura 57. Cromatograma Thiabendazole - Fruta de Empaque - Muestreo 1 Empaque E1 - Cosecha 2009 - CWX/DVB - GC/NPD 
En todos los casos el análisis unidimensional indicó una distribución normal de los datos, encontrándose los coeficientes de variación dentro del intervalo esperado para el tipo de muestras analizadas. Como puede observarse, todas las muestras presentan residuos de fungicidas benzimidazólicos, variando la clase y combinación de los mismos.

Los resultados para las diferentes temporadas presentan en su mayoría valores aceptables de residuos, no superando los Límites Máximos Permitidos de Residuos (LMRs) correspondientes a la legislación nacional, que corresponden a $10 \mathrm{ppm}$ para thiabendazole y $2 \mathrm{ppm}$ para tiofanato y metiltiofanato (SENASA, 2003).

Los niveles residuales de thiabendazole por debajo de 5 ppm o mg/l en la mayoría de las muestras analizadas, se deben factiblemente a un ajuste a las normas internacionales, particularmente de la Unión Europea, que establece esta concentración como LMRs para dicho fungicida (InfoAgro, 2008).

Si se comparan ambas temporadas agrícolas, se denota una tendencia a la aplicación de thiabendazole por sobre el metiltiofanato y tiofanato, para todos los empaques.

Los resultados fueron compatibles con los datos de trazabilidad suministrados, siendo la variabilidad de los mismos (RSD\%) adecuada para el tipo de muestras analizadas. 


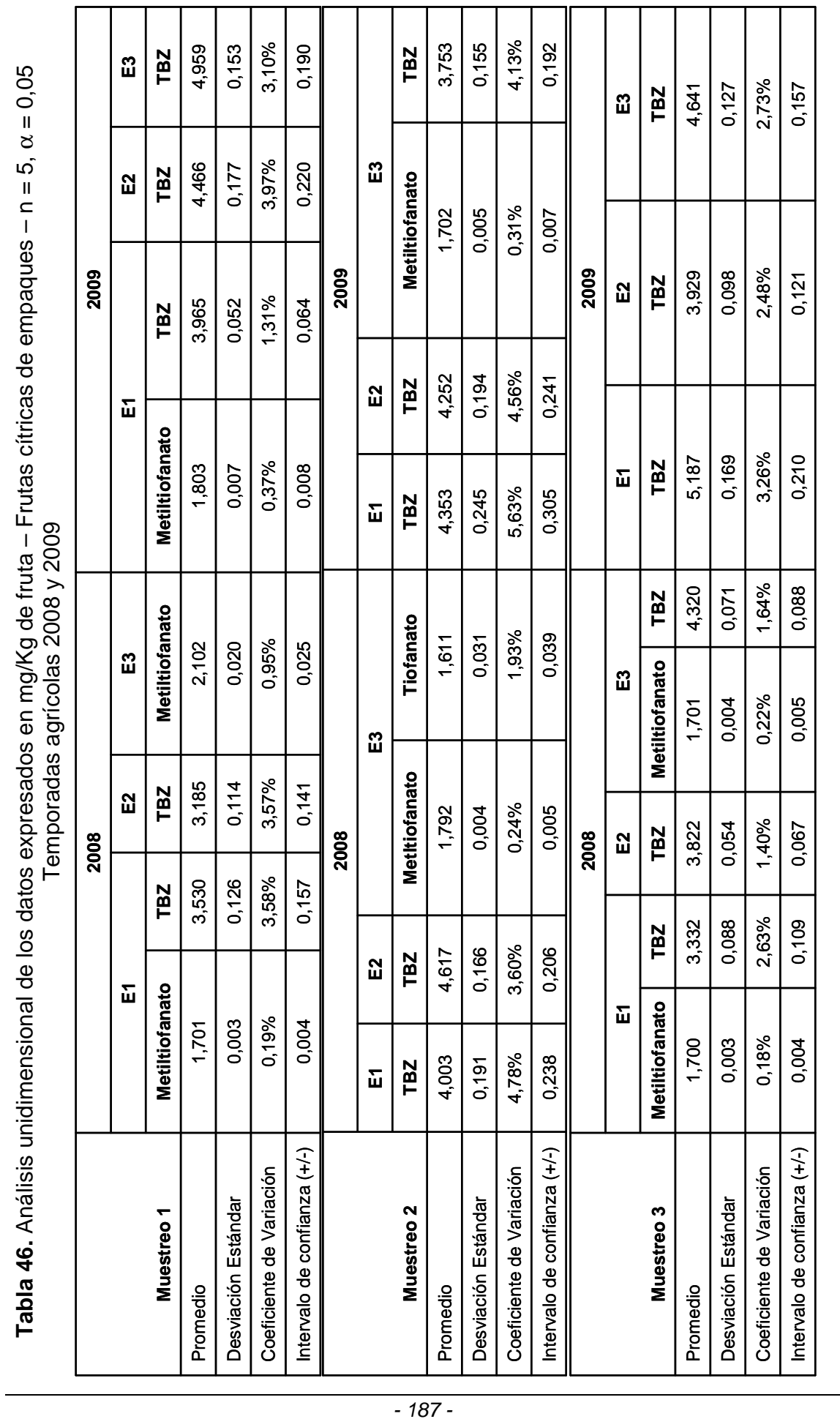




\section{Jugos concentrados de naranja provenientes de la industria}

Las muestras de jugo concentrado de naranja provenientes de diferentes plantas industriales fueron procesadas por quintuplicado y analizadas del modo descrito.

Tal como se indica en el plan de muestreo, las muestras fueron tomadas al azar a partir de muestras recibidas en carácter de servicios, en el Laboratorio de Investigación de Residuos de Plaguicidas en Alimentos de la Facultad de Ciencias de la Alimentación.

El muestreo se realizó durante dos años: 2009 y 2010, seleccionándose 35 muestras por año que se identificaron con números consecutivos del 1 al 35 .

Las muestras, de aproximadamente 65 Brix, fueron diluidas con agua grado 1 en una relación de $5 \mathrm{~g}$ en $100 \mathrm{ml}$, se agitaron y sonicaron durante 5 minutos, filtrándose a través de papel de filtro. El filtrado se llevó a un volumen final de $100 \mathrm{ml}$ ajustando el $\mathrm{pH}$ a 7 con solución de $\mathrm{NaOH} 0,1 \mathrm{~N}$. El volumen total de muestra se filtró a través de membrana de 0,45 $\mu \mathrm{m}$ poro, sometiéndose las mismas al proceso extractivo descrito.

Con el fin de incrementar la sensibilidad del método se partió de un peso inicial de muestra de $20 \mathrm{~g}$, se incrementó el tiempo de extracción a 30 minutos y se calibró con muestras adicionadas a $1,0-2,5-5,0-10,0-15,0$ y 20,0 ppb $\circ \mu \mathrm{g} / \mathrm{l}$.

Las muestras de jugo concentrado y las muestras adicionadas se procesaron del mismo modo que en el caso anterior. 
Se determinaron las curvas de regresión lineal a partir de las respuestas cromatográficas obtenidas para muestras adicionadas. Se realizó el análisis unidimencional correspondiente y se determinó en cada caso la desviación estándar, coeficiente de variación e intervalo de confianza.

A partir de las respuestas cromatográficas obtenidas en alturas de pico y las curvas de calibración correspondientes, se determinaron los valores de concentración de los analitos en las soluciones acuosas de jugo sometidas al proceso extractivo.

La concentración de los mismos en las muestras, expresados en $\mu \mathrm{g} / \mathrm{Kg}$ de jugo concentrado, se determinó en función del peso de jugo procesado (20 g).

Los datos se procesaron estadísticamente, para cada muestra se realizó el análisis unidimensional de los datos correspondientes a las concentraciones expresadas en $\mu \mathrm{g} / \mathrm{Kg}$ de fruta, para $n=5$ y $\alpha=0,05$ y se determinó en cada caso la desviación estándar, coeficiente de variación e intervalo de confianza.

Los resultados indicaron presencia de TBZ en 12 de las 35 muestras analizadas correspondientes al muestreo 2009, y 10 de las 35 muestras correspondientes al 2010, no registrándose presencia de residuos de metiltiofanato y tiofanato en ninguno de los casos.

En los jugos de naranja concentrados muestreados y analizados en el 2010, se detectaron en algunas muestras niveles residuales de TBZ a concentraciones sensiblemente menores al año anterior. Los resultados correspondientes se indican en la tabla 47. 


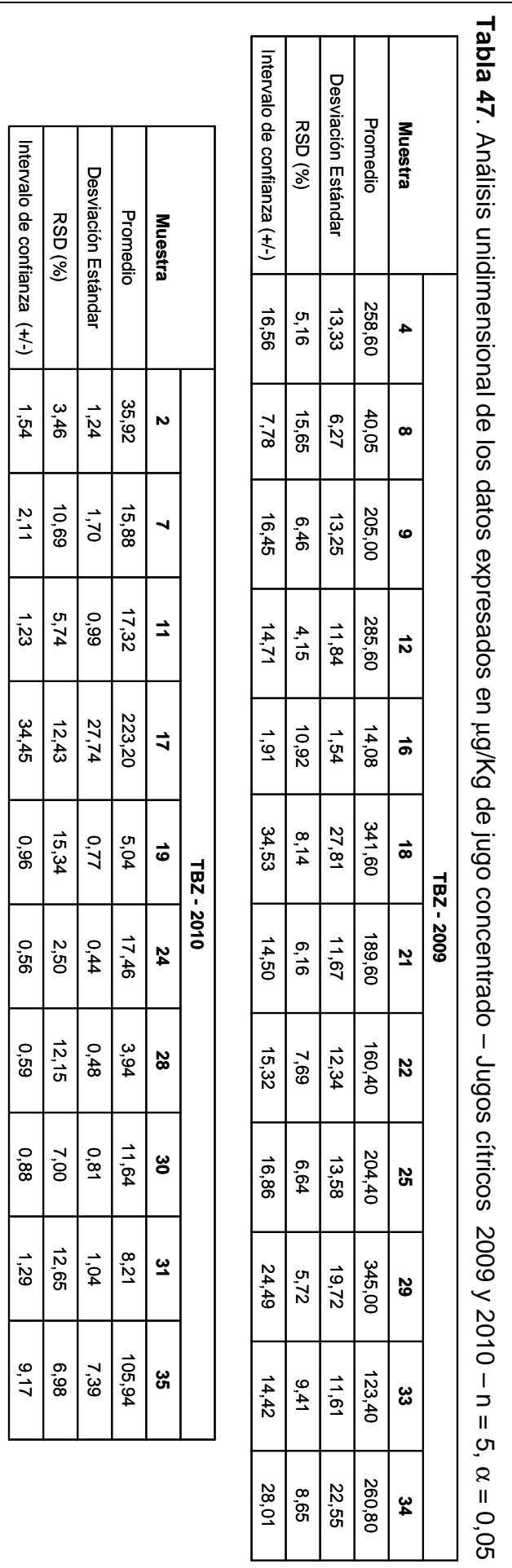

- 190 - 
En todos los casos el análisis unidimensional de los datos obtenidos indicó una distribución normal, encontrándose los coeficientes de variación dentro de los valores esperados para el tipo de muestras analizadas. Los resultados fueron concordantes con los datos de trazabilidad, respecto a las frutas de ingreso en linea de producción.

La diferencia en los niveles residuales en los jugos es debida posiblemente al origen de las frutas al ingreso de la línea en la industria.

Esto ocurre habitualmente ya que muchas veces se procesan en las industrias frutas que han sido tratadas en el "drencher" o en la línea de empaque con diferentes dosis y concentraciones de fungicidas, lo que genera una diferencia en la carga inicial de residuos en frutas que ingresan en la línea de producción de jugos.

Los niveles de residuos de TBZ que se han detectado, en investigaciones previas (Montti et al., 1998; Gerard et al., 2000), en fruta tratada en línea de empaque se encuentran en un rango de 3,5 a $4,9 \mathrm{mg} / \mathrm{kg}$ fruta entera, siendo diferente para fruta tratada en drencher que oscilan entre 0,1 y $0,45 \mathrm{mg} / \mathrm{kg}$ de fruta entera.

Por otra parte los diferentes tipos de aplicaciones en la línea de empaque, en soluciones acuosas antes del encerado de las frutas o junto con las ceras al agua, si bien no modifican el contenido residual de los fungicidas en las frutas recientemente tratadas, inciden en la persistencia de los mismos, ya que las ceras bloquean la mayoría de los fungicidas con ciertas propiedades de liposolubilidad, la cual además es favorecida por el alto contenido de aceites esenciales de la corteza de los frutos. 
El lavado, como etapa en la línea de proceso en la industria que tiende a dismunir la carga inicial en fruta, no alcanza a eliminar la totalidad de los residuos, generando un contenido residual variable en productos industriales.

En virtud de lo explicitado, surge la posibilidad de que los niveles detectados en jugos concentrados tengan cierta correlación con las diferentes cargas iniciales de residuos en las frutas procesadas en la industria.

Sin embargo es necesario destacar que en la industria los volúmenes de muestras procesadas diariamente son grandes y es posible que muchas veces se mezclen diferentes lotes de la misma variedad, generando una gran variabilidad de los resultados en los jugos.

Por otra parte, es peciso considerar que otras industrias utilizan frutas sin tratamientos previos con fungicidas, ya que disponen de plantaciones propias o controladas que les permite obtener productos libres de estos residuos. Generalmente esta producción de jugos es destinada a los mercados internacionales.

Finalmente es importante mencionar que la mezcla de lotes de jugos concentrados con diferentes contenidos residuales de plaguicidas, constituye una práctica industrial destinada a ajustar los niveles de sus productos a los límites permitidos por la legislación tanto nacional como internacional. 


\subsection{DETERMINACIÓN MULTIRESIDUO DE BENZIMIDAZOLES POR MICROEXTRACCIÓN EN FASE SÓLIDA Y CROMATOGRAFÍA GASEOSA CON DETECTOR DE MASA (SMPE/GC/MSD)}

\section{Generalidades}

La espectrometría de masas constituye uno de los medios analíticos de aplicación más generalizada, que aporta información cuali y cuantitativa acerca de la composición atómica y molecular de materiales orgánicos e inorgánicos (Balizs, 1999; Blasco et al., 2002, Albero et al., 2005; Codex Alimentarius, 2005).

La principal ventaja de la espectrometría de masa radica en su especificidad para la identificación de compuestos desconocidos o la confirmación de la presencia de compuestos en una preparación.

Por otra parte, presenta una elevada sensibilidad que resulta principalmente de la acción del sistema analizador como un filtro de masa-carga que reduce las interferencias de fondo, así como de la sensibilidad de los detectores multiplicadores de electrones que se utilizan.

Si bien los detectores de masas son altamente sensibles, su sensibilidad resulta muchas veces inferior a los detectores específicos como por ejemplo el de nitrógeno-fósforo. La excelente especificidad de la espectrometría de masa se debe a 
los patrones de fragmentación característicos, los cuales aportan información acerca del peso y de la estructura molecular (Van Bramer, 1998). La espectrometría de alta resolución aporta información relativa a las composiciones elementales de iones y sus fragmentos. En muchos casos, junto con las informaciones de las espectrometrías de infrarrojo, ultravioleta/visible y resonancias magnéticas nuclear, se puede arribar a la identificación definitiva o a la elucidación estructural de compuestos químicos (Van Bramer, 1998; Codex Alimentarius, 2005; Leandro et al., 2007).

Dada la menor sensibilidad del sistema de detección de masas, respecto a otros detectores específicos, algunos equipos suelen incorporar sistemas de inyección de vaporización con temperatura programada (PTV) que permiten incrementar los volúmenes de inyección de muestra y por lo tanto la magnitud de las respuestas cromatográficas, lo que implica una importante ventaja para la determinación de plaguicidas a niveles traza.

Sin embargo es necesario establecer y optimizar algunas de las múltiples variables que inciden sobre la eficiencia de la metodología para la detección e identificación cromatográfica (Mol et al., 1996; Stan \& Linkerhägner, 1996; Engewald et al., 1999; Hada et al., 2000; Heiden et al., 2001; Zrostlíková et al., 2001; Concha-Graña et al., 2002; Teske y Engewald, 2002; Smith, R., 2003). Las inyecciones múltiples se efectúan programando el muestreador automático acoplado al PTV y controlado desde la "ChemStation".

Este tipo de inyector presenta ventajas relevantes respecto a otros sistemas de inyección de muestra, ya que aporta nuevas alternativas operativas que permiten (Stan \& Linkerhägner, 1996; 
Engewald et al., 1999): el calentamiento del inyector con rampas de temperatura adicionales, la refrigeración del inyector, la utilización del modo "split/splitless" con introducción de muestra tanto en frío como en caliente, el empleo del modo con división a pulsos ("pulsed splits") o del modo sin división a pulsos ("pulsed splitless"), la utilización del modo venteo de solvente para inyectar grandes volúmenes de muestra y posibilitar su concentración en el "liner".

Los aportes de la espectrometría de masas y el PTV al sistema cromatográfico posibilitan la confirmación de la presencia de los analitos evaluados en las matrices de estudio (Veneziano et al., 2004; Codex Alimentarius, 2005; Danaher et al., 2007), permitiendo verificar la efectiva extracción de los mismos de las diferentes muestras.

\section{Materiales y método}

\section{Reactivos}

Etilacetato, Acetonitrilo, Diclorometano y Metanol (Merck) calidad cromatográfica (gaseosa). Cartuchos rellenos con $0,5 \mathrm{~g}$ de Adsorbente Diol (Alltech)

Estándares certificados de thiabendazole, metiltifanato y tiofanato (Accu Standard Inc.).

Agua grado 1. Hidróxido de sodio, $\mathrm{MgSO}_{4}$ y $\mathrm{Na}_{2} \mathrm{SO}_{4}$ anhidro. $\mathrm{NaCl}$ (Anedra). 


\section{Equipamiento}

Cromatógrafo gaseoso Hewlett Packard GC 6890, equipado con dos sistemas de inyección: inyector automático "split/splitless" e inyector de vaporización con temperatura programada (PTV), muestreador automático HP 7683, columna capilar HP5 MS (30 m x 0,25 mm x 0,25u m). Detector selectivo de masa HP 5973. "ChemStation" HP. Biblioteca NIST y RTLPest.

Equipo E. Pure - Barnstead, para la obtención de agua grado 1.

Agitador magnético Mistral Large Magnestir II - Lab Line Mod 1170-1, y baño de ultrasonido NEY-Dental International con controles ajustables.

Fibras de sílica fundida recubierta con carbowax/divinilbenceno (CW/DVB); marca Supelco de $65 \mu \mathrm{m}$. Se empleó como soporte de la fibra una Jeringa SPME marca Supelco y un soporte de muestreo manual SPME para 8 viales de $4 \mathrm{ml}$ y un adaptador para viales de mayor volumen.

Balanza analítica Ohaus, Freezer electrolux, Centrífugas Gelec 130-D y Gelec G-142-D. Procesadora Ultracomb.

Filtros de papel Double Ring 101 y fritz 0,45 $\mu$ Alltech.

Colector al vacío ("Vacuum Manifold") Altech.

\section{Preparación de estándares}

Se prepararon soluciones estándares individuales y mezcla de metiltiofanato, tiofanato y thiabendazole, a concentración de 1 y 
10 ppm o mg/l en etilacetato, para la selección y optimización de las condiciones cromatográficas.

Para el análisis cualitativo de muestras sometidas al proceso extractivo por SPME, se prepararon soluciones acuosas de mezcla de estándares a $50 \mathrm{ppb} \circ \mu \mathrm{g} / \mathrm{l}$ neutralizadas a pH 7 con hidróxido de sodio.

\section{Muestreo, submuestreo y preparación de las muestras}

Las muestras analizadas con el fin de corroborar la efectiva separación de los analitos, correspondieron a las indicadas en el desarrollo de la metodología por SPME, por lo que el plan de muestreo, submuestreo y preparación de las muestras en el laboratorio, corresponde al indicado oportunamente en el ítem 1.2 - Determinación Multiresiduo de benzimidazoles por Microextracción en Fase Sólida y Cromatografía Gaseosa con Detector de Nitrógeno-Fósforo (SMPE/GC/NPD).

Las muestras analizadas fueron:

- Fruta: naranja valencia

- Jugo concentrado de naranja

- "Vino cítrico" de naranja: producto obtenido por fermentación alcohólica de jugo de naranja.

Se destinaron al análisis cualitativo por SPME/GC/MSD, triplicados de cada tipo de muestra adicionada con mezcla de estándares a $50 \mathrm{ppb}$.

Para la identificación de los analitos por PTV modo Venteo de Solvente y GC-MSD, se analizaron muestras de frutas, jugos, "vinos cítricos" y aceites esenciales de naranja, los cuales fueron 
extraídos aplicando una modificación del método QuEChERS (Quick, Easy, Cheap, Effective, Rugged \& Safe). Este método desarrollado en el Departamento de Agricultura de Estados Unidos, aprobado por la AOAC (Método 2007.01) y en Europa bajo prEN-15662, es un proceso de dos etapas: extracción y clean-up.

\section{Condiciones cromatográficas}

Condiciones cromatográficas GC/MSD - PTV modo splitsplitless

Utilizando el sistema de inyección PTV en modo "splitsplitless" se establecieron las condiciones cromatográficas, se obtuvieron los datos espectroscópicos de los analitos testeados, los cuales se compararon con la información disponible en el "software" de la biblioteca NIST y RTLPest.

Se determinaron los tiempos de retención (RT) de los analitos y se seleccionaron los iones característicos para cada compuesto, identificándose los "target ión" o ión principal y los iones "qualifiers" o iones calificadores.

Los iones "qualifiers" se seleccionaron desde el espectro de masa del compuesto, ya que la incorporación de estos iones otorga mayor información al software, al comparar las cantidades relativas de los mismos respecto al "target ion", logrando una mejor identificación del compuesto (Codex Alimentarius, 2005). Los mismos se determinaron a partir de soluciones de estándares en etilacetato a 10 ppm, inyección de $2 \mu$, cromatrografía gaseosa 
y espectrometría de masas (en modo SCAN y PTV en modo "splits/splitless").

La identificación de los analitos permitió la continuidad del desarrollo metodológico para la optimización de las condiciones por GC-MSD-PTV en modo venteo de solvente.

\section{Condiciones cromatográficas GC/MSD - PTV modo venteo de} solvente

Se establecieron condiciones cromatográficas previas, a fin de optimizar los parámetros del inyector en modo venteo de solvente. Tales condiciones comprendieron el flujo de venteo del solvente, tiempo de purga, velocidad de calentamiento, volumen de muestra por inyección y número de inyecciones en un programa de inyecciones múltiples (Bosboom et al., 1996; Mol et al., 1996; Van Hout et al., 1999). Las condiciones se optimizaron inyectando soluciones de estándares de metiltiofanato, tiofanato, y thiabendazole de 1 ppm en etilacetato.

Respecto a la temperatura inicial, rampa y temperatura final de inyector, se establecieron diferentes rampas de temperatura del inyector (Hada et al., 2000), para una temperatura inicial de $50^{\circ} \mathrm{C}$ y una final de $300^{\circ} \mathrm{C}$, evaluándos e en cada caso las respuestas cromatográficas en altura de pico.

Una vez optimizada la velocidad de calentamiento del inyector, se evaluaron las respuestas cromatográficas a diferentes velocidades de flujo de venteo: 75, 100, 120, 180 y $200 \mathrm{ml} / \mathrm{min}$.

Para determinar volumen, número e intervalo de inyección en el programa de inyecciones múltiples, fue necesario establecer 
ciertas consideraciones respecto a la capacidad del volumen del "inlet", ya que volúmenes elevados en cada inyección podrían saturar al mismo; además el número elevado de inyecciones en el modo de venteo de solvente, puede producir pérdidas de los analitos por arrastre y consecuentemente, en ambos casos, una menor respuesta cromatográfica (Gonzalez y Nardillo, 1999).

El intervalo entre inyecciones se vincula con las características fisicoquímicas del solvente, la retención de los analitos en el "inlet" y del venteo del solvente (Grob \& Biedermann, 1996). Esto implica que el intervalo debe ser tal que asegure un adecuado venteo del solvente sin pérdida de analitos entre cada inyección.

Para determinar el volumen de inyección, número de inyecciones e intervalo entre inyección en el programa de inyecciones múltiples, se inyectaron volúmenes de 2; 3 y $5 \mu \mathrm{l}$ de muestra para $4 ; 5$ y 6 inyecciones con intervalos de $2 ; 3 ; 4$ y 6 segundos.

El tiempo de purga del inyector se establece en función del tiempo de transferencia de la muestra, debiendo ser ligeramente superior al mismo a fin de evitar pérdidas de analitos (Zrostlíková, 2001). El tiempo de transferencia adoptado fue de 2 min y el de purga de 2,5 min.

Los ensayos de optimización se llevaron a cabo por triplicado de soluciones estándares individuales y mezcla de estándares en etilacetato. 


\section{Condiciones cromatográficas SPME/GC/MSD}

Para la identificación de los analitos por microextracción en fase sólida (SPME) y cromatografía gaseosa con espectrometría de masas (GC/MSD), se utilizó el otro puerto de inyección disponible en el cromatógrafo y se procedió al cambio del "inlet" adecuado para esta metodología. Los ensayos se efectuaron teniendo en cuenta los datos obtenidos previamente en la metodología de GC/MSD-PTV, respecto al "ión target" e iones "qualifiers" de cada analito en cuestión.

Las condiciones cromatográficas fueron similares a las establecidas para GC/MSD-PTV en modo venteo de solvente, realizando los ajustes necesarios para la adecuada desorción de los analitos desde la fibra en el inyector. En este sentido fue necesario ajustar el tiempo de "splitless" y la temperatura inicial del horno.

\section{Condiciones de extracción}

Las condiciones de extracción de los analitos a partir de soluciones mezcla de estándares y muestras adicionadas, corresponden a las seleccionadas y optimizadas en el ítem 1.2 Determinación Multiresiduo de benzimidazoles por Microextracción en Fase Sólida y Cromatografía Gaseosa con Detector de Nitrógeno-Fósforo (SMPE/GC/NPD); las cuales se resumen a continuación: 
- Condiciones del medio: soluciones acuosas de estándares y muestras adicionadas neutralizadas a $\mathrm{pH} 7$ con hidróxido de sodio.

- Polímero de recubrimiento: carbowax/divinilbenceno (CWX/DVB) de $65 \mu \mathrm{m}$.

- Volumen de muestra: $50 \mathrm{ml}$

- Sistema de agitación: agitación magnética a 2000 rpm.

- Tiempo de inmersión: 10 minutos.

La preparación de frutas, jugos, "vinos cítricos" y aceites esenciales para la identificación de los analitos por PTV modo Venteo de Solvente y GC-MSD, se llevó a cabo el método QuEChERS con modificaciones.

Se pesan aproximadamente $20 \mathrm{~g}$ de muestra, a las que se adiciona $2 \mathrm{~g}$ de $\mathrm{NaCl}$ y $10 \mathrm{~g}$ de $\mathrm{MgSO}_{4}$, se homogeniza la mezcla en vortex durante 5 minutos y posteriormente se extrae con $20 \mathrm{ml}$ de $\mathrm{CH}_{2} \mathrm{CL}_{2}$ en baño de ultrasonido. Se separa la fase orgánica y se repite el proceso extractivo. Las fracciones del extracto son filtradas con papel de filtro y $2 \mathrm{~g}$ de $\mathrm{Na}_{2} \mathrm{SO}_{4}$ anhidro. El filtrado obtenido es transferido a la columna de Diol activada previamente con el mismo solvente. Posteriormente se lava la misma con $5 \mathrm{ml}$ de $\mathrm{CH}_{2} \mathrm{Cl}_{2}$ y se lleva a sequedad. Los analitos son eluídos con acetonitrilo hasta un volumen final de $25 \mathrm{ml}$. Para muestras de frutas que pueden tener mayores niveles residuales de estos fungicidas se efectúa una dilución previa a la determinación cromatográfica, de modo tal de lograr que su concentración se encuentre comprendida dentro del rango lineal. 


\section{Resultados y discusión}

\section{Condiciones cromatográficas}

Condiciones cromatográficas GC/MSD - PTV modo splitsplitless

Las experiencias con el inyector PTV en modo "Splitsplitless", permitiron determinar los tiempos de retención de los analitos correspondientes y la selección de los iones característicos para cada compuesto, identificándose los "target ión" y los iones "qualifiers", los cuales se indican en la tabla 48.

Tabla 48. Benzimidazoles - GC/MSD - PTV en modo "split/splitles"

\begin{tabular}{|c|c|c|c|c|}
\hline Compuesto & $\begin{array}{c}\text { Peso } \\
\text { Molecular }\end{array}$ & $\begin{array}{c}\text { Tiempo de } \\
\text { retención } \\
\text { (min) }\end{array}$ & $\begin{array}{c}\text { Ion } \\
\text { "target” } \\
\text { (m/z) }\end{array}$ & $\begin{array}{c}\text { Iones } \\
\text { “qualifiers" } \\
\text { (m/z) }\end{array}$ \\
\hline Metiltiofanato & 342,70 & 6,66 & 191 & $105-132-159$ \\
\hline Tiofanato & 370,45 & 6,83 & 205 & $105-133-160$ \\
\hline Thiabendazole & 201,26 & 7,29 & 201 & 174 \\
\hline
\end{tabular}

Los resultados de las respuestas cromatográficas obtenidos a partir de los ensayos efectuados, permitieron establecer finalmente las condiciones más adecuadas para la determinación de los analitos, siendo las mismas:

- Cromatógrafo Gaseoso HP 6890N. Detector selectivo de masa HP5973N. Columna Agilent HP - 5MS 0,25 mm x $30 \mathrm{~m} \mathrm{x}$ $0,25 \mu \mathrm{m}$. Interface a temperatura de $280^{\circ} \mathrm{C}$. Gas car rier: Helio $99,9995 \%$ de pureza que previamente pasa a través de 
trampa de humedad e hidrocarburos. Velocidad de flujo: $1 \mathrm{ml} / \mathrm{min}$. Presión: 7,65 psi. Modo: flujo constante.

- Programa de temperatura del horno: Temperatura inicial: $50{ }^{\circ} \mathrm{C}$ durante $1,20 \mathrm{~min}$. Rampa: a $40 \mathrm{C} / \mathrm{min}$ aumenta hasta $280^{\circ} \mathrm{C}$ y permanece $7 \mathrm{~min}$.

- Inyector automático Agilent 7683. Volumen de inyección: $2 \mu$ l. Sistema de inyector de vaporización con temperatura programada (PTV) en modo "split-splitless". Temperatura del inyector: 250 'C. Tiempo de "splitless": $1 \mathrm{~min}$. Flu jo de "splitless": $1 \mathrm{ml} / \mathrm{min}$. Flujo de purga: $50 \mathrm{ml} / \mathrm{min}$ durante $2 \mathrm{~min}$. Flujo de ahorro: $20 \mathrm{ml} / \mathrm{min}$. Tiempo de ahorro: $2 \mathrm{~min}$.

- Condiciones instrumentales del MSD: Temperatura de la fuente de iones: $230^{\circ} \mathrm{C}$. Temperatura del Quadrupolo : $150{ }^{\circ} \mathrm{C}$. Energía del electrón: 70 eV. "Solvent delay": 6 min.

Condiciones cromatográficas GC/MSD - PTV modo venteo de solvente

Las experiencias para la optimización de las condiciones por GC-MSD-PTV en modo venteo de solvente, permitieron establecer como temperatura inicial del horno, $50{ }^{\circ} \mathrm{C}$ durante $1,2 \mathrm{~min}$ - rampa de $40^{\circ} \mathrm{C} / \mathrm{min}$ hasta $280^{\circ} \mathrm{C}$ durante $7 \mathrm{~min}$.

Se empleó gas carrier helio con 99,9995\% pureza. Detector de masa: energía de ionización $70 \mathrm{eV}$; fuente de iones $230{ }^{\circ} \mathrm{C}$; quadrupolo, $150{ }^{\circ} \mathrm{C}$. Modo scan entre 40 a $550 \mathrm{~m} / \mathrm{z}$ con 0,2 segundos de scan. Análisis cuantitativo modo SIM.

Se observó que las respuestas cromatográficas son máximas para todos los analitos individuales a una velocidad de 
calentamiento del inyector de $700 \mathrm{\circ} / \mathrm{min}$, por lo que para el análisis de multiresiduos se estableció dicha velocidad como óptima.

Optimizada la rampa de temperatura del inyector y del análisis de las curvas obtenidas a diferentes velocidades de flujo de venteo de solvente, se estableció un flujo óptimo de venteo de $200 \mathrm{ml} / \mathrm{min}$.

Se determinó que las condiciones óptimas para inyección de las muestras se logran inyectando 4 veces un volumen de muestra de $5 \mu \mathrm{l}$ con un intervalo de 6 segundos.

Los resultados de las respuestas cromatográficas obtenidos a partir de los ensayos efectuados, permitieron establecer finalmente las condiciones más adecuadas para la determinación de los analitos, siendo las mismas:

- Cromatógrafo Gaseoso HP 6890N. Detector selectivo de masa HP5973N. Columna Agilent HP - 5MS 0,25 mm x $30 \mathrm{~m} \times$ $0,25 \mu \mathrm{m}$. Interface a temperatura de $280^{\circ} \mathrm{C}$. Gas car rier: Helio $99,9995 \%$ de pureza que previamente pasa a través de trampa de humedad e hidrocarburos. Velocidad de flujo: $1 \mathrm{ml} / \mathrm{min}$. Presión: 7,65 psi. Modo: flujo constante.

- Programa de temperatura del horno: Temperatura inicial: $50{ }^{\circ} \mathrm{C}$ durante $1,20 \mathrm{~min}$. Rampa: a 40 C/min aumenta hasta $280^{\circ} \mathrm{C}$ y permanece $7 \mathrm{~min}$.

- Inyector automático Agilent 7683. Volumen de inyección: $5 \mu \mathrm{l}$ 4 veces con un intervalo de 6 segundos. Sistema de inyector de vaporización con temperatura programada (PTV) en modo venteo de solvente. 
- Programa de temperatura del inyector: Temperatura inicial $50{ }^{\circ} \mathrm{C}$ durante $1 \mathrm{~min}$. Rampa: a $700^{\circ} \mathrm{C} / \mathrm{min}$ aumenta ha sta 250 C y permanece $10 \mathrm{~min}$. Presión: 7,64 psi. Flujo de venteo: $200 \mathrm{ml} / \mathrm{min}$. Flujo de purga: $50 \mathrm{ml} / \mathrm{min}$. Flujo de ahorro: 20 $\mathrm{ml} / \mathrm{min}$ a los $5 \mathrm{~min}$.

- Condiciones instrumentales del MSD: Temperatura de la fuente de iones: $230{ }^{\circ} \mathrm{C}$. Temperatura del Quadrupolo : $150{ }^{\circ} \mathrm{C}$. Energía del electrón: 70 eV. "Solvent delay": 6 min.

\section{Condiciones cromatográficas SPME/GC/MSD}

Las condiciones cromatográficas fueron similares a las establecidas para GC/MSD-PTV en modo venteo de solvente. EI ajuste del tiempo de "splitless" y temperatura inicial del horno, tuvieron como fin la adecuada desorción de los analitos desde la fibra en el inyector.

- Cromatógrafo Gaseoso HP 6890N. Detector selectivo de masa HP5973N. Columna Agilent HP - 5MS 0,25 mm x $30 \mathrm{~m} \times$ $0,25 \mu \mathrm{m}$. Interface a temperatura de $280^{\circ} \mathrm{C}$. Gas carrier: Helio $99,9995 \%$ de pureza que previamente pasa a través de trampa de humedad e hidrocarburos. Velocidad de flujo: $1 \mathrm{ml} / \mathrm{min}$. Presión: 7,65 psi. Modo: flujo constante.

- Programa de temperatura del horno: Temperatura inicial: $50{ }^{\circ} \mathrm{C}$ durante $3,50 \mathrm{~min}$. Rampa: a $40{ }^{\circ} \mathrm{C} / \mathrm{min}$ aumenta hasta $280{ }^{\circ} \mathrm{C}$ y permanece $7 \mathrm{~min}$.

- Puerto de inyección equipado con "liner" Supelco ID 0,75 mm. Temperatura del inyector: 250 `. Tiempo de "splitl ess": 3 min. 
Flujo de "splitless": $1 \mathrm{ml} / \mathrm{min}$. Flujo de purga: $50 \mathrm{ml} / \mathrm{min}$.

- Condiciones instrumentales del MSD: Temperatura de la fuente de iones: $230^{\circ} \mathrm{C}$. Temperatura del Quadrupolo: $150{ }^{\circ} \mathrm{C}$. Energía del electrón: 70 eV. "Solvent delay": 6 min.

\section{Identificación de benzimidazoles por SPME/GC/MSD y PTV modo venteo de solvente y GC/MSD}

Los resultados corresponden a la determinación cualitativa de los fungicidas benzimidazólicos: metiltiofanato, tiofanato y thiabendazole; extraídos a partir de soluciones estándares, muestras adicionadas y muestras incognita.

En todos los casos, los resultados obtenidos a partir de las muestras sometidas al proceso extractivo por SPME y analizadas cromatográficamente por espectrometría de masas, permitieron identificar los analitos evaluados, evidenciando la efectividad del polímero para la extracción en las condiciones establecidas.

Para la identificación por PTV en modo venteo de solvente y GC/MSD y para las diferentes matrices se inyectaron 4 veces un volumen de muestra de $5 \mu \mathrm{l}$ con un intervalo de 6 segundos. Las respuestas cromatográficas presentaron en modo SCAN tiempos de retención diferentes, pero en modo SIM los iones observados se corresponden a los anteriormente indicados.

La figura 58 muestra el cromatograma correspondiente a una muestra de fruta cítrica adicionada con solución mezcla de estándares de metiltiofanato, tiofanato y thiabendazole a 50 ppb sometida al procesao extractivo por SPME. En el mismo, las respuestas cromatográficas se expresan en abundancia de pico, 
siendo los espectros correspondientes a los diferentes analitos los indicados en la figura 59.

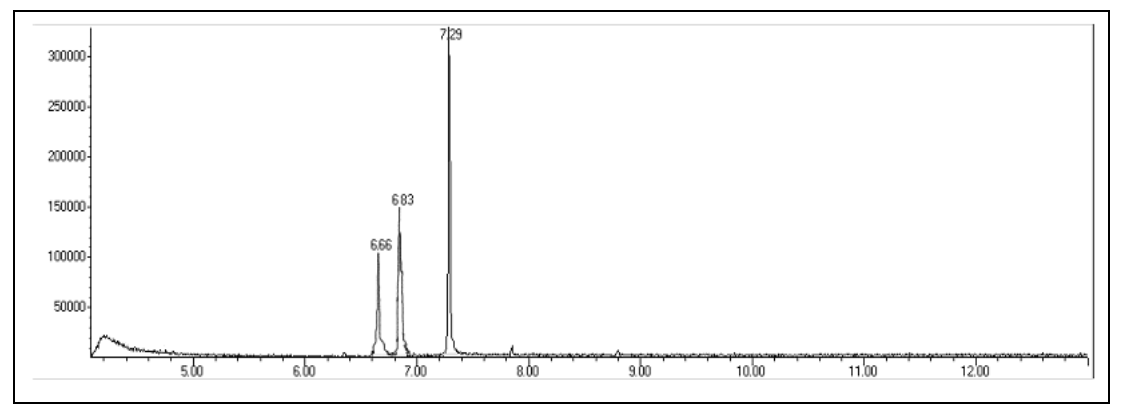

Figura 58. Cromatograma benzimidazoles - Frutas cítricas adicionadas a 50 ppb CWX/DVB - GC/MSD

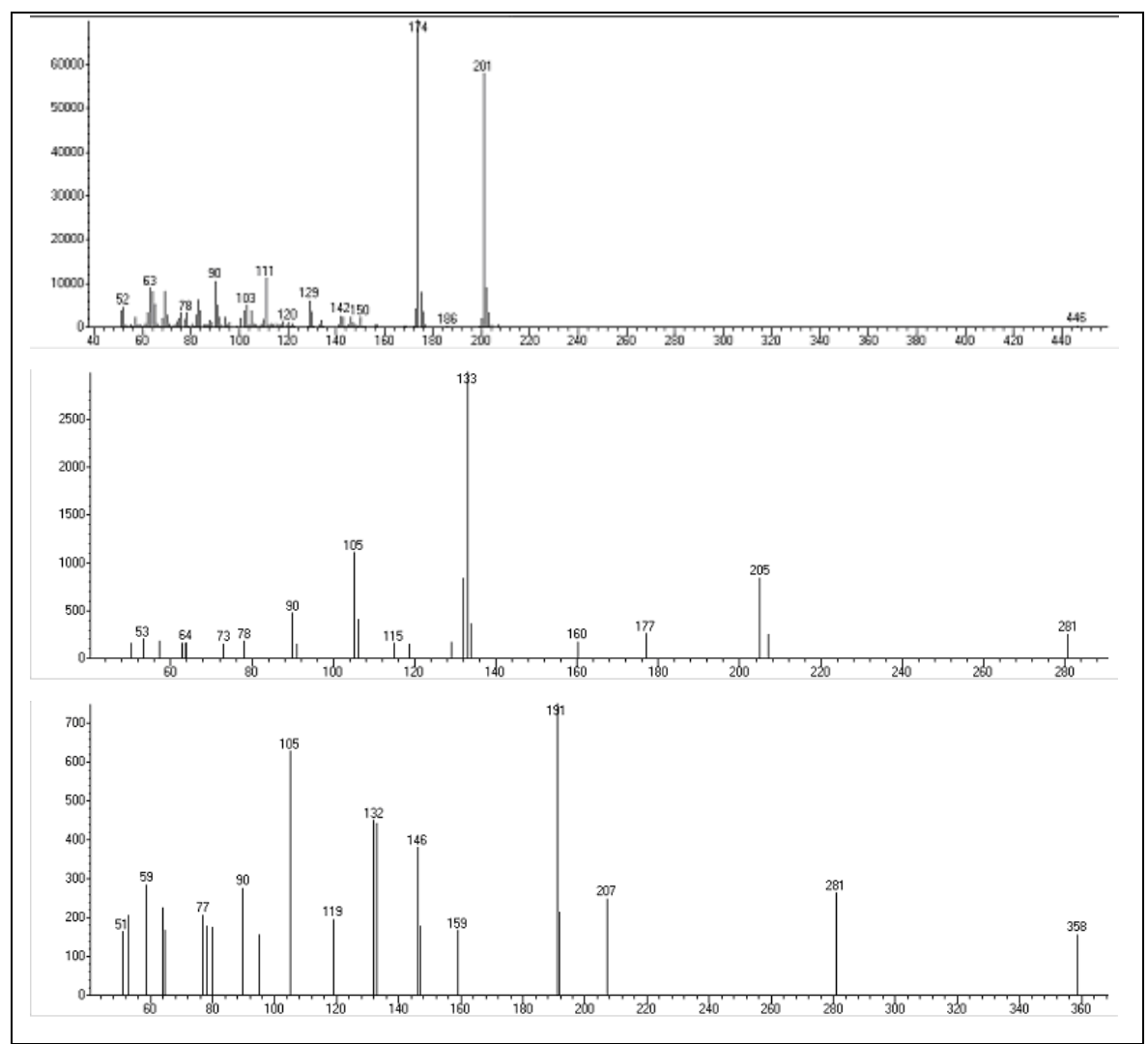

Figura 59. Espectro de masas benzimidazoles - TBZ, Tiofanato y Metiltiofanato 
Como puede observarse la separación y resolución es adecuada, permitiendo el sistema de detección de masas la identificación de los analitos efectivamente extraídos por la fibra.

Cabe destacar que si se requiere efectuar la cuantificación de los analitos por esta metodología analítica, es necesario calibrar con muestras adicionadas dado que existe efecto matriz. 
2. Extracción en Fase Sólida $y$ Cromatografía Líquida - SPE/HPLC 


\subsection{DETERMINACIÓN SIMULTÁNEA DE BENZIMIDAZOLES POR EXTRACCIÓN EN FASE SÓLIDA Y CROMATOGRAFÍA LIQQUIDA DE ALTA RESOLUCIÓN CON DETECTOR DE ARREGLO DE DIODOS - SPE/HPLC/DAD}

\section{$\underline{\text { Generalidades }}$}

La extracción en fase sólida (SPE) como metodología de extracción precede a la SPME (Lord \& Pawliszyn, 2000), con ventajas específicas que la ubican hoy día en la metodología alternativa cuando, las características propias de la matriz, los analitos, las condiciones de extracción y/o carencia de metodologías validadas, dificultan la aplicación de la SPME.

El vasto desarrollo de la SPE acoplada con cromatografía líquida de alta resolución, ha permitido resolver un gran número de aplicaciones vinculadas a la cuantificación de residuos de plaguicidas en diferentes matrices (Gomyo et al., 1992; Fritz, 1999; Jeannot et al., 2000; Kataoka, 2000; Poole, 2000; Brito et al., 2002; Boudina et al., 2003; Zamora Picón et al., 2003; Albero et al., 2005; Juan-Garcia, 2005).

Si bien existen innumerables desarrollos e información respecto a la aplicación de la cromatografía líquida para la determinación de benzimidazoles en diferentes matrices (Bean \& Henion, 1997; Bernal et al., 1997; Anastassiades \& Schwack 1998; Ito et al., 1998; Balizs, 1999; Lacassie et al., 2001; De 
Ruyck et al., 2002; Blasco et al., 2002; Danaher et al., 2003; Jansson et al., 2004; Veneziano et al., 2004; Ortelli et al, 2004; Belmonte Vega et al., 2005; Dowling et al., 2005; Nozal, 2005; Dangond Araujo y Guerrero Dallos, 2006; Danaher et al., 2007; Singh et al., 2007; Soler y Picó, 2007; Walorczyk, 2009), su aplicación utilizando extracción en fase sólida como método extractivo en matrices cítricas, constituye en la actualidad un campo aún en desarrollo.

La liposolubilidad característica de muchos benzimidazoles convierte a las vesículas oleosas de los cítricos en importantes reservorios de residuos, los cuales pueden persistir en la matriz a través de las diferentes etapas del proceso extractivo (Coscolla, 1993; Montti et al., 1998).

En este sentido, el desarrollo de una metodología para la determinación de benzimidazoles en aceites esenciales cítricos cobra especial relevancia, dadas las características específicas de la matriz de análisis y su particular interacción con los analitos a analizar.

\section{Materiales y método}

\section{Reactivos}

Se utilizaron los siguientes reactivos: Acetonitrilo grado HPLC (Sintorgan), Metanol grado HPLC (Sintorgan), Ácido Fosfórico grado HPLC (Anedra), Fosfato diácido de potasio 
(Biopack), Ácido acético glacial (Biopack), Diclorometano grado HPLC (Sintorgan), Agua grado 1.

Adsorbentes Florisil (Alltech), Diol (Alltech), Sílica (Alltech).

Estándares certificados de Thiabendazol (Pestanal) y Carbendazim (Accu Standard Inc).

\section{Equipamiento}

Se utilizó un cromatógrafo Shimadzu LC-20AT Prominence equipado con SIL-20 A automuestreador de 98 viales, CTO-20 A horno con columna VP ODS 250L x 4.6, DGU-20 A5 desgasificador, CBM-20 A unidad de comunicación con "software" CLASS-VP versión 6.14 SP1 y SPD M-20 A detector de arreglo de diodos (DAD).

Distribuidor de vacío para extracción en fase sólida (SPE), control de flujo para cada tubo de extracción, "Vacuum Manifold" Alltech.

Columnas de SPE: cartuchos de polipropileno de $25 \mathrm{ml}$. Fritz de 0,45 $\mu \mathrm{m}$ (Alltech). Filtros de papel Whatman $\mathrm{N}^{\circ} 90$.

Para la obtención de agua grado 1 se utilizó un equipo $\mathrm{E}$. Pure - Barnstead.

Balanza analítica Ohaus, Freezer electrolux.

\section{Desarrollo metodológico}

El desarrollo metodológico comprendió las siguientes etapas:

- Ejecución del plan de muestreo. 
- Preparación y conservación de las muestras para su análisis en el laboratorio.

- Optimización de las condiciones cromatográficas: selección del tipo de columna, longitud de onda, composición de la fase móvil, temperatura de columna, velocidad de flujo, volumen de inyección.

- Tratamiento previo de la muestra - extracción, clean up y concentración: selección del adsorbente, acondicionamiento de la columna, definición de las condiciones de operación para la extracción, selección del eluyente, conservación del eluato.

- Análisis cuantitativo: adopción del método de cuantificación.

- Validación de la metodología analítica: determinación del rango lineal del método, precisión, exactitud, sensibilidad (límites de detección y cuantificación).

El diseño metodológico para el desarrollo de las etapas indicadas estuvo en estrecha vinculación con experiencias previas y se compatibilizó con la información científica disponible al respecto (Gomyo et al., 1992; Anastassiades \& Schwack, 1998; Ito et al., 1998; Balizs, 1999;; Fritz, 1999; Jeannot et al., 2000; Kataoka, 2000; Poole, 2000; Lacassie et al., 2001; Blasco et al., 2002; Brito et al., 2002; De Ruyck et al., 2002; Boudina et al., 2003; Danaher et al., 2003; Zamora Picón et al., 2003; Jansson et al., 2004; Veneziano et al., 2004; Ortelli et al, 2004;Albero et al., 2005; Belmonte Vega et al., 2005; Dowling et al., 2005; Nozal, 2005; Juan-Garcia, 2005; Danaher et al., 2007; Singh et al., 2007; Soler y Picó, 2007; Walorczyk, 2009). 


\section{Condiciones cromatográficas}

Se utilizó cromatografía de fase reversa siendo la columna octadecilsilano (ODS) con una fase constituida por un solvente polar, mezcla de agua y un modificador orgánico, a los que se adicionó sales o buffers. Las longitudes de ondas fueron seleccionadas para ambos analitos en función de las respuestas cromatográficas.

Se estableció la temperatura de columna y la velocidad óptima de flujo para una adecuada separación de los picos.

Los solventes utilizados en la fase móvil fueron agua, metanol y acetonitrilo (Hada et al., 2000; Heidin et al., 2001; Zrostlíkaová et al., 2001; Concha-Graña et al., 2002; Teske y Engewald, 2002; Danaher et al., 2003; Soler y Picó, 2007; Leseuer et al., 2008; Romero- González et al., 2008). La proporción de los componentes orgánicos y buffers de la fase móvil, se seleccionó mediante ensayos a diferentes gradientes.

Experiencias previas (Chaulet et al., 2000; Gerard et al., 2000) permitieron establecer como fase móvil la mezcla de soluciones de $\mathrm{H}_{2} \mathrm{KPO}_{4} 5 \mathrm{mM}$ - Ácido acético 0,01\% (Fernández et al., 1993) como fase acuosa (Fase A) y Acetonitrilo-metanol (50:50 v/v) - Ácido acético 0,01\% como componentes orgánicos (Fase B) (Ito et al., 1998).

Las diferentes proporciones de la fase acuosa y orgánica fueron evaluadas a fin de optimizar el proceso cromatográfico. Las proporciones analizadas fueron:

- Fase Móvil $1(A: B)=30: 70 \mathrm{v} / \mathrm{v}$

- Fase Móvil $2(A: B)=40: 60 \mathrm{v} / \mathrm{v}$ 
- Fase Móvil $3(A: B)=50: 50 \mathrm{v} / \mathrm{v}$

- Fase Móvil $4(A: B)=60: 40 \mathrm{v} / \mathrm{v}$

- Fase Móvil $5(A: B)=70: 30 \mathrm{v} / \mathrm{v}$

\section{Preparación de estándares}

A partir de estándares certificados de los fungicidas a analizar - Thiabendazole y Carbendazim - se prepararon soluciones en metanol de $1000 \mathrm{ppm} 0 \mathrm{mg} / \mathrm{l}$. En virtud de la concentración esperada de los analitos en las muestras y a fin de establecer la curva de calibración y el rango lineal del método, se prepararon por triplicado soluciones estándares de los analitos individuales y mezclas de los mismos en fase móvil a diferentes concentraciones.

Las soluciones de los analitos individuales se utilizaron para identificar los tiempos de retención de cada uno de ellos.

\section{Plan de muestreo}

Las muestras de aceites esenciales de naranja fueron tomadas en forma aleatoria por profesionales de la industria regional, a partir de lotes de aceites cítricos de la producción correspondiente al período 2009.

Se realizaron 6 muestreos de 6 lotes, tomándose 3 muestras por lote de un volumen de $100 \mathrm{ml}$. Las mismas correspondieron a lotes caracterizados como aceites prensados en frío, descerados y almacenados en tambores de $200 \mathrm{Kg}$ en condiciones de refrigeración. 
El método de submuestreo adoptado, fue el de preparación de una muestra de laboratorio compuesta. Es decir que a partir de porciones o unidades individuales representativas, se combinaron para formar una mezcla homogénea o muestra compuesta.

Las muestras fueron identificadas, rotuladas y conservadas en freezer hasta su procesamiento para análisis.

\section{Preparación de muestras adicionadas}

Las muestras provenientes de la industria fueron identificadas, según su trazabilidad en: aceites esenciales orgánicos libres de los fungicidas evaluados y muestras reales.

Los aceites identificados como orgánicos fueron testeados previamente a fin de corroborar la ausencia de fungidas. Los mismos se utilizaron como blancos de muestras y muestras adicionadas a diferentes concentraciones de thiabendazole y carbendazim.

Todas las muestras fueron procesadas según la metodología propuesta a fin optimizar y validar el método.

\section{Tratamiento previo de las muestras}

La preparación de las muestras constituyó una etapa decisiva en el desarrollo del método de análisis, en especial teniendo en cuenta que se trata de la determinación de niveles trazas en una matriz muy compleja.

Para la selección del método más apropiado se tuvieron en cuenta las propiedades físicas y químicas del analito (Danaher et 
al., 2007), su concentración estimada en la muestra, la naturaleza de la matriz, la forma en que el analito se presenta en la misma, y la compatibilidad de los medios de solubilización y extracción con el sistema cromatográfico.

El tratamiento previo de las muestras consistió fundamentalmente en la eliminación del contenido de ceras y demás impurezas, capaces de interferir en el proceso de extracción de los analitos de la matriz. Con este fin las muestras almacenadas en frío fueron filtradas a través de papel Whatman $N^{\circ} 90$.

Muestras de 0,25 a $1 \mathrm{~g}$ de aceite esencial orgánico filtrado, identificadas como libres de fungicidas, fueron adicionadas con soluciones estándar de thiabendazole y carbendazim. Las mismas fueron diluidas con diclorometano hasta un volumen final de $10 \mathrm{ml}$. Similar procedimiento se efectuó para los blancos de reactivo y muestra.

\section{Extracción y concentración en fase sólida (SPE)}

La extracción en fase sólida tiene lugar mediante mecanismos de sorción-desorción de los analitos en la superficie del material activo de las columnas. El equilibrio entre la concentración de los analitos en la fase estacionaria y la fase móvil, debe desplazarse en un sentido u otro, según se pretenda la retención o elución de los mismos.

La selección de las condiciones óptimas para la extracción dependen tanto de la naturaleza del/los analitos como de la matriz que lo/s rodea. 
La extracción de residuos de pesticidas mediante SPE requiere la optimización de las variables que afectan tanto a la retención como a la elución de los mismos. Dicha optimización puede convertirse en una serie de repeticiones de experimentos contradictorios si no se sigue un plan de optimización que permita controlar y evaluar el efecto de las variables que intervienen en la extracción (Fritz, 1999).

En tal sentido, se llevó adelante el siguiente esquema de trabajo, basado en un proceso iterativo que permite la optimización progresiva de todas las variables que intervienen en el proceso de extracción (Wells y Michael, 1987):

\section{Control de la retención}

Volumen fijo de muestra con una concentración determinada de pesticidas

Fijar el tipo y cantidad de adsorbente

2. Optimización de la elución - estudio del efecto del eluyente.

Comparar la eficacia de diferentes disolventes.

Estudio del efecto del volumen de eluyente

3. Optimización de la retención - pH de la muestra Volumen de muestra

Masa de adsorbente

Concentración de la muestra 
Cualquier procedimiento de SPE, utiliza los pasos que se describen a continuación (figura 60):

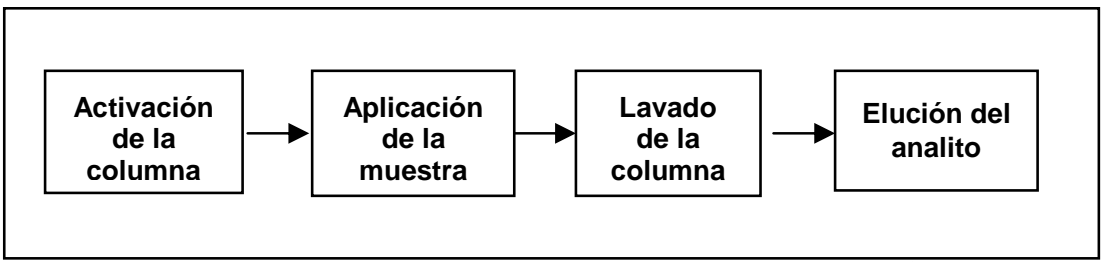

Figura 60. Etapas de un proceso de Extracción en Fase Sólida

\section{Selección del adsorbente}

Para la selección del adsorbente, en función de la naturaleza de las muestras y propiedades fisicoquímicas de los analitos (Di Muccio et. al, 1999; Chaulet et al., 2000; Jeannot et al., 2000; Brito et al., 2002; Zamora Picón et al., 2003; Belmonte Vega et al., 2005; Dowling et al., 2005), se efectuaron ensayos con Diol, Silica y Florisil, adoptándose el adsorbente más adecuado en función de los porcentajes de recuperación obtenidos.

Experiencias previas han demostrado que una cantidad de relleno de 0,5 g es óptima para la retención adecuada de la masa de analitos analizados (Montti et al., 1998).

\section{Activación de la columna}

Esta operación tiene por objeto solvatar los grupos funcionales del material de relleno de la columna. Los analitos no pueden interactuar con el relleno de la columna si sus grupos no se encuentran totalmente "activados". 
Con este fin se adaptó la columna de SPE, conteniendo $0,5 \mathrm{~g}$ del material de relleno seleccionado, al distribuidor de vacío y se activó el lecho de la misma con un volumen definido del solvente apropiado.

\section{Aplicación de la muestra}

La muestra se aplicó en la columna regulando el caudal mediante el control de vacío (aproximadamente 1-2 $\mathrm{ml} / \mathrm{min}$ ) de modo tal de permitir una adecuada retención de los analitos.

\section{Lavado de la columna - "clean up" y concentración}

Esta operación permite la eliminación de las impurezas que hubiesen quedado retenidas en el adsorbente. Generalmente se debe utilizar un solvente relativamente débil con el cual el analito no eluya. El lavado de la columna si bien es recomendable, no constituye una etapa indispensable.

En este caso se realizó un enjuague del recipiente contenedor de la muestra y posterior lavado de la columna con el mismo solvente (diclorometano).

\section{Elución del analito}

Una vez efectuada la concentración de los analitos en la columna y minimizadas las interferencias de la matriz ("clean up"), otra etapa de incidencia en la extracción del analito de la fase sólida es la optimización del proceso de elución. 
Esta optimización involucra determinar la adecuada composición y volumen del eluyente, que logren la máxima fuerza elutora y por ende una mayor recuperación del analito retenido en la columna.

Es tendencia general que la composición del eluyente sea similar a la fase móvil, ya que con ello se minimizan las interferencias. En función de ello se realizaron ensayos con diferentes proporciones de las soluciones que componen la misma:

- Fase A: solución de $\mathrm{H}_{2} \mathrm{KPO}_{4} 5 \mathrm{mM}$ - Ácido acético 0,01\% como fase acuosa.

- Fase B: Acetonitrilo-metanol (50:50 v/v) - Ácido acético 0,01\% como componentes orgánicos.

Las proporciones analizadas a fin de optimizar el proceso de elución fueron:

- Eluyente $1(A: B)=45: 55 \mathrm{v} / \mathrm{v}$

- Eluyente $2(A: B)=$ Fase móvil $2=40: 60 \mathrm{v} / \mathrm{v}$

- Eluyente $3(A: B)=55: 45 \mathrm{v} / \mathrm{v}$

En todos los casos la elución se efectuó hasta un volumen final de eluato de $8 \mathrm{ml}$.

\section{Análisis estadístico}

Establecidas las condiciones cromatográficas, el tratamiento de las muestras, el proceso extractivo, "clean up" y concentración; se procedió a determinar la curva de linealidad, 
intervalo de confianza, la precisión, exactitud, límites de detección y cuantificación del método.

El procesamiento estadístico de los datos se realizó mediante versión de prueba del software Statgraphics Centurión $\mathrm{XV}$.

Los parámetros estadísticos correspondientes al análisis unidimensional de los datos incluyeron las medidas de tendencia central, de variabilidad y de forma; los coeficientes de asimetría y curtosis estandarizados permitieron establecer si la muestra procede de una distribución normal

Para determinar la linealidad del método se procesaron 10 soluciones de estándares de thiabendazole y carbendazim en fase móvil, a las siguientes concentraciones: $0,1-0,25-0,5-0,75-$ 1,0 - 2,5 - 5,0 ppm. Para todas las concentraciones se determinó el coeficiente de variación y la desviación estándar para $n=10$ y $\alpha=0.05$. Se trazó la curva de linealidad y determinaron los intérvalos de confianza del método.

En el análisis de regresión lineal se determinó la independencia y normalidad de los residuos a partir de los estadísticos Durbin Watson y Kolmogorov para un nivel de confianza del $95 \%$.

Se estableció la ecuación de la recta y el estadístico $R^{2}$ a fin de indicar la relación entre las variables (respuestas cromatográficas vs. concentración).

La precisión del método fue determinada, para soluciones de estándares y muestras adicionadas, a partir de 10 soluciones mezcla de los analitos de 0,5 ppm, $(n-1)=9$ y $\alpha=0,05$. 
A partir de quintuplicados de muestras de aceites esenciales adicionados a las mismas concentraciones de los estándares de calibración, se determinó la recuperación media de los analitos, desviación estándar y coeficiente de variación.

Los límites de detección y cuantificación fueron evaluados a partir de soluciones mezcla de estándares a bajas concentraciones, para $n=10$ y $\alpha=0,05$. Del mismo modo se determinó la sensibilidad del método en muestras adicionadas.

Los mismos se estimaron a partir de la curva de regresión para bajas concentraciones de los analitos y 15 determinaciones individuales ( $\left.n^{\prime}\right)$. De dicha curva se determinó la pendiente $(b)$ y por extrapolación a concentración cero, se obtuvo un estimado de la respuesta del blanco $\left(Y_{b l}\right)$.

A partir de la desviación estándar correspondiente a cada concentración, se determinó la recta correspondiente y por extrapolación se estimó la desviación estándar del blanco $\left(S_{b l}\right)$.

Los límites de detección y cuantificación se calcularon a partir de las ecuaciones (7) y (8), en las cuales se considera 3 y 10 veces la desviación estándar del blanco respectivamente.

$$
\begin{aligned}
& \text { Límite de detección }=\frac{Y_{b l}+3 S_{b l}}{b} \cdot \frac{1}{\sqrt{n^{\prime}}} \\
& \text { Límite de Cuantificación }=\frac{Y_{b l}+10 S_{b l}}{b} \cdot \frac{1}{\sqrt{n^{\prime}}}
\end{aligned}
$$




\section{Resultados y discusión}

\section{Condiciones cromatográficas}

Las longitudes de onda fueron seleccionadas para ambos analitos en función de las respuestas cromatográficas. Se estableció una longitud de onda de $303 \mathrm{~nm}$ para thiabendazole y de $285 \mathrm{~nm}$ para carbendazim.

La temperatura de la columna se estableció en $40^{\circ} \mathrm{C}$ y la velocidad flujo óptimo se determinó experimentalmente para una adecuada separación de los picos, resultando adecuada una velocidad de $0,8 \mathrm{ml} / \mathrm{min}$.

Dada la capacidad máxima del inyector automático de $40 \mu \mathrm{l}$, se estableció como volumen de inyección para todas las muestras de $30 \mu \mathrm{l}$.

La proporción de los componentes orgánicos y buffers de la fase móvil, se seleccionó mediante ensayos a los diferentes gradientes mencionados.

- Fase Móvil $1(A: B)=30: 70 \mathrm{v} / \mathrm{v}$

- Fase Móvil $2(A: B)=40: 60 \mathrm{v} / \mathrm{v}$

- Fase Móvil $3(A: B)=50: 50 \mathrm{v} / \mathrm{v}$

- Fase Móvil $4(A: B)=60: 40 \mathrm{v} / \mathrm{v}$

- Fase Móvil $5(A: B)=70: 30 \mathrm{v} / \mathrm{v}$

Siendo la composición de las fases:

- Fase A: solución de $\mathrm{KPO}_{4} \mathrm{H}_{2} 5 \mathrm{mM}$ - Ácido acético 0,01\% como fase acuosa. 
- Fase B: Acetonitrilo-metanol (50:50 v/v) - Ácido acético 0,01\% como componentes orgánicos.

Las diferentes proporciones de la fase acuosa y orgánica fueron evaluadas a fin de optimizar el proceso cromatográfico, adoptándose la Fase Móvil 2, es decir la mezcla en una proporción 40:60 v/v de soluciones de $\mathrm{H}_{2} \mathrm{KPO}_{4} 5 \mathrm{mM}$ y Acetonitrilo/Metanol aciduladas con $0,01 \%$ de ácido acético.

\section{Selección del adsorbente, "clean up" y concentración}

Para la selección del adsorbente, en función de la naturaleza de las muestras y propiedades fisicoquímicas de los analitos se efectuaron ensayos con Diol, Silica, Florisil, adoptándose en función de los porcentajes de recuperación obtenidos, el Diol como absorbente más adecuado.

Para la extracción, "clean up" y concentración de los analitos en la fase sólida, se emplearon columnas rellenas con 0,5 g de Diol. La activación del adsorbente se llevó a cabo adicionando 2-3 ml de diclometano.

\section{Selección del eluyente}

Según lo indicado se realizaron ensayos con diferentes proporciones de las soluciones que componen la misma:

- Fase A: solución de $\mathrm{KPO}_{4} \mathrm{H}_{2} 5 \mathrm{mM}$ - Ácido acético 0,01\% como fase acuosa. 
- Fase B: Acetonitrilo-metanol (50:50 v/v) - Ácido acético 0,01\% como componentes orgánicos.

Las proporciones analizadas a fin de optimizar el proceso de elución fueron:

- Eluyente $1(A: B)=45: 55 \mathrm{v} / \mathrm{v}$

- Eluyente $2(A: B)=$ Fase móvil $2=40: 60 \mathrm{v} / \mathrm{v}$

- Eluyente $3(A: B)=55: 45 \mathrm{v} / \mathrm{v}$

La selección del eluyente se realizó en función de los porcentajes de recuperación obtenidos (Tabla 49), resultando el más adecuado el eluyente 2 que corresponde a la misma fase móvil adoptada.

Tabla 49. Rangos de \% de recuperación para diferentes eluyentes - Aceites esenciales adicionados a 0,5 ppm - Inyección $30 \mu \mathrm{l}-\mathrm{n}=5$ y $\alpha=0,05$

\begin{tabular}{|c|c|c|}
\hline \multicolumn{1}{|c|}{ Eluyente } & \multicolumn{2}{|c|}{$\%$ recuperación } \\
\cline { 2 - 3 } & Thiabedazol & Carbendazim \\
\hline Eluyente $1(A: B)=45: 55 \mathrm{v} / \mathrm{v}$ & $87,5-89,6$ & $88,7-91,2$ \\
\hline Eluyente $2(A: B)=40: 60 \mathrm{v} / \mathrm{v}$ & $90,7-94,2$ & $95,3-97,1$ \\
\hline Eluyente $3(A: B)=55: 45 \mathrm{v} / \mathrm{v}$ & $82,4-85,3$ & $84,8-86,5$ \\
\hline
\end{tabular}

\section{Linealidad}

\section{Soluciones estándares}

Se determinó linealidad a partir de las respuestas cromatográficas, expresadas en alturas, obtenidas de 10 soluciones estándares de thiabendazole y carbendazim en fase móvil a $0,10-0,25-0,50-0,75-1,00-2,50-5,00$ ppm. 
Los resultados obtenidos fueron analizados estadísticamente para $\mathrm{n}=10$ y $\alpha=0,05$. El análisis unidimensional de los datos indicó para todas las concentraciones de los analitos una distribución normal de las observaciones. Los resultados se muestran en la tabla 50.

Tabla 50. Análisis unidimensional - Soluciones estándares en fase móvil Inyección $30 \mu \mathrm{l}-\mathrm{n}=10, \alpha=0,05$

\begin{tabular}{|c|c|c|c|c|c|c|c|}
\hline Analito & \multicolumn{7}{|c|}{ Thiabendazole } \\
\hline $\begin{array}{c}\text { Concentración } \\
\text { ppm }\end{array}$ & $\mathbf{0 , 1 0}$ & $\mathbf{0 , 2 5}$ & $\mathbf{0 , 5 0}$ & $\mathbf{0 , 7 5}$ & $\mathbf{1 , 0 0}$ & $\mathbf{2 , 5 0}$ & $\mathbf{5 , 0 0}$ \\
\hline Media & 1138 & 3267 & 6029 & 9130 & 12018 & 31276 & 61826 \\
\hline $\begin{array}{c}\text { Desviación } \\
\text { Estándar }\end{array}$ & 7 & 14 & 41 & 105 & 113 & 147 & 104 \\
\hline RSD \% & 0,66 & 0,42 & 0,67 & 1,15 & 0,94 & 0,47 & 0,17 \\
\hline $\begin{array}{c}\text { Intervalos de } \\
\text { confianza +/- }\end{array}$ & 5 & 10 & 29 & 75 & 81 & 105 & 75 \\
\hline Analito & & & $\mathbf{6}$ Carbendazim & & \\
\hline $\begin{array}{c}\text { Concentración } \\
\text { ppm }\end{array}$ & $\mathbf{0 , 1 0}$ & $\mathbf{0 , 2 5}$ & $\mathbf{0 , 5 0}$ & $\mathbf{0 , 7 5}$ & $\mathbf{1 , 0 0}$ & $\mathbf{2 , 5 0}$ & $\mathbf{5 , 0 0}$ \\
\hline Media & 767 & 1986 & 3994 & 5955 & 8064 & 19926 & 39973 \\
\hline $\begin{array}{c}\text { Desviación } \\
\text { Estándar }\end{array}$ & 8 & 14 & 25 & 67 & 69 & 71 & 103 \\
\hline RSD \% & 1,07 & 0,69 & 0,61 & 1,12 & 0,86 & 0,36 & 0,26 \\
\hline $\begin{array}{c}\text { Intervalos de } \\
\text { confianza +/- }\end{array}$ & 6 & 10 & 18 & 48 & 49 & 51 & 74 \\
\hline
\end{tabular}

En la figura 61 se muestra el cromatograma obtenido para una muestra de solución de estándares a 10 ppm en el cual es posible observar los tiempos de retensión para cada uno de los analitos y la definición de los picos correspondientes.

El análisis de regresión lineal permitió establecer la ecuación de la recta (respuestas cromatográficas en alturas de 
pico vs. concentración) y el estadístico $\mathrm{R}^{2}$ para cada analito.

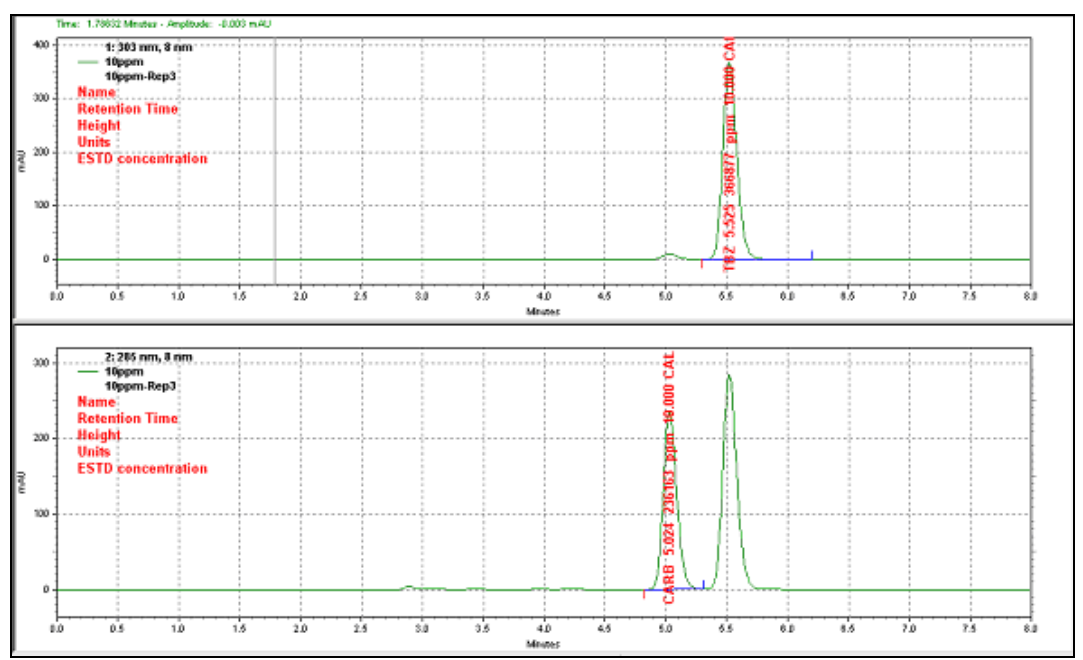

Figura 61. Cromatograma - Solución de estándares a 10 ppm - Inyección $30 \mu \mathrm{l}$

En la figura 62 se indican las curvas de regresión correspondientes.

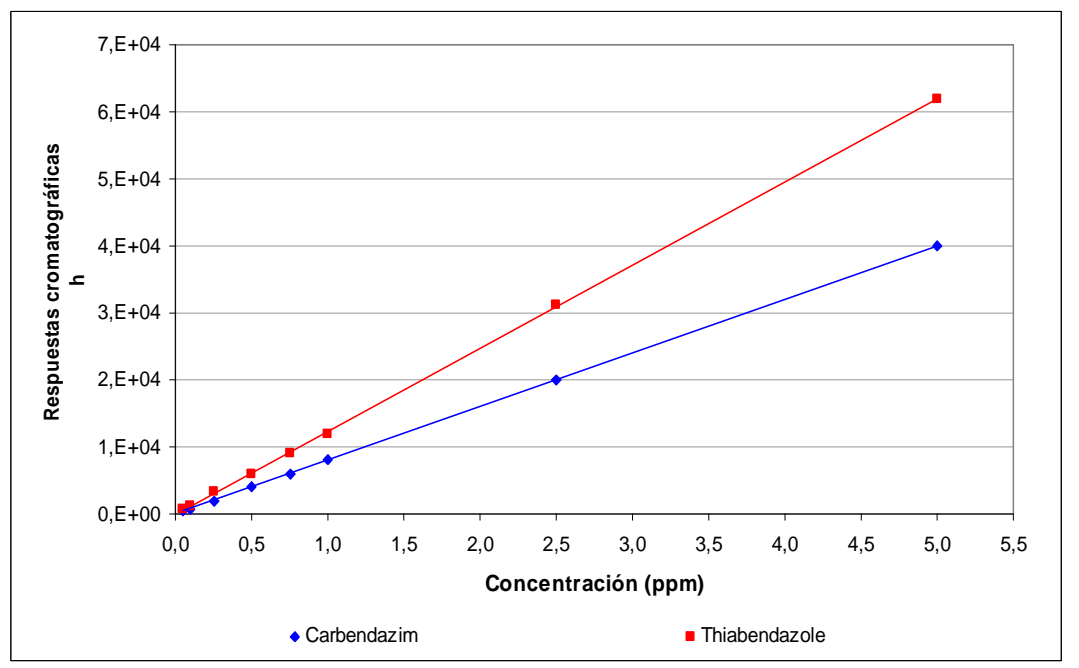

Figura 62. Regresión lineal - Soluciones estándares benzimidazoles en fase móvil - Volumen inyección $30 \mu \mathrm{l}$ 
Las figuras 63 y 64 muestran las rectas de regresión para cada analito con indicación de los límites de confianza y de predicción correspondientes.

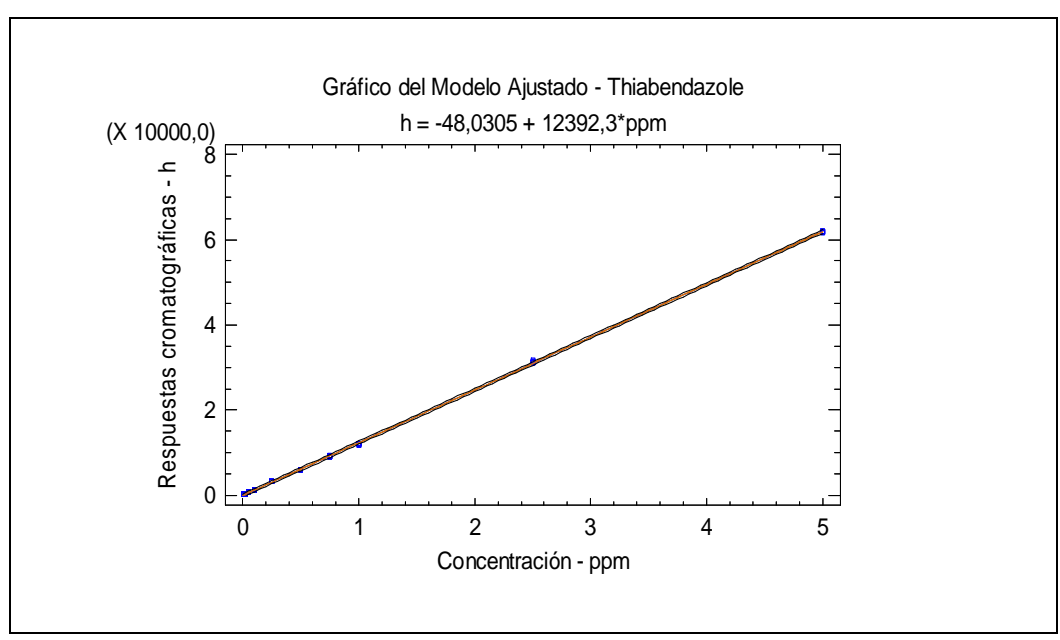

Figura 63. Regresión lineal - Thiabendazole - Soluciones estándares de benzimidazoles en fase móvil - Volumen de inyección $30 \mu \mathrm{l}$

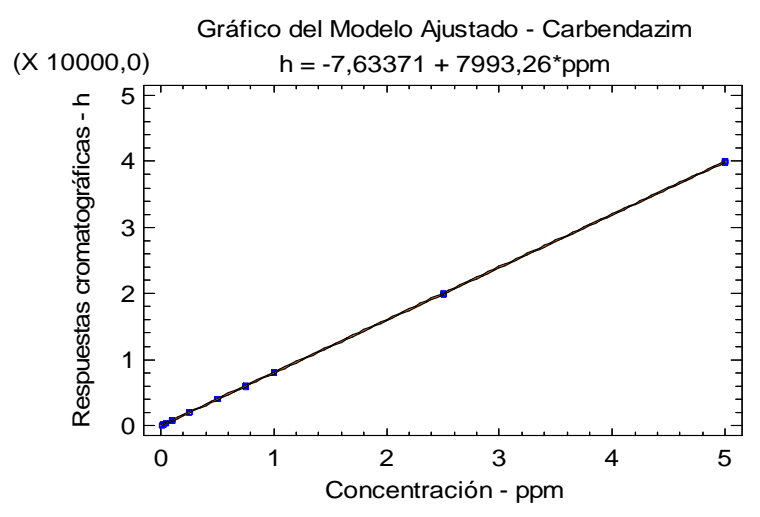

Figura 64. Regresión lineal - Carbendazim - Soluciones estándares de benzimidazoles en fase móvil - Volumen de inyección $30 \mu \mathrm{l}$ 
Las ecuaciones del modelo ajustado para cada analito fueron:

$\mathrm{h}_{\text {Thiabendazole }}=-48,03+12392,3 \mathrm{ppm}$ Thiabendazole

Coeficiente de Correlación $=0,99994$

$R^{2}=99,98 \%$

$\mathrm{h}_{\text {Carbendazim }}=-7,63+7993,26 \mathrm{ppm}$ Carbendazim

Coeficiente de Correlación $=0,99998$

$R^{2}=99,99 \%$

Donde:

$\mathrm{h}=$ respuestas cromatográficas expresadas en alturas de pico.

ppm = concentración expresadas en partes por millón o mg/l

El análisis de varianza indicó que existe en todos los casos una relación estadísticamente significativa entre las respuestas cromatográficas (alturas de pico) y la concentración (ppm) con un nivel de confianza del 95,0\%.

El estadístico $R^{2}$ y el coeficiente de correlación muestran para los distintos analitos un ajuste lineal entre las variables.

En todos los casos se establecieron los valores predichos de las respuestas cromatográficas para el modelo ajustado y los residuos correspondientes.

Los estadísticos Durbin Watson y Kolmogorov permitieron establecer la independencia de los residuos y una distribución normal de los mismos para un nivel de confianza del $95 \%$. 


\section{Muestras adicionadas}

Se determinó linealidad a partir de las respuestas cromatográficas, expresadas en alturas de pico, obtenidas de 10 muestras adicionadas con estándares de thiabendazole y carbendazim a $0,10-0,25-0,50-0,75-1,00-2,50-5,00$ ppm.

El análisis unidimensional de los datos indicó para todas las concentraciones de los analitos una distribución normal de las observaciones. Los resultados se muestran en la tabla 51.

Tabla 51. Análisis unidimensional - Valores medios expresados en alturas de pico - Aceite esencial adicionado - Inyección $30 \mu \mathrm{l}-\mathrm{n}=10, \alpha=0,05$

\begin{tabular}{|c|c|c|c|c|c|c|c|}
\hline Analito & \multicolumn{7}{|c|}{ Thiabendazole } \\
\hline $\begin{array}{c}\text { Concentración } \\
\text { ppm }\end{array}$ & 0,10 & 0,25 & 0,50 & 0,75 & 1,00 & 2,50 & 5,00 \\
\hline Altura Media & 983 & 3163 & 6142 & 9789 & 12410 & 30021 & 60109 \\
\hline $\begin{array}{l}\text { Desviación } \\
\text { Estándar }\end{array}$ & 37 & 35 & 19 & 74 & 47 & 68 & 104 \\
\hline RSD \% & 3,76 & 1,11 & 0,31 & 0,76 & 0,38 & 0,23 & 0,17 \\
\hline $\begin{array}{l}\text { Intervalos de } \\
\text { confianza +/- }\end{array}$ & 26 & 25 & 14 & 53 & 34 & 49 & 74 \\
\hline Analito & \multicolumn{7}{|c|}{ Carbendazim } \\
\hline $\begin{array}{c}\text { Concentración } \\
\text { ppm }\end{array}$ & 0,10 & 0,25 & 0,50 & 0,75 & 1,00 & 2,50 & 5,00 \\
\hline Altura Media & 553 & 1901 & 3822 & 5584 & 7396 & 18883 & 38877 \\
\hline $\begin{array}{c}\text { Desviación } \\
\text { Estándar }\end{array}$ & 20 & 36 & 49 & 48 & 64 & 139 & 149 \\
\hline RSD \% & 3,58 & 1,92 & 1,28 & 0,85 & 0,86 & 0,74 & 0,38 \\
\hline $\begin{array}{l}\text { Intervalos de } \\
\text { confianza +/- }\end{array}$ & 14 & 26 & 35 & 34 & 46 & 100 & 107 \\
\hline
\end{tabular}


En la figura 65 se muestra, a modo de ejemplo, el cromatograma obtenido para una muestra de aceite esencial adicionado a 5 ppm.

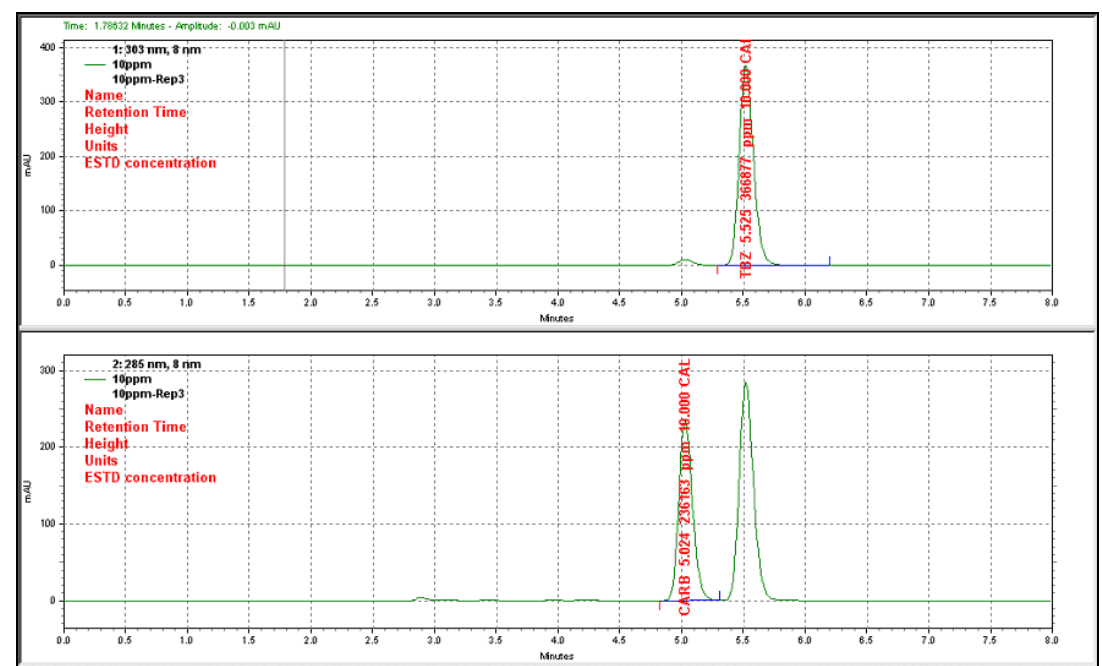

Figura 65. Cromatograma - Aceite esencial adicionado a 5 ppm - Volumen Inyección $30 \mu \mathrm{l}$

Se estableció la ecuación de la recta a partir de las respuestas cromatográficas, en alturas de pico, para cada concentración y el estadístico $\mathrm{R}^{2}$ para cada analito.

La figura 66 muestra las curvas de regresión correspondientes. Las figuras 67 y 68 muestran las rectas de regresión para cada analito con indicación de los límites de confianza y de predicción correspondientes. 


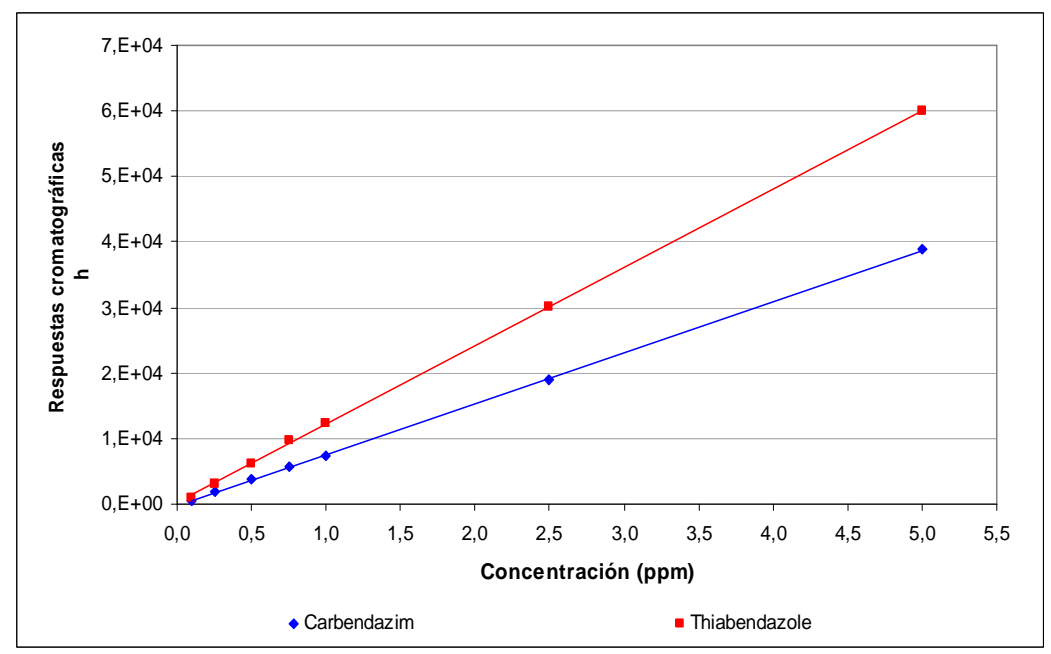

Figura 66. Regresión lineal - Aceites esenciales adicionados - Volumen inyección $30 \mu \mathrm{l}$

Las ecuaciones del modelo ajustado para cada analito fueron:

$\mathrm{h}_{\text {Thiabendazole }}=-29,65+12041,5 \mathrm{ppm}$ Thiabendazole

Coeficiente de Correlación $=0,99991$

$R^{2}=99,98 \%$

$\mathrm{h}_{\text {Carbendazim }}=-397,41+7823,3$ ppm Carbendazim

Coeficiente de Correlación $=0,99984$

$R^{2}=99,97 \%$

Donde:

$\mathrm{h}=$ respuestas cromatográficas expresadas en alturas de pico.

ppm = concentración expresadas en partes por millón o mg/l. 


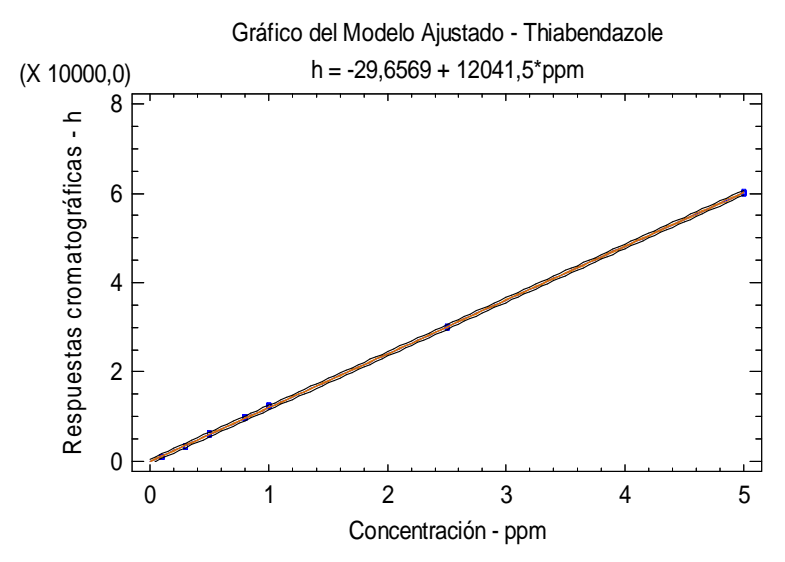

Figura 67. Regresión lineal - Thiabendazole - Aceites esenciales adicionados Volumen de inyección $30 \mu \mathrm{l}$

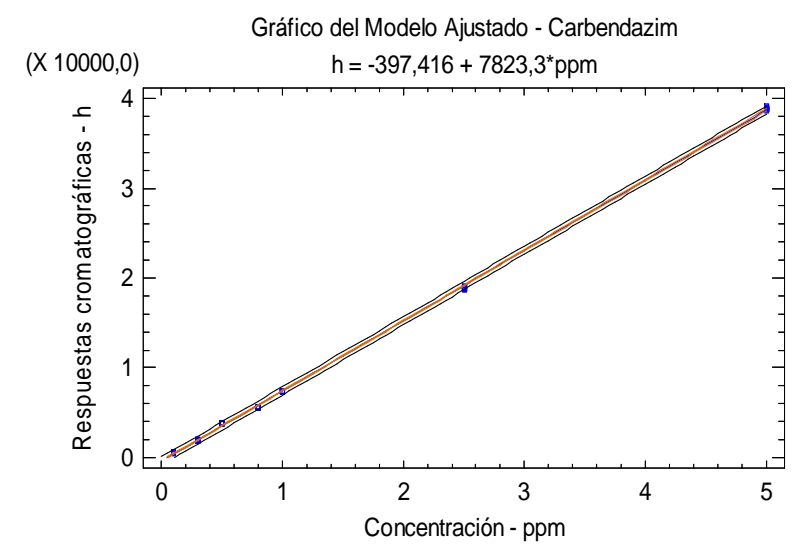

Figura 68. Regresión lineal - Carbendazim - Aceites esenciales adicionados Volumen de inyección $30 \mu \mathrm{l}$ 
El análisis de varianza indicó en todos los casos la existencia de una relación estadísticamente significativa entre las respuestas cromatográficas (alturas de pico) y la concentración (ppm) con un nivel de confianza del 95,0\%; mostrando un ajuste lineal entre las variables a través del estadístico $R^{2}$ y el coeficiente de correlación.

En todos los casos se establecieron los valores predichos de las respuestas cromatográficas para el modelo ajustado y los residuos correspondientes.

Para ambos analitos, los estadísticos Durbin Watson y Kolmogorov indicaron la independencia de los residuos y una distribución normal de los mismos para un nivel de confianza del $95 \%$.

\section{Comparación de rectas de regresión - Estándares vs. aceites esenciales cítricos adicionados}

Se realizó el análisis comparativo de las rectas de regresión correspondiente a soluciones de estándares y aceites adicionados a fin de establecer si existe efecto matriz y definir la metodología de calibración del método.

Las gráficas comparativas de las rectas de regresión para cada analito, se muestran en las figuras 69 y 70 .

En la tabla 52 se detallan para cada analito las pendientes y ordenadas al origen de las rectas de regresión correspondientes a soluciones de estándares y muestras adicionadas. 


\section{Gráficas Comparativas de Modelos Ajustados para Thiabendazole}

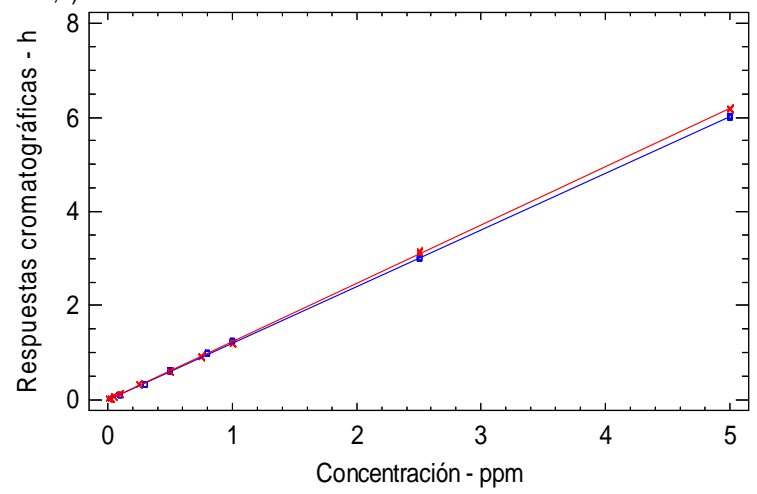

TBZ

$\because$ Aceite esencial

* Std de estándares y aceites adicionados

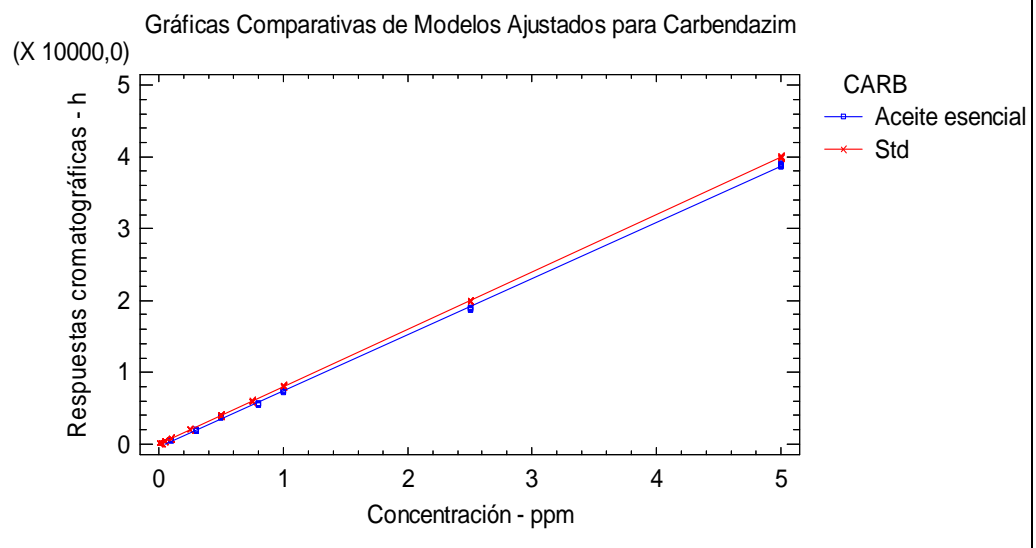

Figura 70. Comparación de rectas de regresión - Carbendazim - Soluciones de estándares y aceites adicionados 
Tabla 52. Interceptos y pendientes - Comparación rectas de regresión Soluciones de estándares y aceites adicionados

\begin{tabular}{|c|c|c|c|c|}
\hline \multirow{2}{*}{ Matriz } & \multicolumn{2}{|c|}{ Thiabendazole } & \multicolumn{2}{c|}{ Carbendazim } \\
\cline { 2 - 5 } & Intercepto & Pendiente & Intercepto & Pendiente \\
\hline Soluciones estándares & $-48,03$ & 12392,3 & $-7,63$ & 7993,26 \\
\hline Aceites adicionados & $-29,65$ & 12041,5 & $-397,41$ & 7823,3 \\
\hline
\end{tabular}

Mediante test ANOVA se determinó si existen diferencias significativas entre los puntos de corte y pendientes de las curvas correspondientes a soluciones estándares y aceites adicionados.

El valor-P para las pendientes y los puntos de corte resultó menor que 0,01 para ambos analitos, por lo que existen diferencias estadísticas entre las pendientes e interceptos de las rectas correspondientes a soluciones estándares y aceites adicionados, para un nivel de confianza del $99 \%$.

Los resultados demuestran la existencia de efecto matriz, por lo que, en todos los casos en los que se determine benzimidazoles en aceites esenciales cítricos aplicando esta metodología, es necesario efectuar calibración previa con muestras adicionadas.

\section{Precisión}

Se determinó precisión a partir de los datos de las respuestas cromatográficas expresadas en alturas de pico, correspondientes a 10 soluciones de estándares de una misma concentración - 0,5 ppm, para un volumen de inyección de $30 \mu \mathrm{l}$, en condiciones repetitivas y reproducibles. En cada caso se 
determinó para $n=10$ y $\alpha=0,05$; desviación estándar, coeficiente de variación porcentual (RSD \%) y mediante test de Student los intervalos de confianza de la media.

La precisión del método para muestras adicionadas se determinó en idénticas condiciones para $n=10$ y $\alpha=0,05$.

Los resultados obtenidos para cada analito se muestran en la tabla 53, los mismos permiten establecer para ambos casos que el método es preciso con un nivel de confianza del $95 \%$.

Tabla 53. Precisión - Valores medios de respuestas cromatográficas expresadas en alturas de pico - Soluciones estándares de benzimidazoles y aceites esenciales adicionados - Volumen de inyección $30 \mu \mathrm{l}-\mathrm{n}=10$ y $\alpha=0,05$

\begin{tabular}{|c|c|c|c|c|}
\hline \multirow{2}{*}{ Analitos } & \multicolumn{4}{|c|}{ Soluciones estándares } \\
\cline { 2 - 5 } & Promedio & $\begin{array}{c}\text { Desviación } \\
\text { estándar }\end{array}$ & RSD \% & $\begin{array}{c}\text { Intervalo de } \\
\text { confianza }\end{array}$ \\
\hline Thiabendazole & 6029 & 41 & $0,67 \%$ & 29 \\
\hline Carbendazim & 3994 & 25 & $0,61 \%$ & 18 \\
\hline \multirow{2}{*}{ Analitos } & \multicolumn{4}{|c|}{ Aceites esenciales adicionados } \\
\cline { 2 - 5 } & Promedio & $\begin{array}{c}\text { Desviación } \\
\text { estándar }\end{array}$ & RSD \% & $\begin{array}{c}\text { Intervalo de } \\
\text { confianza }\end{array}$ \\
\hline Thiabendazole & 6142 & 19 & $0,31 \%$ & 14 \\
\hline Carbendazim & 3822 & 49 & $1,28 \%$ & 35 \\
\hline
\end{tabular}

\section{Límites de cuantificación y detección}

Los límites de detección y cuantificación fueron evaluados a partir de soluciones estándares de thiabendazole y carbendazim a cuatro bajas concentraciones, para $n=10$ y $\alpha=0,05$. Del mismo modo se determinó la sensibilidad del método en muestras adicionadas. 
En la tabla 54 se indican los resultados obtenidos. En la misma, los límites correspondientes a soluciones estándares y aceites adicionados se expresan para cada analito, en ppb (partes por billón) $\circ \mu \mathrm{g} / \mathrm{l}$ de la solución y en ng de masa inyectada para un volumen de inyección $30 \mu \mathrm{l}$.

Tabla 54. Límite de detección y cuantificación - Soluciones estándares y aceites adicionados - Volumen de inyección $30 \mu \mathrm{l}-\mathrm{n}=10$ y $\alpha=0,05$

\begin{tabular}{|c|c|c|c|c|}
\hline \multirow{2}{*}{ Analitos } & \multicolumn{5}{|c|}{ Soluciones estándares } \\
\cline { 2 - 5 } & Límite de detección & Límite de cuantificación \\
\cline { 2 - 5 } & $\mathrm{ppb}$ & $\mathrm{ng}$ & $\mathrm{ppb}$ & $\mathrm{ng}$ \\
\hline \multirow{2}{*}{ Thiabendazole } & 47 & 1,4 & 58 & 1,7 \\
\hline Carbendazim & 52 & 1,6 & 68 & 2,0 \\
\hline \multirow{2}{*}{ Analitos } & \multicolumn{5}{|c|}{ Muestras adicionadas } \\
\cline { 2 - 5 } & Límite de detección & Límite de cuantificación \\
\cline { 2 - 5 } & $\mathrm{ppb}$ & $\mathrm{ng}$ & $\mathrm{ppb}$ & $\mathrm{ng}$ \\
\hline \multirow{2}{*}{ Thiabendazole } & 63 & 1,9 & 68 & 2,0 \\
\hline Carbendazim & 67 & 2,0 & 75 & 2,2 \\
\hline
\end{tabular}

Los resultados muestran que el método es sensible para la determinación simultánea de thiabendazole y carbendazim en soluciones estándares y aceites esenciales adicionados.

\section{Exactitud}

Las muestras de aceites esenciales se procesaron según la metodología explicitada. Muestras de 0,25 a $1 \mathrm{~g}$ de aceite esencial orgánico, identificadas como libres de fungicidas, fueron adicionadas con soluciones estándar de thiabendazole y carbendazim. 
La exactitud del método se determinó a partir del las respuestas cromatográficas expresadas en alturas de pico, obtenidas de quintuplicados de muestras adicionadas a las siguientes concentraciones: $0,10-0,25-0,50-0,75-1,00-$ 2,50 - 5,00 ppm. Los resultados obtenidos se detallan en la siguiente tabla 55.

Se determinaron los parámetros estadísticos correspondientes y mediante test de Student, se estableció que no existen diferencias estadísticamente significativas entre la recuperación media y el $100 \%$ para un nivel de confianza del $95 \%$.

Tabla 55. Exactitud del método - Soluciones acuosas de frutas adicionadas $n=35$ y $\alpha=0,05$.

\begin{tabular}{|c|c|c|c|c|c|c|c|}
\hline Analito & \multicolumn{7}{|c|}{ Thiabendazole } \\
\hline $\begin{array}{c}\text { Concentración } \\
\text { ppm }\end{array}$ & 0,10 & 0,25 & 0,50 & 0,75 & 1,00 & 2,50 & 5,00 \\
\hline $\begin{array}{l}\text { Recuperación } \\
\text { media \% }\end{array}$ & 90,92 & 91,05 & 91,25 & 91,99 & 92,39 & 92,46 & 94,03 \\
\hline $\begin{array}{c}\text { Desviación } \\
\text { estándar }\end{array}$ & 1,08 & 0,97 & 1,67 & 0,91 & 0,97 & 1,04 & 1,17 \\
\hline RSD \% & 1,18 & 1,07 & 1,83 & 0,99 & 1,05 & 1,12 & 1,25 \\
\hline $\begin{array}{l}\text { Intervalo de } \\
\text { confianza +/- }\end{array}$ & 0,36 & 0,49 & 0,84 & 0,46 & 0,49 & 0,53 & 0,59 \\
\hline Analito & \multicolumn{7}{|c|}{ Carbendazim } \\
\hline $\begin{array}{c}\text { Concentración } \\
\text { ppm }\end{array}$ & 0,10 & 0,25 & 0,50 & 0,75 & 1,00 & 2,50 & 5,00 \\
\hline $\begin{array}{c}\text { Recuperación } \\
\text { media \% }\end{array}$ & 95,92 & 96,12 & 97,62 & 95,24 & 96,92 & 97,57 & 96,11 \\
\hline $\begin{array}{c}\text { Desviación } \\
\text { estándar }\end{array}$ & 0,55 & 0,31 & 1,16 & 0,74 & 0,80 & 0,67 & 0,32 \\
\hline RSD \% & 0,57 & 0,32 & 1,19 & 0,78 & 0,82 & 0,68 & 0,33 \\
\hline $\begin{array}{l}\text { Intervalo de } \\
\text { confianza +/- }\end{array}$ & 0,18 & 0,10 & 0,39 & 0,25 & 0,26 & 0,22 & 0,11 \\
\hline
\end{tabular}




\section{Aplicación del método a muestras de aceites esenciales provenientes de industria}

Las muestras fueron tomadas por profesionales de la industria regional, a partir de lotes de aceites cítricos de la producción correspondiente al período 2009. Las mismas correspondieron a lotes caracterizados como aceites prensados en frío, descerados y almacenados en tambores de $200 \mathrm{Kg}$ en condiciones de refrigeración.

Se efectuaron 6 muestreos de cada lote tomándose al azar triplicados de muestras de aceites esenciales de naranja. El método de submuestreo adoptado, fue el de preparación de una muestra de laboratorio compuesta. Es decir que a partir de porciones o unidades individuales representativas, se combinaron para formar una mezcla homogénea o muestra compuesta.

Las muestras compuestas se procesaron según la metodología descrita y determinaron los niveles residuales de thiabendazol y carbendazim en forma conjunta.

De las 36 muestras analizadas, 8 reportaron presencia de thiabendazol en un intervalo de 0,254 - 0,078 ppm y, 5 de carbendazim en un intervalo de 0,210 - 0,106 ppm. De las muestras con detección positiva solo 2 contenían presencia de ambos fungicidas.

Los resultados obtenidos fueron concordantes con los datos de trazabilidad sumnistrados por la industria, en cuanto a la carga residual de fungicidas en fruta ingresada en la línea de producción. 
Por lo tanto, es de prever la existencia de una relativa concordancia entre la carga residual de la fruta ingresante en la línea de producción de la industria, y el contenido residual de estos analitos en los aceites esenciales. 

CAPÍTULO IV

Discusión General y CONCLUSIONES 



\section{DISCUSIÓN GENERAL Y CONCLUSIONES}

En nuestro país los cultivos cítricos orgánicos son muy escasos y de muy bajo volumen de producción por lo que, en la mayoría de los cultivos se utilizan las prácticas agrícolas tradicionales para el control de plagas, tanto en pre o poscosecha. La aplicación de fungicidas, entre los que se encuentran los benzimidazólicos, se efectúan en diversas ocasiones tales como en el "drencher" y/o en los empaques, dada su capacidad de prevenir diversas enfermedades causadas por hongos (Barberá, 1989; Gomyo et al., 1992; Coscolla, 1993; Ito et al., 1998; Pattanasupong et al., 2004; Lima et al., 2006; Danaher et al., 2007; Kinay et al., 2007; Smilanick et al., 2008) que afectan a los frutos y generan importantes pérdidas comerciales.

El carácter sistémico de estos plaguicidas y su capacidad de persistencia en el tejido vegetal, hacen posible la presencia de residuos en los frutos cítricos y en los distintos productos agroindustriales obtenidos a partir de los mismos. En este sentido, los resultados obtenidos en la presente tesis doctoral evidencian la persistencia de residuos de los benzimidazoles analizados tanto en frutas de empaque como en jugos concentrados provenientes de la industria, siendo concordantes con lo publicado por diversos autores tales como: Montti et al., (1998); Yamazaki \& Ninomiya, (1999); Gerard et al., (2000); Schirra et al., (2000); Fernández et al., (2001); Ito et al., (2003); Stajnbaher, D., (2003); Ortelli et al., 
(2004); Veneziano et al., 2004; Albero et al., (2005); Nozal et al., (2005); Blasco et al., (2006); García-Reyes et al., (2006); Bogialli y Di Corcia, (2007); Kinay et al., (2007); Romero-González et al., (2008); Radišic et al., (2009); Dreassi et al., (2010); Gilbert et al., (2010),; Yoshioka et al., (2010).

En función de las exigencias cada vez mayores de los organismos reguladores y los mercados importadores, respecto a los niveles de detección y cuantificación de los residuos de plaguicidas en productos frescos y procesados, se establecieron como objetivos aplicar y optimizar diversas metodologías analíticas a fin de lograr la adecuada determinación de los mismos en las diferentes matrices cítricas.

En la revisión bibliográfica se pudo observar una marcada tendencia al análisis de multiresiduos de plaguicidas, hecho que se compatibiliza con la necesidad de reducir costos, tiempo de análisis y uso de solventes tóxicos. La mayoría de los autores utilizan técnicas extractivas y métodos cromatográficos similares a los aplicados en el presente trabajo para la identificación y cuantificación de estos analitos, aunque se observan algunas modificaciones en las diferentes etapas del proceso metodológico, lo cual también es aplicable para los métodos cromatográficos de cuantificación.

Los fundamentos teóricos que sustentan las metodologías adoptadas han sido propuestos y aplicados por numerosos autores, siendo los más recientes aquellos que utilizan adsorbentes específicos para retener los analitos extraídos de la muestra y/o eliminar las impurezas, como la SPE y el método QuEChERS; y aquellos que efectúan la extracción con fibras de 
sílica recubiertas con diferentes polímeros selectivos como la SPME o, técnicas similares, como el método de dispersión de matriz en fase sólida (MSPD), extracción con membranas o barras magnéticas recubiertas de absorbentes específicos (SBSE) (Pawliszyn, 1997; Beltran et al., 2000; Kataoka et al., 2000; Lambropoulou et al., 2000; Lord y Pawliszyn, 2000; Poole et al., 2000; Pérez-Trujillo et al., 2002; Teske y Engewald, 2002; Stajnbaher et al. 2003; Juan-García et al., 2004; Mastovska y Lehotay, 2004; Sjaak y Pawliszyn, 2004; Ouyang et al., 2005; Juan-García et al., 2005; Xiao-Gang et al., 2005; Dietz et al., 2006; Msagati y Nindi, 2006; Sauret-Szczepansky et al., 2006; Zimmermann et al., 2006; Danaher et al., 2007; Fenoll et al., 2007; Leandro et al., 2007; Ortiz y Sarabia, 2007; Rozet et al., 2007; Lesueur et al., 2008; Nguyen et al., 2008; González-Rodríguez et al., 2008a-2008b; González- Rodríguez et al., 2009; Walorczyk et al., 2009; Guo et al., 2010; Wilkowska y Biziuk, 2010).

Las publicaciones de los diferentes autores citados, aportaron información relevante que fue utilizada en distintas etapas del desarrollo metodológico de la presente tesis doctoral, brindando un marco referencial importante para el análisis de los resultados obtenidos.

Para la selección del solvente de las soluciones de estándares destinadas a la optimización de las condiciones cromatográficas (GC-NPD) por inyección directa, se adoptaron los recomendados por Navarro et al. (2002); Ouyang et al. (2005) y Stajnbaher (2008), siendo en casi todas las publicaciones el etilacetato el solvente más utilizado. Se determinó la curva de calibración (masa inyectada vs. concentración), precisión y 
sensibilidad del sistema, resultando estos parámetros semejantes a los correspondientes a dichos autores.

En el desarrollo y optimización del proceso extractivo por SPME, se tuvieron en cuenta los diferentes aspectos y procedimientos aplicados por distintos autores, entre los que se pueden citar: Pawliszyn (1997); Beltran et al. (2000); Lord y Pawliszyn (2000); Kataoka et al. (2000); Lambropoulou et al. (2000); Dietz et al. (2006); Sauret-Szczepansky et al. (2006).

Los criterios adoptados para establecer el rango de concentración para las diferentes matrices fueron establecidos en función de lo publicado por Blasco et al., (2002); Navarro et al., (2002); Zambonin et al., (2004).

Los procedimientos de comparación de fibras para determinar la eficiencia de los diferentes polímeros fueron similares a los realizados por Pawliszyn (1997); Dietz et al. (2006) y Zimmermann et al. (2006).

Los resultados obtenidos respecto a la optimización de los procesos extractivos en las diferentes matrices, presentan similitudes importantes respecto a los obtenidos por otros autores, fundamentalmente en lo que respecta a la determinación de la eficiencia extractiva, perfiles de concentración, coeficientes de difusión e importancia de las constantes de distribución absorbente/agua para interpretar la cinética del proceso de la SPME; aunque en algunos casos el tratamiento previo de las muestra puede diferir ya que, al tratarse de análisis multiresiduos de diferentes plaguicidas y/o tipos de matrices, deben modificarse algunos parámetros tales como el $\mathrm{pH}$, temperatura y tipos de polímeros. Así por ejemplo, Menezes Filho et al. (2010), en el 
análisis multiresiduos de muestras acuosas de frutas (mangos) logra extraer al TBZ utilizando como polímero el poliacrilato (P.A.), a $50{ }^{\circ} \mathrm{C}$ y a 30 minutos de inmersión de la fibra, sin embargo este polímero no dio respuestas adecuadas para las matrices cítricas en las condiciones establecidas.

Diversas publicaciones han sido consideradas a los fines de adoptar los métodos para la identificación y cuantificación de los analitos en matrices acuosas, frutas, jugos y vinos por cromatografía líquida y gaseosa con diferentes tipos de detectores (Anastassiades et al., 1998; Ito et al., 1998; Di Muccio et al., 1999; Yamazaki y Ninomiya, 1999; Hada et al., 2000; Fernández et al., 2001; Navarro et al., 2002; Teske y Engewald, 2002; Anastassiades et al., 2003; López-Blanco et al., 2003; Smith , R.,2003; Stajnbaher et al., 2003; Ortelli et al., 2004; Zambonin et al., 2004; Thurman et al., 2005; Bogialli y Di Corcia, 2007; Sagratini et al., 2007; Soler y Picó, 2007; Venkateswarlu et al., 2007; Cacho et al., 2008; Romero-González et al., 2008; Radisia et al., 2009; Barahona et al., 2010; Dreassi et al., 2010; Gilbert López et al., 2010; Guo et al., 2010; Menezes Filho et al., 2010; Xiangyang Qi, 2010; Yoshioka et al., 2010). De las mismas se recopiló información relevante respecto a condiciones cromatográficas, selección de solventes para la preparación de estándares, volumen de inyección, longitudes de onda, etc; permitiendo los mas recientes como marco de referencia para el análisis de los resultados obtenidos.

Los rangos de concentraciones para las soluciones estándares y muestras adicionadas fueron seleccionadas de acuerdo a los LMRs, tal como lo plantean algunos de los autores 
anteriormente mencionados. Los resultados correspondientes a los parámetros de calibración, precisión, recuperación y sensibilidad del método, fueron concordantes con los obtenidos por diversos autores, aunque los límites de detección y cuantificación varían en función de la especificidad y sensibilidad del sistema de detección utilizado. Los porcentajes de recuperación obtenidos en general para todas las muestras, fueron en algunos casos mayores a los citados en las referencias bibliográficas correspondientes. Asimismo los coeficientes de variación relativos presentaron valores dentro de los rangos considerados adecuados para este tipo de matrices y menores que los reportados por algunos autores para matrices similares (Lambropoulou et al., 2000; Blasco et al., 2002; Navarro et al., 2002; Sanchez-Brunete et al., 2002; Ortelli et al., 2004; Zambonin et al., 2004; Barahona et al., 2010; Dreassi et al., 2010; Menezes Filho et al., 2010; Xiangyang Qi et al., 2010).

La metodología de calibración adoptada fue establecida a partir de muestras adicionadas en el intervalo de concentraciones en las que se consideran los LMRs, siendo la misma coincidente con los criterios establecidos en las referencias bibliográficas, ya que el efecto matriz es observable en todos los casos.

Los niveles residuales detectados en muestras de frutas y jugos concentrados han sido muy variables, sin embargo dichos valores son comparables a los determinados por los autores anteriormente citados.

En muestras reales de "vinos cítricos" no se han detectado residuos de estos fungicidas, a diferencia de los observados para vinos de uva por Zambonin et al. (2004). Sin embargo, se han 
observado residuos en este tipo de matriz pero aplicando otras metodologías de detección, tales como los utilizados por Navarro et al. (2000); Juan-García et al. (2004); Nozal et al. (2005); Venkateswarlu et al. (2007).

En la optimización de los parámetros y utilización del PTV para la determinación e identificación por GC-MSD, el procedimiento adoptado fue similar al desarrollado por Stajnbaher et al. (2003), aunque se utilizó un inserto diferente en el PTV, el número de inyecciones fue semejante pero con un volumen mayor de muestras, obteniéndose resultados adecuados para la identificación de los espectros de masa de los analitos evaluados.

Para la determinación de estos fungicidas en las diferentes matrices por PTV en modo venteo de solvente y GC/MSD se adoptó el método QuEChERS, aunque se introdujeron algunas modificaciones al mismo, ya que se utilizó como solvente extractante el diclorometano y posterior clean up con diol, pero se utilizó para extraer los analitos del adsorbente el mismo solvente informado en la mayoría de las publicaciones, es decir el acetonitrilo (Hada et al., 2000; Heidin et al., 2001; Zrostlíkaová et al., 2001; Concha-Graña et al., 2002; Teske y Engewald, 2002; Soler y Picó , 2007; Leseuer et al., 2008; Romero- González et al., 2008; Gilbert-López et al., 2010; Guo et al., 2010).

Respecto a la determinación de TBZ y carbendazim en aceites esenciales cítricos de naranja, los datos bibliográficos sobre la temática son escasos o no se han informado. El procedimiento adoptado para la metodología extractiva fue la SPE y los resultados de recuperación, precisión sensibilidad del método fueron adecuados, los que pueden ser relativamente 
comparados con los publicados para frutas cítricas, bebida a base de frutas, jugos y otras matrices vegetales que aplican metodologías semejantes (Anastassiades y Schwack 1998; Ito et al., 1998; Di Muccio et al., 1999; Chaulet et al., 2000; Danaher et al., 2007; Soler y Pico, 2007; Cacho et al., 2008; RomeroGonzález et al., 2008; Gilbert et al., 2010).

Finalmente, y en función de los resultados obtenidos, es posible arribar a las siguientes conclusiones generales $y$ específicas:

1. La microextracción en fase sólida acoplada a cromatografía gaseosa con detector de Nitróneno-Fósforo (SPME/GC/NPD), constituye una metodología analítica apta para la determinación multiresiduo de fungicidas benzimidazólicos, tales como metiltiofanato, tiofanato y thiabendazole, en matrices cítricas.

Sustentan la misma las siguientes conclusiones específicas:

- Los fungicidas benzimidazólicos, de aplicación en cítricos, factibles de ser analizados por esta metodología fueron: metiltiofanato, tiofanatao y thiabendazole. Las matrices involucradas fueron: frutas cítricas, jugos cítricos concentrados y productos cítricos fermentados ("vino cítrico").

- Los resultados correspondientes a la determinación de estos fungicidas por cromatografía gaseosa con detector de nitrógeno-fósforo e inyección directa (GC/NPD), 
indicaron que el método es adecuado, siendo lineal en el rango de concentraciones previsto, preciso y sensible. El mismo permitió establecer las bases para la continuidad del desarrollo metodológico.

- La optimización de las condiciones de extracción por SPME permitieron establecer los parámetos más adecuados del proceso extractivo. La mayor transferencia de los analitos desde la matriz se logró adoptando el modo de extracción directo con carbowax/divinilbenceno como polímero de recubrimiento a un tiempo de extracción de 10 minutos con agitación magnética y neutralidad del medio acuoso, para un volumen de muestra de $50 \mathrm{ml}$.

- Las condiciones cromatográficas establecidas para la determinación por SPME/GC/NPD, en función de las optimizadas por inyección directa, con un incremento de tiempo de "splitless" y reducción del diámetro del "liner"; permitieron la completa desorción de los analitos en el puerto de inyección y la adecuada resolución e identificación de los picos en los cromatogramas.

- Los perfiles de tiempo de extracción para soluciones acuosas de estándares y muestras adicionadas, permitieron establecer tiempos de equilibrio, masa total absorbida, volumen mínimo de muestra, constantes de distribución y coeficientes de difusión para cada analito y matriz.

- El método resultó lineal para el intervalo de concentración previsto con adecuada exactitud, dado los elevados porcentajes de recuperación obtenidos, y elevada 
sensibilidad. Los límites de detección y cuantificación permitieron establecer que el método es adecuado para la determinación de niveles traza de estos fungicidas.

- La comparación de rectas de regresión correspondientes a soluciones de estándares y muestras adicionadas, indicó en todos los casos la existencia de efecto matriz; por lo que se estableció la calibración con matriz adicionada como método para el análisis de muestras incógnitas.

- La metodología optimizada se aplicó a la determinación de residuos de los fungicidas indicados en 18 muestras de frutas cítricas de empaque y 70 muestras de jugos cítricos concentrados de la industria, con adecuada reproducibilidad y resultados satisfactorios, compatibles con los datos de trazabilidad suministrados.

- La aplicación de la metodología optimizada para la determinación de los mismos analitos por cromatografía gaseosa y espectrometría de masas (SPME/GC/MSD), previa optimización de los parámetros del inyector de vaporización de temperatura programada en modo "split/spliless" y venteo de solvente, permitió identificar los analitos extraídos por la fibra en función de sus espectros correspondientes.

- La comparación de las metodologías por inyeccion directa y desorción de los analitos desde la fibra, en función de las respuestas cromatográficas y/o masa inyectada, indicó un incremento de la sensibilidad del método por SPME respecto a los tradicionales de extracción (líquido-líquido, SPE). 
- La metodología optimizada (SPME/GC/NPD) logra incrementar la sensibilidad y especificidad analítica, reducir costos y tiempo de análisis y, minimizar o eliminar el uso de solventes orgánicos de elevada pureza y toxicidad.

2. La extracción en fase sólida acoplada a cromatografía líquida de alta resolución con detector de arreglo de diodos (SPE/HPLC/DAD) permite la determinación simultánea de thiabendazole y carbendazim en aceites esenciales cítricos.

Sustentan la misma las siguientes conclusiones específicas:

- Los fungicidas benzimidazólicos factibles de ser analizados por esta metodología en aceites eseciales cítricos fueron: thiabendazole y carbendazim.

- Las condiciones cromatográficas establecidas para la determinación por HPLC/DAD permitieron la adecuada resolución e identificación de los picos en los cromatogramas: longitud de onda de $303 \mathrm{~nm}$ para thiabendazole y de $285 \mathrm{~nm}$ para carbendazim, temperatura de columna $40{ }^{\circ} \mathrm{C}$, velocidad de flujo $0,8 \mathrm{ml} / \mathrm{min}$, vo lumen de inyección $30 \mu \mathrm{l}$, fase móvil mezcla 40:60 v/v $\mathrm{H}_{2} \mathrm{KPO}_{4} 5$ $\mathrm{mM}$ y Acetonitrilo/Metanol aciduladas con $0,01 \%$ de ácido acético.

- La optimización de las condiciones de extracción por SPE permitieron establecer los parámetos mas adecuados del proceso extractivo, adoptándose como adsorbente Diol y como eluyente la propia fase móvil. 
- Los resultados correspondientes a la determinación de los fungicidas por SPE/HPLC/DAD en soluciones de estándares y muestras adicionadas indicaron que el método es adecuado, siendo lineal en el rango de concentraciones previsto, con adecuada exactitud, dado los elevados porcentajes de recuperación obtenidos y elevada sensibilidad. Los límites de detección y cuantificación permitieron establecer que el método es adecuado para la determinación de niveles traza de estos fungicidas.

- La comparación de rectas de regresión correspondientes a soluciones de estándares y muestras adicionadas, indicó la existencia de efecto matriz; por lo que se estableció la calibración con matriz adicionada como método para el análisis de muestras incógnitas.

- La metodología optimizada se aplicó a la determinación de residuos de los fungicidas indicados en 36 muestras de aceites esenciales de la industria, con resultados concordantes con los datos de trazabilidad sumnistrados, en cuanto a la carga residual de fungicidas en fruta ingresada en la línea de producción.

- La metodología desarrollada permite, respecto a los métodos tradicionales de extracción (líquido-líquido), reducir el uso de solventes orgánicos de elevada pureza y toxicidad, disminuir costos y tiempo de análisis.

Las metodologías aplicadas y optimizadas permiten brindar al sector citrícola una herramienta de fundamental importancia 
para la atención y control de las problemáticas vinculadas con la producción, industrialización y comercialización de sus productos; que hace preveer una elevada factibilidad de transferencia al medio. 

CAPÍTULO V

REFERENCIAS BIBLIOGRÁFICAS 



\section{REFERENCIAS BIBLIOGRÁFICAS}

Albero, B.; Sánchez-Brunete, C. \& Tadeo, J.L. (2005). Multiresidue determination of pesticides in juice by solid-phase extraction and gas chromatography-mass spectrometry. Talanta, 66, 917-924.

Anastassiades, M. \& Schwack, W. (1998). Analysis of carbendazim, benomyl, thiophanate methyl and 2,4dichlorophenoxyacetic acid in fruits and vegetables after supercritical fluid extraction. Journal of Chromatography $A$, 825, 45-54.

Arthur, C and Pawliszyn, J. (1990). Solid Phase Microextraction with Thermal Desorption Using Fused Silica Optical Fibers. Analytical Chemistry, 62, 2145.

Balizs, Gabor. (1999). Determination of benzimidazole residues using liquid chromatography and tandem mass spectrometry. Journal of Chromatography B, 727, 167-177.

Barahona, F.; Gjelstad, A.; Pedersen-Bjergaard, S.; Rasmussen, K.E. (2010). Hollow fiber-liquid-phase microextraction of fungicides from orange juices. Journal of Chromatography $A$, 1217, 1989-1994. 
Barberá, C. (1989). Pesticidas Agrícolas. 4º Edic. Editorial Omega. Barcelona.

Bean, K. A. \& Henion, J. D. (1997). Determination of carbendazim in soil and lake water by immunoaffinity extraction and coupled-column liquid chromatography-tandem mass spectrometry. Journal of Chromatography A, 791, 119-126.

Belardi, R. and Pawlinszyn, J. (1989). The Application of Chemically Modified Fused Silica Fibers in the Extraction of Organics from Water Matrix Samples and their Rapid Transfer to Capillary Columns. Water Pollution Research Journal of Canada, 24, 179.

Belmonte Vega, A.; Garrido Frenich, A. \& Martínez Vidal, J. L. (2005). Monitoring of pesticedes in agricultural water and soil samples from Andalusia by liquid chromatography coupled to mass spectrometry. Analytica Chimica Acta, 538, 117-127.

Beltran, J.; López, F.J. \& Hernández, F. (2000). Solid-phase microextraction in pesticide residue analysis. Journal of Chromatography A, 885, 389-404.

Bernal, J. L.; del Nozal, M. J.; Toribio, L.; Jiménez, J. J. \& Atienza, J. (1997). High-performance liquid chromatographic determination of benomyl and carbendazim residues in apiarian samples. Journal of Chromatography A, 787, 129136. 
Blasco, C.; Font, G. \& Picó, Y. (2002). Comparison of microextraction procedures to determine pesticides in oranges by liquid chromatography-mass spectrometry. Journal of Chromatography A, 970, 201-212.

Bogialli S.; Di Corcia A. (2007). Matrix solid-phase dispersion as a valuable tool for extracting contaminants from foodstuffs. $J$. Biochem. Biophys. Methods, 70, 163-179.

Bosboom, J.C.; Janssen, H.; Mol, H.G.J.; Cramers, C.A. (1996). Large-volume injection in capillary gas chromatography using a programmed-temperature vaporizing injector in the oncolumn or solvent-vent injection mode. Journal of Chromatography A, 724, 384-391.

Boudina, A.; Emmelin, C.; Baaliouamer,A.; Grenier-Loustalot,M.F.; Chovelon J.M. (2003). Photochemical behaviour of carbendazim in aqueous solution. Chemosphere, 50, 649655.

Brito, N. M.; Navickiene, S.; Polese, L.; Jardim, E. F. G. ; Abakerli, R. B. \& Ribeiro, M. L. (2002). Determination of pesticide in coconut water by liquid-liquid extraction and gas chromatography with electron-capture plus thermionic specific detection and solid-phase extraction and highperformance liquid chromatography with ultraviolet detection. Journal of Chromatography A, 957, 201-209.

Cacho, C.; Schweitz, L.; Turiel, E.; Pérez-Conde C. (2008). Molecularly imprinted capillary electrochromatography for 
selective determination of thiabendazole in citrus samples. Journal of Chromatography A, 1179, 216-223.

Chaulet, M. R.; Montti, M. T.; Gerard, J. A.;Raviol, F.; Subovich G. (2000). Determinación de Thiabendazole en Aceite Esencial de Naranja Valencia. Series de Ciencia e Ingeniería de Alimentos. Investigación El Postgrado del IAD-DTA. Editorial de la Universidad Politécnica de Valencia. Valencia, España. Vol. II - I.S.B.N. N84-9705-013-4 - p.p. 115-124.

Choudhury,T.; Gerhart,K.; Mawhinney,T. (1996). Solid-Phase Microextraction of Nitrogen-and Phosphorus-Containing Pesticides from Water and Gas Chromatographic Analysis. Environmental Science Technology, 30, 3259-3265.

Codex Alimentarius. Normas Alimentarias FAO/OMS. Límites Máximos de Residuos (LMR) de Plaguicidas en Alimentos. $<$ http://www.codexalimentarius.net/mrls/pestdes/jsp/pest_qs.jsp> Consulta, 2008.

Codex Alimentarius. Normas Alimentarias FAO/OMS. (1999). Métodos de muestreo recomendados para la determinación de residuos de plaguicidas a efectos del cumplimiento de los LMR. CAC/GL 33, p.p. 10-11.

Codex Alimentarius. Normas Alimentarias FAO/OMS. (2005). Directrices para el Uso de la Espectrometría de Masas (EM) en la Identificación, Confirmación y Determinación Cuantitativa de Residuos. CAC/GL 56. 
Concha-Graña, E.; Turnes-Carou, M. I.; Muniategui-Lorenzo, S.; López-Mahía, P.; Fernández-Fernández, E. \& PradaRodríguez, D. (2002). Optimization of a programmed splitsplitless injector in the chromatographic-mass spectrometric determination of organochlorine pesticides. Journal of Chromatography A, 958, 17-24.

Coscolla, R. (1993). Residuos de Plaguicidas en Alimentos Vegetales. Ed. Mundi-Prensa. Madrid.

Danaher, M.; O’Keeffe, M.; Glennon, J.D. (2003). Development and optimisation of a method for the extraction of benzimidazoles from animal liver using supercritical carbon dioxide. Analytica Chimica Acta, 483, 313-324.

Danaher, M.; De Ruyck, H.; Crooks, S.R.H.; Dowling G.; O’Keeffe, M. (2007). Review of methodology for the determination of benzimidazole residues in biological matrices. Journal of Chromatography $B, 845,1-37$.

Dangond Araujo, J. y Guerrero Dallos, J. (2006). Metodología para la determinación de residuos de fungicidas benzimidazólicos en fresa y lechuga por HPLC-DAD. Rev. Colombiana de Química, [online], vol. 35, no. 1, p. 67-79. ISSN 0120-280 4. $<$ http://www.scielo.org.co/scielo.php?script=sci_arttext\&pid= S0120-28042006000100007\&l ng =es\&nrm=iso>. Consulta, 2007. 
Dansa, A. (2007). Perfil del Mercado de Cítricos.

$<$ http://www.sagpya.mecon.gov.ar/new/0-

0/programas/dma/frutas/perfil_citricos_2006.pdf > Consulta, 2007.

De Ruyck, H.; Daeseleire, E.; De Ridder, H.; Van Renterghem, R. (2002). Development and validation of a liquid chromatographic-electrospray tandem mass spectrometric multiresidue method for anthelmintics in milk. Journal of Chromatography A, 976, 181-194.

Di Muccio, A.; Girolimetti, S.; Barbini, D.A.; Pelosi, P.; Generali, T.; Vergori, L.; De Merulis, G.; Leonelli, A.; Stefanelli, P. (1999). Selective clean-up applicable to aqueous acetone extracts for the determination of carbendazim and thiabendazole in fruists and vegetables by high-performance liquid chromatography with UV detection. Journal of Chromatography A, 833, 61-65.

Dietz, C.; Sanz, J \& Cámara, C. (2006). Recent developments in solid-phase microextraction coatings and related techniques. Journal of Chromatography A, 1103, 183-192.

Dowling, G.; Cantwell, H.; O’Keeffe, M. \& Smyth, M. R. (2005). Multi-residue method for the determination of benzimidazoles in bovine liver. Analytica Chimica Acta, 529, 285-292.

Dreassi, E.; Zanfini, A.; Zizzari, A. T.; La Rosa, C.; Botta, M.; Corbini, G. (2010). Lc/Esi/Ms/Ms determination of 
postharvest fungicide residues in citrus juices. LWT - Food Science and Technology 43, 1301-1306.

Eckert, J.W. and J.M. Ogawa. (1985). The chemical control of postharvest diseases: subtropical and tropical fruits. Annual Review of Phytopathology. 23, 421-454.

Engewald, W.; Teske, J. \& Efer, J. (1999). Programmed temperature vaporisers-based large volume injection in capillary gas chromatography. Journal of Chromatography A, 842, 143-161.

Federación Argentina del Citrus (FEDERCITRUS). (2007). Actividad citrícola Argentina. <http:Ilwww.federcitrus.org/ actividad-citricola-2007.pdf> Consulta, 2008.

Federación Argentina del Citrus (FEDERCITRUS). (2010). Actividad citrícola Argentina. <http:|lwww.federcitrus.org/ actividad-citricola-2010. pdf> Consulta, 2010.

Fenoll, J.; Hellín, P.; Martínez, C.M.; Miguel, M. \& Flores, P. (2007) Multiresidue method for analysis of pesticides in pepper and tomato by gas chromatography with nitrogen-phosphorus detection. Food Chemistry, 105, 711-719.

Fernández, F.; Beltran J. and J.V. Sancho, J.V. (1993). Study of multi-residue methods for the determination of selected pesticides in groundwater. The Science of the total Environment, 132, 297-312. 
Fritz, J.S. (1999). Analytical Solid-Phase Extraction. John Wiley \& Sons, Inc. New York.

García-Reyes, J.F.; Ferrer, C.; Gómez-Ramos M. J.; Molina-Díaz, A.; Fernández-Alba, A.R. (2007). Determination of pesticide residues in olive oil and olives. Trends in Analytical Chemistry, Vol. 26, No. 3.

Gerard, J.; Montti, M.; Chaulet, M.; Raviol, F.; Garavello, F.; Subovich, G. (2000). Penetracion y Persistencia del Thiabendazole en Naranja Valencia. Series de Ciencia e Ingeniería de Alimentos. Investigación El Postgrado del IADDTA. Editorial de la Universidad Politécnica de Valencia. Valencia, España. Vol. II - I.S.B.N. N84-9705-013 -4 - p.p. 241-252.

Gilbert-López, B.; García-Reyes, J. F.; Mezcua, M.; RamosMartos, N.; Fernández-Alba, A.R.; Molina-Díaz, A. (2010). Multi-residue determination of pesticides in fruit-based soft drinks by fast liquid chromatography time-of-flight mass spectrometry. Talanta, 81, 1310-1321.

Gomyo, Takeshi; Ozawa, Michihiro; Kobayashi, Shigeru. (1992). Analytical Method for Determining the Total Content of Methyl Benzimidazole Carbamate Fungicides in Water by Column Switching Liquid Chromatography Mass Spectrometry. Analytical Sciences, Vol. 8, 687-690. 
Gonzalez, F.R.; Nardillo, A.M. (1999). Retention index in temperature-programmed gas chromatography. Journal of Chromatography A, 842, 29-49.

González Rodríguez, R. M.; Rial Otero, R.; Cancho Grande, B. \& Simal Gándara, J. (2008a). Determination of 23 pesticide residues in leafy vegetables using gas chromatography-ion trap mass spectrometry and analyte protectants. Journal of Chromatography A, 1196-1197, 100-109.

González Rodríguez, R. M.; Rial Otero, R.; Cancho Grande, B. \& Simal Gándara, J. (2008b). Occurrence of fungicide and insecticide residues in trade samples of leafy vegetables. Food Chemistry, 107, 1342-1347.

González Rodríguez, Cancho Grande, B., Torrado-Agrasar, J., Mazaira-Pérez, J. (2009) Evolution of tebuconazole residues through the winemaking process. Food Chemistry, 117, 529537.

Grob, K. \& Biedermann, M. (1996). Vaporising systems for large volume injection or on-line transfer into gas chromatography: classification, critical remarks and suggestions. Journal of Chromatography A, 750, 11-23.

Guo, B.; Huang, Z.; Wang, M.; Wang, X.; Zhang, Y.; Chen, B.; Li, Y.; Yan, H.; Yao, S.(2010). Simultaneous direct analysis of benzimidazole fungicides and relevant metabolites in agricultural products based on multifunction dispersive solidphase extraction and liquid chromatography-mass 
spectrometry. Journal of Chromatography A, 1217, 47964807.

Hada, M.; Takino, M.; Yamagami, T.; Daishima, S. \& Yamaguchi, K. (2000). Trace analysis of pesticide residues in water by high-speed narrow-bore capillary gas chromatography-mass spectrometry with programmable temperature vaporizer. Journal of Chromatography A, 874, 81-90.

Heiden, A. C.; Kolahgar, B. \& Pfannkoch, E. (2001). Benefits of Using Programmed Temperature Vaporizers (PTVs) instead of Hot Split/Splitless Inlets for Measurements of Volatiles by Liquid, Headspace, and Solid Phase MicroExtraction (SPME) Techniques.

InfoAgro. Límite Máximo de Residuos en la Legislación Española. (2008). $<$ <ttp://www.infoagro.com/abonos/lmr_cultivo.asp?id=2> y <http://ec.europa.eu/sanco_pesticides/public/index.cfm> Consulta, 2008.

Instituto Nacional de Tecnología Agropecuaria - INTA. (2006). Informes Regionales.

$<$ http://www.sagpya.mecon.gov.ar/new/0-

0/programas/dma/frutas/perfil_citricos_2006.pdf>. Consulta, 2007.

Ito, Yuko; Ikai, Yoshitomo; Oka, Hisao; Hayakawa, Junko; Kagami, Tadaaki. (1998). Application of ion-exchange cartridge cleanup in food analysis I. Simultaneous determination of 
thiabendazole and imazalil in citrus fruit and banana using high-performance liquid chromatography with ultraviolet detection. Journal of Chromatography A, 810, 81-87.

Jansson; C.; Pihlström, T.; Österdahl, B.; Markides, K. (2004). A new multi-residue method for analysis of pesticide residues in fruit and vegetables using liquid chromatography with tandem mass spectrometric detection. Journal of Chromatography A, 1023, 93-104.

Jeannot, R.; Sabik, H.; Sauvard, E. \& Genin, E. (2000). Application of liquid chromatography with mass spectrometry combined with photodiode array detection and tandem mass spectrometry for monitoring pesticides in surface waters. Journal of Chromatography A, 879, 51-71.

Juan-García, A.; Mañes, J.; Font, G. \& Picó, Y. (2004). Evaluation of solid-phase extraction and stir-bar sorptive extraction for the determination of fungicide residues at low- $\mu \mathrm{g} \mathrm{kg-1}$ levels in grapes by liquid chromatography-mass spectrometry.

Juan-Garcia, A.; Picó, Y. \& Font, G. (2005). Capillary electrophoresis for analyzing pesticides in fruits and vegetables using solid-phase extraction and stir-bar sorptive extraction. Journal of Chromatography A, 1073, 229-236.

Justo, Alicia M.; Rivera, Ines. (2007). Inserción de Argentina en el Mercado Mundial de Cítricos. En: Estudios Socioeconómicos de los Sistemas Agroalimentarios y Agroindustriales. Instituto Nacional de Tecnología Agropecuaria (INTA). № 1, p. 16. 
Kataoka, H.; Lord, H. L. \& Pawlinszyn, J. (2000). Applications of solid-phase microextraction in food analysis. Journal of Chromatography A, 880, 35-62.

Kinay, P.; Mansour, M.F.; Gabler, F.M.; Margosan, D.A.; Smilanick, J.L. (2007). Characterization of fungicide-resistant isolates of Penicillium digitatum collected in California. Crop Protection, 26,647-656.

Kooijman, S.A.L.M.; Jager, T. \& Kooi, B. W. (2004). The relationship between elimination rates and partition coefficients. Chemosphere 57, 745-753.

Lambropoulou, D. A.; Konstantinou, I. K. \& Albanis, T. A. (2000). Determination of fungicides in natural waters using solidphase microextraction and gas chromatography coupled with electron-capture and mass spectrometric detection. Journal of Chromatography A, 893, 143-156.

Lacassie, E.; Marquet, P.; Gaulier, J.; Dreyfuss, M.; Lachâtre, G. (2001). Sensitive and specific multiresidue methods for the determination of pesticides of various classes in clinical and forensic toxicology. Forensic Science International, 121, 116125.

Leandro, C.C.; Hancock, P.; Fussell, R.J. \& Keely, B.J. (2007) Quantification and screening of pesticide residues in food by gas chromatography-exact mass time-of-flight mass spectrometry. Journal of Chromatography A, 1166, 152-162. 
Lesueur, C.; Knittl, P.; Gartner, M.; Mentler, A. \& Fuerhacker, M. (2008) Analysis of 140 pesticides from conventional farming foodstuff samples after extraction with the modified QuECheRS method. Food Control, 19, 906-914.

López-Blanco, M.C.; Blanco-Cid, S.; Cancho-Grande, B.; SimalGándara, J. (2003). A pplication of single-drop microextraction and comparison with solid-phase microextraction and solid-phase extraction for the determination of a- and b-endosulfan in water samples by gas chromatography-electron-capture detection. Journal of Chromatography A, 984, 245-252.

Lord, Heather; Pawliszyn, Janusz. (2000). Evolution of solid-phase microextraction technology. Journal of Chromatography $A$, 885, 153-193.

Lord, Heather; Pawliszyn, Janusz. (2000). Microextraction of drugs. Journal of Chromatography A, 902, 17-63.

Mastovska, K. \& Lehotay, S. J. (2004). Evaluation of common organic solvents for gas chromatographic analysis and stability of multiclass pesticide residues. Journal of Chromatography A, 1040, 259-272.

Mazzuz, C. F. (1996). Calidad de Frutos Cítricos. Manual para su gestión desde la recolección hasta la expedición. Ediciones Horticultura S.L. España. 
Meneses Filho, A. M.; Neves dos Santos, F.; Pereira, A.P. (2010). Development, validation and application of a methodology based on solid-phase micro extraction followed by gas chromatography coupled to mass spectrometry (SPME/GCMS) for the determination of pesticide residues in mangoes. Talanta, 81, 346-354.

Meneses Filho A.M.; Neves dos Santos F.; Pereira P.A. (2010). Development, validation and application of a method based on DI-SPME and GC-MS for determination of pesticides of different chemical groups in surface and groundwater samples. Microchemical Journal, 96,139-145.

Miller, J. C.; Miller, J. N. (1993). Estadística para Química Analítica. Addison-Wesley Iberoamerican S.A. Wilmington, Delaware.

Montti M., Gerard J., Chaulet M., 1998. "Penetración y Persistencia del Thiabendazole en Naranja Valencia y Jugos Concentrados. Estratto da Essenze - Derivati Agrumari Anno LXVIII n.2, 124-139.

Montti, T.; Chaulet, M.; Garavello, F.; Gerard, J. (2000). Determinación de Imazalil en Soluciones Acuosas por Microextracción en Fase Sólida. Series de Ciencia e Ingeniería de Alimentos. Investigación El Postgrado del IADDTA. Editorial de la Universidad Politécnica de Valencia. Valencia, España. Vol. II - I.S.B.N. N 84-9705-013-4 - p.p. 441- 460 . 
Mol, H. G. J.; Janssen, H. G.; Cramers, C. A. \& Brinkman, U. A. Th. (1996). Large-volume injection in gas chromatographic trace analysis using temperature-programmable (PTV) injectors. Trends in analytical chemistry, vol. $15, n^{\circ} 4$.

Navarro, M.; Picó, R.; Marín, R. \& Mañes, J. (2002). Application of matrix solid-phase dispersion to the determination of a new generation of fungicides in fruits and vegetables. Journal of Chromatography A, 968, 201-209.

Nguyen, T.D.; Yu, J.E.; Lee, D.M. \& Lee, G.H. (2008) A multiresidue method for the determination of 107 pesticides in cabbage and radish using QuEChERS sample preparation method and gas chromatography mass spectrometry. Food Chemistry, 110, 207-213.

Nozal, M.J.; Bernal, J.L.; Jimenez, J.J.; Martín, M.T. \& Bernal, J. (2005). Determinaton of azolic fungicides in wine by solidphase extraction and high-performance liquid chromatography-atmospheric pressure chemical ionizationmass spectrometry. Journal of Chromatography A, 1076, 9096.

Official Merthods of Analysis of the Association of Official Analytical Chemists - AOAC. (1990). Agricutural Chemicals Contaminants and Drugs. Vol. I. 15 th Edition.

Organización Mundial de la Salud (OMS). Organización de las Naciones Unidas para la Agricultura y la Alimentación (OMS). Programa Conjunto FAO/OMS sobre Normas 
Alimentarias (2007). Manual de Procedimientos. Comisión del Codex Alimentarius. 17 Ed., p. 46.

$<\mathrm{ftp}: / / \mathrm{ftp} . f a 0$. rg/docrep/fao/010/a1472s/a1472s01.pdf> Consulta 2007.

Ortelli, D.; Edder, P. \& Corvi, C. (2004). Multiresidue analysis of 74 pesticides in fruits and vegetables by liquid chromatographyelectrospray-tandem mass spectrometry. Analytica Chimica Acta, 520, 33-45.

Ortiz, M. C. \& Sarabia, L. (2007). Quantitative determination in chromatographic analysis based on n-way calibration strategies. Journal of Chromatography A, 1158, 94-110.

Ouyang, G.; Chen, Y.; Setkova, L. \& Pawliszyn, J. (2005). Calibration of solid-phase microextraction for quantitative analysis by gas chromatography. Journal of Chromatography A, 1097, 9-16.

Pattanasupong, A.; Nagase, H.; Sugimoto, E.; Hori, Y.; Hirata, K.; Tani, K.; Nasu, M. \& Miyamoto, K. (2004). Degradation of Carbendazim and 2,4-Diclorophenoxyacetic Acid by Immobilized Consortium on Loofa Sponge. Journal of Bioscience and Bioengineering, Vol. 98, №1, 28-33.

Pawliszyn, Janusz. (1997). Solid Phase Microextraction. Theory and Practique. Ed. Wiley-VCH. Canadá. 
Poole, C.F.; Gunatilleka, A.D. \& Sethuraman, R. (2000). Contributions of theory to method development in solidphase extraction. Journal of Chromatography A, 885, 17-39.

Quattrocchi Oscar A., Albelaira Sara, Laba Raúl F. (1992). Introducción a la HPLC. Aplicación y Práctica. Artes Gráficas Farro S.A. Buenos Aires.

Radišic', M.; Grujic', S.; Vasiljevic', T.; Lauševic, M. (2009). Determination of selected pesticides in fruit juices by matrix solid-phase dispersion and liquid chromatography-tandem mass spectrometry. Food Chemistry, 113, 712-719.

Romero-González, R.; Garrido, Frenich A.; Martínez Vidal, J.L. (2008). Multiresidue method for fast determination of pesticides in fruit juices by ultra performance liquid chromatography coupled to tandem mass spectrometry. Talanta 76, 211-225.

Rozet, E.; Hubert, C.; Ceccato, A.; Dewé, W.; Ziemons, E.; Moonen, F.; Michail, K.; Wintersteiger, R.; Streel, B.; Boulanger, B. \& Hubert, P. (2007). Using tolerance intervals in pre-study validation of analytical methods to predict instudy results. The fit-for-future-purpose concept. Journal of Chromatography A, 1158, 126-137.

Sauret-Szczepanski, N.; Mirabel, P. \& Wortham, H. (2006). Development of an SPME-GC-MS/MS method for the determination of pesticides in rainwater: Laboratory and field experiments. Environmental Pollution, 139, 133-142. 
Secretaría de Agricultura, Ganadería, Pesca y Alimentos. Subsecretaría de Economía Agropecuaria. Dirección de Agricultura. (2004). Producción de Cítricos en Argentina. Informe elaborado por Ing. Agr. Víctor Juan Luppiz.

$<$ http://www.sagpya.mecon.gov.ar/new/0-

0/nuevositio/publicaciones/citrikos2004.pdf> Consulta, 2005.

Servicio Nacional de Sanidad y Calidad Agroalimentaria (SENASA). (2003). Tolerancias ó Limites máximo de residuos de plaguicidas en productos y subproductos agropecuarios. Res. 256/2003, Anexo I.

Servicio Nacional de Sanidad y Calidad Agroalimentaria SENASA. (2006). Oficina de estadísticas de Comercio Exterior - Dic 2006.

Singh, S.B.; Foster, G.D. \& Khan, S.U. (2007). Determination of Thiophanate Methyl and Carbendazim Residues in Vegetables Samples using Microwave Assisted Extraction. Journal of Chromatography A, 1148, 152-157.

Sjaak de Koning, S.; Kirano, M.; Janssen, H. G. \& Brinkman, U.A. Th. (2004). AT-column, a novel concentrating technique for large-volume injections in gas chromatography. Journal of Chromatography A, 1023, 165-174.

Smilanick, J. L.; Mansour, M. F.; Gabler, F. M.; Sorenson, D. (2008). Control of citrus postharvest green mold and sour rot by potassium sorbate combined with heat and fungicides. Postharvest Biology and Technology 47, 226-238. 
Smith, R. M. (2003). Before the injection-modern methods of sample preparation for separation techniques. Journal of Chromatography A, 1000, 3-27.

Soler, C., \& Picó, Y. (2007). Recent trends in liquid chromatography-tandem mass spectrometry to determine pesticides and their metabolites in food. Trends in Analytical Chemistry, 26(2), 103-115.

Stajnbaher, D. \& Zupancic-Kralj, L. (2003) Multiresidue method for determination of 90 pesticides in fresh fruits and vegetables using solid-phase extraction and gas chromatography-mass spectrometry. Journal of Chromatography A, 1015, 185-198.

Stan, H.J. \& Linkerhägner, M. (1996). Large-volume injection in residue analysis with capillary gas chromatography using a conventional autosampler and injection by programmedtemperature vaporization with solvent venting. Journal of Chromatography A, 727, 275-289.

Stein, B.; Torres Leal, G. (1991). Podredumbre marrón de las frutas cítricas. Avance Agroindustrial. v.12. 45, 23-24.

Teske, J. \& Engewald, W. (2002). Methods for, and applications of, large-volume injection in capillary gas chromatography. Trends in Analytical Chemistry, vol. 21, N9+10.

Van Bramer, Scott E. (1998). An Introduction to Mass Spectrometry. Widener University. Department of Chemistry. $<$ http://science.widener.edu/ svanbram>. Consulta, 2006 
Van Hout, M.W.J; Zeeuw, R.A. de; Franke, J.P.; Jong, G.J. de. (1999). Evaluation of the programmed temperature vaporiser for large-volume injection of biological samples in gas chromatography. Journal of Chromatography B, 729, 199210.

Veneziano, A.; Vacca, G.; Arana, S.; De Simone, F. \& Rastrelli, L. (2004). Determination of carbendazim, thiabendazole and thiophanate-mathyl in banana (Musa acuminata) simples imported to Italy. Food Chemistry, 87, 383-386.

Venkateswarlu, P.; Rama Mohan, K.; Ravi Kumar, Ch.; Seshaiah, K. (2007). Monitoring of multi-class pesticide residues in fresh grape samples using liquid chromatography with electrospray tandem mass spectrometry. Food Chemistry 105. 1760-1766.

Vettorazi, G. (1979). International Regulatory Aspects for Pesticide Chemical. CRC. Pres.

Walorczyk, S. \& Gnusowski, B. (2009). Development and validation of a multi-residue method for the determination of pesticides in honeybees using acetonitrile-based extraction and gas chromatography-tandem quadrupole mass spectrometry. Journal of Chromatography A, 1216, 65226531.

Wells, M.; Michael J. (1987). Reversed-phase SPE for aqueous environmental samples preparation in hervicide residue analysis. Journal of Chromatography Science, 25, 345- 352. 
Wilkowska, A.; Biziuk, M. (2011). Determination of pesticide residues in food matrices using the QuEChERS methodology. Food Chemistry, 125, 803-812.

Xiangyang Q. (2010). Development of a matrix solid-phase dispersion-sonication extraction method for the determination of fungicides residues in ginseng extract. Food Chemistry, 121, 758-762.

Xiao-Gang, C., Xiao-Zhong, H., Hui-Yuan Y. (2005). Determination of 266 pesticide residues in apple juice by matrix solid-phase dispersion and gas chromatography-mass selective detection. Journal of Chromatography A, 1063, 201-210.

Yoshioka N.; Akiyama Y.; Teranishi K.(2004). Rapid simultaneous determination of o-phenylphenol, diphenyl, thiabendazole, imazalil and its major metabolite in citrus fruits by liquid chromatography-mass spectrometry using atmospheric pressure photoionization. Journal of Chromatography $A$, 1022, 145-150.

Yoshioka, N.; Akiyama, Y.; Matsuoka, T.; Mitsuhashi, T. (2010). Rapid determination of five post-harvest fungicides and metabolite in citrus fruits by liquid chromatography/time-offlight mass spectrometry with atmospheric pressure photoionization. Food Control 21, 212-216.

Zamora Picón, D.; Martínez Vidal; J.L.; Martínez Galera, M.; Garrido Frenich, A.; López González, J.L.; Arahal, M.R. (2003). Correction of predicted concentration in the use of 
solventbased calibration lines for determining carbendazim, fuberidazole and thiabendazole in water after a SPE step. Talanta, 60, 335-344.

Zimmermann, T, Ensinger, W. J., Schmidt, T. C. (2006). Depletion solid-phase microextraction for the evaluation of fiber-sample partition coefficients of pesticides. Journal of Chromatography A, 1102, 51-59.

Zrostlíková, J.; Hajslová, J.; Godula, M. \& Mastovská, K. (2001). Performance of programmed temperature vaporizer, pulsed splitless and on-column injection techniques in analysis of pesticide residues in plant matrices. Journal of Chromatography A, 937, 73-86. 